Prepared for the U.S. Department of Energy

under Contract DE-AC05-76RL01830

\title{
Utility of Social Modeling in Assessment of a State's Propensity for Nuclear Proliferation
}

\begin{abstract}
GA Coles
AJ Brothers

PD Whitney
\end{abstract}

AC Dalton

JR Olson

AM White
SK Cooley

PM Youchak

SV Stafford

June 2011 


\section{DISCLAIMER}

This report was prepared as an account of work sponsored by an agency of the United States Government. Neither the United States Government nor any agency thereof, nor Battelle Memorial Institute, nor any of their employees, makes any warranty, express or implied, or assumes any legal liability or responsibility for the accuracy, completeness, or usefulness of any information, apparatus, product, or process disclosed, or represents that its use would not infringe privately owned rights. Reference herein to any specific commercial product, process, or service by trade name, trademark, manufacturer, or otherwise does not necessarily constitute or imply its endorsement, recommendation, or favoring by the United States Government or any agency thereof, or Battelle Memorial Institute. The views and opinions of authors expressed herein do not necessarily state or reflect those of the United States Government or any agency thereof.

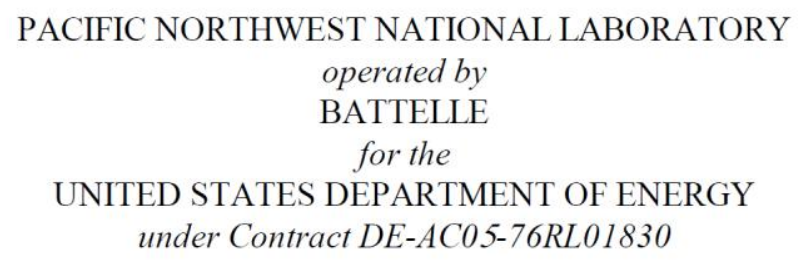

Printed in the United States of America

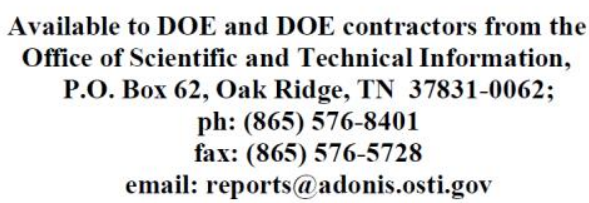

Available to the public from the National Technical Information Service, U.S. Department of Commerce, $\mathbf{5 2 8 5}$ Port Royal Rd., Springfield, VA 22161 ph: (800) 553-6847 fax: (703) 605-6900

email: orders@ntis.fedworld.gov

online ordering: http://www.ntis.gov/ordering.htm

This document was printed on recycled paper. 


\section{Utility of Social Modeling in Assessment of a State's Propensity for Nuclear Proliferation}

$\begin{array}{lll}\text { GA Coles } & \text { AC Dalton } & \text { SK Cooley } \\ \text { AJ Brothers } & \text { JR Olson } & \text { PM Youchak } \\ \text { PD Whitney } & \text { AM White } & \text { SV Stafford }\end{array}$

June 2011

Prepared for

the U.S. Department of Energy

under Contract DE-AC05-76RL01830

Pacific Northwest National Laboratory

Richland, Washington 99352 



\section{Summary}

This is the third and final report documenting research for the U.S. Department of Energy (DOE) National Nuclear Security Administration (NNSA) Office of Nonproliferation Research and Development NA-22 Simulations, Algorithms, and Modeling program that investigates how social modeling can be used to improve proliferation assessment for informing nuclear security, policy, safeguards, design of nuclear systems and research decisions. Social modeling has not previously been used to any significant extent in proliferation studies. This report focuses on the utility of social modeling as applied to the assessment of a State's propensity to develop a nuclear weapons program.

During the literature review and preliminary assessment conducted and documented in the first stage of this project (PNNL-18438, Utility of Social Modeling for Proliferation Assessment: Preliminary Assessment), we concluded that there are clearly opportunities to use social models to improve the understanding and assessment of proliferation-related problems particularly State-level proliferation. We discovered that since the advent of nuclear weapons political scientists have theorized about factors that indicate whether a State is pursuing the development of nuclear weapons program. The social factors identified by political scientists include indicators such as national identity, leadership, politics, domestic security, and economic interdependence which complement technical factors such as economic capability, nuclear capability, and availability of fissile material. For the purposes of this research, we refer to these social and geopolitical indicators as "social factors." We assert that social modeling offers a way to leverage this body of theory and analyses to support proliferation assessments.

We built a Bayesian network (BN) State proliferation propensity model to leverage the quantitative analytical capability of a BN and to facilitate the consideration of social factors along with technical ones. We supported this modeling by first reviewing the literature primarily by political scientists on factors related to the propensity of a State to proliferate. The models that we ultimately developed represent the evolution and culmination of our thinking over several iterations of model development. We initially identified the two major factors relevant to proliferation as being motivation and nuclear capability, which defined the basic structure of our initial model (Coles 2009a). Motivation was construed as a function of political factors such as regional stability, the level of integration into the world political community, and whether there is a perceived nuclear threat as a result of weapons development among neighbors. Nuclear capability is considered to consist of technical knowledge, material resources, and economic ability. Literature reviews confirmed the pertinence of these observations with regard to State-level proliferation and that this basic structure, which has been a recurring theme in the literature, provides a basis for more detailed modeling. There have been attempts by researchers to quantify the impact of various factors on proliferation propensity. The methodology used by these researchers consists of regression analysis of various types. These studies were useful to us in that they confirmed the fundamental structure in our model and suggested refinements in terms of further specification.

A significant refinement to our modeling was accounting for the impact of the "non-proliferation regime" to consider the effectiveness of efforts to minimize proliferation by the IAEA and other international organizations. These efforts include encouragements to sign nonproliferation treaties and to create economic and political sanctions against nations that pursue proliferation activities, which are acknowledged in a handful of proposed quantitative approaches (e.g., Kwon and Ko 2009). Our initial model was quantified using expert judgment. 
We constructed a dataset using existing data compiled by political scientists and data based on our own research of that body of literature covering the years from 1939 to 2000 and over 150 countries. We performed data analysis, including correlation analysis, cluster analysis, principal component analysis, and created dendrograms, in an attempt to better understand the relationship between variables. We also looked for correlations between variables that lag in time recognizing that acquisition of nuclear weapons occurs in phases over a span of several years. Additionally, we identified sources of data that might be leveraged in future refinements of our models.

In our approach, we identified and incorporated key theoretical constructs into the basic model structure, calibrated the model parameters with expert elicitation using laboratory subject matter experts, and used the merged existing datasets to validate the model. We then exercised different validation tests to gauge the accuracy of the model and made further refinements. These tests included a primary validation exercise to test the utility of social modeling in proliferation assessment. The results of this primary validation exercise show that use of only technical or only social factors is inferior to using a combination of technical factors and social factors to predict proliferation. Although our model is intended to be used for forecasting, a central feature of our primary validation test was the use of "backcasting". What we mean by "back-casting" is that the model was used to predict the proliferation propensity for a given State in a past year by using model inputs from the year for which the prediction was being made. If we just used the current year to validate our model the data would be limited as the number of States' in some stage of proliferation is few. This approach to validating the model makes available more cases to test the validity of the model. A given prediction (i.e. "back-cast") was then compared to data considered in this research to represent proliferation "truth". The proliferation truth about a country was considered to be the proliferation category determined by Singh and Way in their dataset (i.e. Not interested, Exploring, Pursuing, Acquiring).

We acknowledge that our final models are not perfectly calibrated but as they currently exist they produce logical and consistent results and show in general that considering social factors results in better predictions than considering technical factors alone. We propose that further refinement using the BN diagnostic model (e.g. further refinement of the conditional probability estimates at particular nodes) in a way that further minimizes the distances between the predictions and "truth" would produce an even better prediction model. The BN model is easy to refine and perform "what if" scenarios. We maintain that the virtues of $\mathrm{BN}$ models for analysis and exploration include:

- The structure and the numerical parameters can be learned from data or they can be elicited from experts, or they can be a mixture of both;

- It is easy to run cases specific to a particular country;

- Readily available off-the-shelf software displays the models and supports direct interaction with the models;

- Software calculates diagnostic information indicating importance of model components; and

- BN models can combine variables from different models.

One limitation of the current the current BN proliferation propensity model is that it represents a snapshot of proliferation propensity for a given country and a specific time so in this way does not capture feedback. The model can be used to see how propensity has changed over the years, but it does not make explicit the dynamic cause and effect interactions in a world in which some countries are motivated to acquire nuclear weapons and other countries are trying to prevent the spread of nuclear weapons. A 
conceptual proliferation propensity model is presented in this report that uses System Dynamics (SD) modeling, which is a type of modeling that allows one to understand the interactions of cause and effect relationships in complex systems in which there is feedback.

We propose that even without explicitly considering feedback mechanisms that SD modeling may offer further refinement of the current BN proliferation propensity model that could be the basis for a tool that provides useful information to a range of experts and decision makers. We suggest that the $\mathrm{BN}$ proliferation propensity model calibrated to produce back-casts as accurately as possible provides a valid basis for such a tool. The range of experts and decision makers that might find such a tool useful includes international safeguards inspectorates, nuclear energy policy and nonproliferation decision-makers, and national licensing and regulatory authorities and export control. We describe in this report how to interface and update the model using publically available BN software and ways in which the model can be used by analysts to understand the contributors and sensitivities of the factors contributing to proliferation. 



\section{Acknowledgments}

This report represents work funded by the U.S. Department of Energy National Nuclear Security Administration Office of Nonproliferation and Verification Research and Development (NA-22). 



\section{Acronyms and Abbreviations}

AHP

AP

$\mathrm{BACH}$

$\mathrm{BN}$

CART

CINC

CLD

COW

CPD

CSA

CTBT

DOE

FCS

GDP

$\mathrm{G}^{2}$

GIF

IAEA

INMN

MID

NNSA

NNWS

NPR

NPT

NR

NWFZ

PPI

PR\&PP

RNFS

SAM

SD

SME

SQP

WMD
Analytical Hierarchy Process

Additional Protocol

Bayesian Analysis of Competing Hypotheses

Bayesian Network

classification and regression tree

Composite Index of National Capabilities

Causal Loop Diagram

Correlates of War

conditional probability distribution

Comprehensive Safeguards Agreement

Comprehensive Test Ban Treaty

U.S. Department of Energy

Fuel-Cycle States

gross domestic product

gross domestic product squared

Generation IV International Forum

International Atomic Energy Agency

Institute of Nuclear Materials Management

Militarized Interstate Disputes

National Nuclear Security Administration

Non-Nuclear Weapons State

nonproliferation regime

Nuclear Nonproliferation Treaty

nuclear reliance

Nuclear Weapons-Free Zone

Proliferation Propensity Index

Proliferation Resistance and Physical Protection

reliable nuclear fuel services and supply

Simulation, Algorithms \& Modeling

System Dynamics

subject matter expert

Significant Quantity Protocol

weapons of mass destruction 



\section{Contents}

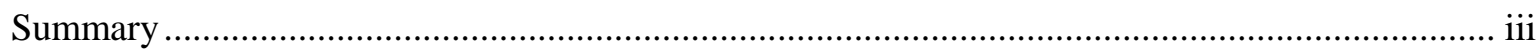

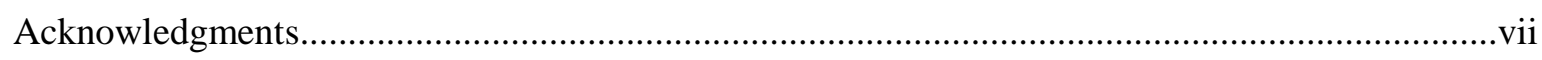

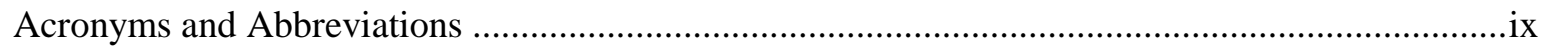

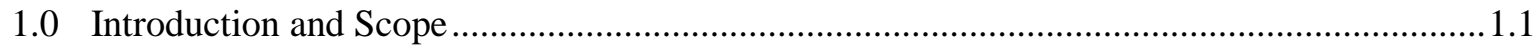

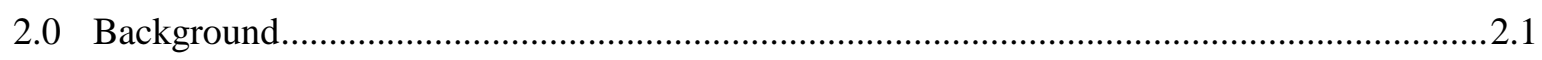

2.1 Major Theoretical Perspectives in Nuclear Proliferation .............................................. 2.1

2.2 Quantitative Studies of Nuclear Proliferation ........................................................2.10

2.3 Comparison of Modeling Approaches ..................................................................2.16

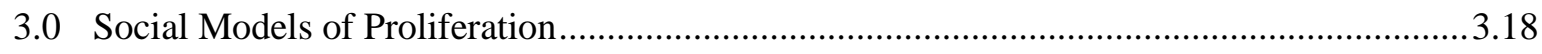

3.1 Preface to BN Proliferation Propensity Modeling …...................................................18

3.2 BN Proliferation Propensity Model Description ............................................................ 3.2

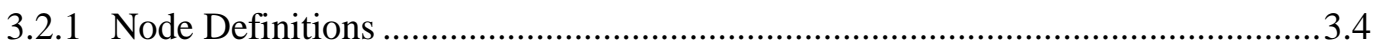

3.2.2 Model Parameters and Expert Judgment ........................................................... 3.7

3.3 Data Compilation and Analyses in Support of Modeling .............................................13

3.3.1 Overview of Singh and Way Data..................................................................... 3.14

3.3.2 Overview of Jo and Gartzke Data ..................................................................16

3.3.3 Comparison and Analysis of Singh \& Way and Jo \& Gartzke Data...................3.19

3.3.4 Augmentation of the Combined Dataset ............................................................2.25

3.3.5 Future Dataset Expansion Possibilities ............................................................3.30

3.4 Validation of BN Proliferation Propensity Model ..........................................................3.31

3.4.1 Validation Test Using a Utility of Social Modeling Metric ................................3.32

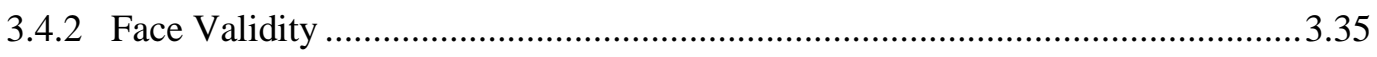

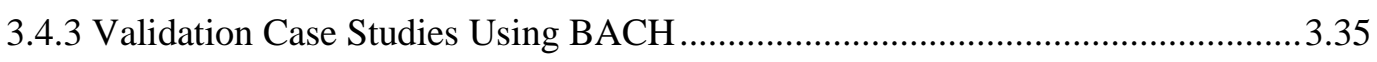

3.5 BN Proliferation Propensity Model Assessment Results .............................................3.39

3.6 Another Modeling Approach: System Dynamics Modeling ........................................3.51

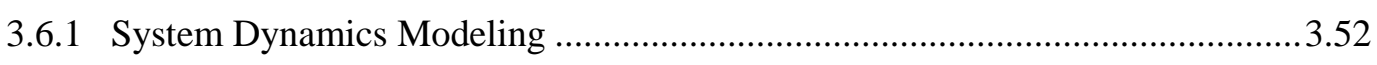

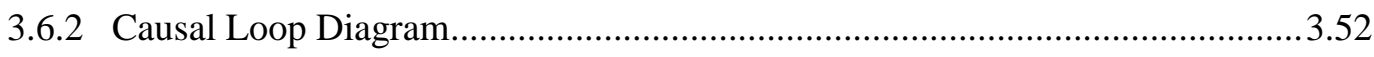

3.6.3 Stock and flow Model ................................................................................5.

4.0 User Framework for BN Proliferation Propensity Model ................................................... 4.1

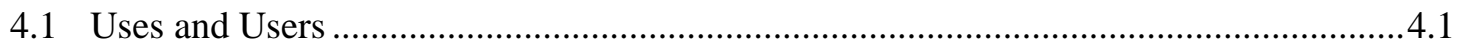

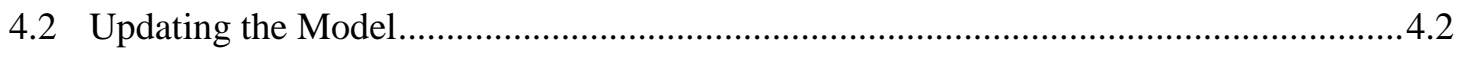

4.3 User Interaction and Analysis Functions.............................................................. 4.7

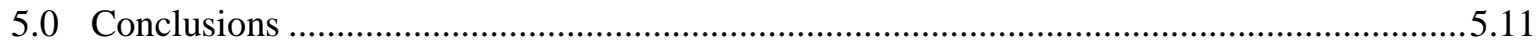

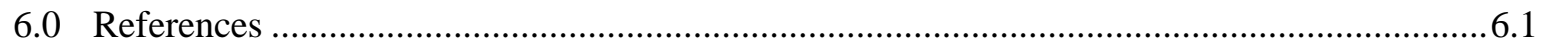

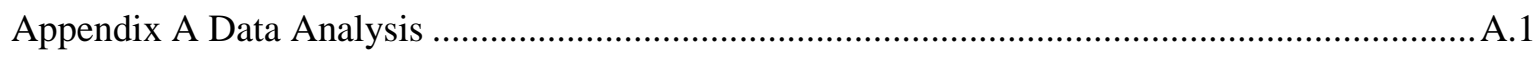

Appendix B Identification of Other Datasets........................................................................ B. 1 
Appendix C BACH Proliferation Propensity Model Queries .................................................... 1 


\section{Figures}

Figure 2.1. Nuclear Propensity of Pakistan (from Meyer 1984) ................................................2.11

Figure 3.1. Causal Version of Composite Model..............................................................................3.3

Figure 3.2. Diagnostic Version of Composite Model ...................................................................

Figure 3.3. Discretization of Frequency Distribution for the Percentage of Democracies .............3.8

Figure 3.4. Comparison of Risk Importance of Motivation to Capability for Two Assumptions 3.10

Figure 3.5. Derivation of Conditional Probability Distribution for Proliferation Risk .................3.11

Figure 3.6. Our Conceptual Model of the Jo and Gartzke Dataset .............................................3.20

Figure 3.7. Our Conceptual Model of the Singh and Way Dataset.................................................22

Figure 3.8. Image Plot of Correlation Matrix for Selected Variables .........................................3.23

Figure 3.9. Technical Bayesian Net for Predicting Proliferation Propensity (Causal Version)....3.34

Figure 3.10. BACH Representation of a Previous Version of Proliferation Propensity Model....3.36

Figure 3.11. Evidential Reliability and Bias on a Credibility Scale .........................................3.37

Figure 3.12. Gabon Proliferation Propensity ...........................................................................3.38

Figure 3.13. Ghana Proliferation Propensity .........................................................................3.38

Figure 3.14. Nigeria Proliferation Propensity .........................................................................3.38

Figure 3.15. Senegal Proliferation Propensity .........................................................................3.39

Figure 3.16. South Africa Proliferation Propensity ..................................................................3.39

Figure 3.17 Uganda Proliferation Propensity .......................................................................3.39

Figure 3.18 South Africa Proliferation Propensity Time series ..................................................40

Figure 3.19 Australia Proliferation Propensity Time Series ........................................................4.

Figure 3.20 Belgium Proliferation Propensity Time Series .......................................................42

Figure 3.21 Canada Proliferation Propensity Time Series ............................................................4.

Figure 3.22 Germany Proliferation Propensity Time Series ..........................................................43

Figure 3.23 Afghanistan Proliferation Propensity Time Series ...................................................4.4

Figure 3.24 Libya Proliferation Propensity Time Series ..........................................................45

Figure 3.25 North Korea Proliferation Propensity Time Series..................................................45

Figure 3.26 Pakistan Proliferation Propensity Time Series ......................................................46

Figure 3.27 India Proliferation Propensity Time series ..................................................................47

Figure 3.28 Iran Proliferation Propensity Time series ................................................................47

Figure 3.29 Israel Proliferation Propensity Time Series ...........................................................48

Figure 3.30 South Africa Proliferation Propensity Time Series .................................................4.48

Figure 3.31 Ecuador Proliferation Propensity Time Series ........................................................49

Figure 3.32 Nigeria Proliferation Propensity Time series ........................................................50

Figure 3.33 Panama Proliferation Propensity Time Series ........................................................5.50

Figure 3.34 Thailand Proliferation Propensity Time Series........................................................3.51

Figure 3.35. Causal Loop Diagram for System Dynamics Model for Proliferation Propensity ... 3.53 
Figure 3.36. Stock and Flow Model of Nuclear Proliferation.....................................................5.54

Figure 3.37. Motivation to Proliferate - Democratic versus Autocratic ..........................................55

Figure 4.1. Example Root Node - Level of Democracy ............................................................ 4.3

Figure 4.2. Example Properties Table for a Root Node ............................................................ 4.3

Figure 4.3. Example Forecast Node - Domestic Conditions ......................................................4.4

Figure 4.4. Example Defined Probabilities Table for an Example Forecast Node ........................4.5

Figure 4.5. Diagnostic Model Related to Motivation Node......................................................... 4.5

Figure 4.6. Defined Probability Table for Example Indicator Node .............................................. 4.6

Figure 4.7. Instantiation of Indictor Nodes Related to Motivation in Diagnostic Model ...............4.6

Figure 4.8. Example What If Analysis on Effect of Nonproliferation Regime - Step 1 ..............4.7

Figure 4.9. Example What If Analysis on Effect of Nonproliferation Regime - Step 2 ...............4.8

Figure 4.10. Example Diagnostic Testing of Final Proliferation Propensity Model......................4.9

\section{Appendix Figures}

Figure A.1. Pairwise Scatter Plots for All Countries and Country-Years.......................................5

Figure A.2. Pairwise Scatter Plots for Selected Variables and Country-Years...............................6

Figure A.3. Time Lag Correlations between Motivation (“motiv2”) \& Nuclear Technology

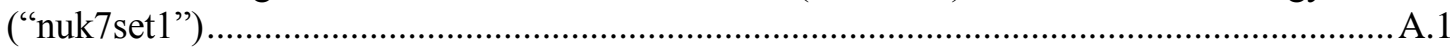

Figure A.4. Time Lag Correlations between Nuclear Technology ("nuk7set1") \& Motivation

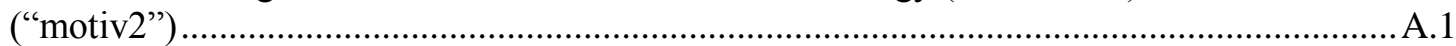

Figure A.5. Time Lag Correlations between "disputes" and Motivation ("motiv2") ...................A.2

Figure A.6. Time Lag Correlations between "polity" and Motivation ("motiv2") ......................A.2

Figure A.7. Time Lag Correlations between "openness" and "polity" ..........................................

Figure A.8. Time Lag Correlations between "allies" and "GDPcap" .......................................... 3

Figure A.9. Pairwise Color Block Plot History for "motiv2" and "disputes" for Canada .............A.4

Figure A.10. Pairwise Color Block Plot History for "motiv2" and "disputes" for Pakistan.......... A.4

Figure A.11. Pairwise Color Block Plot History for "motiv2" and "disputes" for Iran................. A.5

Figure A.12. Pairwise Color Block Plot History for "motiv2" and "disputes" for South Africa... A.5

Figure A.13. Pairwise Color Block Plot History for "rivalry" and "disputes" for Canada............ A.6

Figure A.14. Pairwise Color Block Plot History for "rivalry" and "disputes" for Pakistan .......... A.6

Figure A.15. Pairwise Color Block Plot History for "rivalry" and "disputes" for Iran .................A.7

Figure A.16. Pairwise Color Block Plot History for "rivalry" and "disputes" for South Africa ... A.7

Figure A.17. K Means Lines Plot for Selected Variables ........................................................ A.8

Figure A.18. K Means Bubble Chart for All Countries and Country-Years................................. .9

Figure A.19. Principal Component Analysis for All Countries and Country-Years..................... A.10

Figure A.20. CART Dendrogram Analysis for All Countries and Country-Years........................11 


\section{Tables}

Table 2.1. Explanatory Powers/Limitations of Existing Proliferation Theories (from OgilvieWhite 1996)

Table 2.2. Comparison of Nuclear Nonproliferation Factors

Table 2.3. State-Level factors as Proliferation Indicators (from Williams, 2010)

Table 2.4. Comparison Predictive Variables for Acquire from Singh and Way Regression Models (compiled from Singh and Way 2004).

Table 3.1. Combined Judgments of Importance to Motivation .....

Table 3.2. Diagnostic Values and Judged Importance for Motivation Indicators.

Table 3.3. General Comparison of Singh and Way and Jo and Gartzke Datasets

Table 3.4. Time Lag Correlations between Motivation and Nuclear Technology.

Table 3.5. Nonproliferation Regime Coded for Inclusion in the Combined Dataset

Table 3.6. "Nonproliferation Regime as a Barrier" Algorithm

Table 3.7. "Nonproliferation Regime as a Motivator" Algorithm

Table 3.8. Mapping from Explore/Pursue/Acquire Judgments to Proliferation Propensity Levels3.33 Table 3.9 Proliferation Propensity Ranking for Early Validity Test

\section{Appendix Tables}

Table 4.1. Potential Users and Uses of BN Proliferation Model 4.1

Table A.1. Identification of Important Potential Correlations A. 1

Table A.2. Pairwise Correlation of Variables Matrix A.3 



\subsection{Introduction and Scope}

This is the third and final report documenting research for the U.S. Department of Energy (DOE) National Nuclear Security Administration (NNSA) Office of Nonproliferation Research and Development NA-22 Simulations, Algorithms, and Modeling (SAM) program that investigates how social modeling can be used to improve proliferation assessment for informing nuclear security, policy, safeguards, design of nuclear systems and research decisions. To our knowledge, social modeling has not previously been used to any significant extent in quantitative proliferation studies. This report focuses on the utility of social modeling as applied to the assessment of a State's propensity to develop a nuclear weapons program.

Our first report (Coles 2009a) is a literature search that was organized into five topics (i.e., theories of proliferation, proliferation assessment, safeguards analysis, non-state proliferation, and social and cultural modeling) also provides a preliminary evaluation of opportunities for social modeling. In this report, our literature review suggests that since the cold war political scientists have sought to identify the root causes of nuclear weapons proliferation from a host of perspectives such as domestic security, national identity, leadership, politics, and technical and economic capability, and have built frameworks for understanding proliferation. We note, however, that while historically analysts tested their theories empirically, only a few studies developed quantitative models that explore the relative importance of individual variables as indicators of proliferation. In this report we identified this body of social political information as a promising source of social information from which to build social models.

Our second report (Coles 2009b) describes a way to enhance evaluation of the proliferation resistance of the facility by considering social information. The proliferation factors we considered are the proliferation resistance metrics defined as part of the Generation IV International Forum (GIF) proliferation resistance assessment approach: 1) proliferation technical difficulty, 2) proliferation cost, 3) proliferation time, 4) proliferation material, 5) detection probability, and 6) detection resource efficiency. This report showed that considering proliferation resistance factors in social-political context provides a useful way to characterize the proliferation threat to which a facility might be subject, and it describes a corresponding facility-level evaluation approach.

The present report evaluates the utility of social modeling in assessment of a State's propensity for nuclear weapons proliferation. In this report we propose social modeling approaches and present a Statelevel Bayesian network (BN) proliferation propensity model. Our BN model incorporates contributors to proliferation identified from political science literature and other sources. We validate our model using datasets covering the last half-century and published for two quantitative analyses of State proliferation. We exercise our BN model against a number of country cases representing different perceived levels of proliferation risk. We also introduce a different approach to modeling proliferation using system dynamics (SD) and present a conceptual model developed to illustrate how feedback effects might be explicitly considered. We provide a discussion of the potential uses and users of our BN probability propensity model and an explanation of how to update and use it for analysis. We also describe how the $\mathrm{BN}$ model could be further refined to become a proliferation assessment tool for decision making. In summary, this report presents:

1. A description of the compilation of "social factors" data and associated literature to support modeling and analysis of those data 
2. A BN model for predicting a State's proliferation propensity along with its associated dataset compilation and data analysis

3. Calibration, validation, and verification of the $\mathrm{BN}$ proliferation propensity model

4. BN model prediction? Back-casting results

5. A complementary dynamical model concept (SD modeling) for predicting proliferation propensity

6. Discussion of the use, users, and process for updating the model and potential further analysis and development of the model 


\subsection{Background}

During the literature review and preliminary assessment conducted in the first stage of this project (Coles 2009a), we concluded that there opportunities to use social models to substantially improve the understanding and assessment of proliferation-related problems, particularly State-level proliferation. We discovered that since the cold war political scientists have theorized about various factors that may indicate whether a State is pursuing the development of nuclear weapons. The social factors identified by political scientists include indicators such as national identity, leadership, politics, domestic security, and economic interdependence which complement technical factors such as economic capability, nuclear capability, and availability of fissile material. For the purposes of this research, we refer to these social and geopolitical indicators as "social factors." We assert that social modeling offers a way to leverage this body of theory and analyses to support proliferation assessments.

We discovered a range of definitions used for the term "nuclear proliferation." From the viewpoint of the International Atomic Energy Agency (IAEA), proliferation is State diversion or undeclared production of nuclear materials from facilities operated within a State. A broader definition is sometimes used at the domestic level that includes the theft of nuclear materials by a sub-national group or other States. In the most general sense, the term "nuclear proliferation" is used in open literature to describe the spread of nuclear weapons, fissile material, or weapons-applicable nuclear technology and information to entities that are not recognized as "nuclear weapons States" by the IAEA. For the purpose of this research we define nuclear proliferation to be State sponsorship of material acquisition, processing, and weaponization activities with the intent to develop at least one nuclear weapon.

This section discusses the major theoretical perspectives related to nuclear proliferation, discusses specific quantitative studies that have been performed, and compares modeling approaches used in these studies. These perspectives and the social factors associated with them provide the basis for the proliferation propensity model that is the basis for assessing the utility of social modeling which is the subject of this report.

\subsection{Major Theoretical Perspectives in Nuclear Proliferation}

Since the advent of nuclear weapons, scholars and policy-makers have grappled with the challenge of stopping the proliferation of nuclear weapons. Scholars have debated the causes of State-sponsored nuclear proliferation and attempted to determine its predictability. Analysts have advanced a substantial number of theories to explain nuclear proliferation and have often tried to support those theories using case studies. During this development of nonproliferation thinking, theorists built a shared vocabulary and common conceptualizations to help explain and differentiate theories. Also during this development a handful of quantitative studies have emerged and are discussed in detail in Section 2.2.

In 1962, John F. Kennedy notably predicted that the world faced a cascade of nuclear weapons proliferation as nuclear technology and knowledge continued to spread. This prediction mirrored the common belief in the "Technological Imperative" common at the time, i.e. the belief that acquisition of

\footnotetext{
${ }^{1}$ The Technological Imperative assumes that once a country has acquired the technical capacity to manufacture a nuclear weapon that it's only a matter of time before it does.
} 
nuclear energy technology would inevitably yield nuclear weapons technology. Fortunately, this proved to be an inaccurate forecast.

Political scientists have continued since then to determine the root causes of proliferation and build frameworks for understanding nuclear weapons proliferation. In 1970, the proliferation paradigm shifted with the development of a legal and normative treaty known as the Nuclear Non-Proliferation Treaty (NPT). The NPT introduced a system of constraints and normalized an inspection regime for nuclear energy programs. This built transparency into the secretive world of nuclear weapons development to enable the peaceful spread of nuclear energy without the negative side-effects of nuclear weapons proliferation. Nonetheless, the system has not worked perfectly and it has been challenged on a regular basis by some states.

Several authors have attempted to answer the question, "who will be next?" with a series of different approaches. In the early years of nuclear proliferation literature, authors like Epstein addressed this question in his article Why States go - And Don't Go - Nuclear (Epstein 1977) with academic reasoning based on well-known theories of political science. As new nuclear weapons development ebbed following the Chinese test despite the continuing spread of nuclear energy technology, theorists were challenged to explain the phenomenon. Thinkers began to qualitatively argue motivations related to the security environment were important to understanding proliferation.

One of the early books written on why States decide to pursue nuclear weapons is The Dynamics of Nuclear Proliferation by Stephen Meyer (1984). Meyer contradicts the deterministic notion that the pace of nuclear proliferation is controlled only by a Technological Imperative and suggests that other factors account for the past decisions of nations to acquire or forgo development of nuclear weapons. He espouses a Motivational Hypothesis that sees latent capacity ${ }^{2}$ as a necessary, but not sufficient, condition. It assumes that some specific politico-military condition is necessary to motivate a deliberate proliferation decision.

From the perspective of the Motivational Hypothesis, decisions to initiate nuclear weapons programs can be understood in the context of three categories of incentives: 1) international political power and prestige incentives, 2) military and security incentives, and 3) domestic politics incentives. Based on these categories, Meyer compiles a list of proliferation incentives from literature available at the time (i.e., 1962-1982) by identifying factors that would answer the research question: "From a decisionmaking perspective, the possession of atomic weapons could be helpful if the government wishes to...." This list was then translated from incentives into motive conditions. Meyer came up with a list of 15 motive conditions (i.e., predictor variables):

1. Nuclear threat

2. Latent capacity threat

3. Overwhelming conventional threat

4. Regional power status/pretensions

5. Global power status/pretensions

6. Pariah status ${ }^{3}$
9. Regional nuclear proliferation

10. Defense expenditure burden

11. Nuclear ally

12. Legal treaties enforcement

13. Risk of unauthorized seizure

14. Possible nuclear intervention

\footnotetext{
${ }^{2}$ Meyer defines latent capacity as sufficient technical, industrial, material, and financial resources to support a wholly indigenous nuclear weapons program.

${ }^{3}$ Countries that for one reason or other have been shunned by their neighbors, if not by the international community in general, are considered to have pariah status.
} 
7. Domestic turmoil

8. Loss of war

15. Peaceful reputation

Meyer's work is also groundbreaking because he is one of the first authors to move from qualitative research methods like case studies into quantitative empirical studies of motivational theories.

Authors continued to deliberate over the question of what factors contribute to proliferation, and with the end of the Cold War a significant paradigm shift occurred in the nuclear weapons world. As the U.S. and the Soviet Union stood down their arms races with new arms control agreements, other changes in the nonproliferation environment occurred that warranted attention by theorists and undermined existing conceptions of proliferation. The coalition liberation of Kuwait in 1992 and short incursion into Iraq unveiled just how far Saddam Hussein had gone towards acquiring a nuclear weapon. Alternatively, South Africa came clean and disarmed itself of nuclear weapons under the supervision of the IAEA. States in the former Soviet Union returned possession of Soviet-era nuclear weapons to the Russian Federation and the world focused on dealing with the challenges of secretive nuclear weapons program development. In 2006, North Korea changed the paradigm even more by testing its own nuclear weapon following its 2003 withdrawal from the NPT. All of these activities challenged traditional understandings of the mechanics of proliferation and the capabilities required to proliferate.

Ogilvie-White (1996) that when the "...complexities of the nuclear proliferation process are considered, it is not surprising to find that none of the existing theories of nuclear proliferation provide a satisfactory explanation of the proliferation dynamics, although many provide important pieces of the puzzle" (p. 55). Table 2.1 adapted from that article summarizes the strengths and weaknesses of the models she investigated.

Table 2.1. Explanatory Powers/Limitations of Existing Proliferation Theories (from Ogilvie-White 1996)

\begin{tabular}{|c|c|c|c|}
\hline Theory or model & What it is & $\begin{array}{l}\text { Strengths as a theory of nuclear } \\
\text { proliferation }\end{array}$ & $\begin{array}{l}\text { Weaknesses as a theory of } \\
\text { nuclear proliferation }\end{array}$ \\
\hline Classical realism & $\begin{array}{l}\text { Acquisition of nuclear } \\
\text { weapons is rational } \\
\text { response to protecting } \\
\text { national interests }\end{array}$ & $\begin{array}{l}\text { Explains role of security } \\
\text { considerations }\end{array}$ & Ignores domestic determinants \\
\hline Neo-realism & $\begin{array}{l}\text { Variant of classical realism } \\
\text { to include power structure } \\
\text { of international politics } \\
\text { (whether unipolar, bipolar, } \\
\text { or multipolar) }\end{array}$ & $\begin{array}{l}\text { Presents an elegant, logically } \\
\text { deduced explanation of nuclear } \\
\text { proliferation, but side-steps } \\
\text { empirical difficulties }\end{array}$ & $\begin{array}{l}\text { Explains systemic outcomes, not } \\
\text { unit-level outcomes } \\
\text { Predictions and explanations are } \\
\text { misleading and inaccurate }\end{array}$ \\
\hline $\begin{array}{l}\text { Neo-liberal } \\
\text { institutionalism }\end{array}$ & $\begin{array}{l}\text { Democratic states pursuing } \\
\text { liberal economic policies } \\
\text { may decide that it is not in } \\
\text { their interests to develop an } \\
\text { overt arsenal, due to their } \\
\text { extensive reliance on the } \\
\text { global economy }\end{array}$ & $\begin{array}{l}\text { Explains domestic determinants, } \\
\text { such as economic and political } \\
\text { factors }\end{array}$ & $\begin{array}{l}\text { Leaves decision-making out of } \\
\text { analysis }\end{array}$ \\
\hline $\begin{array}{l}\text { Organizational } \\
\text { theory }\end{array}$ & $\begin{array}{l}\text { Emphasizes the role of } \\
\text { organizations in nuclear } \\
\text { decision making }\end{array}$ & $\begin{array}{l}\text { Analyzes implementation of } \\
\text { decisions } \\
\text { Explains role of organizations in } \\
\text { irrational behavior }\end{array}$ & $\begin{array}{l}\text { Underestimates impact of } \\
\text { individuals and new information }\end{array}$ \\
\hline Belief systems & Actions are linked to & Focuses on role of individuals and & Difficult to quantify. Cannot \\
\hline
\end{tabular}




\begin{tabular}{llll}
\hline theory & $\begin{array}{l}\text { beliefs which are } \\
\text { fundamental to } \\
\text { understanding foreign } \\
\text { policy decision making }\end{array}$ & $\begin{array}{l}\text { groups and explains irrational } \\
\text { decisions }\end{array}$ & explain causes of beliefs \\
Learning models & $\begin{array}{l}\text { Beliefs can change as a } \\
\text { result of learning shared } \\
\text { technical information, } \\
\text { leading to new policies }\end{array}$ & $\begin{array}{l}\text { Explains impact of new } \\
\text { information }\end{array}$ & $\begin{array}{l}\text { Cannot explain what lessons } \\
\text { are likely to be learned under what } \\
\text { circumstances }\end{array}$ \\
$\begin{array}{l}\text { Social } \\
\begin{array}{l}\text { Construction of } \\
\text { Technology } \\
\text { (SCOT) theory }\end{array}\end{array}$ & $\begin{array}{l}\text { Uses organizational theory } \\
\text { to challenge idea that states } \\
\text { actors that act in the }\end{array}$ & $\begin{array}{l}\text { Explains role of technology. } \\
\text { Places nuclear proliferation in } \\
\text { historical and social contexts }\end{array}$ & Very descriptive \\
\hline
\end{tabular}

Authors like Singh and Way (2004), and Jo and Gartzke (2007) attempted to work through these challenges by developing large datasets and performing quantitative tests using statistical regression. Their datasets broadly cover many of the factors political scientists believe are connected with proliferation. At the same time, researchers like Sagan (1997) and Rublee (2008) continued advancing qualitative research about social factors related to proliferation.

Rublee (2008) points out that since the NPT came into force almost 40 years ago, only four States have acquired nuclear weapons. Rublee argues that social psychology can help us understand this nearuniversal signing and compliance with the NPT. She brings new terms to the debate: "persuasion," "social conformity," and "identification." She claims that nuclear forbearance can be explained by 1) persuasion (behavior resulting from genuine transformation of preferences), 2) social conformity (behavior resulting from the desire to maximize social benefits or minimize social costs without a change in underlying preferences), and 3) identification (behavior resulting from the desire or habit of following the actions of an important other). Rublee applies these concepts from social psychology literature to examine how they might explain nuclear proliferation by States. She discusses the normative messages with which international actors are being bombarded and discusses what she calls "linking," "activation," and "consistency." Linking connects a norm to well-established values. To explain activation she points out that "In some cases norms are in direct competition with each other, and the norm that has been emphasized tends to win out", or is "activated". The term "consistency" refers to the idea that there is s psychological need to be consistent, so the best predictor of future behavior is past behavior. Her message is that through social psychology, we can specify the mechanisms by which the norm of nonproliferation has influenced policy makers.

Other major works on proliferation theory include but are not limited to: The Nuclear Tipping PointWhy States Reconsider Their Nuclear Options (Campbell 2004), a collection of writing published in 2004 by editors Kurt Campbell, Robert Einhorn, and Mitchell Reiss; The Psychology of Nuclear Proliferation: Identity, Emotions, and Foreign Policy by Jacque Hymans (2006) who emphasizes the impact of State leadership; Technology and the Proliferation of Nuclear Weapons by Richard Kokoski (1996) who examines crucial technologies affecting nuclear weapon proliferation and their potential ramifications for the NPT regime; Nuclear Proliferation after the Cold War by Mitchell Reiss and Robert Litwalk (1994), who talk about how some of the factors contributing to proliferation have changed since the break-up of the Soviet Union.

To help paint a picture of the large amount of research to date we created a summary table that addresses ideas from several authors. From our literature search we observed that these theories generally 
attempt to evaluate the capabilities and willingness of State proliferators to undertake an effort to develop or acquire a nuclear weapons capability. These theories define key causes, factors, or determinants that influence the decision of a country to develop nuclear weapons. These factors are organized and described differently by different authors, but this research team classified them into the following groups:

1. Technical capability

2. National and international security

3. Domestic politics

4. National identity and psychology.

We view the first group as technical factors and the next three to be social factors. Table 2.2 provides our summary of factors used by several analysts to describe their proliferation theory.

Table 2.2. Comparison of Nuclear Nonproliferation Factors

\begin{tabular}{|c|c|c|c|c|}
\hline Source & $\begin{array}{c}\text { Technical Capability } \\
\text { Factors } \\
\end{array}$ & $\begin{array}{c}\text { International } \\
\text { Security Factors } \\
\end{array}$ & $\begin{array}{c}\text { Domestic Politics } \\
\text { Factors } \\
\end{array}$ & $\begin{array}{l}\text { National Identity \& } \\
\text { Psychology Factors }\end{array}$ \\
\hline $\begin{array}{l}\text { Singh and } \\
\text { Way2004 }\end{array}$ & $\begin{array}{l}\text { - Latent capability } \\
\text { - Economic capacity }\end{array}$ & $\begin{array}{l}\text { - Security threat } \\
\text { - Security alliance }\end{array}$ & $\begin{array}{l}\text { - Regime type } \\
\text { - Political change } \\
\text { - Economic openness } \\
\text { - Economic change }\end{array}$ & - Symbolism ${ }^{(\mathrm{b})}$ \\
\hline Sagan, 1997 & - Latent capability & - Nuclear threat & $\begin{array}{l}\text { - } \text { Military activism }^{(\mathrm{c})} \\
\text { - } \text { Political activism }^{(\mathrm{d})} \\
\text { - } \text { Nuclear industry } \\
\text { activism }^{(\mathrm{e})}\end{array}$ & $\begin{array}{l}\text { - Symbolism } \\
\text { - Institutional } \\
\text { isomorphism }\end{array}$ \\
\hline $\begin{array}{l}\text { Jo and Gartzke } \\
2007\end{array}$ & $\begin{array}{l}\text { - Latent capability } \\
\text { - Technology diffusion } \\
\text { - Economic capacity }\end{array}$ & $\begin{array}{l}\text { - Security threat } \\
\text { - Security alliance } \\
\text { - Diplomatic isolation }\end{array}$ & $\begin{array}{l}\text { - Regime type } \\
\text { - Domestic unrest }\end{array}$ & $\begin{array}{l}\text { - Symbolism } \\
\text { - International norms }\end{array}$ \\
\hline Rublee 2008 & & & $\begin{array}{l}\text { - Activism (for and } \\
\text { against) }\end{array}$ & $\begin{array}{l}\text { - } \text { Consistency }^{(\mathrm{h})} \\
\text { - Linking with } \\
\text { established values }^{(\mathrm{i})}\end{array}$ \\
\hline Hymans 2006 & & & & $\begin{array}{l}\text { - National identity } \\
\text { consensus }\end{array}$ \\
\hline Epstein 1977 & & $\begin{array}{l}\text { - Security threat } \\
\text { - Security alliance } \\
\text { - Weapons superiority }\end{array}$ & $\begin{array}{l}\text { - Nuclear hedging }{ }^{(\mathrm{j})} \\
\text { - Legal barriers }\end{array}$ & $\begin{array}{l}\text { - Symbolism } \\
\text { - International norms } \\
\text { - Regional status } \\
\text { - International status } \\
\text { - Economic status }\end{array}$ \\
\hline Mozley 1998 & & $\begin{array}{l}\text { - Security threat } \\
\text { - Diplomatic isolation }\end{array}$ & - Regime type & - Regional status \\
\hline Meyer 1984 & - Economic capacity & $\begin{array}{l}\text { - Diplomatic isolation } \\
\text { - International legal } \\
\text { commitments } \\
\text { - Preemptive } \\
\text { diplomatic } \\
\text { intervention by } \\
\text { major power }\end{array}$ & $\begin{array}{l}\text { - Domestic unrest } \\
\text { - Recent, major } \\
\text { military defeat } \\
\text { - Risk of } \\
\text { unauthorized } \\
\text { seizure }\end{array}$ & $\begin{array}{l}\text { - International status } \\
\text { - Regional status } \\
\text { - International norms } \\
\text { - Peaceful reputation }\end{array}$ \\
\hline Reiss 2004 & $\begin{array}{l}\text { - Technological } \\
\text { difficulty }\end{array}$ & $\begin{array}{l}\text { - Security threat } \\
\text { - Bargaining tool }\end{array}$ & $\begin{array}{l}\text { - Activism (for and } \\
\text { against) } \\
\text { - Legitimacy of } \\
\text { government }^{(1)}\end{array}$ & $\begin{array}{l}\text { - Symbolism } \\
\text { - International norms }\end{array}$ \\
\hline Campbell 2004 & - Technology diffusion & $\begin{array}{l}\text { - Security alliance } \\
\text { - U.S. foreign and } \\
\text { security policy }\end{array}$ & - Domestic unrest & - International norms \\
\hline Einhorn 2004 & $\begin{array}{l}\text { - Latent Capability } \\
\text { - Technology diffusion } \\
\text { - Materials diffusion }\end{array}$ & $\begin{array}{l}\text { - Security threat } \\
\text { - Security alliance }\end{array}$ & $\begin{array}{l}\text { - Domestic unrest } \\
\text { - Hedging } \\
\text { - Nuclear-phobia }{ }^{(m)}\end{array}$ & - International norms \\
\hline
\end{tabular}




\begin{tabular}{|c|c|c|c|c|}
\hline Kwon 2009 & $\begin{array}{l}\text { - Technological } \\
\text { Capability } \\
\text { - Economic Capacity } \\
\text { - Safeguards } \\
\text { - Physical Protection } \\
\text { - Export control }\end{array}$ & $\begin{array}{l}\text { - Security threats } \\
\text { - Security guarantee } \\
\text { - Diplomatic isolation }\end{array}$ & $\begin{array}{l}\text { - Transparency } \\
\text { - Domestic unrest } \\
\text { - Activism (for and } \\
\text { against) } \\
\text { - Leadership } \\
\text { propensity for } \\
\text { nuclear weapons } \\
\text { - Public influence }\end{array}$ & $\begin{array}{l}\text { - International norms } \\
\text { - Duration of } \\
\text { Participation in NPT } \\
\text { - Linking with } \\
\text { established values } \\
\text { (internalization) } \\
\text { - Regional status } \\
\text { - International status } \\
\text { - Diplomatic activities } \\
\text { (prove compliance w/ } \\
\text { international norms) }\end{array}$ \\
\hline Sweeney 2009 & $\begin{array}{l}\text { - Economic Capacity } \\
\text { - Latent capability } \\
\text { - Economic capacity }\end{array}$ & $\begin{array}{l}\text { - Security threat } \\
\text { - Enduring Rivalry } \\
\text { - Regional } \\
\text { Proliferation } \\
\text { - Diplomatic Isolation } \\
\text { - Bargaining tool } \\
\text { - Security alliance } \\
\text { - Preemptive } \\
\text { diplomatic } \\
\text { intervention by } \\
\text { major power } \\
\text { - International legal } \\
\text { commitments } \\
\end{array}$ & $\begin{array}{l}\text { - Institutional inertia } \\
\text { - Political change } \\
\text { - Risk of } \\
\text { unauthorized } \\
\text { seizure } \\
\text { - Economic change } \\
\text { - Economic openness } \\
\text { - Activism (for and } \\
\text { against) }\end{array}$ & $\begin{array}{l}\text { - International status } \\
\text { - Nationalism } \\
\text { - Peaceful reputation } \\
\text { - International norms }\end{array}$ \\
\hline Source & $\begin{array}{c}\text { Technical Capability } \\
\text { Factors }\end{array}$ & $\begin{array}{c}\text { International Security } \\
\text { Factors }\end{array}$ & $\begin{array}{c}\text { Domestic Politics } \\
\text { Factors }\end{array}$ & $\begin{array}{l}\text { National Identity \& } \\
\text { Psychology Factors }\end{array}$ \\
\hline
\end{tabular}


(a) Latent Capability - A factor related to a State's technical and industrial capacity that allows it to build nuclear weapons or pursue a nuclear weapons program.

(b) Symbolism - A factor related to the idea that nuclear weapons can also play an important symbolic role in a State's self-image. Nuclear weapons can be imagined as fulfilling functions similar to those of flags, airlines, and Olympic teams.

(c) Military Activism - Efforts of the military to convince decision-makers that a nuclear weapon is, or is not, in the State's best interest.

(d) Political Activism - Efforts of politicians to convince decision-makers that a nuclear weapon is, or is not, in the State's best interest.

(e) Nuclear Industry Activism - Efforts of the nuclear industry to convince decision-makers that a nuclear weapon is, or is not, in the State's best interest.

(f) Institutional Isomorphism - A factor related to the concept that individuals and institutions naturally begin to mimic one another because of the normative requirements of each individual or institution. The concept is that a State will build a nuclear weapon because "that is what a powerful State does." In essence, institutional isomorphism is a concept of normative behavior.

(g) Activism - General efforts by anyone to convince decision-makers that a nuclear weapon is, or is not, in the State's best interest.

(h) Consistency - A factor related to social psychology and the belief that historical behavior is a good indicator of future behavior because the need to be, and appear, consistent is a powerful motivator for action.

(i) Linking with Established Values - The act of connecting a new social norm to well-established values.

(j) Nuclear Hedging - Refers to any action to either enhance or destroy a nuclear weapons program or a nuclear weapon because of actions that could happen in the future. For example, a State may attempt to develop a nuclear weapons capability rather than a nuclear weapon to avoid backlash from the international community in the short term. Also, a State may give up a nuclear weapon to prevent a future government from gaining access to the weapons (the apartheid government of South Africa).

(k) Bargaining Tool - Some States may attempt to acquire either a nuclear weapons program, or a nuclear weapon, as a bargaining chip in negotiations with a State that has more real leverage. For example, North Korea agreed to give up its plutonium production to receive concessions from the six-party talks.

(1) Legitimacy of Government - A government may pursue a nuclear weapons program or a nuclear weapon to prove that it is capable of defending the State in an effort to build legitimacy.

(m) Nuclear phobia - Some States may have a social aversion to nuclear weapons that makes that State more resistant to proliferation.

In her 2010 report, Williams stated, “...State-level factors which can be assessed cumulatively.... to inform a determination of proliferation plausibility" in order to identify facilities of high safeguards importance. Her intention is to support IAEA efforts to analyze acquisition that a State may use to acquire nuclear weapons capability. She used her methodology to assess three test cases: 1) a declared nonnuclear weapons state that is an nonproliferation Regime Treaty (NPT) signatory (e.g. Iran), 2) a declared nuclear weapons State that is not an NPT signatory (e.g. Pakistan), and 3) a declared nuclear weapons state that withdrew from the NPT to develop its nuclear weapons capability (e.g. the Democratic People's Republic of Korea). State level factors as proliferation indicators from the Williams report are shown in Table 2.3. 
Table 2.3. State-Level factors as Proliferation Indicators (from Williams, 2010)

\begin{tabular}{|l|}
\hline Domestic Political Factors \\
\hline Citizen-perceived illegitimacy of national leaders \\
\hline Degree of internal aggressive/hostile factions \\
\hline Strength of democratic institutions \\
\hline Indicators of civil society \\
\hline History of colonization or occupation \\
\hline Political isolation \\
\hline
\end{tabular}

\begin{tabular}{|l|}
\hline Geostrategic Factors \\
\hline Strained IAEA relations \\
\hline Strained treaty org relations \\
\hline Strained export control relations \\
\hline Adoption of Comprehensive Safeguards Agreements \\
\hline Adoption of Additional Protocol \\
\hline Resistance to Nuclear Weapons Free Zone participation \\
\hline Regional instability \\
\hline International tensions \\
\hline Refusal of testing moratorium \\
\hline Refusal of Fissile Material Cutoff Treaty \\
\hline
\end{tabular}

\begin{tabular}{|l|}
\hline Defense Factors \\
\hline Defense budget \\
\hline Defense budget trends \\
\hline Willingness to use weapons of mass destruction \\
\hline Absence of no-first-use policy? \\
\hline Lack of deterrent \\
\hline Missile program \\
\hline
\end{tabular}

\begin{tabular}{|l|}
\hline Societal/Human Security and other Factors \\
\hline Civil society constraints \\
\hline Energy security constraints \\
\hline Manifest destiny \\
\hline
\end{tabular}

\begin{tabular}{|l|}
\hline Domestic Nuclear Capabilities \\
\hline Nuclear Industry \\
\hline Participation in professional nuclear sector activities \\
\hline Nuclear regulatory framework \\
\hline Plans to alter nuclear program \\
\hline Nuclear-government relations \\
\hline Nuclear Science Technology \\
\hline Uranium mining and milling \\
\hline Ability to convert uranium to chemical form \\
\hline Enrichment capability \\
\hline Fuel fabrication capability \\
\hline Heavy water production \\
\hline Graphite production \\
\hline Uranium metal conversion capability \\
\hline Light water reactors \\
\hline Plutonium production reactors \\
\hline Fuel reprocessing capability \\
\hline Weaponization capability \\
\hline Isotope demand \\
\hline Sensitive scientific collaboration \\
\hline Manufacture of sensitive equipment \\
\hline Discrepancies, anomalies, material not accounted for \\
\hline History of nuclear smuggling \\
\hline Proliferant contact \\
\hline Relevant scientific and technical expertise \\
\hline Production of weapons-grade material \\
\hline Nuclear Testing \\
\hline \\
\hline
\end{tabular}

\begin{tabular}{|l|}
\hline Societal/Human Security and other Factors (cont.) \\
\hline Gross National Product per capita \\
\hline Lack of openness \\
\hline Restricted access to expertise \\
\hline
\end{tabular}

The focus of the Williams study was to identify factors that could be used by IAEA State evaluators to characterize the proliferation potential of a State, and as such gives more consideration to nonproliferation regime elements such as specific NPT elements (e.g., Comprehensive Safeguards Agreement ${ }^{4}$, Additional Protocol $^{5}$ and other international agreements (e.g., Nuclear Weapons Free Zone agreements) than found in

\footnotetext{
${ }^{4}$ The IAEA has safeguards agreements in force with over 170 States around the world. Most of these are comprehensive safeguards agreements concluded pursuant to the Treaty on the Non-Proliferation of Nuclear Weapons (NPT). Other types of agreements are known as voluntary offer safeguards agreements (in force with the five NPT nuclear-weapon States) and item specific safeguards agreements (in force with three States not party to the NPT). (http://www.iaea.org/OurWork/SV/Safeguards/sv.html)

${ }^{5}$ The Additional Protocol is a legal document granting the IAEA inspection authority complementary to that provided in underlying safeguards agreements. A principal aim is to enable the IAEA inspectorate to provide assurance about both declared and possible undeclared activities. Under the Protocol, the IAEA is granted expanded rights of access to information and sites. Additional protocols (which are typically modeled after the Model
} 
many other articles. International institutional controls provide an impediment to the development of nuclear weapons.

Additional Protocol-INFCIRC/540) mark the culmination of major safeguards strengthening measures of the 1990s. (http://www.iaea.org/Publications/Factsheets/English/sg_overview.html) 


\subsection{Quantitative Studies of Nuclear Proliferation}

Historically, analysts typically tested their theories empirically. Montgomery and Sagan note in their 2009 article "The Perils of Predicting Proliferation" that mainstream proliferation literature has generally focused on in-depth individual case or cross-case-study variation for a few countries rather than attempting to test hypothesis in a systematic way across all States over a long period of time. The data about nuclear weapons are scarce and it is difficult to code independent variables like prestige, bureaucratic power and normative effects of the international system. Nonetheless, a handful of quantitative studies of significance has been performed, particularly in the last decade.

One of the early and seminal quantitative studies on why States decide to pursue nuclear weapons is The Dynamics of Nuclear Proliferation by Stephen Meyer (1984) in which "nuclear propensity" was defined as "...the extent of a nation's explicit (but time varying) predisposition towards initiating the manufacture of nuclear weapons." Nuclear propensity was defined as a function of motive conditions, whose value ranges between 0 and 1 . When calculating the nuclear propensity for a country to go nuclear, Meyer accounts for multiple motive conditions as well as the dampening effects of dissuasive motives. Historical data was used to test his Motivational Hypothesis (described in Section 2.1). Cases in which motive may be present and dissuasive conditions absent were examined to see if there was a systemic relationship between proliferation decisions and motive conditions. The percentage of proliferation decisions for countries where a motive was present was compared to the average. The finding that proliferation decisions were significantly higher than the average of the entire set supports the motivation hypothesis.

Moreover, hee calculated the proliferation propensity on a year-by-year basis and discussed the results for a number of countries. Figure 2.1 shows the nuclear propensity for Pakistan as calculated for 1960 to 1980. The figure shows a sharp increase in nuclear propensity for Pakistan beginning about 1970. In fact Pakistan began its nuclear weapons program in 1972. Other countries that have made proliferation decisions discussed in his analysis include Britain, South Africa, France, India, South Korea, Brazil, Argentina, Taiwan, and Pakistan. Meyer's work is a significant milestone in the thinking about nuclear proliferation and is often referenced in later literature.

Singh and Way (2004) quantitatively tested competing theories by using regression models to examine the strength of the relationship between the decisions to proliferate and the predictive variables. The authors organize the variables into three categories: Technological Determinants, External Determinants, and Domestic Determinants. Technological Determinants are variables concerning the technological and industrial capacity to build nuclear weapons. External Determinants are related to the political stability within the region and whether a State has a nuclear protector. Domestic Determinants refer to the internal conditions of the State, such as the degree of democratization and economic interdependence. Because their data are used in our modeling effort, we discuss the meaning of their predictor variables in Section 3.1 Data Analysis. 


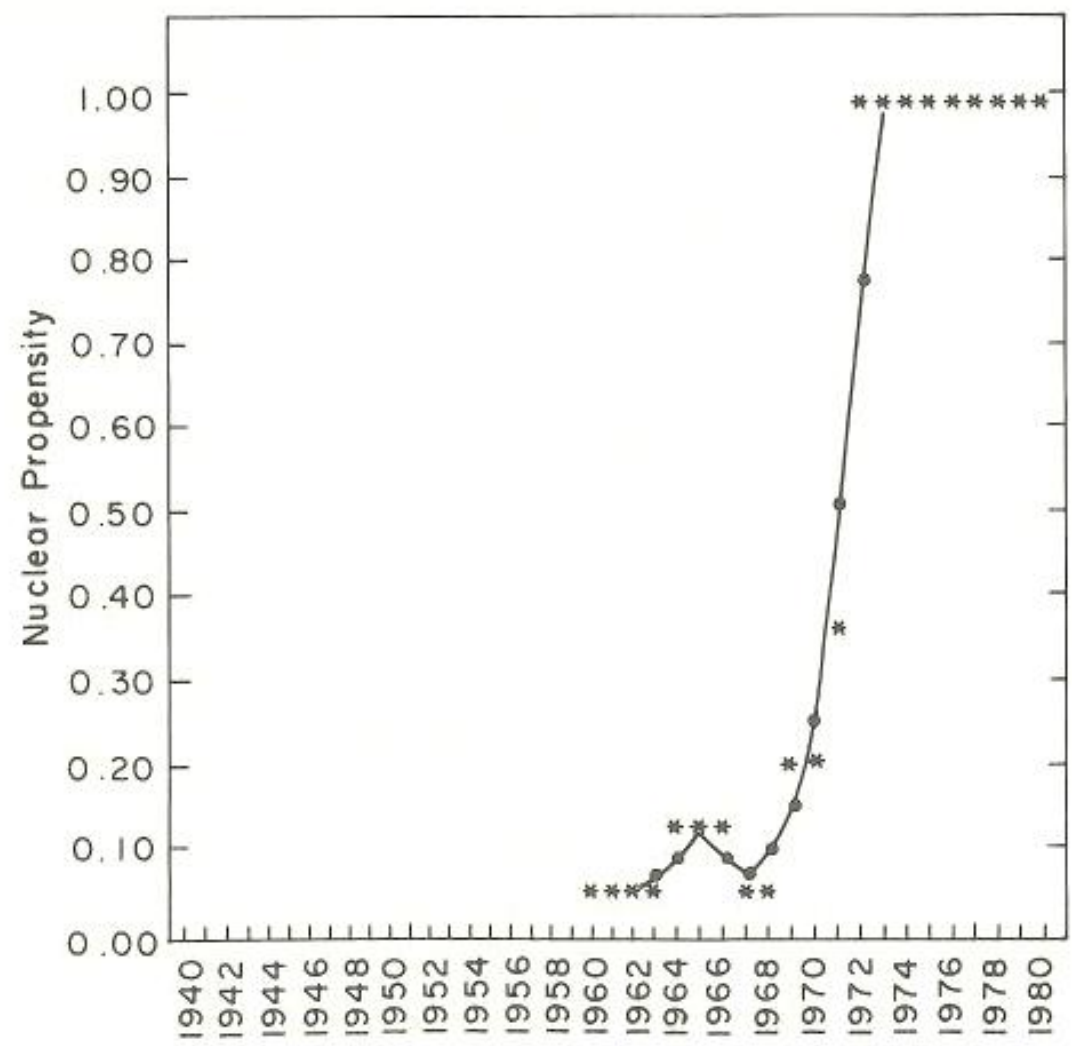

Figure 2.1. Nuclear Propensity of Pakistan (from Meyer 1984)

Singh and Way analyze their data using two different regression models: a hazard model and a logistic regression model. Ordinarily, a hazard model assumes inevitability, for example it might be assumed that machines eventually fail. However, the particular functional form for the hazard model chosen by Singh and Way has a parameter that is empirically determined, that allows the hazard to either increase, decrease, or remain constant over time. Table 2.4 summarizes some of their results. The advantage of the logistic regression model is that the dependent variable is a probability. Unlike leastsquares regression models, the regression coefficients in these models are difficult to interpret; in particular, the magnitude of the regression coefficients cannot be related to a specific change in the independent variable. The results from the hazard model are presented by Singh and Way in both the standard form and the log relative hazard forms. Increase in Log relative values can be interpreted as an increase in likelihood. Another issue with Singh and Way's analysis is that inconsistent variable names were used in reporting the regression results. While statistical significance tests explicitly show which variables were most significant, it is not clear for those variables that are of the same level of significance (many are significant at the .001 level) what their relative importance is. For the logistic model the impact of the coefficients is best judged by the significance level. Most of these have a significance level of .001 and it is impossible to determine their relative importance. The column titled "Substantive Effects" in Table 2.4 indicates the relative impact that the variables have on Acquire as the independent variable using the hazard function model, but information is not available for all the 
Table 2.4. Comparison Predictive Variables for Acquire from Singh and Way Regression Models (compiled from Singh and Way 2004)

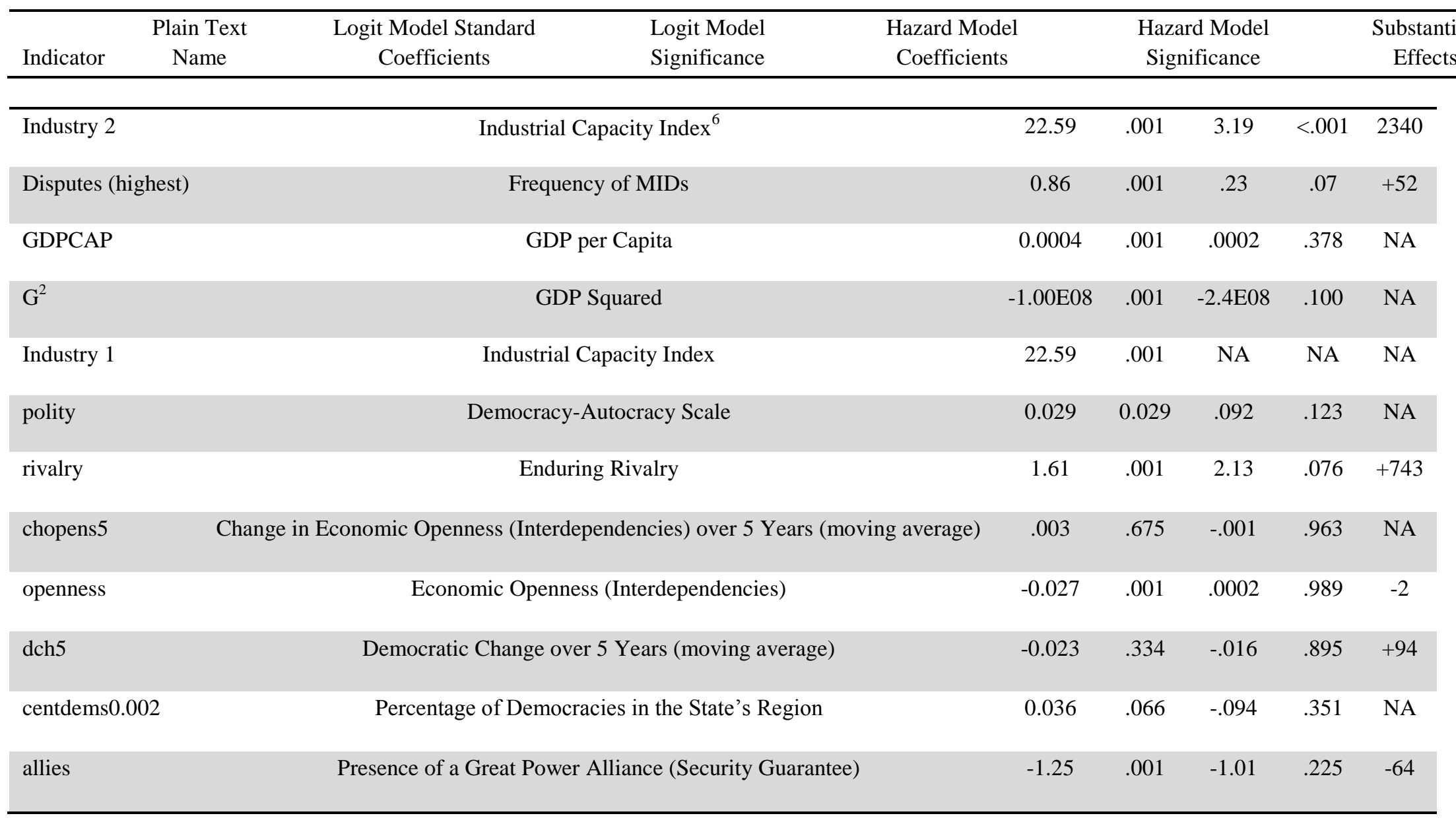

\footnotetext{
${ }^{6}$ The project team interpreted from the Singh and Way information "Industry 2" to be energy, electricity and steel production and consumption based on aggregate and per capita energy consumption, electricity production and generating capacity, and steel production per page 869 of their article (Singh and Way 2004).
} 
independent variables in the Singh and Way dataset. In summary, while one can determine which independent variable coefficients achieved significance, their relative importance is difficult to determine.

In Jo and Gartzke (2007), "Determinants of Nuclear Weapons Proliferation," the authors report the results of another quantitative evaluation of explanations of nuclear proliferation similar to those in Singh and Way (2004). The two dependent variables that Jo and Gartzke define are countries that possess nuclear weapons in a given year and countries that have an active nuclear weapons development program in a given year. Jo and Gartzke organize their theory into measures of opportunity and willingness and grouped the independent variables accordingly. Measures of opportunity include technology related to latent nuclear weapons production capability, economic capacity, and trade restrictions related to fissile material. The "latent nuclear weapons production capability" variable is a complex variable made up of seven components: uranium deposits, metallurgists, chemical engineers, nuclear engineers/physicists/chemists, electronic/explosive specialists, nitric acid production capacity, and electrical production capacity. This reflects more sophistication than comparable technical variables included in Singh and Way (2004). The measures of willingness consist of factors related to international security, domestic politics, norms of international behavior, and national status.

The authors used a probit regression analysis to investigate the impact of his independent variables on the incidence of a nuclear weapons program. A censored probit analysis was done for nuclear weapons possession when a state was already pursuing a nuclear weapons program. The significance of the determinants was estimated through the regression while further sensitivity to the determinant variable was tested by maximizing each variable and measuring the response. The assessment results show that security and technological capabilities are important determinants of whether States form nuclear weapons programs, while security concerns, economic capabilities, and domestic politics help explain the possession of nuclear weapons. The new insight that Jo and Gartzke offer is that security and technological capabilities are important determinants of whether States form nuclear weapons programs while security concerns, economic capabilities, and domestic politics help explain the possession of nuclear weapons. The study also reinforces earlier conclusions that proliferation occurred when opportunity was combined with willingness.

Kwon (2009) presents an integrated multi-criteria analysis method for quantitative proliferation assessments. The proposed methodology considers the political, social, and cultural dimensions of nuclear proliferation. This methodology is comprised of three steps: (1) identifying the factors that influence credibility formation and employing them to construct a criteria tree that will illustrate the relationships among these factors; (2) defining the weight coefficients of each criterion through pairwise comparisons of the Analytical Hierarchy Process (AHP); and (3) assigning numerical scores to a state under each criterion and combining them with the weight coefficients in order to provide an overall assessment of the state. The functionality of this methodology is examined by assessing the current level of nuclear nonproliferation credibility of four countries: Japan, North Korea, South Korea, and Switzerland. This work is different from previous work in two respects. First, its quantitative approach is based on AHP rather than regression analysis. Second, it specifically considers details of the non-proliferation regime such as safeguards, export control, physical protection, compliance, transparency and diplomatic activities. This approach acknowledges that, with the materialization of the NPT in the 1970s, the collective efforts of the international community to prevent the proliferation of nuclear weapons, materials, and technologies were formally organized. Since then, the treaty has been solidified by a network of treaties and accords and has become the largest international governing system. These treaties 
and accords include all the measures required to enforce safeguards against nuclear weapons, materials, and technologies; control exports of the above; and provide physical protection against them.

In contrast to consideration of the nonproliferation regime, the impact of foreign assistance on proliferation is a piece of the proliferation problem that remains underdeveloped, although Kroenig (2010) addresses this issue to some extent. Empirical records provide reasons for why nuclear assistance might be an important proliferation concern. While States have not been known to provide sensitive nuclear assistance to terrorists, they have on a number of occasions transferred sensitive nuclear material or technology to other States. From 1959 to 1965, France provided Israel with sensitive nuclear assistance and two years after that Israel is believed to have constructed its first nuclear weapon. China assisted Pakistan with its nuclear program in the early 1980s by supplying uranium enrichment technology, weapons grade uranium, and a nuclear weapons design. After that Pakistan assisted Iran, Libya, and North Korea. While Libya gave up its nuclear program, Iran and North Korea have not. Kroenig (2010) analyzed the impact of foreign assistance in Importing the Bomb: Technology Transfer and the Spread of Nuclear Weapons. Datasets of sensitive nuclear assistance from 1945-2000 were developed from nuclear weapons databases maintained by the Nuclear Threat Initiative and from prominent reviews. For this study Kroenig coded proliferation as the result of weapons test or assembling a deliverable nuclear weapon. Cox survival models were used to estimate the significance of variables representing sensitive nuclear assistance in combination with other proliferation determinants developed by Singh and Way. Through this work Kroenig lays further foundation for quantitative proliferation assessments. In related work,Fuhrman (2008) analyzes dual-use exports from the U.S. from 1991-2001 in Exporting Mass Destruction? The Determinants of Dual-Use Trade. However, neither datasets used by Kroenig or Fuhrmann were available at the time of the research.

Nelson and Sprecher (2010) in Are sensitive technologies enablers of civil nuclear power? An empirical study quantitatively assesses factors associated with the extent to which a given State relies on nuclear energy to generate electricity (termed "Nuclear Reliance," or NR). Nelson and Sprecher compile a dataset of 14 hypothesized independent variables for the purpose of the research. From those variables he identifies five independent variables that collectively predict NR with high confidence $(\mathrm{p}<0.05$, for all predictors). Using these predictors as a model Nelson addresses other questions. The most significant of these questions regard the historical effectiveness of the nonproliferation regime regarding the spread of sensitive fuel-cycle technologies, the premise underlying fuel assurance programs forgoing development of sensitive technologies would be a bargain, and the persistent lack of recipient States willing to accept a fuel assurance programs.

The predictor variables that Nelson and Sprecher (2010) identifies are 1) Historic Alignment - as a surrogate for secondary material and technology assurance, 2) Relative coal reserves - as a ready, reliable, and inexpensive alternative fuel source for the generation of electricity, 3) Fuel-cycle state - a State that is not a nuclear weapons state but nonetheless attempts to attain some level of nuclear material or technology, 4) International Commercialization - a measure of the degree of incentive to the domestic NR of a State that derives from its success in the international market for nuclear materials and technology, and 5) Polity - the standard political science attribute measuring the degree to which a State has democratic tendencies, intended here as surrogate for regime stability.

In a pair of papers (Phillips 2010; Kreyling 2010), Jon Phillips asserts that "State-level nuclear proliferation is a complex technical, political-military and socio-economic behavior beyond the reach of simple quantitative models. Even so, it is useful to develop simple models that mimic the complex problem 
to the "first order" so that insights can be obtained into the relationships, dynamics and possible tipping points given opposing influences that combine to enhance the "potential" for a non-nuclear weapons State (NNWS) to commence a nuclear weapon program." His principal interest is in providing an analytical framework for evaluating the non-proliferation merit of potential reliable nuclear fuel services and supply ${ }^{7}$ (RNFS) arrangements. In the process he proposes an algorithm that calculates what he refers to as a Proliferation Potential Index (PPI). The PPI incorporates the well-accepted ideas that technical capability and the motivational factors are important for understanding nonproliferation, but unlike other analysts Phillips pays extensive attention to the role of the nonproliferation regime. Phillips postulates that for each NNWS, a proliferation potential index, $\Phi$, can be defined in as follows:

$\Phi,=\mathrm{TC}_{\mathrm{i}}\left(1-\mathrm{NP}_{\mathrm{i}}\right) \mathrm{NM}_{\mathrm{i}}$

with principle influences normalized such that: $0 \leq \mathrm{TC}_{\mathrm{i}} \leq 1 ; 0 \leq \mathrm{NP}_{\mathrm{i}} \leq 1 ; 0 \leq \mathrm{NM}_{\mathrm{i}} \leq 1$, implying that: $0 \leq \Phi_{\mathrm{i}} \leq 1$.

The subscript $i$ denotes the NNWS being analyzed, and TC, NM, and $N P$ are indices that denote the technical capability of the State, national motivation, and nonproliferation regime effectiveness, respectively. He breaks down each of these contributors into further considerable detail. For example Phillips proposes another model that estimates the combined effect of each institutional element of the nonproliferation regime. Each term of the model has a compliance or detection factor and an enforcement factor. Compliance assessment is based on observation of State behavior with regard to its undertakings. Detection relates to member State intelligence capabilities that are used to inform the process. The products of the likelihood of effective enforcement is the critical link to estimate regime effectiveness model for $\mathrm{NP}_{\mathrm{i}}$ is stated as

$\mathrm{NP}_{\mathrm{i}}=\mathrm{f}_{\mathrm{n}}\left(\mathrm{ITD}_{\mathrm{i}}, \mathrm{ITE}_{\mathrm{i}}, \mathrm{NTC}_{\mathrm{i}}, \mathrm{NTE}_{\mathrm{i}}, \mathrm{MSD}_{\mathrm{i}}, \mathrm{CSAC}_{\mathrm{i}}, \mathrm{APC}_{\mathrm{i}}, \mathrm{SGE}_{\mathrm{i}}, \mathrm{OTC}_{\mathrm{i}}, \mathrm{OTE}_{\mathrm{i}}\right)$,

where:

- ITD denotes illicit trafficking detection

- ITE denotes illicit trafficking enforcement

- NTC denotes nuclear trade compliance

- NTE denotes nuclear trade enforcement

- MSD denotes member State detection

- CSA denotes Comprehensive Safeguards Agreement (CSA) compliance

- APC denotes Additional Protocol (AP) compliance

- SGE denotes safeguards enforcement

- OTC denotes other treaty compliance

- OTE denotes other treaty enforcement

${ }^{7}$ Reliable nuclear fuel services and supply (RNFS) have generally involved proposals to develop multilateral and bilateral arrangements to provide nuclear fuel services and assurances of supply in exchange for agreements to defer development of new State enrichment and reprocessing programs. 
Phillips contends that the practical institutional barriers to proliferation include: "1) cooperative and non-cooperative investigations to verify peaceful end use of technology, 2) bilateral and multilateral legal consent obligations and verification requirements attached to the trade regime, 3) associated continuous monitoring of the flow of nuclear and dual use commodities, and 5) broad monitoring of nuclear program signatures at ultra-trace levels. The pathways that are impeded include: 1) diversion of nuclear material, 2) misuse of facilities, 3) detection of undeclared nuclear activity, 4) ability to procure nuclear goods and services on the open market to serve illicit purposes, 5) ability to escape detection when procuring nuclear goods and services on the black market, and 6) ability to escape detection of weapon development and testing programs.",

In a special edition of the Journal of Conflict Resolution devoted to proliferation analysis, Montgomery and Sagan (2009) identify challenges with predicting proliferation while specifically acknowledging the quantitative work of Singh and Way and Jo and Gartzke. They note that there are still challenges with scarce open-source data about proliferation activities and with coding complex factors such as prestige and bureaucratic influence, and that poor proxies are often used for such concepts as the nonproliferation regime. They maintain that most studies tend to provide insights that most experts already know and understand, thus failing to provide additional information to policy makers. Furthermore, the current quantitative literature often ignores or glosses over data crucial for policy making and wider debates. As a final cautionary note they warn against hasty application of quantitative results to policy making.

\subsection{Comparison of Modeling Approaches}

Of the quantitative approaches we investigated only quantitative studies using regression analysis have been published. Although alternative proposed approaches exist such as Phillips's PPI model and Kwon's proposed multi-criteria analysis have not been quantitatively tested across a broad range of countries. Perhaps the most significant quantitative studies are the Singh andWay and Jo and Gartzke studies.

Although these two studies identify which independent variables are significant in predicting proliferation, as noted earlier, the type of regression models used make it difficult to determine the relative importance of the predictor variables. We addressed the question of relative importance using the BN and the concept of "diagnosticity" (discussed later in this section). Singh and Way point out that, for their models, one cannot interpret the regression coefficients as the change in the dependent variable in relation to a unit change in the independent variable. For the hazard model, they offer both the standard coefficients and the coefficients in the log relative form. The latter can be interpreted in terms of the percentage increase in the value of the dependent variable, but the order in which the variables are regressed may affect the results. For the logistic regression, it is also the case that the regression coefficients are not directly interpretable. The authors provide significance tests whose p-values are an indication of the relative importance of the coefficients. However, there are two problems with using pvalues to rank the importance of the independent variables. First, many coefficients have the same significance level of $\mathrm{p}=0.001$; second, again the order in which the independent variables are entered into the regression equation will affect their significance. In a BN, diagnosticity provides a way of measuring which variables are most useful in distinguishing among alternative hypotheses for a given state of knowledge. For BNs, diagnosticity is a measure of how much the uncertainty in the variable of interest would be reduced if one knew the value of the indicator. The diagnosticity calculation based on the 
amount of potential entropy reduction as defined by Jensen (1996). A feature of the BN software we used to implement the BNs is the ability to calculate diagnosticity. The greater the magnitude of the diagnostic value the greater the diagnosticity. How to best compare diagnosticity to the relative importance of the independent variables based on the Singh and Way regression models remains an open issue.

Additionally we identified BN modeling in earlier stages (Coles 2009a, Coles 200b) as having a number of other advantages such as:

- The structure and the numerical parameters can be learned from data or they can be elicited from experts, or they can be a mixture of both;

- It is easy to run cases specific to a particular country;

- Readily available off-the-shelf software displays the models and supports direct interaction with the models;

- Software calculates diagnostic information indicating importance of model components; and

- $\quad$ BN models can combine variables from several models

BNs, sometimes called belief networks, causal probabilistic networks, or causal networks (Pearl 1988), are directed acyclic graphs in which nodes represent random variables and arcs represent probabilistic dependences among them. The structure of a BN is a qualitative representation of the interactions among the set of variables being modeled. The structure of the directed graph can be created to illustrate causal relationships of the modeled domain, although this is not necessary. A causal structure can give useful insight into the interactions among the variables and allows for prediction of the effects of changing parameters.

A BN also represents the quantitative relationships among the modeled variables in the form of a joint probability distribution. Each node is assigned a probability distribution conditional on its direct predecessors (as illustrated in the BN discussion in Section 3.0). Nodes with no predecessors are assigned prior probability distributions. For example, a simple node might be assigned the prior probability distribution over its two outcomes: Success and Failure.

Node forecast is performed by determining a probability distribution over a set of outcomes (e.g., Good, Moderate, Poor) conditional on the outcomes of its predecessor (e.g., a simple node with the outcome of Success and Failure). Both the structure and the numerical parameters of a BN can be learned from data, as the structure is simply a representation of independencies in the data and the numbers are a representation of the joint probability distributions that can be inferred from the data. The structure and the numerical parameters of a BN can also be elicited from experts. Finally, both the structure and the numerical probabilities can be a mixture of expert knowledge and measurements and objective frequency data.

For BNs, diagnosticity is a measure of how much the uncertainty in the variable of interest (motivation, for example) would be reduced if one knew the value of the indicator. Ultimately, diagnosticity is the ability to distinguish among hypotheses. A feature of the BN software we used to implement the BNs is the ability to calculate diagnosticity. In this case, the hypothesis under investigation is whether a country has acquired nuclear weapons. 
The diagnosticity calculation is based on the amount of potential entropy reduction as defined by Jensen (1996). Entropy is also known as Uncertainty in Shannon Information Theory (Roos 2005) and is calculated as:

$$
\mathrm{U}(\mathrm{X})=-\sum_{i=1}^{n} p\left(x_{i}\right) \log _{2} p\left(x_{i}\right)
$$

where $\mathrm{U}(\mathrm{X})$ is the entropy of the discrete random variable $\mathrm{X}$ and $p\left(x_{i}\right)$ is the probability that $\mathrm{X}$ takes the value $x_{i}$.

The diagnosticity is the difference between the entropy of the prior distribution and the expectation of the entropy in the posterior distributions, which is defined as the entropy in the posterior distributions weighted by the "pre-posterior" distributions. Calculation of diagnosticity is a feature o fthe BN software (i.e., GeNIe) we used.

The diagnosticity of the predictors identified in the Singh and Way study were calculated in an early $\mathrm{BN}$ model and presented in an earlier report (Coles 2009b), and is omitted here. The greater the diagnosticity of a predictor the larger the impact it will have in deciding whether a State is acquiring nuclear weapons. Variables with the highest diagnostic value are the most helpful in deciding among the competing hypotheses (acquiring or not) because they will have the greatest impact on reducing the uncertainty.

\subsection{Social Models of Proliferation}

In this section, we describe the development of our BN models, supporting data compilation and analysis, model parameter calibration, model validation, assessment results related to showing utility of social modeling, and other significant modeling efforts. In addition to the BN model effort, we also explored the application of a system dynamic (SD) modeling framework to state-level proliferation. Accordingly, a preliminary proliferation propensity SD is also described here.

\subsection{Preface to BN Proliferation Propensity Modeling}

We were motivated to develop a model that could be used by analysts to assess the proliferation propensity of countries. We wanted a model that would provide a relative proliferation potential metric based upon factors that had been identified in the literature. The model that we developed and presented here is a composite and represents an evolution and culmination of model development. We initially identified the two major factors relevant to proliferation as being motivation and nuclear capability, which 
defined the basic structure of our initial model (Coles 2009). Motivation was seen as resulting from political factors such as regional stability, the level of integration into the world political community, and whether there is a perceived nuclear threat as a result of weapons development among neighboring States. Nuclear capability was seen as the means by which proliferation could be accomplished consisting of factors related to technical knowledge, material resources, and economic ability. Literature reviews reinforced these observations and provided the information to develop these ideas in more detail, but the basic structure has been a recurring theme. There have been attempts by researchers to quantify the impact of various factors on proliferation propensity (discussed in Section 2.2), which consist primarily of regression analysis of various types. These studies were useful in that they confirmed the fundamental structure our model and suggested refinements in terms of further specification. We compared the diagnosticity of the variables in our Bayesian net model with their importance in the regression models as part of an initial validation. The virtues of BN models are extolled elsewhere in this report but, in general, we are of the opinion that $\mathrm{BN}$ modeling facilitates exploration and assessment insights better than the existing regression models.

A key element added to our model, which has not been emphasized in much of the political science literature, was the impact of the "non-proliferation regime." It measures the effectiveness of efforts to minimize proliferation by the IAEA and other international organizations. These efforts include encouragements to sign nonproliferation treaties and to create economic and political sanctions against nations that pursue proliferation activities and are acknowledged in a handful of proposed quantitative approaches (Phillips 2010, Williams 2010, and Kwon 2009). Our preliminary model was quantified using expert elicitation of laboratory subject matter experts (SMEs) in nuclear proliferation, risk analysis, decision making, and political science. Subsequently models were more complex and incorporated data from Singh and Way (2004) and Jo and Gartzke (2007) as further developed and enhanced by us. While this data was useful in defining base rates, has allowed us to exercise the model for specific countries and was fundamental to the validation test of the model, the conditional probability tables are still based upon expert judgment in various forms.

\subsection{BN Proliferation Propensity Model Description}

This section presents our BN proliferation propensity model including a detailed description of each the nodes. We will provide a discussion of priors and posteriors and how both data and expert judgment was used in the model. For future research, opportunities for model improvement exist for nodes that are informed by expert judgment.

BN modeling evolutions resulted in two distinct variants. One version is a causal model, shown in Figure 3.1. The gold colored nodes in the Figure 3.1 and Figure 3.2 are based on variables in the Sing and Way dataset, and the blue colored nodes are based on Jo and Gartzke variables. The three green nodes are based on variables added to the dataset by PNNL researchers. In this version, the direction of the arrows is from causes to effects. So for example, the impact of regional stability on motivation, which has the mediating variable, geopolitical security, has arrows from regional stability to geopolitical security and from geopolitical security to motivation). 


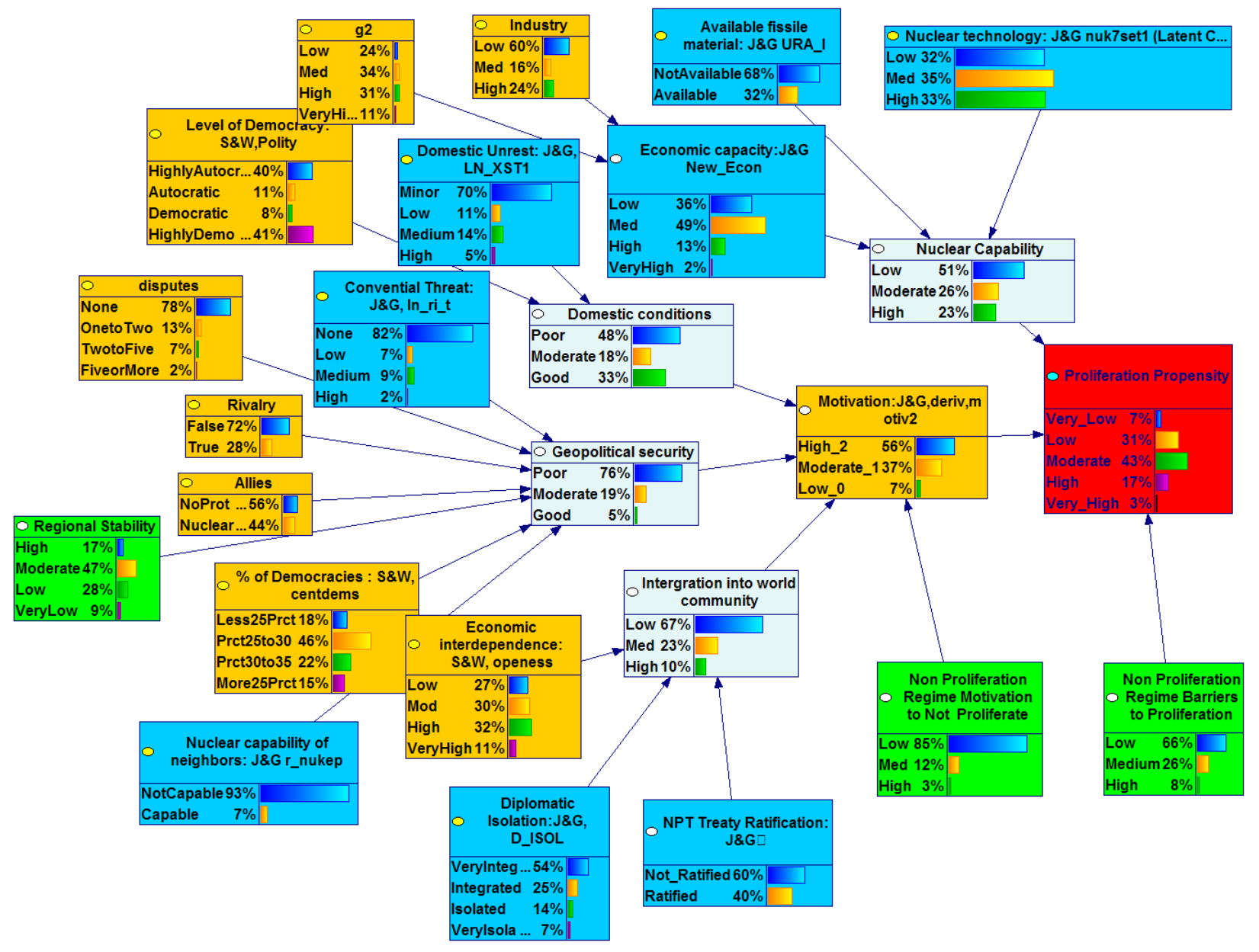

Figure 3.1. Causal Version of Composite Model

We created a second model that we refer to as a "diagnostic model." We eventually chose this model for performing validation tests and to test our hypothesis about the utility of social modeling because we thought it was the better predictive model. The diagnostic model has the arrows relevant to motivation reversed and the intervening variables removed. The variables related to motivation can be thought of as indicators of the level of motivation. The causal model is the direct evolution of our model building efforts, but there are a couple of reasons for building the diagnostic model as a variant. First, the causal model was not as sensitive to changes in the input variables as the diagnostic model. The diagnostic model provides a direct link to all the variables that are relevant to motivation. The other reason was that it was easier to assess the conditional probability distributions in the diagnostic model. Part of the reason for including the intervening variables in the causal model was to minimize the number of parents for any given variable. This is not an issue with the diagnostic model. The discussion that follows will focus on the diagnostic model, which is shown in Figure 3.2. 


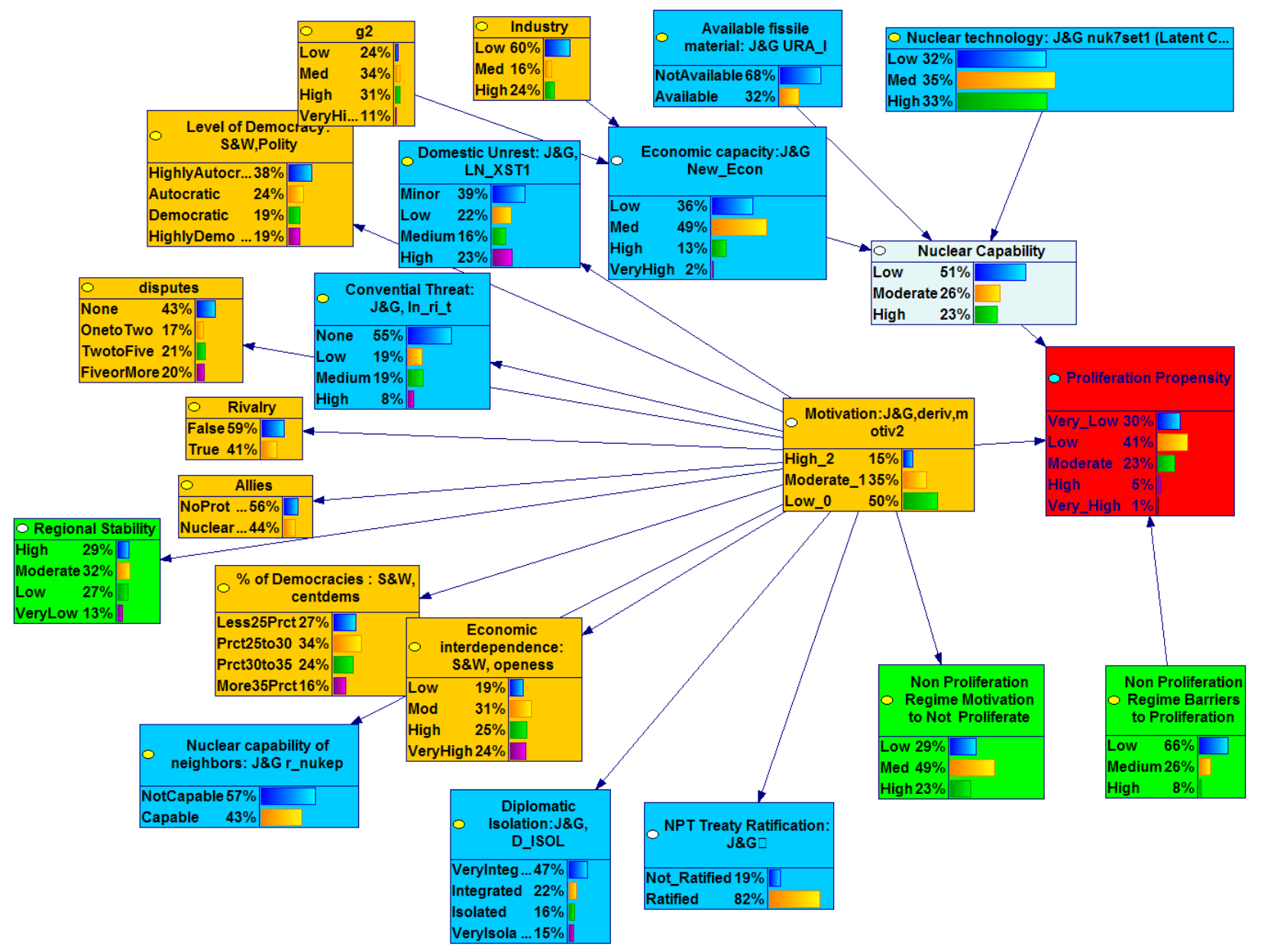

Figure 3.2. Diagnostic Version of Composite Model

\subsubsection{Node Definitions}

Systematic quantitative studies conducted by Singh and Way (2004) and Jo and Gartzke (2007) provide particularly valuable insight into the possible driving forces that lead a state to "go nuclear". In our study, going nuclear is defined as the acquisition of nuclear arms/development of nuclear weapons programs. Below we describe the nodes in our BN model. Together, these studies suggest three groups of plausible explanatory variables: technological determinants such as a State's gross domestic product (GDP) per capita and industrial capacity; external factors such as a State's involvement in enduring rivalries, militarized disputes and defense pacts; and factors internal to the socio-political environment of a State such as polity, openness, and integration with the global political and economic system. Pooling the data from these studies, we developed a BN model to examine the relationship between these variables and a state's propensity to go nuclear.

1. Available Fissile Material Node. This node measures whether a country already possesses nuclear explosive materials for nuclear weapons. The availability of fissile material is a prerequisite for any nuclear weapons program. The materials of interest in our study are uranium deposits and processed uranium (Source: Jo and Gartzke 2007). The availability of fissile materials is a prerequisite for any nuclear weapons program. The production, enrichment, 
transaction, and transportation of fissile material are under strict international surveillance and regulations. For a discussion on fissile material and the acquisition of fissile material, see On Nuclear Terrorism by Levi (2007).

2. Nuclear Capability Node. This node addresses the question of whether a country has the economic capacity, technical know-how, and sufficient fissile material to build nuclear arms. It is the confluence of a country's current economic capability, latent technical know-how and current possession of fissile material.

3. Economic Capacity Node. This node represents the strength of a country's economy in relation to developing nuclear weapons programs. Economic capacity is an index operationalized as a country's average annual energy consumption and iron/steel production (Source: Jo and Gartzke 2007).

4. Nuclear Technologies Node. The node addresses contributing technologies considered as necessary for latent nuclear weapons production capability and indicates a state's capability of producing nuclear weapons. These contributors are: 1) uranium deposits, 2) metallurgists, 3) chemical engineers, 4) nuclear engineers/physicists/chemists, 5) electronic/explosive specialists, 6) nitric acid production capacity, and 7) electricity production capacity (Source: Jo and Gartzke 2007).

5. Industry Node. This node represents a State's industrial capability relevant to nuclear weapons programs and focuses on electricity and steel production (Source: Singh and Way 2004). It has three levels. It is coded as low if a country does not have domestic steel production capacity and its electricity production capacity does not meet the 5000 Megawatt threshold, medium if a country's domestic and electricity production meet this electricity production capacity and high if a country's capacity exceeds the threshold.

6. $\mathbf{G}^{2}$ Node. This node is the gross domestic product (GDP) per capita squared and is an indicator of the level of State's economic development (Source: Singh and Way, 2004). In this model, GDP per capita is squared to account for a possible non-linear relationship between GDP per capita and proliferation propensity. Compared to GDP, GDP per capita more appropriately measures the level of individual productivity, and is be more closely related to the necessary technical knowledge and skills needed for developing nuclear weapons.

7. Domestic Unrest Node. This node is an indicator of a State's internal regime stability. It is proportional to the total number of reported anti-governmental demonstrations, strikes, and riots and is weighed by the country's population (Source: Jo and Gartzke 2007).

8. Conventional Threat Node. This node indicates conventional military threat indicated by the relative balance/imbalance of military powers and capabilities between a state and its rivals Source: Jo and Gartzke 2007). It takes on values of none, low, medium, and high. It compares the national capability scores of a state's rivals to that of the state.

9. Regional Stability Node. This node addresses regional security, indicating the security environment at the regional level based on the average number of militarized conflicts reported in each country within a region. We constructed the data for this variable (See section 3.3.4). Higher numbers of conflicts indicate a low level of regional stability. Divisions of regions are based on geographic proximity. 
10. Disputes Node. This node addresses disputes and indicates the degree of interstate security threats that a State encounters. This node is based on a 5-year moving average of the annual count of interstate militarized disputes experienced by a State (Source: Singh and Way 2004).

11. Rivalry Node. This node addresses whether a State was involved in at least one enduring rivalry or militarized dispute in a given year. This node represents dichotomous states: a State is involved in one or more rivalries or not.

12. Allies Node. This node addresses whether a State has nuclear protection from one of the major powers (Source: Singh and Way 2004). This node represents dichotomous states: a state has a nuclear protector or has signed a "defense pact" with one of the major power states (i.e., United States, Russia, United Kingdom, France, and China) or not.

13. \% of Democracies Node. This node addresses the prevalence of democracy among a State's neighbors (Source: Singh and Way 2004). It is based on the percentage of democratic countries with high democracy scores out of all neighboring countries for a given state. A democratic polity is considered to be less motivated to proliferate and the presence of neighboring democratic states may provide a relatively stable and peaceful external environment thus helping deter proliferation.

14. Nuclear Capabilities of Neighbors Node. This node addresses whether a State's rival states possess nuclear weapons programs (Source: Jo and Gartzke 2007). This node represents dichotomous states: capable, if any of its rivalries have such programs, and not capable otherwise.

15. Economic Interdependence Node. This node addresses the extent to which a State's economy is open and integrated with the international economic system (Source: Singh and Way 2004). A high level of economic interdependence is considered to be a negative motivator to nuclear proliferation. It is based on total export and import as a percentage of a country's GDP. Openness to international economic exchange is indicative of the interdependent relationship that a state develops with other states. Research suggests that factors such as engagements in international trade, openness to foreign investments, international trade-related tax policy, and the mobility of capital are all important indicators of economic interdependence.

16. Diplomatic Isolation Node. This node addresses whether diplomatic isolation is present when a state lacks official diplomatic relationships with its relevant states (Source: Jo and Gartzke 2007). Relevant States are defined as those that are within 150 miles of a given state and the world's major powers. This node is based on the ratio between the number of states with which a state has no diplomatic relationships and the total number of its neighboring states and major powers.

17. Integration into World Community Node. This node addresses the level at which a country is integrated into the global system economically and politically. It is conditioned on the level of economic interdependence, diplomatic isolation, and a State's NPT ratification status. A high level of integration into the world community is considered a negative motivator to nuclear proliferation.

18. Level of Democracy Node. This node indicates the level of democracy based on democracy and autocracy scores for a given State. The polity scores are based on: 1) competitiveness of political participation; 2) openness of executive recruitment; 3) competiveness of executive recruitment, and 4) constraints on the chief executive. The autocracy score is assessed in the same dimensions as is democracy plus the level of regulation of political participation (Marshall and Jaggers, 2009). 
19. Geopolitical Security Node. This node indicates a geopolitical security measure for a given state. It reflects the frequency of a State's inter-state militarized conflicts and disputes, intensity and persistence of regional rivalry and conventional military threat, number of allies, nuclear weapons capabilities of neighboring States, regional stability, and the prevalence of democratic States in the region.

20. Domestic Conditions Node. This node measures the internal socio-political stability and the level of democratization of a country. For example, a high frequency of domestic unrest coupled with a low democracy score suggests poor domestic conditions. By comparison, a low level of domestic unrest and a high democracy score indicate good domestic conditions.

21. NPT Treaty Ratification Node. This node indicates whether a country has ratified the NPT (except for the five declared nuclear powers). This node represents dichotomous states: a State ratified the NPT or not.

22. Motivation Node. This node addresses the degree and complexity of the driving forces that lead a state to proliferate. These driving forces may be rooted in a broad range of factors, for instance, a state's political ambition driven by national pride or desire to counteract an enduring rival who already possesses nuclear arms or desire to expand its international influence.

23. Non-proliferation Regime Motivation to Not Proliferate Node. This node addresses the impact of the nonproliferation regime on the motivation of a State to proliferate and is based on nonproliferation regime agreements signed on to such as the Additional protocol, the CSA, and the Comprehensive Test Ban Treaty (CTBT). We constructed the data for this variable (See section 3.3.4).

24. Non-proliferation Regime Barriers to Proliferation Node. This node addresses the impact of the nonproliferation regime as a barrier to State proliferation and is based on nonproliferation regime agreements signed on to. We constructed the data for this variable. (See section 3.3.4).

25. Proliferation Propensity Node. This outcome node assesses the likelihood that a state is going to proliferate. Five levels of proliferation propensity are designated: 1) Very Low; 2) Low; 3) Moderate; 4) High; 5) Very High.

\subsubsection{Model Parameters and Expert Judgment}

This section discusses how model parameters were developed for the model that we consider the most evolved, the diagnostic model presented in Figure 3.2 of Section 3.2. This section also discusses the quantification of the priors and posteriors for our proliferation propensity model node probabilities and how both data and expert judgment was used in the model. The construction of the BN model structure was informed by relevant research literature and expert knowledge. The calculation of model parameters often come from two sources: expert knowledge or data. Since our plan is to use the combined dataset to validate the model, we relied heavily on experts' judgment to estimate the model parameters. The modelers and subject matter experts on the team estimated the conditional probability distributions (CPD) for the nodes and iteratively refined them.

Probability distributions for root nodes come directly from the database. The frequency distributions for all countries and all years were plotted and a suitable discretization chosen. The GeNIe software ${ }^{8}$ has

\footnotetext{
${ }^{8}$ http://genie.sis.pitt.edu/Decision Systems Laboratory, University of Pittsburgh
} 
the capability of assisting in the process. Figure 3.3 is a snapshot of the discretization chosen for Percentage of Democracies, which is the variable, "centdems," in the Sing and Way dataset. As can be seen in the figure, the categories for Percentage of Democracies are less than 25 percent, 25-30 percent, 30-35 percent, and greater than 35 percent. The discretizations were initially chosen based on uniform widths over the variable range. These were sometimes adjusted to better balance frequencies within categories.

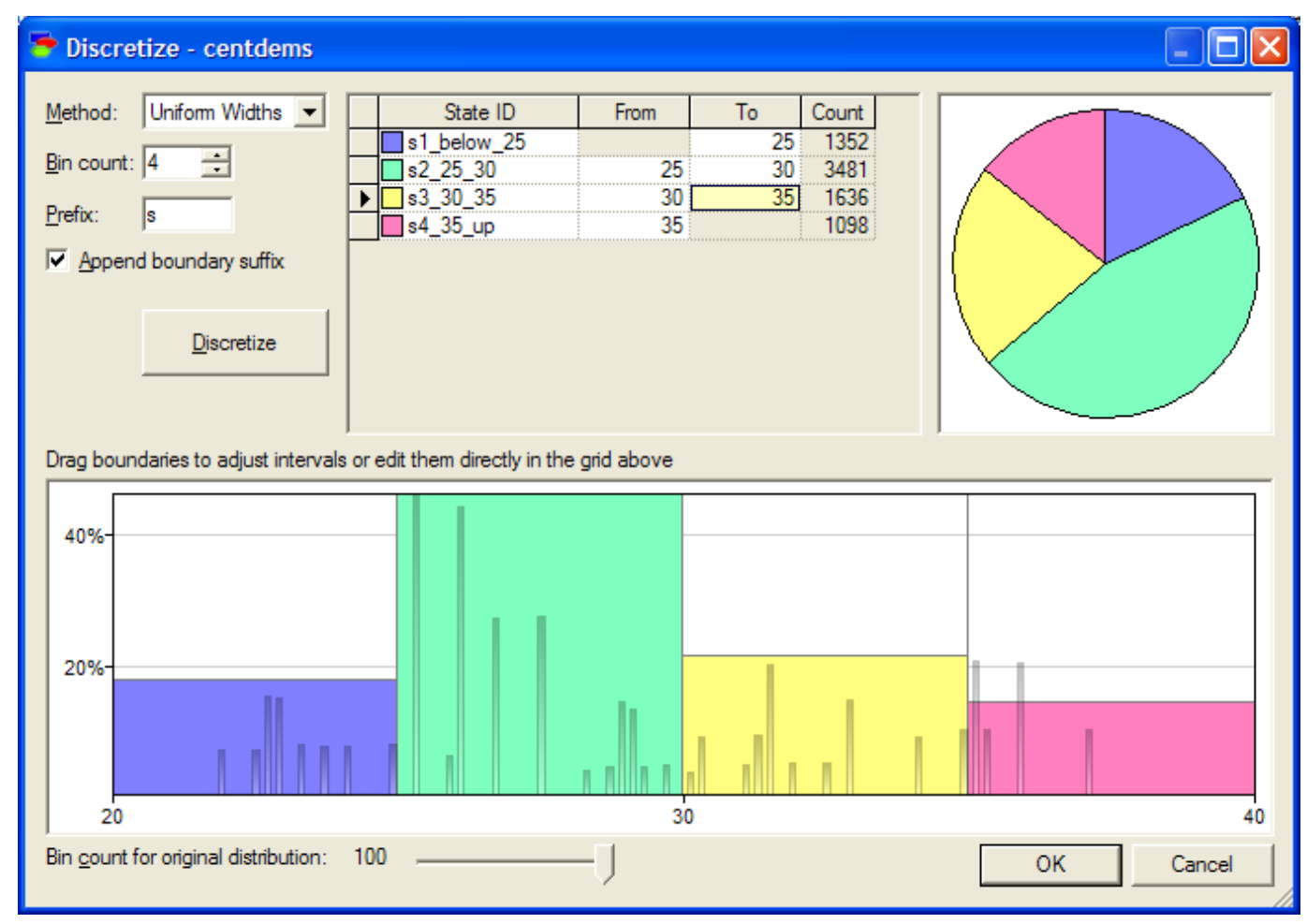

Figure 3.3. Discretization of Frequency Distribution for the Percentage of Democracies

Our initial intention was to learn all distributions from data, but this proved infeasible. The discretization shown was done to support the learning. We were able to use the frequency distribution from the data to define the probability distributions for root nodes. All root node distributions that were based on our composite dataset described in Section 3.3 drew heavily from Singh and Way or the Jo and Gartzke datasets. We used our composite dataset to learn all the probability distributions in earlier versions of this model. As discussed in Section 3.2 the earliest form of our model was a causal model in which the arrows went from the indicators to the proliferation propensity node. The causal model, which is presented in Figure 3.1, has intermediate nodes such as domestic conditions that were not in the datasets. These variables were created to group together variables that had a similar focus to make the model conceptually more understandable and it also had the added effect of minimizing the number of parents for any given child so that the conditional probability distributions would be more tractable. The down side is that the algorithm for learning the probability distributions from data could solve for these probabilities only in the absence of probabilities for these intervening variables. A later version of our model was the diagnostic model in which all the arrows went from the node of interest (i.e. proliferation propensity node) to the indicators. The diagnostic version is shown in Figure 3.2. Although this model 
excludes the intermediate variables, its structure does not easily lend itself to the possibility of learning probabilities from data. So, although this represents future development work, we committed to learning parameters based on expert judgment, and that process used will be discussed in more detail in the next section.

\subsubsection{Condition Probability Distribution for Proliferation Propensity}

Literature reviews support the notion that proliferation propensity should depend on both capability and motivation and that these are the primary factors. Our original conditional probability distribution for proliferation propensity was developed based on just these two parents. The distribution was modified in the node, non-proliferation regime barriers, was added to our model. This section explains how we arrived at the distribution as a function of motivation and capability.

Capability is a necessary condition for proliferation, but can be acquired over time given motivation. Without motivation, capability might appear to present low proliferation risk. However, with sufficient capability the option to proliferate might lead to greater motivation under certain conditions. In any event, both motivation and capability are key components to proliferation propensity and the question becomes: what is the relative importance of these two factors.

One way to answer the question of the relative importance of motivation and capability would be to look at the data. However, the number of proliferators is too small to get a meaningful estimate from the data. In developing a CPD for proliferation propensity based on expert judgment, we explored the implications of weighting them differently on the resulting CPD. For example, one can argue that motivation is more important in that without motivation, no decision will be made to proliferate despite technical capability.

One way to explore their relative importance is by using a proliferation risk model:

$$
\text { Risk }=a^{*} \text { Motivation }+b^{*} \text { Capability }
$$

This additive model assumes that either is sufficient to result in some risk. This contrasts with a multiplicative model which would require that both exist for there to be any risk. The additive model is consistent with the introductory discussion to this section. The relative importance can be expressed as the ratio of $a / b$. Consider two possibilities: the ratio of motivation to capability is $3: 1$ versus $3: 2$. These two possibilities are explored in Figure 3.4. If motivation and capability take on three levels: 0, 1, and 2, then the calculated risk levels, using Equation (4), would be as shown in Figure 3.4. Note that the qualitative risk levels are similar for both models. We chose the ratio of 3:2 and used these qualitative levels to guide us in assigning probabilities. 


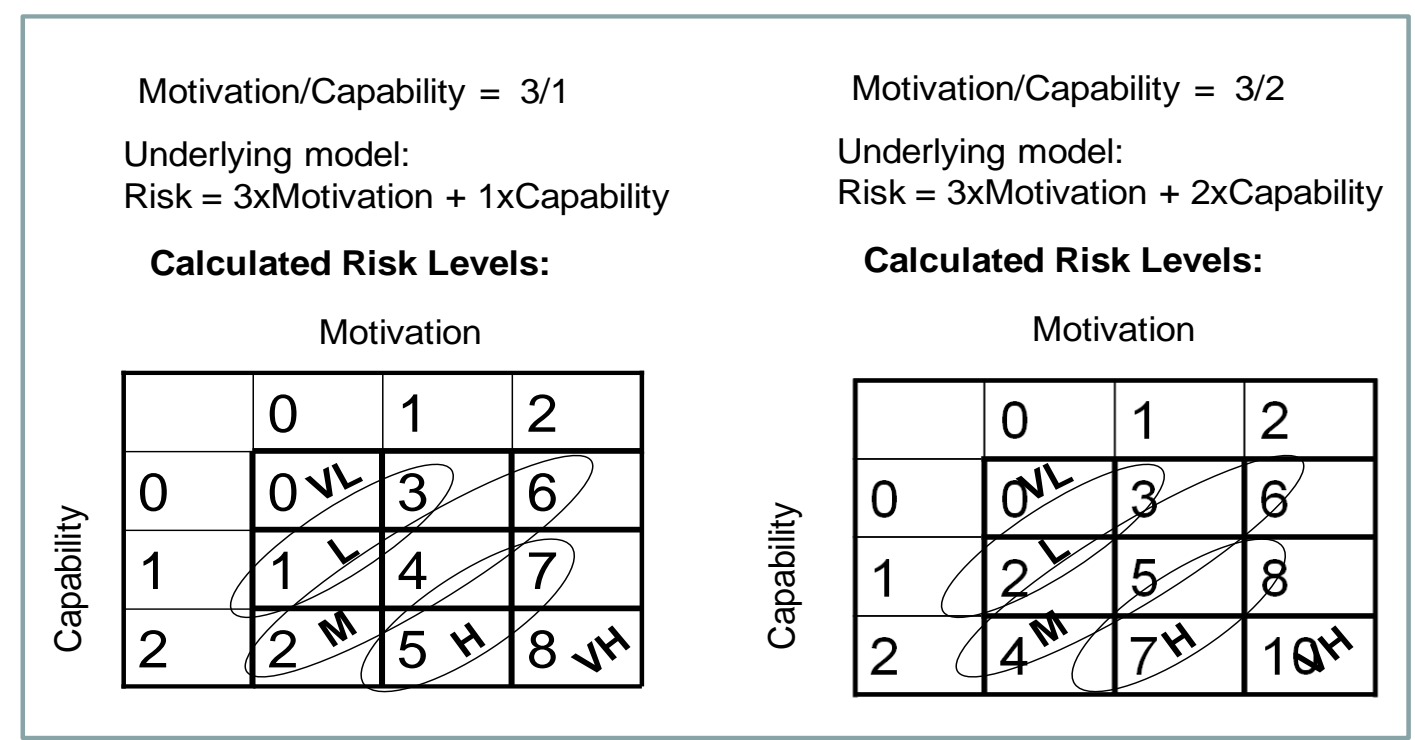

Figure 3.4. Comparison of Risk Importance of Motivation to Capability for Two Assumptions

In Figure 3.5 we show how probabilities were assigned. The upper left hand panel of this figure is the risk level as a function of motivation and capability as calculated by the model based on a 3:2 ratio of motivation to capability. These numbers lead to qualitative characterization of the risk as a function of qualitative characterizations of the levels of motivation and capability as shown in the upper right panel. So, low motivation and low capability result in very low proliferation risk. If both motivation and capability are high, the proliferation risk is very high, and intermediate levels fall in between. So for example, moderate levels of both capability and motivation result in moderate proliferation risk. If motivation is high and capability is low this is a high-moderate risk level as contrasted with high capability and low motivation which is a low-moderate risk level and consistent with the notion of weighting motivation more than capability. The bottom panel in the figure shows how the qualitative functional relationships were quantified in the CPD. The numbers in the CPD are consistent with the qualitative judgments derived from the simple mathematical model. Other CPDs were derived from similar thought processes. 
Calculated Risk Levels: Motivation
Qualitative Risk Levels

Motivation
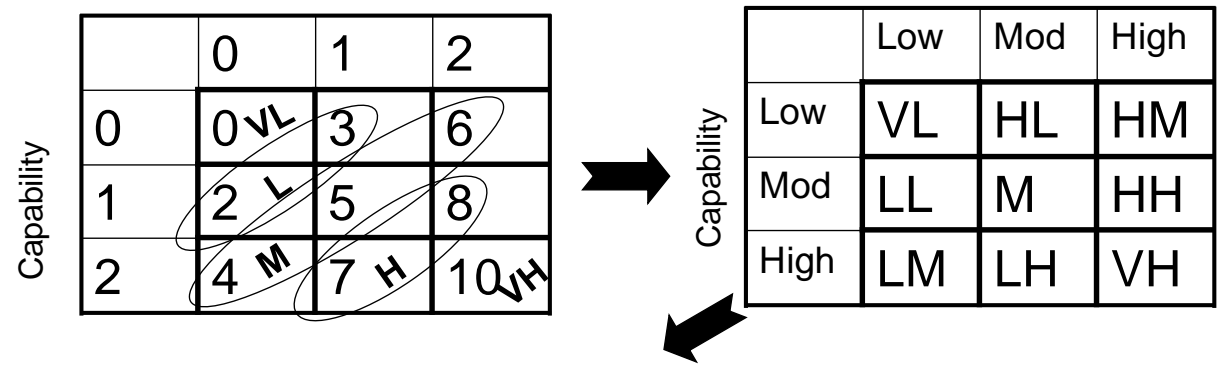

Proposed Conditional Probability Distribution for Proliferation Risk

\begin{tabular}{|c|c|c|c|c|c|c|c|c|c|}
\hline Motivation:J8G... & \multicolumn{3}{|c|}{ Low_O } & \multicolumn{3}{|c|}{ Moderate_1 } & \multicolumn{3}{|c|}{ High_2 } \\
\hline Nuclear Capabi.. & Low & Moderate & High & Low & Moderate & High & Low & Moderate & High \\
\hline Very_Low & 0.9 & 0.02 & 0.1 & 0 & 0 & 0 & 0 & 0 & 0 \\
\hline Low & 0.1 & 0.9 & 0.2 & 0.8 & 0.15 & 0.1 & 0.1 & 0 & 0 \\
\hline Moderate & 0 & 0.08 & 0.7 & 0.2 & 0.8 & 0.3 & 0.7 & 0.1 & 0 \\
\hline High & 0 & 0 & 0 & 0 & 0.05 & 0.6 & 0.2 & 0.7 & 0.1 \\
\hline Jery_High & 0 & 0 & 0 & 0 & 0 & 0 & 0 & 0.2 & 0.9 \\
\hline
\end{tabular}

Figure 3.5. Derivation of Conditional Probability Distribution for Proliferation Risk

\subsubsection{Conditional Probability Distribution for Motivation Indicators}

The condition probability distributions for the indicators for motivation were determined with a unique method that has potential for more development as a formal expert elicitation process. There are thirteen indicators relevant to motivation in the model. In the causal model the motivation forecast node and indicator variables are separated by intervening variables so that motivation has only four parents rather than thirteen. Even so, we made use of a "Noisy OR-gate" (Henrion 1989, 1991) in order to simplify the CPD assessment. For the diagnostic model, with the arrows reversed, each of the indicators has just one parent, motivation. Initially, CPDs were developed that seemed to reasonably reflect the likelihood of observing that indicator for each level of motivation. However it was desired to create CPDs that better reflect the relative importance of each of the indicators rather than just considering each one independently. It was also desired that these distributions reflect the collective judgments of several experts. To this end we created rankings of relative importance for the indicators. A set of cards with the indicator names were used by three laboratory SMEs to assess the ranked importance of the indicators. Table 3.1 shows the ranking of the three SMEs and how the individual judgments were combined to create an overall ranking. The ranking values range from 1 to 13 with 1 being the highest rank and 13, the lowest. 
Table 3.1. Combined Judgments of Importance to Motivation

\begin{tabular}{|l|c|c|c|c|}
\hline \multirow{2}{*}{\multicolumn{1}{|c|}{ Variable }} & \multicolumn{2}{c|}{$\begin{array}{c}\text { Judged } \\
\text { Importance to } \\
\text { Motivation }\end{array}$} & \multicolumn{3}{c|}{$\begin{array}{c}\text { Subject Matter Expert } \\
\text { Rankings }\end{array}$} \\
\cline { 3 - 5 } & SME 1 & SME 2 & SME 3 \\
\hline Nuclear Capability of Neighbors & 1 & 1 & 6 & 2 \\
\hline Non Proliferation regime motivation to Not Proliferate & 2 & 4 & 2 & 3 \\
\hline Disputes & 3 & 3 & 7 & 1 \\
\hline Allies & 4 & 2 & 4 & 7 \\
\hline NPT Treaty Radification & 5 & 8 & 3 & 4 \\
\hline Regional Stability & 6 & 6 & 8 & 6 \\
\hline Rivalry & 7 & 11 & 5 & 5 \\
\hline Conventional Threat & 8 & 10 & 1 & 8 \\
\hline Domestic Unrest & 9 & 8 & 9 & 11 \\
\hline Diplomatic Isolation & 10 & 7 & 12 & 9 \\
\hline Economic Interdependence & 11 & 5 & 13 & 10 \\
\hline Level of Democracy & 12 & 13 & 10 & 12 \\
\hline Percentage of Democracies & 13 & 12 & 11 & 13 \\
\hline
\end{tabular}

The next step was to create the thirteen CPDs, one for each indicator, so that their relative importance in the model would correspond to how their importance was the judged by the SMEs. A way to calculate the relative importance of an indicator in a BN is by determining its "diagnosticity." Diagnosticity is a measure of how much the uncertainty in the variable of interest would be reduced if one knew the value of the indicator. A feature of the BN software we used to implement the BNs is the ability to calculate diagnosticity. The greater the magnitude of the diagnostic value the greater the diagnosticity. Through trial and error, we adjusted the indicator CPDs so that the rankings of their diagnosticity would correspond to the judged importance to motivation. The results are shown in Table 3.2. As can be seen in the table, although the magnitudes of diagnostic values are not identical to the rankings given by the SMEs, the general ordering of their magnitude is similar.

Table 3.2. Diagnostic Values and Judged Importance for Motivation Indicators

\begin{tabular}{|l|c|c|}
\hline \multicolumn{1}{|c|}{ Variable } & $\begin{array}{c}\text { Judged Importance to } \\
\text { Proliferation Motivation }\end{array}$ & Diagnostic Value \\
\hline $\begin{array}{l}\text { Nuclear Capability of Neighbors } \\
\text { mon proliferation regime }\end{array}$ & 1 & 0.312 \\
\hline Disputes & 2 & 0.329 \\
\hline Allies & 3 & 0.265 \\
\hline NPT Treaty radification & 4 & 0.171 \\
\hline Regional Stability & 5 & 0.111 \\
\hline Rivalry & 6 & 0.092 \\
\hline Conventional Threat & 7 & 0.098 \\
\hline Domestic Unrest & 8 & 0.080 \\
\hline Diplomatic Isolation & 9 & 0.074 \\
\hline Economic Interdependence & 10 & 0.048 \\
\hline Level of Democracy & 11 & 0.086 \\
\hline Percentage of Democracies & 12 & 0.068 \\
\hline
\end{tabular}


With increasingly available datasets concerning nonproliferation such as Kroenig (2009), Fuhrmann, (2008), and Nelson and Sprecher (2010), as well as new datasets synthesized by PNNL researchers, we anticipate that opportunities for model improvement exist for nodes that are informed by expert judgment and that model validation with data will become more feasible and defensible.

\subsection{Data Compilation and Analyses in Support of Modeling}

In the following subsections, we provide descriptions of the datasets used in developing the statelevel BN proliferation propensity model. We discuss the variables from Singh and Way (2004), and Jo and Gartzke (2007) datasets in some detail as we borrow heavily from these sources. Based on these data, the research team conducted extensive data combination, consolidation, modification, and analyses, all of which are discussed. We also describe data collected and derived by PNNL researchers to augment the Singh and Way and Jo and Gartzke datasets. We conclude the section by providing additional data sources identified by PNNL researchers as a useful reference for future research.

In view of the major theoretical arguments and empirical studies described in the previous section, the research team decided to utilize the datasets compiled by Singh and Way (2004), and Jo and Gartzke (2007) to identify the relationships between key variables to determine the model structure. Despite a number of limitations associated with these data (Montgomery and Sagan 2009), there are nonetheless a few major advantages to exploring them. First, early proliferation studies tend to employ the case study method with rich and extensive analysis of specific countries. Although useful, these case studies do not lend themselves easily to theory testing and validation, and their findings have limited generalizability. By contrast, studies by Singh and Way and Jo and Gartzke are among the pioneering efforts in quantitatively testing competing hypotheses about proliferation and offer a systematic approach to organizing the vast amount of existing information, knowledge, and insight in accordance with proliferation theories. Second, their data are remarkably comprehensive, spanning the boundaries of over 100 states in the world, tracing the development of technical, social, and political trends over several decades. Thus, rather than presenting a snapshot view of proliferation activities, the data delivers a broad coverage that not only makes it possible to model state-level proliferation on a large scale but also enables the modelers to take into consideration the dynamics of these societal forces in relation to proliferation. Third, using the data collected by well-established research projects such as the $\mathrm{COW}^{9}$ and Polity $\mathrm{IV}^{10}$ helps reduce the data collection needs at this stage of modeling. Consequently, much of the resources were invested in creating, critiquing, and strengthening the structural soundness and validity of our model instead of collecting data. Future studies could certainly benefit from data of higher quality or even new data. We believe that these datasets are sufficient for the objective of our current project since the BN model we developed is intended as an important initial step toward improving integrative proliferation

\footnotetext{
${ }^{9}$ The Correlates of War Project was founded in 1963 by J. David Singer, a political scientist at the University of Michigan. The original and continuing goal of the project has been the systematic accumulation of scientific knowledge about war. The fundamental goal of the project was not just to measure the temporal and spatial variation in war but rather to identify factors that would systematically explain this variation. The list of data sets assembled by the project has continued to grow over the years. As of January 2005, the project continues under Director Paul Diehl, and Associate Director D. Scott Bennett. See http://www.correlatesofwar.org/cowhistory.htm.

${ }^{10}$ The Polity IV Project is a continuation of Polity research and coding the authority characteristics of states in the world system for purposes of comparative, quantitative analysis. The original Polity conceptual scheme was formulated, and the original Polity I data collected, under the direction of Ted Robert Gurr; the Polity scheme was informed by foundational, collaborative work with Harry Eckstein [9], Patterns of Authority: A Structural Basis for Political Inquiry (New York: John Wiley \& Sons, 1975).
} 
modeling, a full accomplishment of which calls for additional research efforts beyond the scope of this project.

\subsubsection{Overview of Singh and Way Data}

In the Singh and Way (2004) study, proliferation was analyzed as a stepwise process moving from a state manifesting no interest in nuclear weapons, to exploration of weapons programs, and then to the pursuit and acquisition of nuclear weapons. Their dataset provides coverage for 154 countries from 1945 to 2000. The unit of analysis is country-year.

Singh and Way (2004) tested the effect of three competing propositions and categorized explanatory variables accordingly. First, they incorporated factors that reflect the technical determinist proposition, which argues that technical factors such as states' economic prosperity, citizenry literacy level, and the nation's industrial capacity are indicators of the state's latent nuclear capacity. With a high level of latent nuclear ability, whether or not a state will pursue or acquire nuclear weapons is simply a matter of choice. Second, they took into account the influence of socio-political factors external to a state such as its regional and international security environment to test whether or not these forces affect a state's willingness to go nuclear. Lastly, they include factors internal to a state, such as its political regime type, politics, and dominant national sentiment, which might generate a motivating impetus pushing the state to consider nuclear options. The Singh and Way technological determinants are:

- GDP per capita. This variable represents the level of economic development, and is presumed to be intimately related to the technical, scientific and production knowledge integral to developing nuclear weapons. The data were extracted from the Penn World Table (Heston 2002). The value ranges from $\$ 281$ to $\$ 44,000$. The authors preferred GDP per capita to GDP in order to highlight nuanced variations among countries' economic development levels, which tend to be masked by aggregate data.

- Industrial capacity index. This variable represents the level of domestic steel production and electricity generation capacity and is presumed to be related to the technical ability to produce nuclear weapons. The variable is coded 1 if a country has domestic steel production and if its electricity generation capacity exceeds 5,000 MW. Note the authors created two dichotomous variables, industry 1 and industry 2 , by setting two different thresholds for industrial capacity. It remains unclear which variable was used in their analysis. The electricity generation data was from the United Nations Energy Statistical Yearbook and steel production data came from COW National Material Capabilities ${ }^{11}$.

- Energy, electricity, and steel production and consumption. This variable is the aggregate per capita consumption of energy, electricity, and steel production. This variable supplements the Industrial Capacity measure described above. Data sources include COW Composite Index of Capabilities, Penn World Table, and the United Nations Statistical Yearbooks.

The Singh and Way External Determinants are:

\footnotetext{
${ }^{11}$ The National Material Capabilities data set contains annual values for total population, urban population, iron and steel production, energy consumption, military personnel, and military expenditure of all state members, currently from 1816-2001. The widely-used Composite Index of National Capability (CINC) index is based on these six variables and included in the data set
} 
- Enduring rivalry. This variable indicates whether a State is engaged in an enduring rivalry. It is operationalized as a dichotomous variable to measure whether in a given year a state was engaged in an enduring rivalry. The data source was Security, bargaining, an end of the interstate rivalry by Bennett (1996). Enduring rivalries pose substantial security threats as Diehl (1998) points out that enduring rivalries often facilitate wars and militarized conflicts. Thus, in order to gain a competitive advantage over its rivals, a state might be eager to develop a nuclear arsenal, which could escalate a nuclear arms race.

- Frequency of dispute involvement. This variable indicates level of dispute involvement and is used to denote the level of security threat intensity. It is derived using the militarized interstate dispute (MID) data. The authors compute the 5-year moving average of the number of militarized interstate disputes in which a state was involved in a given year. Militarized interstate disputes refer to those instances where "the threat, display or use of military force short of war by one member state is explicitly directed towards the government, official representatives, official forces, property, or territory of another state" (Jones 1998, p. 168). A high value listed under "disputes" in the dataset indicates a high level of regional insecurity.

- Security guarantee. This variable indicates where a State has forged an alliance with major powers. It is operationalized as a dichotomous variable. Forging credible alliances with nuclear powers for protection renders unnecessary indigenous weapons programs, thus may help deter proliferation (Thayer 1995). The variable includes only those defense pacts that provide significant security protection. Major Powers include the U.S., the Soviet Union/Russian, the UK (1952- ), France (1960- ), and China (1964- ). The data source is the Expected Utility Generation and data management program (EUGene).

The Singh and Way Internal Determinants are:

- Democracy and democratization. This variable indicates the level of democratization. It is derived from the Polity IV project to control for the regime type of the States (Marshall and Jaggers, 2009). Three separate variables were created. First, "polity" is operationalized as the difference between a State's democracy score and its autocracy rating score. ${ }^{12}$ To capture the trend in democratization, the authors calculated a State's polity score over 3, 5, and 10 year, respectively, to account for democratic transition. Lastly, democracy prevalence is defined as the share of democratic States whose polity scores for a given year is at least 7. (Data source: Marshall and Jaggers 2009, Polity IV codebook http://www.systemicpeace.org/inscr/p4manualv2007.pdf.) Proliferation literature remains elusive about the effect of democratization and democratic transition on proliferation outcomes. In some cases such as Argentina, democratization helped contain the proliferation intent while in other cases such as Pakistan and India democratization was fueled by and catered to the proliferative sentiment (Mistry 2003).

- Economic interdependence and liberalization. This variable indicates the degree of a State's economic exposure to other countries. It is operationalized as (export value + import value)/GDP. The trade data comes from the Penn World Table and International Monetary Fund (IMF). An

\footnotetext{
${ }^{12}$ Polity IV offers two 11-point scale ratings for democracy and autocracy, respectively. Polity score is simply the difference between the two. For example, for Country A, if its democracy measure is 8 and autocracy measure is 0 , then its polity score is $8(8-0)$.
} 
additional variable was created to account for the trends in economic liberalization over 3, 5, and 10 -year periods.

- Status inconsistency/symbolic motivations. This variable represents the impact of motivational factors such as prestige deficit, status inconsistency, and symbolic motivations. It is measured by the status differential between a State and the U.S. as well as between the State and regional leaders. Given its dominance, the U.S. was chosen as the symbol of global power. Comparing the status differential between a State and a regional leader is also important because status inconsistency not only exists globally but also locally. Measuring countries' status differentials against the U.S. and regional powers is a way of articulating how "satisfied" a state is with its regional and global status, suggesting possible status-driven motivation for some states to go nuclear. $^{13}$

\subsubsection{Overview of Jo and Gartzke Data}

The cross-section time-series data in Jo and Gartzke (2007) extend from 1932 to 1992 with "countryyear' as the unit of analysis. In this study, to account for the marked linearity in the proliferation process, proliferation is dissected into two related phenomena: the presence of nuclear weapons production programs and the possession of nuclear weapons conditional on the existence of a weapons program. Thus, the dichotomous dependent variables include: 1) whether or not a state has a nuclear weapons development program in a given year, and 2) whether or not a state has nuclear weapons in a given year if the state already has an active weapons development program.

Jo and Gartzke's conceptual framework encompasses two broad categories of variables: opportunity and willingness. Opportunity variables include availability of nuclear technical knowledge and relevant nuclear materials, and a state's economic capacity. Willingness variables measure a state's motivation to proliferate, including a state's international security concerns, internal political conditions, and a state's global and regional power status. We describe these variables in detail below. The Jo and Gartzke variables related to opportunity are:

- Latent nuclear weapons production capability. This variable represents the latent capacity of a State to produce nuclear weapons. It is measured using a seven-component index that indicates the level of nuclear-related resources and capacities in the possession of a State. The authors used indicators for latent capacity based on Meyer's (1984) earlier work. They examined it from three perspectives (resource demand components) and categorized Meyer's resource demand list and indicators accordingly. The resource demand components are, "nuclear material," "munitions fabrication," and "nuclear facilities." From that, the authors chose seven indicators that they felt accurately indicated latent capability. Those factors are (in no particular order), "Uranium deposits," "Steel or aluminum production," "Nitric or sulfuric acid production," "Nonorganic nitric fertilizer production," "Three nuclear reactor years," "Vehicle and radio (or television) production," and "Production of at least $200 \mathrm{MW}$ of electricity." This measure assumes that a state preserves its capabilities once they are attained. This variable ranges from 0 to 7 with 7 being the highest level of latent capability. See Jo and Gartzke (2007) pp. 172-3 and http://dss.ucsd.edu/ egartzke/ for additional information.

\footnotetext{
${ }^{13}$ Although the authors described this variable on Page 870 in Singh and Way (2004), it is not listed in their regression result table (Table 2.4, 2004) because the inclusion of this variable led to the loss of over 1,000 data points due to missing observations (see footnote 24, p. 874 Singh and Way (2004)).
} 
- Economic capacity. This variable represents the economic capacity of a State. It is measured by using annual consumption of energy and production of iron and steel. The authors chose to focus on energy consumption and metal production instead of GDP because GDP data are only available for most countries in recent years. The energy consumption and industrial output data are from the COW National Material Capabilities Data. A State's economic capacity is operationalized as the mean of the sum of a State's share of energy consumption over the total energy consumption in that year and the share of its iron and steel production over the total iron and steel production in a given year (see data documentation at http://www.correlatesofwar.org/COW2\%20Data/Capabilities/NMC_Documentation.pdf). Economic Capacity $i=\left(\begin{array}{c}\text { Energy } \\ \sum \text { Energy }\end{array}{ }^{+ \text {Iron } / \text { Steel } /} / \sum\right.$ Iron $/$ Steel $) / 2$.

- Diffusion. This variable represents the rate of nuclear weapons technology spread. It is operationalized as the log transformation of the count of years since 1938. The authors acknowledge that substituting the log transformation with the raw number of years since 1938 did not make a significant difference in the analysis. Note, however, Montgomery and Sagan (2009) criticized the use of time as the foundation of technology diffusion calculation and they argue diffusion may depend on many state-specific contextual considerations rather than time alone.

The Jo and Gartzke variables representing willingness are organized into three groups: 1) International security, 2) Domestic politics, and 3) Norms and status:

- Conventional threat (as contributing to International Security). This variable represents the degree of conventional threat. It is measured by 1) identifying a State's rivals and summing these rivals' conventional military Composite Index of National Capabilities (CINC) scores; 2) dividing the sum by the CINC score of the State of interest; 3) adding one to the ratio computed from Step1 and 2, and transforming the sum into a natural log. The CINC score is an index of six variables including a state's military personnel, military expenditure, total population, urban population, iron and steel production, and primary energy consumption. ${ }^{14}$ Rivalry information (not included in the formula, but used to reduce the number of calculations) is drawn from Bennet's coding of rivals (Bennet 1996).

Conventional threat $t_{i . t}=\ln \left(\sum_{j=1}^{n} \frac{C I N C_{j, t}}{C I N C_{i, t}}+1\right)$

- Nuclear threat (as contributing to International Security). This variable represents the degree of nuclear threat against a State. It is measured using the existence of nuclear weapons programs or weapons in a States' rival State(s). It takes on a value of 0 if none of a state's rivals possess such programs or weapons and 1, otherwise. Coding for rivalries is based on Bennet (1996).

- Nuclear defense pact (as contributing to International Security). This variable represents the impact of nuclear defense pacts on national security. It indicates whether or not a State is a

${ }^{14}$ Detailed data description can be retrieved at http://www.correlatesofwar.org/COW2\%20Data/Capabilities/nmc302.htm\#cinc. 
signee of a defense pact with a recognized nuclear State. It is coded as 1 if a state is protected by a nuclear power under the pact; otherwise, it is 0 .

- Diplomatic isolation (as contributing to International Security). This variable appraises the degree to which a state is diplomatically linked with states that are within a 150-mile radius and with the world's major powers. It is operationalized as the ratio between the number of relevant neighboring states and major powers with which a state has not established any diplomatic relationship and the total number of the state's neighbors and major powers.

- Domestic unrest (as contributing to Domestic politics). This variable represents a States' general political unrest. It is measured by tallying the number of categories of domestic unrest. There are three categories; antigovernment demonstration, strikes, and riots, weighted by a state's population. The variable is scored as a number from zero to three. The authors also created a 1year lag in their analysis but this lag did not make any difference. This measure is drawn from Meyer's earlier work (Meyer 1984).

- Democracy (as contributing to Domestic politics). This variable represents the presumed settling democracy on a State's politics. The variable is measured using the Polity Project III ${ }^{15}$ level of democracy scores and its value ranges from 0 to 10 with 0 being least democratic and 10 , most democratic. This score is an index measured along three dimensions: the level of openness and competition in political participation, institutional constraints on the state's chief executive, and the protection of civil liberties (for details, see http://earthtrends.wri.org/searchabledb/variablenotes.php?theme=10\&varid=509 ).

- $\quad$ NPT membership (as contributing to Norms and Status). This variable represents the normalizing effect of a State's decision to sign the NPT (i.e., It is presumed that States that sign the NPT are less likely to pursue nuclear weapons. It is coded as a dichotomous variable that is 1 if a state is a member of the NPT and 0 otherwise. The data come from the United States Arms Control and Disarmament Agency.

- NPT system effect (as contributing to Norm and status). This variable represents the normalizing effect of more and more members signing up to the NPT. It is measured as the ratio between the total number of NPT member states and the total number of the world's states.

- Major power status (as contributing to Norms and status). This variable indicates which States are considered to be major powers. The classification of major powers from $\mathrm{COW}$ was used. According to the COW data, major power status remained relatively constant. Major power states include the United States (1939-1992), United Kingdom (1939-1992), Soviet Union/Russia (1939-1992), France (1939-1940 and 1945-1992), Germany (1939-1945, 1991-1992), Italy (1939-1943), Japan (1939-1945, 1991-1992), and China (1950-1992) (p. 175).

- Regional Power Status (as contributing to Norms and status). This variable indicates a state's status within a region. Regions are defined in accordance with the COW dataset and CINC. The

\footnotetext{
${ }^{15}$ Note the democratic score used here is slightly different from the Polity Project IV in that Polity III is on a scale of 0-10, whereas Polity IV uses Democracy minus Autocracy. Polity IV Level of Democracy and Level of Autocracy Scores capture the full spectrum of policy regime types, from autocracies, to anocracies, to democracies. These polity scores then range from -10 , as in the case of hereditary monarchies, to +10 for consolidated democracies. These scores can also be divided into three regime categories: autocracies $(-10 \sim-6)$, anocracies $(-5 \sim$ $+5)$ and the states whose scores are coded as $-66,-77$, and -88 also belong to this category, and democracies ( $+6 \sim$ +10) (see http://www.systemicpeace.org/polity/polity4.htm for detail).
} 
resulting regional power states are listed on Page 175 in Jo and Gartzke (Jo and Gartzke, 2007). Note a state cannot be both a major power and a regional power at the same time. China, for example, is coded as a regional power between 1939 and 1949, and as a major power from 1950 to 1992 .

\subsubsection{Comparison and Analysis of Singh \& Way and Jo \& Gartzke Data}

There are considerable conceptual similarities between Jo and Gartzke, and Singh and Way. To represent the conceptual models and key factors in these studies, we systematically compared the two datasets and performed preliminary data analyses to identify the data structure for our model. In the following sections, we will provide a comparative view of the two conceptual frameworks and discuss the preliminary data analysis results.

As Table 3.3 shows, both studies are based on cross-sectional time series data with country-year as their unit of analysis. In Singh and Way proliferation is defined as a three-stage process moving from exploring nuclear weapons options to pursuing weapons programs and to eventually obtaining such weapons. By comparison, Jo and Gartzke dissect the proliferation process into two phases: pursuing nuclear arms development programs and possessing such weapons.

Table 3.3. General Comparison of Singh and Way and Jo and Gartzke Datasets

\begin{tabular}{|c|c|c|}
\hline & Singh and Way (2004) & Jo and Gartzke (2007) \\
\hline Data Duration & $1945-2000$ & $1939-1992^{16}$ \\
\hline $\begin{array}{l}\text { Unit of } \\
\text { Analysis }\end{array}$ & Country-Year & Country-Year \\
\hline $\begin{array}{l}\text { Dependent } \\
\text { Variable }\end{array}$ & $\begin{array}{ll}\text { - } & \text { Explore Weapons } \\
\text { - } & \text { Pursue Weapons } \\
& \text { Acquire Weapons }\end{array}$ & $\begin{array}{ll}\text { - } & \text { Pursuit of Weapons } \\
\text { Possession of Weapons }\end{array}$ \\
\hline Models Used & $\begin{array}{ll}\text { - } & \text { Multinomial Logit } \\
\text { Hazard Model }\end{array}$ & $\begin{array}{ll}\text { - } & \text { Probit } \\
\text { - } & \text { Censored Probit }\end{array}$ \\
\hline $\begin{array}{l}\text { Number of } \\
\text { Observations }\end{array}$ & $\begin{array}{c}154 \text { Countries } \\
\text { Explore }-5215 \\
\text { Pursue }-5578 \\
\text { Acquire }-5784\end{array}$ & $\begin{array}{c}8278 \text { Country-Year } \\
\text { Noncensored Model - } 4697 \\
\text { Censored Mode }-440\end{array}$ \\
\hline Conclusion & $\begin{array}{l}\text { Important Proliferation } \\
\text { Contributors: } \\
\text { - low level of economic } \\
\text { development } \\
\text { - external threat } \\
\text { environment } \\
\text { - lack security guarantees } \\
\text { low level of economic }\end{array}$ & $\begin{array}{l}\text { Important Proliferation } \\
\text { Contributors Weapons Programs } \\
\text { Development: } \\
\quad \text { - security concerns } \\
\quad \text { technological capabilities } \\
\text { Important Proliferation } \\
\text { Contributors Weapons } \\
\text { Possession: }\end{array}$ \\
\hline
\end{tabular}

${ }^{16}$ Although some Jo and Gartzke data was available through 2002, much of the dataset available from them covered the years from 1939 to 1992. See http://dss.ucsd.edu/ egartzke/htmlpages/data.html. Accessed March 30, 2011. 


\begin{tabular}{|l|c|l|}
\hline & Singh and Way (2004) & \multicolumn{1}{|l|}{ Jo and Gartzke (2007) } \\
\hline integration & $\begin{array}{l}\text { : security concerns } \\
\end{array}$ & $\begin{array}{l}\text { economic capabilities } \\
\text { domestic politics }\end{array}$ \\
\hline
\end{tabular}

Conceptually, in Jo and Gartzke's study, proliferation is constructed as a two-stage conditional process: the pursuit of weapons programs, and the possession of nuclear arms given the existence of active weapons programs as shown in Table 3.3.

Following Most and Starr (1989), the authors investigated State-level proliferation potential from two crucial aspects: proliferation opportunity (technical capability) and willingness (motivation). More specifically, opportunity addresses the factors associated with resource availability and technological competency that makes it possible for a state to proliferate. Such material capacity constitutes the "necessary but not sufficient" condition for proliferation (see Reiss 1988, p. 247). Willingness encompasses those non-technical forces that critically shape a State's internal and external environment and its dominant political sentiment regarding its security vulnerabilities and defense strategic options, which in turn may affect its proliferation decisions. Willingness, in particular, is represented by four indicators: international security, domestic politics, international norms, and status. The relationship among these variables is represented in Figure 3.6.

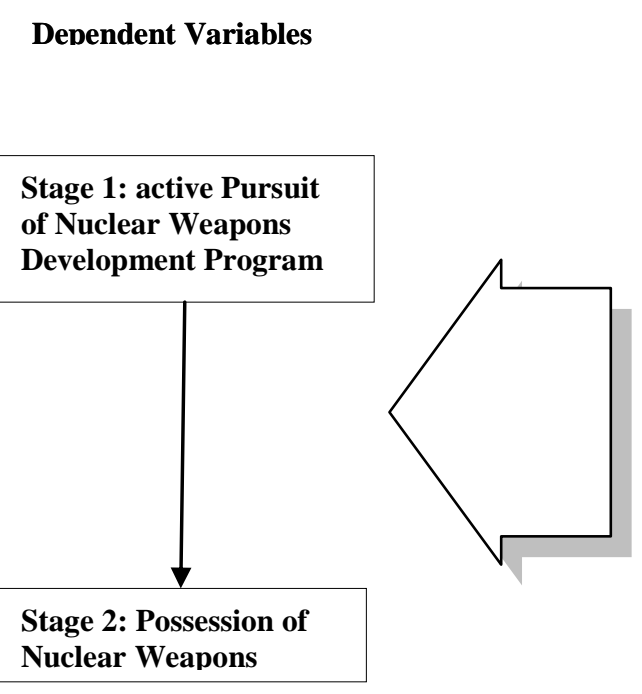

\begin{tabular}{|c|c|c|}
\hline \multicolumn{3}{|c|}{ Explanatory Variables } \\
\hline \multirow{3}{*}{ Opportunity } & \multicolumn{2}{|c|}{$\begin{array}{l}\text { Latent Nuclear Weapons Production } \\
\text { Capability }\end{array}$} \\
\hline & \multicolumn{2}{|c|}{ Economic Capacity } \\
\hline & \multicolumn{2}{|c|}{$\begin{array}{l}\text { Diffusion of Nuclear Technology and } \\
\text { Knowledge }\end{array}$} \\
\hline \multirow{10}{*}{ Willingness } & \multirow{4}{*}{$\begin{array}{l}\text { International } \\
\text { Security }\end{array}$} & Conventional Threat \\
\hline & & Nuclear Threat \\
\hline & & Nuclear Defense Pact \\
\hline & & Diplomatic Isolation \\
\hline & \multirow{2}{*}{$\begin{array}{l}\text { Domestic } \\
\text { Politics }\end{array}$} & Domestic Unrest \\
\hline & & Democracy \\
\hline & \multirow{2}{*}{ Norms } & NPT Membership \\
\hline & & NPT System Effect \\
\hline & \multirow{2}{*}{ Status } & Major Power Status \\
\hline & & Regional Power Status \\
\hline
\end{tabular}

Figure 3.6. Our Conceptual Model of the Jo and Gartzke Dataset

By contrast, Singh and Way (2004) organized the explanatory variables into three categories: technology, conditions that are external to a State and conditions that are internal to a State. Similar to Jo and Gartzke, Singh and Way focused on a state's material capabilities, external threats, effects of democratic regimes, and its status differentials from global and regional powers. A marked distinction 
from Jo and Gartzke's approach is the absence of the treatment of the counter-proliferative effect of the NPT in their model. Additionally, to measure a state's external threats, Singh and Way incorporated interstate militarized conflicts and enduring rivalries without explicitly treating nuclear threats, particularly the threats from neighboring states, as a separate threat category, as in Jo and Gartzke's study. The relationship among these variables is represented in Figure 3.7. 
Dependent Variables

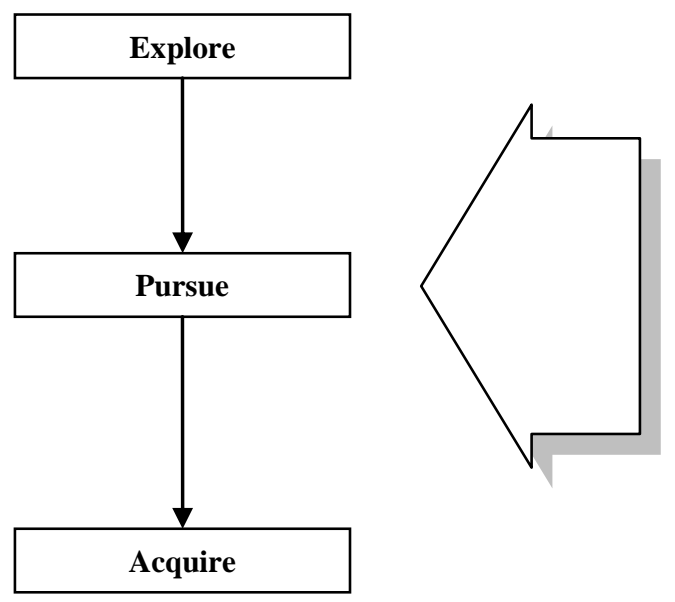

Explanatory Variables

\begin{tabular}{|c|c|}
\hline \multirow{4}{*}{$\begin{array}{l}\text { Technological } \\
\text { Determinants }\end{array}$} & GDP Per Capita \\
\hline & GDP Per Capita Squared \\
\hline & Industrial Capacity Index \\
\hline & $\begin{array}{l}\text { Energy, Electricity, Steel Production } \\
\text { \& Consumption }\end{array}$ \\
\hline \multirow{3}{*}{$\begin{array}{c}\text { External } \\
\text { Determinants }\end{array}$} & Enduring Rivalry \\
\hline & Frequency of Dispute Involvement \\
\hline & Security Guarantee \\
\hline \multirow{4}{*}{$\begin{array}{c}\text { Internal } \\
\text { Determinants }\end{array}$} & Democracy \\
\hline & Democratization \\
\hline & $\begin{array}{l}\text { Economic Interdependence and } \\
\text { Liberalization }\end{array}$ \\
\hline & $\begin{array}{l}\text { Status Inconsistency /Symbolic } \\
\text { Motivation }\end{array}$ \\
\hline
\end{tabular}

Figure 3.7. Our Conceptual Model of the Singh and Way Dataset

As a part of a data analyses exercise, we conducted correlation analysis, cluster analysis, principal component analysis, and created dendrograms to understand the relationship among the variables. To examine the strength of the relationship among the explanatory variables, we ran both pairwise correlation and correlation matrix with visualization tools to identify interdependence among the constructs. Appendix A provides many of the tables and plots resulting from our data analyses. Initially, we asked a political scientist on the research team to identify a list of variables that are theorized by the extant literature as more likely to have a high level of correlations. This preliminary thinking is presented in Table A-1 of Appendix A. We checked these expectations against a matrix of correlations aggregated across all countries and years and looked for relationships. This matrix of correlation is presented in Table A-2 of Appendix A. In many cases our expectations were confirmed. In several cases variables that were correlated were those with a common derivation or were derived from each other, for example Industry 1 and 2 and Gdpcap and Gdpcap squared. There was a negative correlation between Regional Stability and some of the economic indicators, in particular Gdpcap and to a lesser extent for Industry. The plot presented in Figure 3.8 shows a plot of the pairwise correlations of variables for all years and countries in the dataset (see Appendix A.3 for other plots of pairwise correlations). The plot indicates the strength of those correlations using color, where the color red indicates a strong positive correlation, the color green indicates weak correlation and blue indicates strong inverse correlation. However, for the most part, hypothesized relationships among the variables did not hold in general across all country years suggesting that if there were correlations they were country specific due to the differences among countries. We studied the correlations specifically for each country. These country specific data do suggest some relationships. In particular we were interested in variables that were related to motivation. The data set was incomplete in that there were a lot of missing data marked as NAs; consequently, the number of countries for which we were able to compute the correlations was a small subset of the set of the world's countries. Below we discuss some of these correlations. 


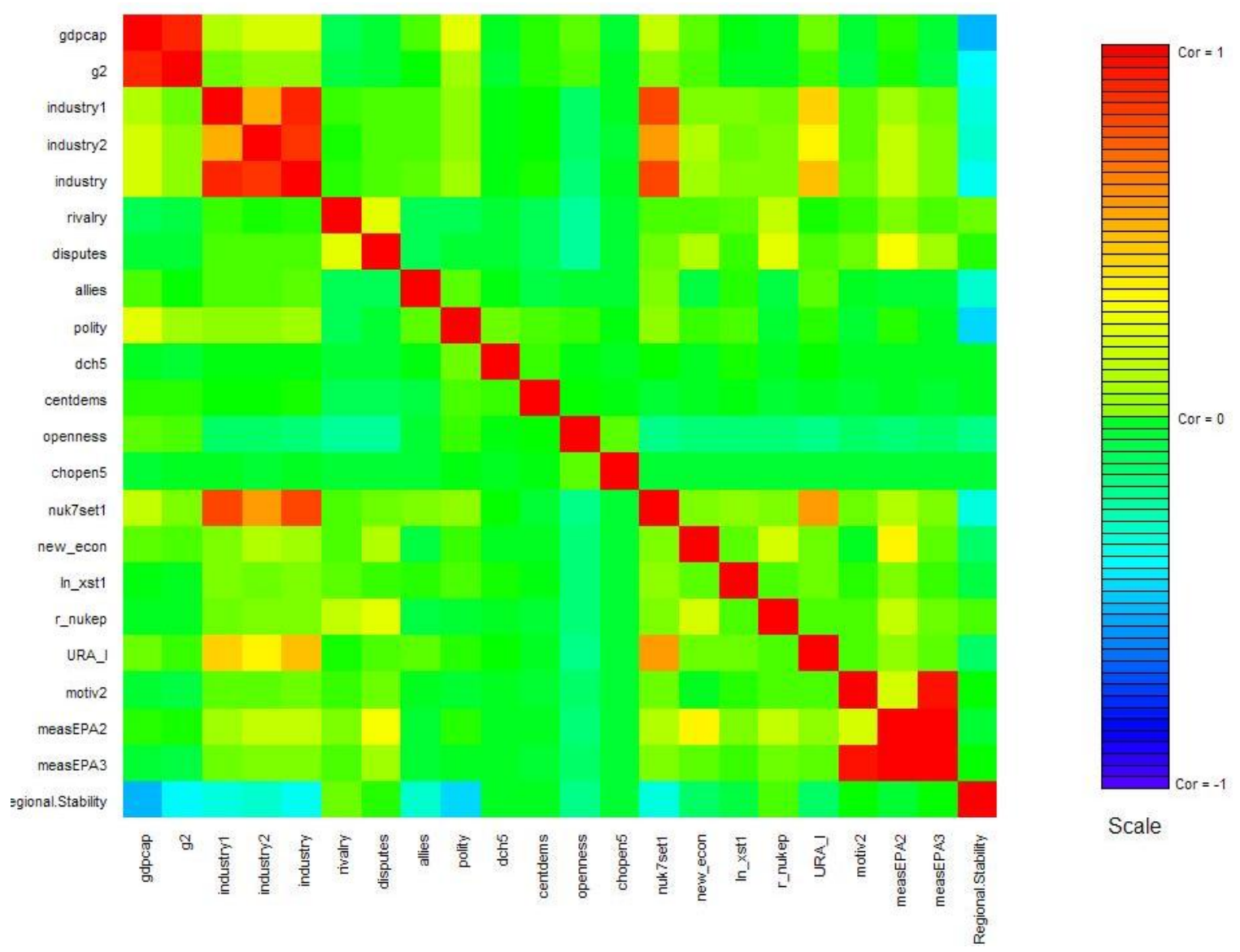

Figure 3.8. Image Plot of Correlation Matrix for Selected Variables ${ }^{17}$

Since the data are time series, we accounted for possible lagged effects between the variables by creating 1, 3, and 5-year lags and then ran correlation analyses for the lagged variables. Table 3.4 shows the time correlations between Motivation (i.e. "motiv2") and Nuclear Technology (i.e. "nuke7set1"). The variable "motiv2" refers to a State that is pursuing (opposed to exploring or acquiring) a nuclear weapons program (described in more detail in Section 3.3.1). The variable "nuke7set" refers to a composite variable of seven factors associated with nuclear material presence, munitions fabrication or nuclear facilities (described in more detail in Section 3.3.2). The lagged correlations are designed to account for the fact that the acquisition of nuclear weapons occurs in phases over a span of several years. For example, it might be argued that nuclear capability follows motivation. A country that is motivated, but lacks capability would develop the capability in years following their decision to acquire weapons. Lagged variables might show this relationship. The top eight countries in the table are, for the most part, countries that have been a proliferation concern, and some of them, such as India, Pakistan, and North Korea, have gone on to develop nuclear weapons. United Kingdom and Russia have negative correlations because they were not motivated to acquire nuclear weapons having had nuclear weapons for the entire time under consideration. Other countries, such as Switzerland, may have the expertise, but don't have the interest. As can be seen in the table for many countries it is true that there is a correlation between

\footnotetext{
${ }^{17}$ The variables that appear on this plot are described in Sections 3.3.1 and 3.32.
} 
Motivation and Nuclear Technology. However, there does not appear to be a general trend of stronger correlation over time. In many cases the correlation became weaker over the defined time lags.

Table 3.4. Time Lag Correlations between Motivation and Nuclear Technology

\begin{tabular}{|l|r|r|r|r|}
\hline Country & Lag 0 & Lag 1 & Lag 2 & Lag 5 \\
\hline Libya & 0.8895 & 0.8706 & 0.8366 & 0.8094 \\
\hline North Korea & 0.7925 & 0.7960 & 0.7808 & 0.7504 \\
\hline Iraq & 0.7730 & 0.7408 & 0.6783 & 0.6199 \\
\hline Brazil & 0.6888 & 0.7145 & 0.6879 & 0.6413 \\
\hline Pakistan & 0.6303 & 0.6518 & 0.6927 & 0.6696 \\
\hline Argentina & 0.5748 & 0.5454 & 0.4948 & 0.4306 \\
\hline India & 0.5275 & 0.5351 & 0.6755 & 0.7365 \\
\hline Iran & 0.4893 & 0.4670 & 0.4158 & 0.3249 \\
\hline Taiwan & 0.4856 & 0.3686 & 0.3144 & 0.2583 \\
\hline Yugoslavia & 0.4412 & 0.5371 & 0.5099 & 0.5331 \\
\hline South Africa & 0.3934 & 0.3884 & 0.3774 & 0.3651 \\
\hline Australia & 0.2722 & 0.3093 & 0.3951 & 0.4338 \\
\hline Romania & 0.2558 & 0.2299 & 0.1784 & 0.1280 \\
\hline South Korea & 0.2452 & 0.3147 & 0.4103 & 0.4578 \\
\hline Sweden & 0.2047 & 0.2640 & 0.3454 & 0.3100 \\
\hline China & 0.0439 & 0.1044 & 0.1580 & 0.2479 \\
\hline Israel & -0.0709 & -0.0374 & 0.0430 & 0.0912 \\
\hline France & -0.1862 & -0.1400 & -0.0167 & na \\
\hline Switzerland & -0.4811 & -0.4406 & -0.3563 & -0.2655 \\
\hline United Kingdom & -0.5990 & -0.4435 & -0.1710 & na \\
\hline Russia & -0.7854 & -0.7509 & -0.7277 & -0.8829 \\
\hline
\end{tabular}

We also plotted time lag data for pairs of variables in an attempt to identify visual clues. Appendix A.4 presents a number of example plots of the lagged correlation between a pair of variables for all years and countries in the dataset. The correlation value is displayed in the vertical direction while different countries are spread across the horizontal axis. We ran the lagged correlations in both directions, for example, we plotted the correlation of the Motivation variable against lagged values of the Nuclear Technology variable, but also plotted the correlation of the Nuclear Technology values against lagged values of the Motivation variable. We could not conclude that that there were stronger or weaker correlations over the defined time lags. We did not identify a significant pattern in the time lag plots.

Additionally, we created pairwise scatter plots for all countries and country-year in the form of country-specific color block plots to understand which factors are sensitive to time dynamics and which ones remains relatively stable over time. These plots are shown in Appendix A. 5 and indicate how correlations trend over decades of time. For example in Figure A. 9 of Appendix A. 5 shows proliferation motivation for Canada to be constant (i.e. a value of 0.0) over the time span whereas disputes increased incrementally starting in the 1980s into 2000. Figure A. 11 of Appendix A. 5 shows that proliferation motivation was low (i.e., 0.0) in the 1950s, 1960s and 1970s, and increased substantially starting in the 1980 s and at the same time that disputes increased in the 1980s. 
To identify the latent structure among the variables to inform our model structure, we also performed K-Means clustering analysis and principal component analysis (PCA), and created a classification and regression tree (CART). The results of K-Means clustering analysis were used to identify the natural clustering within the dataset, and are presented in Appendix A. 6. We analyzed the data using PCA with the intention of using the results to reduce the dimension of the massive dataset the results of which are presented in Appendix A. 7. In the same vein, hierarchical cluster analysis using a divisive dendrogram likes shown in Appendix A. 8 was employed to explore the data. The dendrogram is a mathematical method of revealing natural groupings among the observed data. The vertical lines indicate the distance between two classes of variables. Greater distance, between the variables indicates more dissimilarity between the two groups. The dendrograms are organized in a hierarchy and in this case show the variables most important to forming clusters at the top of the hierarchy.

These preliminary data analyses results lead to a number of key observations. First, variables that are highly correlated are ones that are mathematically related to each other, like GDP and GDP2, or they are ones whose causal relationship is intuitive such as the relationship between the economic level and nuclear capability. Most variables show little or no correlation as evidenced by all the green in Figure 3.8. This is probably due to trying to average correlations across all countries. There are some surprising results. For example regional stability is negatively correlated with the economic indicators, such as industry and GDP per capita. Possibly a certain level of economic achievement is required before a State has substantial political clout to stir up trouble in the region. Note, however, correlations are essentially a measure to detect the strength of relationships between or among variables, and they do not signal causal relationships. Data structure is important but the clusters do not sufficiently inform the modelers how to organize data and concepts to correspond with theories. In creating the graph structure of BN models, domain expert knowledge was fundamental to creating model structure, and data and probability elicitation were used to quantify the relationships. As the modeling literature confirms, one of the main sources of data for developing BN models is expert input, the other being the concepts in the literature. In our approach, we identified and incorporated key theoretical constructs into the basic model structure, calibrated the model parameters with expert elicitation, and used the merged existing datasets to validate the model.

\subsubsection{Augmentation of the Combined Dataset}

As mentioned previously, the datasets with which we used to inform our articulation of the BN model were from Singh and Way (2004), Jo and Gartzke (2007) data, NPT data collected for this project ${ }^{18}$, and data derived from data already compiled. Resulting cross-sectional time series dataset includes 60 variables, and a total of 11,204 observations, and spans from 1939 to 2010. This section focuses on how the dataset was augmented after the Singh and Way, and Jo and Gartzke datasets were combined.

In our conceptualization, proliferation is modeled as a four-phased process. For any state to create a nuclear arsenal, it must begin with an interest in or motivation for developing such programs. It must then commit resources necessary to exploring and pursuing nuclear weapons programs. If these prerequisite attempts are successful, a country may eventually acquire the weapons. The time duration in between the stages is not uniform across countries. In some cases, a country would go through all these steps rapidly while in other cases it may take decades for a country to move from one step onto the next. A country

\footnotetext{
${ }^{18}$ The combined dataset includes the updated explore, pursue, acquire data received from Christopher Way on Jan 28, 2009. NPT data were collected and coded by Jarrod Olson, a scientist at PNNL.
} 

entirely. To represent this process, four outcome variables were created: not interested, explore, pursue, and acquire. The original proliferation outcome data in Singh and Way were coded "1" only for the year in which a change in the proliferation status took place. The years prior to and following such a change were coded as 0 . This coding approach, while highlighting the threshold effect associated with the status change, insufficiently represents the duration effect in the status alteration. To that end, we modified this coding by assigning 1 to all the years after the status change as well, until another change occurred. Thus, the new coding accounts for all the years in which a country was exploring but not pursuing, and likewise, for pursuing but having not yet acquired. By modifying the coding of the proliferation variables, we treat proliferation as consisting of four tangible and distinctive stages, each of which has lasting effects on the proliferant state between the stages.

The research team also augmented the data with a number of calculated variables based on the existing variables. For example, industry 1 and industry 2 are two dummy variables in Singh and Way's dataset that denote industrial capacity with two threshold levels. To combine them, we created the variable, Industry, that takes on the value of 0 if a state's industrial capacity was below both thresholds, 1 if the capacity exceeds the lower threshold (industry 1) but falls short of the higher threshold (industry 2), and 2 if the industrial capacity exceeds the higher cutoff points. Variable discretization was also undertaken to transform numeric data into categorical data to be compatible with the states of the nodes in the model. For instance, numeric variables such as the percentage of democratic states, GDP, and domestic unrest were regrouped into discrete categories such as low, medium, and high. Similarly, the outcome node, Proliferation Propensity, has five states ranging from Very Low, Low, Moderate, to High and Very High.

Another form of derived data that we used to augment the dataset calculation is a variable that we refer to as Regional Stability. Regional Stability was calculated by identifying the world's political regions and calculating regional stability as the average number of disputes for countries in that region. There is not universal agreement on how to partition the nations into political regions. The regions we used were: Australia and Oceana, Southeastern Asia, East Asia, Southwestern Asia, the Middle East, North Africa, South Africa, Eastern Europe, Europe, North America, Central America, and South America.

In addition to utilizing existing datasets, we collected new data to model the effect of the nuclear nonproliferation regime (NPT). We operationalized the impact of the nuclear nonproliferation regime by identifying the presence of various items from the nonproliferation regime and their membership (as True/False statements). These NPT component items include the Comprehensive Safeguards Agreement (CSA), Small Quantity Protocol (SQP), Comprehensive Test Ban Treaty (CTBT), and Nuclear Weapon Free Zone (NWFZ). We then identified the time line of these regimes, and encoded their levels of enforcement. The enforcement appraisal is based on the scope of inspection authority and permitted activities granted by the agreement, and the scope of access to the member states' nuclear infrastructure, resources, samples, equipment, and information. ${ }^{19}$ As demonstrated in the Table 3.5, the Small Quantity Protocol received the lowest enforcement rating; the Comprehensive Safeguards Agreement (CSA) and Nuclear Weapon Free Zone (NWFZ) entail greater enforcement astringency, and the Additional Protocol

\footnotetext{
${ }^{19}$ See http://www.iaea.org/Publications/Factsheets/English/sg_overview.html.
} 
(AP) demands the highest level of enforcement cooperation and is the most difficult regime to elude. ${ }^{20}$ For the CSA, SQP, AP, and CTBT, states are only considered to have an agreement once these items have been brought fully into force, including signature and ratification while NWFZ is only considered "inforce" if the minimum number of parties have signed and ratified the agreement.

Table 3.5. Nonproliferation Regime Coded for Inclusion in the Combined Dataset

\begin{tabular}{|l|l|l|}
\hline \multicolumn{1}{|c|}{ Item } & $\begin{array}{c}\text { Enforcement Rating (1-3, 1 - Low enforcement value, } \\
\mathbf{3}-\text { High enforcement Value) }\end{array}$ & $\begin{array}{c}\text { First year of } \\
\text { existence }\end{array}$ \\
\hline $\begin{array}{l}\text { Comprehensive Safeguards } \\
\text { Agreement (CSA) }\end{array}$ & 2 (Inspectors, but possible to interfere) & 1972 \\
\hline Small Quantity Protocol (SQP) & 1 (Given little attention) & 1972 \\
\hline Additional Protocol (AP) & 3 (Very challenging to cheat) & 1997 \\
\hline $\begin{array}{l}\text { Comprehensive Test Ban Treaty } \\
\text { (CTBT) }\end{array}$ & 1 (Not in force yet, almost entirely normative) & 1996 \\
\hline $\begin{array}{l}\text { Nuclear Weapon Free Zone } \\
\text { (NWFZ) }\end{array}$ & $\begin{array}{l}\text { 2 (Additional scrutiny through verification of NWFZ, } \\
\text { however, not all NWFZ are the same. }\end{array}$ & Depends \\
\hline
\end{tabular}

We describe these nonproliferation regime variables as follows:

- Comprehensive Safeguards Agreements (CSA). These data are coded as a True or False judgment for the year and all the following years that a state had a CSA in force. CSA Voluntary Offers are coded as "true" for date brought into force in nuclear weapon States (NWS). Note Bulgaria is coded as "true" from the beginning of the first CSA in 1972 (INFCIRC/178 ${ }^{21}$ ), which were suspended on 1 May 2009 and replaced with another agreement between NNWSEURATOM $^{22}$, EURATOM and IAEA (INFCIRC/193) on April 5, 1973. Similarly, Czech Republic is coded as "true" from the start of the first CSA in 1997 (INFCIRC/541), which were suspended on 1 October 2009 and replaced with the agreement between NNWS-EURATOM, EURATOM and IAEA (INFCIRC/193) on April 5, 1973. To check data accuracy, the researcher randomly selected the 2008 data and compared them to the IAEA Safeguards Report. States or sovereignties excluded from our dataset include the Holy See, Monaco, Kiribati, Nauru, Tonga, and Tuvalu. Serbia and Serbia \& Montenegro were not counted due to lack of clearly defined history of sovereignty.

- Small Quantity Protocol (SQP). These data are coded true or false for the year and all the following years that a state had an SQP in force. Coding does not differentiate between SQP and modified SQP ${ }^{23}$. Note Tajikistan is coded as false from 2006 forward as it amended its SQP so that SQP no longer applied. It is coded as true from 2004-2005 as the original SQP came into force in 2004.

\footnotetext{
${ }^{20}$ Data about the entry-into-force of each agreement is drawn from 2010 IAEA Safeguards Summary, The CTBTO website and the Arms Control Association website (http://www.armscontrol.org/factsheets/nwfz).

${ }^{21}$ INFIRC (IAEA Information Circular). The INFIRCs cited in this discussion contain the text of agreements between different countries and the IAEA.

${ }^{22}$ EURATOM (European Atomic Energy Community). Two treaties were signed on 25 March 1957 - the Treaty establishing the European Economic Community (EEC) and the Treaty establishing the European Atomic Energy Community (EAEC or EURATOM). Among the aims of the EURATOM Treaty are to ensure civil nuclear materials are not diverted to other uses, particularly military uses. Accessed February 5, 2011 at (http://www.europarl.europa.eu/parliament/archive/staticDisplay.do?id=77\&pageRank=11\&language=EN)

${ }^{23}$ See www.iaea.org/OurWork/SV/Safeguards/sir_table.pdf. Access March 30, 2011.
} 
- Additional Protocol (AP). These data are coded dichotomously (True/False) for the year and all the following years that the AP was in force - signed, approved by IAEA Board, and ratified in country - according to the IAEA status list of safeguards agreements, available from their website. Note voluntary offer states are included as false.

- Comprehensive Test Ban Treaty (CTBT). These data are coded as true or false for the year and all the following years that the CTBT was ratified in the country according to the official website of the Comprehensive Test Ban Treaty Organization. We compared the dataset with CTBTO website to check for errors. Note Andora is not included in the dataset.

- Nuclear Weapon Free Zone (NWFZ). A state is considered a member of a nuclear weapon free zone the first year that it was entered-into-force. These data are coded as 1 for each year the treaty is in force. States were coded NWFZ-eligible the first year that a treaty was in force but was not ratified. ${ }^{24}$ There are five recognized nuclear weapon free zones:

1. Treaty of Rarotonga (South Pacific): Opened for signature on August 5, 1985, and entered into force on December 11, 1986. Note some members of this NWFZ, such as Cook Islands, Kjiribati, Nauru, Niue, Tonga and Tuvalu, are not in our dataset, probably because they are extremely poor and small island nations.

2. Treaty of Bangkok (Southeast Asia): Opened for signature on December 15, 1995, and entered into force on March 27, 1997.

3. Treaty of Tlatelolco (Latin America and the Caribbean): Opened for signature on February 14, 1967, and entered into force October 23, 2002

4. Treaty of Pelindaba (Africa): Opened for signature on April 11, 1996, and entered into force July 15, 2009. Note, there are 28 signatories, but Angola, Cameroon, Central African Republic, Cape Verde, Chad, Comoros, Congo, Djibouti, Democratic Republic of Congo, Egypt, Eritrea, Ghana, Guinea-Bissau, Liberia, Niger, Seychelles, Sierra Leone, Somalia, Sao Tome \& Principe, Sudan, Tunisia, Uganda and Zambia have not ratified the treaty. These states are treated equally as the states that have ratified.

5. Central Asian Nuclear-Weapon-Free Zone Treaty: Opened for signature September 8, 2006, and entered into force March 21, 2009.

Based on the NPT Regime data, we created two additional variables: Barriers and Motivation, to capture the dampening effect of the NPT on states' proliferating intent.

The Barriers variable measures the level of difficulty a state faces with regard to proliferation intentions in the presence of the nonproliferation regime. The nonproliferation regime components are grouped into three categories. Category I includes CSA, SQP, and AP. These three components are interdependent in that CSA is a prerequisite of both SQP and AP. Only when a state is a member of CSA

\footnotetext{
${ }^{24}$ To ensure the coding accuracy, we printed all states with NWFZ as true and checked against a list of states in NWFZ provided by the Arms Control Association Website.
} 
is it then eligible for membership in SQP or AP or both. In Table 3.6, we list all four possible combinations of CSA-related barriers within Category I: CSA only, CSA and SQP, CSA and AP, and CSA, SQP and AP. Category II and III each includes one treaty/agreement (CTBT, and NWFT, respectively) and are independent of Category I. This suggests that even if a state does not sign CSA, it can still be a member of CTBT and/or NWFZ. If a state is not a member of any of the nonproliferation regime protocols or agreements within each given category, its barrier score for that category is 0 . The following table provides the categories, ordinal ratings, and scoring scheme.

Table 3.6. "Nonproliferation Regime as a Barrier" Algorithm

\begin{tabular}{|c|c|c|c|}
\hline Category & Component & Ordinal Rating & Barrier Score \\
\hline \multirow{4}{*}{ I } & CSA Only & Medium & 2 \\
\cline { 2 - 4 } & CSA and SQP & Low & 1 \\
\cline { 2 - 4 } & CSA and AP & High & 3 \\
\cline { 2 - 4 } & CSA and SQP and AP & High & 3 \\
\hline II & CTBT & Low & 1 \\
\hline III & NWFZ & Medium & 2 \\
\hline
\end{tabular}

The overall barrier score is computed as:

Overall barrier score $=$ Category I score + Category II score + Category III score

For instance, if a state is a member of CSA only, it is given a score of 2. In addition, if this state is also a member of CTBT and NWFZ, then its overall barrier score is (CSA Only) $2+(\mathrm{CTBT}) 1+(\mathrm{NWFZ}) 2=5$.

The Motivation variable measures the extent to which the presence of the nonproliferation regime influences a state's proliferation motivation. The operationalization of this variable is similar to that of barriers discussed above. The key difference is the scoring scheme used in computing the motivation scores as shown in Table 3.7. If a state is not a member of any of the nonproliferation regime treaties or protocols within each given category, its motivation score for that category is 0 .

Table 3.7. "Nonproliferation Regime as a Motivator" Algorithm

\begin{tabular}{|c|c|c|c|}
\hline Category & Component & Ordinal Rating & Motivation Score \\
\hline \multirow{4}{*}{ I } & CSA Only & Low & 1 \\
\cline { 2 - 4 } & CSA and SQP & Low & 1 \\
\cline { 2 - 4 } & CSA and AP & High & 3 \\
\cline { 2 - 4 } & CSA and SQP and AP & High & 3 \\
\hline II & CTBT & Medium & 2 \\
\hline III & NWFZ & High & 3 \\
\hline
\end{tabular}

Similarly, the overall motivation score is computed as:

$$
\text { Overall motivation score }=\text { Category I score }+ \text { Category II score }+ \text { Category III score }
$$

For instance, if a state is a member of CSA and AP, it is given a score of 3 for Category I. In addition, if this state is also a member of CTBT but not a member of NWFZ, then its overall barrier score is (CSA and AP) $3+($ CTBT $) 2+($ Not NWFZ) $3=5$. 


\subsubsection{Future Dataset Expansion Possibilities}

In addition to the dataset described in the previous sections, other nuclear proliferation-related datasets have been published recently and still other data seems to be publically available. A notable example is the sensitive nuclear assistance data compiled by Mathew Kroenig (2010). To test the hypothesis regarding the effect of sensitive nuclear assistance on state-level proliferation, Kroenig constructed a dataset for all states from 1945 to 2000. Sensitive nuclear assistance refers to the transfer of materials and technologies that are needed for developing nuclear weapons from nuclear supplier states to non-supplier states. Eligible sensitive nuclear assistance consists of three categories: 1) the design and production of nuclear arms, 2) delivery of weapons-grade fissile material sufficient for weapons production, 3) the construction of enrichment or reprocessing facilities to produce weapons-grade material (Kroenig 2010). Means of assistance that do not qualify as sensitive nuclear assistance include the transfer of platforms for weapons delivery, provision of non-sensitive assistance, and the construction of civilian-use reactors. The data were extracted from a database by the Nuclear Threat Initiative. Reviews of proliferation studies and historical country studies were also consulted in the coding of this variable. It is binary and is coded as 1 if the occurrence of sensitive technical assistance between nuclear states and aspiring non-nuclear states is confirmed; otherwise, it is 0 . In this study, the author also heavily leveraged the data from Singh and Way (2004), which makes this dataset naturally extendable to our model. In future modeling endeavors, it is foreseeable to structure sensitive nuclear assistance as a BN model node and assess how it contributes to the model outcome.

Although not strictly focusing on proliferation, Mathew Fuhrmann (2010) examined the determinants of dual-use commodity exports from U.S. to other countries between 1991 and 2001. Dual-use commodities are measured as the natural logarithms of the aggregate value of dual-use commodities exported (in current US dollars) for the countries in the sample and the aggregate number of approved dual-use commodity export licenses. The data (Fuhrman 2010) were obtained from the U.S. Department of Commerce Bureau of Industry and Security. Predictor variables include democracy (Polity score), US allies (COW Formal Alliance data), U.S. engagement in militarized conflicts (Grimmett 2002 data), weapons of mass destruction (WMD) acquisition and pursuit status, and differences in foreign policy interest between the United States and a given country (Signorino and Ritter 1999 data). The unit of analysis was individual State. His study suggests that democracy is positively and significantly linked to dual-use commodity exports and that a country's WMD status does not critically interfere with its dualuse commodity imports. Note the author argues that the export value might have been inflated for US adversary countries such as Cuba and Iraq while US allies' export numbers might be undervalued. To account for this issue, the author eliminated 23 cases (countries classified as terrorist sponsor states by the U.S. government) from the database and the resulting $\mathrm{N}$ is 128. Despite its focus on the United States and hence the limited generalizability of the findings, this study is nonetheless useful for shedding light on the possible relationships within international trade, especially dual-use commodity imports and exports, on nuclear proliferation. In the BN model presented in this report, we modeled the impact of a country's economic integration into the global economic system on proliferation propensity without explicitly modeling the proliferation effect due to dual-use commodity trade. The latter may be a fruitful area for future modeling effort.

Nelson and Sprechler's (2010) study filled an important research gap surrounding the factors that shape states' reliance on nuclear fuel. The dependent variable, nuclear reliance (NR), is operationalized as the unit-standardized fraction of electricity generated from nuclear power plants in a state. Predictor variables include historic alignment, relative coal reserves, fuel-cycle state status, international 
commercialization, and polity. Historic alignment is a proxy measure for secondary material and technology assurance and is a dichotomous variable whose value is 1 for those states that were members of the Soviet Union, or were (and/or are) members of NATO, SEATO or the Warsaw Pact. Pakistan and Taiwan also belong to this group of states. The rest of the states including Fuel-Cycle States (FCSs) and recognized Nuclear Weapon States (NWSs) are coded as 0. As an inexpensive, reliable alternative to nuclear fuel, coal reserves may influence a country's reliance on nuclear fuel. With the data from the Energy Information Administration, relative coal reserves is constructed as the ratio between a state's coal reserves and its total electricity generation. In addition, being a FCS is hypothesized to influence a state's nuclear reliance and is operationalized as a dummy variable. Another dummy variable, International Commercialization, captures the effect of sales of indigenously produced nuclear energy or technologies internationally. Lastly, regime stability is included to assess the degree to which democratic regimes encourage civilian-use nuclear programs. Polity scores are used as a surrogate measure for regime stability and range from -10 to 10 , which was rescaled to $[0,1]$. Countries that have a population of 20 million or more and countries with a GDP of minimally $\$ 20$ billion are included in the sample, resulting in a sample size of 89. Further, Afghanistan, Puerto Rico, and Uganda were excluded due to lack of data. The eventual sample consists of 86 countries. Similarly, for future modeling research, these data can also be leveraged to characterize the relationship between nuclear reliance and proliferation.

In a separate effort, a PNNL summer intern researcher surveyed publically available political and technical data for use in future refinements of the BN proliferation propensity model. A description of these datasets is provided in Appendix B.

\subsection{Validation of BN Proliferation Propensity Model}

This section discusses approaches we took to validating the $\mathrm{BN}$ proliferation propensity model. The primary approach was a test we specifically designed to address the principal hypothesis of this research which is to demonstrate the utility of social modeling as an indispensable element of proliferation assessment. The other two validation discussions in this section, one on face validity and the other on a set of validation case studies, are not specifically related to the principal hypothesis of this research (i.e. the utility of social modeling) but rather validation of one of the BN proliferation propensity models. The results of this primary validation exercise shows that modeling nuclear proliferation with a combination of technical factors and social factors can produce more rigorous proliferation predictions than modeling with technical factors or social factors alone. Although our model is intended to be used for forecasting, a central feature of our primary validation test was the use of "back-casting" or postdiction. Given that the number of States in some stage of proliferation is few if the current year is used for model validation, we employed this alternative approach in order to makes available more cases to test the validity of the model. What we mean by "back-casting" is that the model was used to predict retroactively the proliferation propensity for a given State in a past year by using model inputs from the year for which the prediction was being made. It is different from extrapolation in that, instead of extending the model based on past and/or current data within a defined domain to make assessments about quantities in an undefined domain, back-casting was, in a sense, made to reproduce the proliferation status of a State actor for a given year in the past. A postdiction (i.e. "back-cast") was then compared to data considered in this research to represent proliferation "truth." A distance function was created to measure the degree to which the back-cast deviates from the truth. The proliferation truth about a country was considered to be the proliferation category determined by Singh and Way in their dataset (i.e. Not interested, Exploring, Pursuing, Acquiring). 
The time series plot produced using the BN proliferation propensity model are presented in the results section (Section 3.5) of this report, and can also be viewed as an additional validation model. These predictions as discussed in Section 3.5 are logically consistent with proliferation history of various States as documented in relevant literature.

\subsubsection{Validation Test Using a Utility of Social Modeling Metric}

To assess the extent to which social modeling contributes to proliferation assessment, we developed the benchmark procedure to understand the degree to which social factors improve the accuracy of a model's assessments of whether a country has (or is actively pursuing) a nuclear weapons program as compared with not using social factors.

For evaluating whether social factors contribute to assessing Proliferation Propensity we used the following test based on the validation data. The following represents the $i^{\text {th }}$ row from the validation data set. Each row corresponds to a country and a year and contains social factors: $s_{i}$, technical factors $t_{i}$, and proliferation state $p_{i}$. Some fixed number of rows is randomly selected from the data set.

\begin{tabular}{l|l|l|l|}
\multicolumn{1}{c}{} & \multicolumn{1}{l}{ Social } & \multicolumn{1}{l}{ Technical } & \multicolumn{1}{l}{ Proliferation State } \\
\cline { 2 - 4 } country-year & $s_{i}$ & $t_{i}$ & $p_{i}$ \\
\cline { 2 - 4 } & &
\end{tabular}

The model under evaluation, denoted ' $m$ ', is applied to the sampled data, both with and without including the social factors. The following is an accuracy estimate for the model - using all of the factors:

$\sum_{i} d\left(m\left(s_{i}, t_{i}\right), p_{i}\right)$ - where the sum is over the randomly selected records in the benchmark data set, and $d(\cdot, \cdot)$ is a distance between proliferation states. This quantity is contrasted with the accuracy of using the technical factors alone: $\sum_{i} d\left(m\left(t_{i}\right), p_{i}\right)$. The (currently) unspecified distance $d(\cdot, \cdot)$ measures the agreement between the model output and the observed proliferation state for the country-year. The distance function $d(\cdot, \cdot)$ is described later in this section.

There are a number of options for an assessment metric comparing the distances with and without the social factors. For instance, analogues of an F-test could be constructed, or a proportional change might be used. We used the following assessment metric:

$$
\sum_{i} d\left(m\left(t_{i}\right), p_{i}\right)-\sum_{i} d\left(m\left(s_{i}, t_{i}\right), p_{i}\right)
$$

Positive values in (1), for a series of tests, indicates that the proliferation assessment is improved by the inclusion of social variables and that social modeling can contribute to a better and richer understanding of State actors' proliferation behavior and their decision context.

The BN calculates Proliferation Propensity as the probability of being in one of the five states:

- Very Low

- Low 
- Moderate

- High

- Very High

The output of the model is a probability distribution over these five states. On the other hand, the Singh and Way definition of proliferation status is a judgment of being in one of four states:

- Not Interested

- Explore

- Pursue

- Acquire

These are categorical judgments. In order to measure the distance between the model output and the judged state of proliferation based on Singh and Way we created a mapping from each of the four Singh and Way proliferation states to a probability distribution over the five proliferation propensity levels (i.e. Very Low, Low, Moderate, High, and Very High) used in the BN proliferation propensity model. Table 3.8 depicts the mapping.

Table 3.8. Mapping from Explore/Pursue/Acquire Judgments to Proliferation Propensity Levels

\begin{tabular}{lccccc}
\hline & Very Low & Low & Moderate & High & Very High \\
\hline $\begin{array}{l}\text { Not } \\
\text { interested }\end{array}$ & 0.99 & 0.009 & 0.0009 & 0.00009 & 0.00001 \\
Explore & 0.09 & 0.4 & 0.4 & 0.09 & 0.02 \\
Pursue & 0.02 & 0.09 & 0.4 & 0.4 & 0.09 \\
Acquire & 0.00001 & 0.00009 & 0.0009 & 0.009 & 0.99 \\
\hline
\end{tabular}

Once we mapped Singh and Way categorical judgments into the same five-dimensional-space as the BN model outputs, we could then define a distance metric to determine how close the model output is to Singh and Way judgments. There are a number of distance metrics one could use to measure distance in five dimensions, but the simplest is Euclidean distance, which is defined for two points, "a" and "b" in five-dimensional-space, as follows:

$$
d=\left[\sum_{i=1}^{\bar{j}}\left(a_{i}-b_{i}\right)^{2}\right]^{1 / 2}
$$

In order to compare the predictive accuracy of a model that makes use of social information with a model that uses only technical information, we needed to define a purely technical model. Considering causal and diagnostic models presented in Section 3.1, the question is: which are the technical variables and which are the social variables? There are three variables that determine proliferation propensity: Nuclear capability, motivation, and non-proliferation regime barriers to proliferation. Motivation is a social variable and all the variables related to motivation in the $\mathrm{BN}$ model are social in nature. The variables that determine the level of motivation such as, regional stability and diplomatic isolation are all social in nature. The one possible exception is nuclear capability of neighbors. However, it is treated as a social 
factor in that it is important as proxy for perceived threat. Thus, it seems reasonable to eliminate motivation and the variables that determine its level from a purely technical model. The non-proliferation regime barriers to proliferation are based on a composite score of participation in non-proliferation treaties. Treaties are social contracts and hence we would argue that these are also social variables. That leaves nuclear capability, which is a function of nuclear technology, available fissile material, and economic capacity as the technical variables. We built technical BN that used only these technical variables to predict proliferation propensity by eliminating the social variables from the diagnostic model shown in Figure 3.22. The resulting model is shown in Figure 3.9.

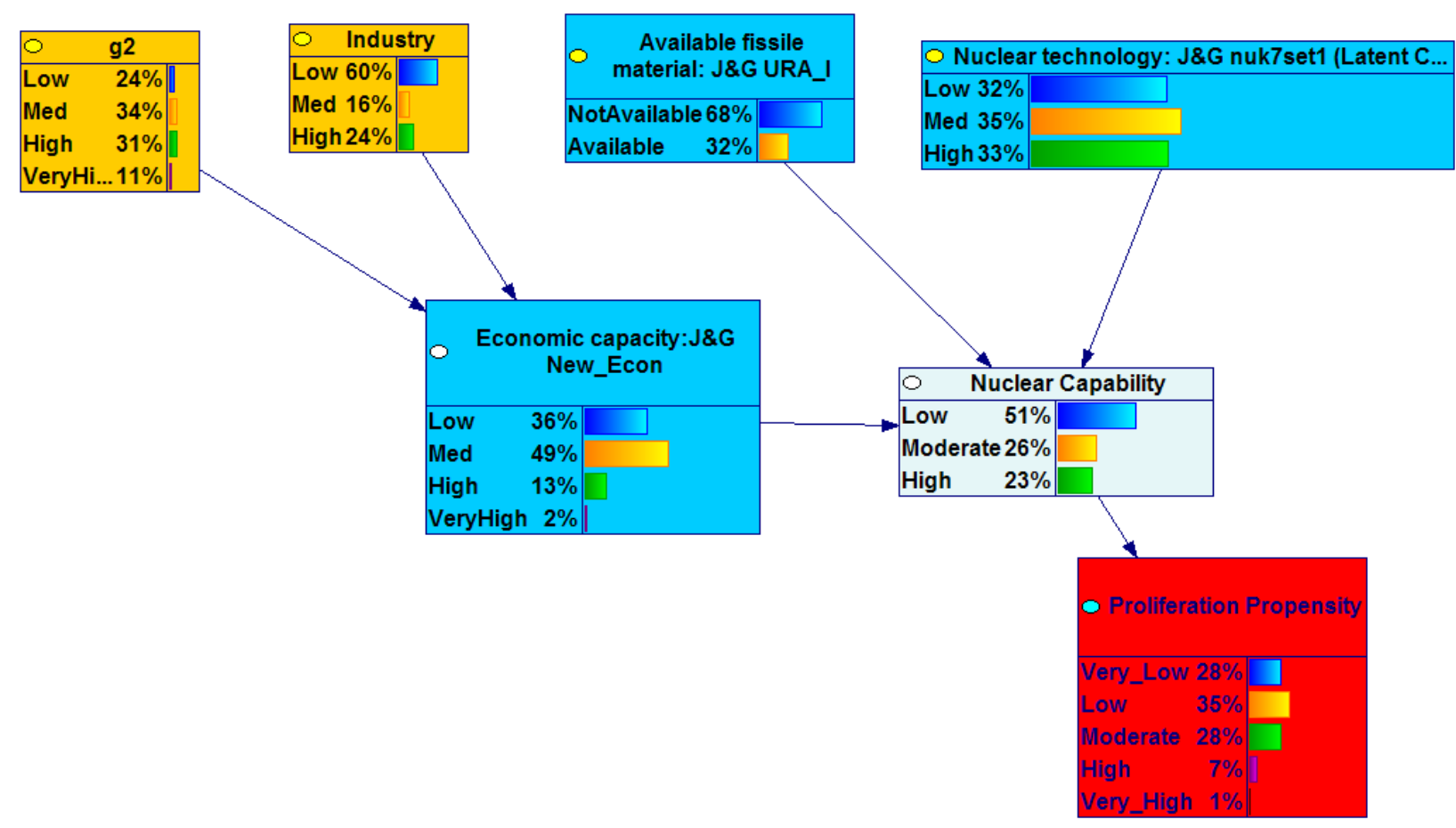

Figure 3.9. Technical Bayesian Net for Predicting Proliferation Propensity (Causal Version)

We exercised both the composite diagnostic $\mathrm{BN}$ and the technical $\mathrm{BN}$ to get proliferation propensity distributions for all countries and all years using the combined dataset as input. We then calculated the distance from the Sing and Way Explore/Pursue/Acquire judgments using the mapping shown in Table 3.8 and the Euclidean distance function. We then compared the distance from the judged proliferation states as computed by the technical model versus the composite model that includes the social variables. The Composite model was closer to the "truth" $59 \%$ of the time across all countries and all years (Chi Squared $=333, \mathrm{p}<.001$ via a sign test). Also, the average distance from the truth for the composite model was 0.73 as compared to 0.83 and 0.86 for the technical and social respectively. These results suggest that there is value in incorporating social factors into proliferation propensity assessment and that the utility of social modeling is indispensable for creating more rigorous predictions of proliferation propensity. There are some caveats to this conclusion. There are some caveats to this conclusion. First, the predictive accuracy is being measured by the judgments as to whether a country was exploring, pursuing, or acquiring a nuclear weapon. These were interpretations by Singh and Way and the actual truth about the proliferation posture of all countries in all years may deviate from appearances. Second, the results are sensitive to the mapping function we used to transform the explore/pursue/acquire judgment into the five dimensional space of proliferation propensity. Different mappings produce different results which we 
confirmed by trying two different truth functions. The particular mapping chosen puts little uncertainty on not interested and acquire, and assumes that the relationship between explore and pursue and proliferation propensity is more fuzzy as defined by more uncertainty in their probability distributions. More work could be done exploring the impact of using different mappings. It is hard to imagine not using the social factors in any model for predicting proliferation propensity because motivation and decision making play such a large role in proliferation literature.

\subsubsection{Face Validity}

Another measure of validity is face validity. Face validity refers to the extent to which a model measures what it is designed to measure. Therefore, when the model's results are congruent with known knowledge or the general expectation about the phenomenon being modeled, the model has face validity. It demonstrates that model seems to work in the way we would expect it to. Exercising the model by weighting values at the extreme ends of the value range resulted in outputs that would be expected. So for example, entering all indicator values associated with low proliferation risk into the model should result in a proliferation propensity distribution characteristic of low risk. Similarly, setting indicator values associated with high risk should result in a proliferation propensity distribution characteristic of high risk. The model does in fact behave this way. In fact, if one sets the model to update immediately, as one enters values for the indicators, one can observe the distribution for proliferation propensity change in the way one would expect. The changes are in the right direction, whether the magnitude of the change is appropriate to the amount of change in the indicator would be difficult to assess. But on the face of it, the model seems to be working in a manner consistent with the expectations of PNNL subject matter experts.

\subsubsection{Validation Case Studies Using BACH}

Another approach to validation is to compile proliferation risk assessment case studies based on the model and compare the outcome against data. The congruence between the case studies and the data indicates some degree of predictive validity of the model. The validation case studies we conducted incorporated an earlier version of the $\mathrm{BN}$ model prior to including non-proliferation regime barriers to proliferation, an evidence gathering and evaluation tool that works in tandem with the model, and experts' assessment into a single process. Below we discuss the application of this three-component approach.

An early version of the model was imported into the Bayesian Analysis of Competing Hypotheses $(\mathrm{BACH})$ software developed by PNNL. BACH integrates evidence gathering with BN models to update the outcome probability calculations for specific countries. A representation of this model is presented in Figure 3.10. BACH is a Java based tool for BN model creation, evidence search and assessment, and evaluation of the effect of evidence on a user's hypotheses. BACH allows the user to create a BN model, document the model creation process including links and references and most significantly, in this case, construct and save evidence queries (which at the moment are internet searches, but can be adapted to be network or database searches) and supports evidence importation and credibility and bias assessment. When evidence is attached or the model is changed, BACH instantly updates the new hypothesis probabilities and the outcome effects.

For the validation, we focused on Africa because many African nations have so far received limited attention in open literature with respect to the issue of nuclear proliferation. Additionally, given their diverse regime types, economic development levels, and proliferating motivations, these nations provide 
interesting and fruitful foci. We use the following countries as our test cases: South Africa, Nigeria, Uganda, Gabon, Senegal, and Ghana to produce country rankings by their proliferation propensity.

In the evidence gathering stage, two researchers each created a list of node-based queries tied to the BN. The two lists were then combined to reduce redundancy and ensure better search term representation. For instance, for the node named "Nuclear Capability," we created a broad search query such as "(Country name) has nuclear capability." In some cases, multiple queries are created for the same node to ensure a broader coverage of evidence. See Appendix $C$ for the list of queries. Note, due to time and resource constraints, we created queries only for those nodes for which tangible evidence and query operationalization are possible. These nodes include Contributing Technologies, GDP ${ }^{2}$, Available Fissile Material, Industry, Domestic Unrest, Level of Democracy, Regional Stability, Percentage of Democracies, Nuclear Capability of Neighbors, Allies, Rivalry, Disputes Conventional Threat, Economic Interdependence, and Diplomatic Isolation. The queries and the associated evidence provide a reasonable range of information representation.

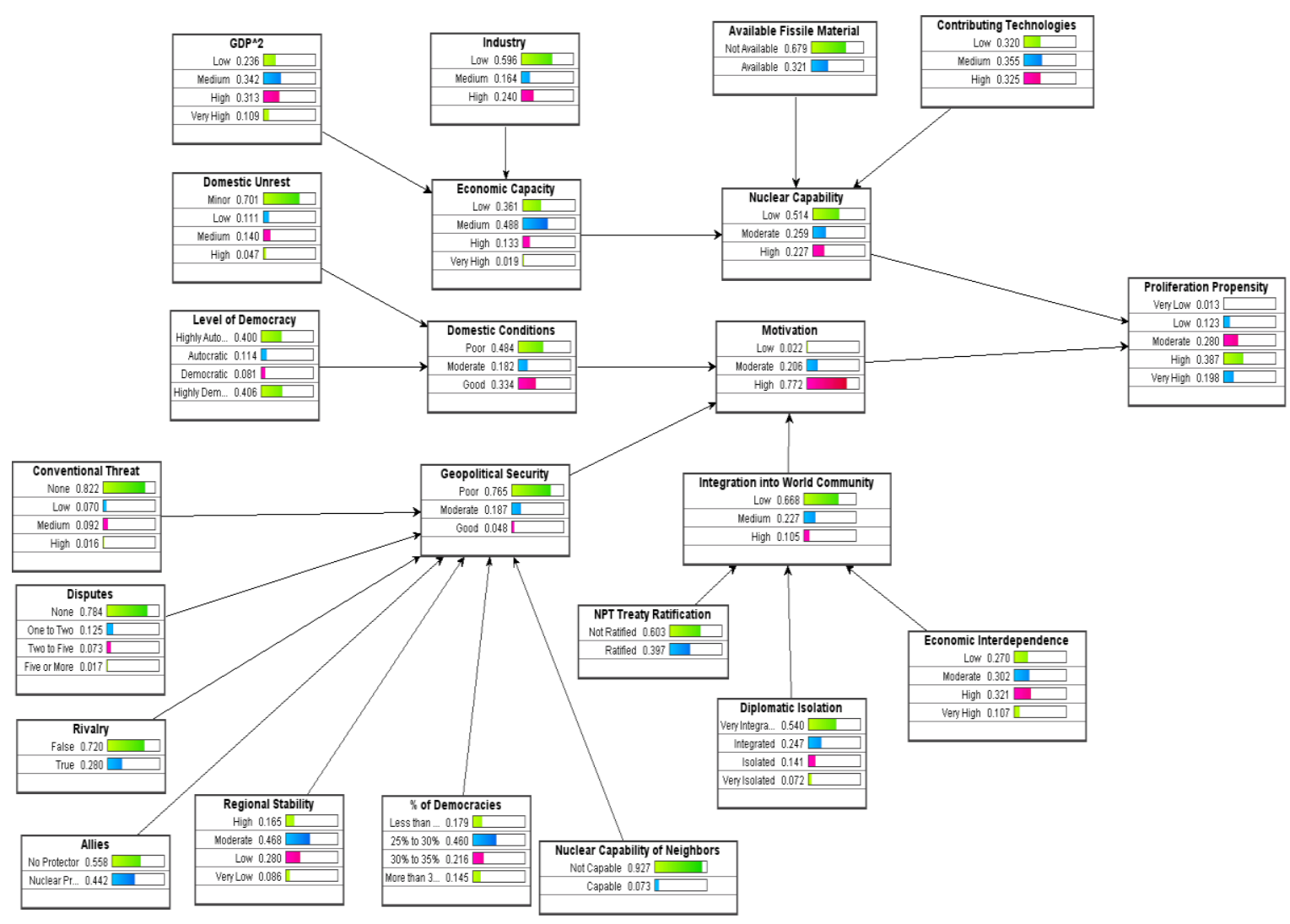

Figure 3.10. BACH Representation of a Previous Version of Proliferation Propensity Model

Then a computer scientist populated the consolidated queries in the model space and aligned the queries with their associated nodes. A researcher executed the queries from $\mathrm{BACH}$, which retrieved results for evaluation. The evaluation is bounded by reliability and bias scale as shown in Figure 3.11. When a piece of evidence is evaluated, the analyst will make a subjective judgment about the reliability and bias of the evidence under consideration. The evaluation criteria include information relevance, bias, 
factuality, information source, author credibility, and timeliness. For instance, if a piece of information is published by a peer-reviewed academic journal, then it is considered more reliable and less biased than information published in personal blogs or local newspapers. By the same token, information gathered from credible web-based databases such as the Central Intelligence Agency World Factbook ${ }^{25}$ is generally considered as relatively unbiased whereas commentaries collected from politically-charged newspaper or websites are considered more biased. Note, although evidence evaluation may be subject to individual analysts' decision biases, the analyst was instructed to be as consistent as possible in his/her evaluation. A recent replication of the case studies yielded similar results to the results presented below, demonstrating considerable resilience of the BN model and the elicitation tool to personal judgmental biases and disparate domain knowledge.

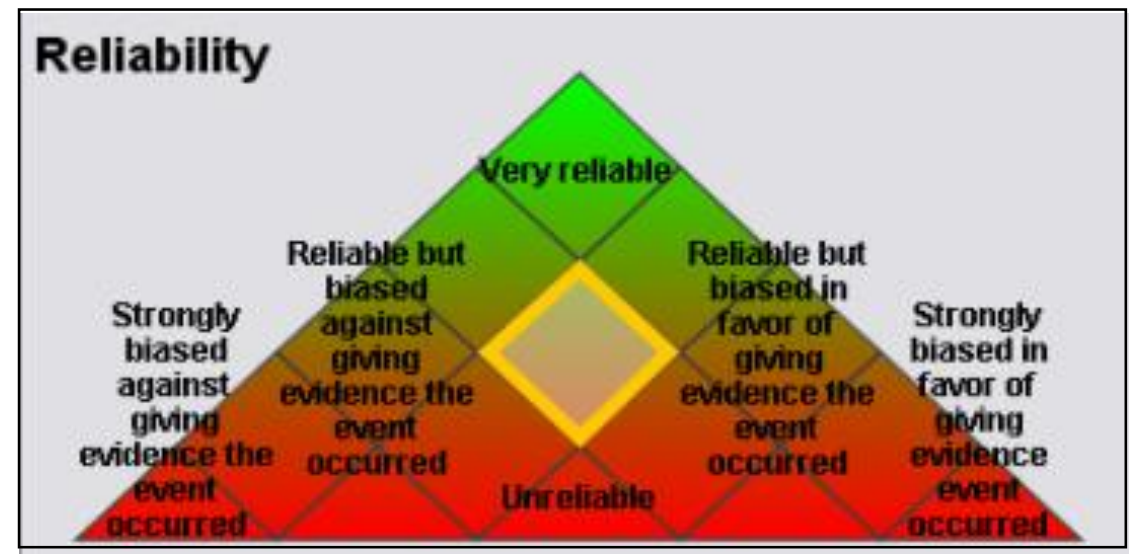

Figure 3.11. Evidential Reliability and Bias on a Credibility Scale

It is important to point out that, for country-specific studies, the size of the evidence pool could be uneven, which could also influence evidence evaluation. Notably, for the Gabon study, both academic and popular information is relatively scarce whereas the information for Nigeria is markedly abundant. In addition, the lack of subscriptions to some academic journals precludes relevant articles from being considered. Finally, it is possible that the application of the evaluation criteria was not consistent throughout the evaluation process. This is a fundamental limitation in subjective decision making and should be addressed in future research.

BACH updated the outcome probabilities for state proliferation propensity to reflect the attached evidence. The outcome node has five states: very low, low, moderate, high, and very high. The outcome change ratio measures the magnitude of propensity change resulting from the attached evidence for a given state and is calculated as [1- (base rate - updated calculation)/base rate]. Table 3.9 shows the order of countries from highest to lowest proliferation propensity to be: South Africa, Nigeria, Ghana, Senegal, Gabon, and Uganda. This ranking was considered to be generally consistent with the opinion of experts (and SMEs with PNNL). Graphs for each of these six countries are shown in Figure 3.12 through Figure 3.17. The left side of the figures is the outcome node after evidence, and the right side is the change in outcomes due to the evidence.

\footnotetext{
${ }^{25}$ The CIA World Factbook provides information on the history, people, government, economy, geography, communications, transportation, military, and transnational issues for 266 world entities. Accessed May 9 , 2011: https://www.cia.gov/library/publications/the-world-factbook/.
} 
Table 3.9 Proliferation Propensity Ranking for Early Validity Test

\begin{tabular}{|c|c|c|c|}
\hline $\begin{array}{c}\text { Propensity } \\
\text { Ranking }\end{array}$ & Country & $\begin{array}{c}\text { Probability in the } \\
\text { "Very High" State }\end{array}$ & $\begin{array}{c}\text { Max Outcome } \\
\text { Change Ratio }\end{array}$ \\
\hline 1 & South Africa & 0.42 & 2.12 \\
\hline 2 & Nigeria & 0.35 & 1.76 \\
\hline 3 & Ghana & 0.18 & 1.34 \\
\hline 4 & Senegal & 0.16 & 1.31 \\
\hline 5 & Gabon & 0.12 & 1.13 \\
\hline
\end{tabular}

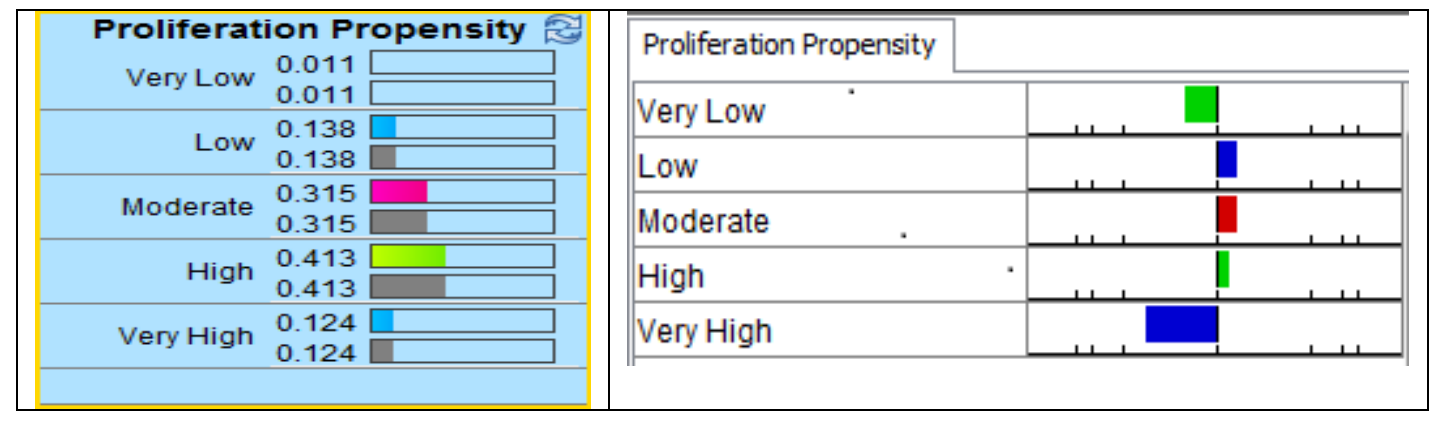

Figure 3.12. Gabon Proliferation Propensity

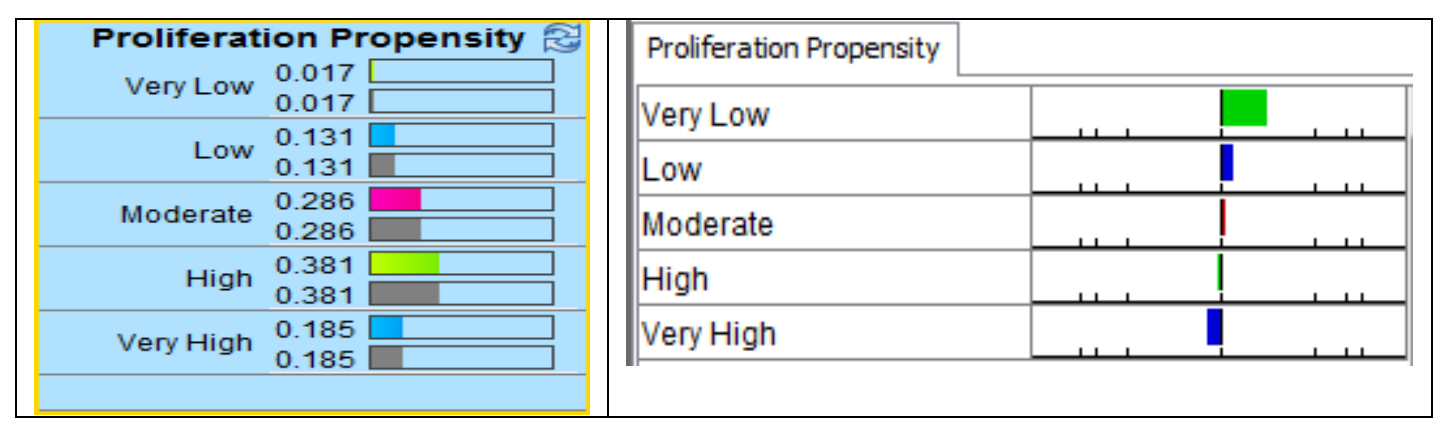

Figure 3.13. Ghana Proliferation Propensity

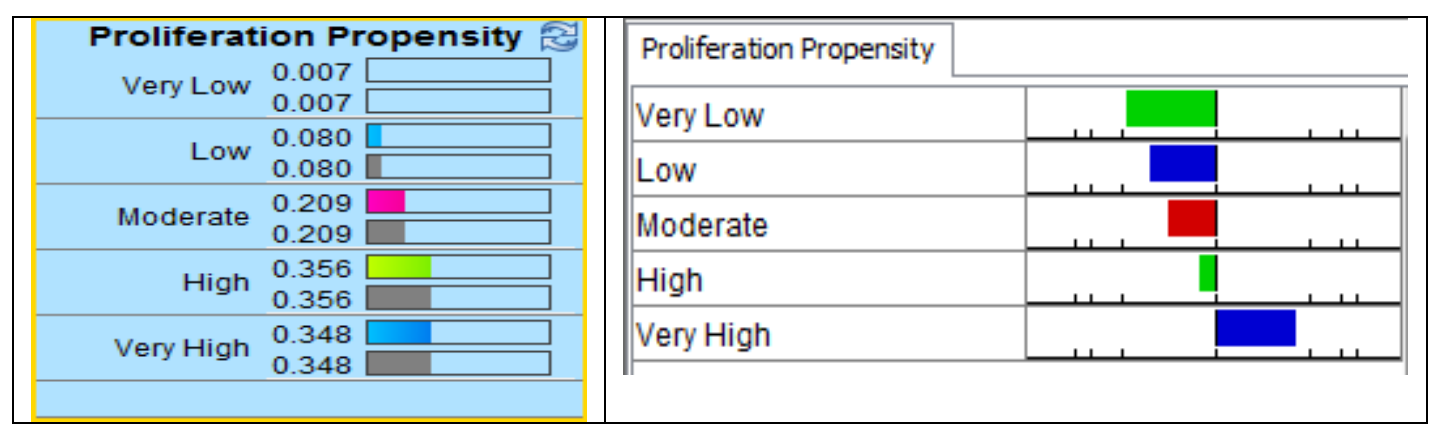

Figure 3.14. Nigeria Proliferation Propensity 


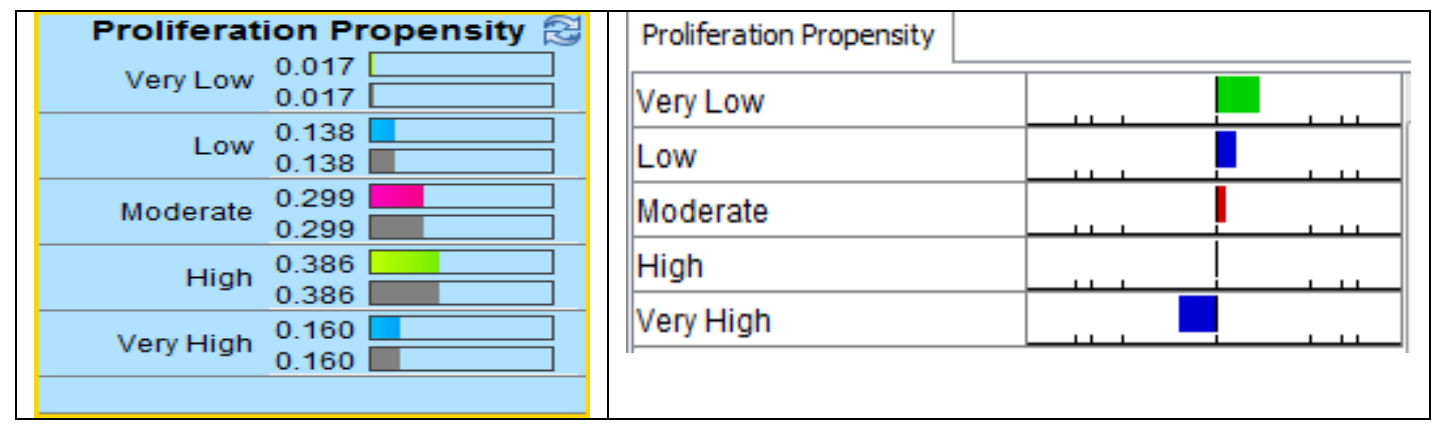

Figure 3.15. Senegal Proliferation Propensity

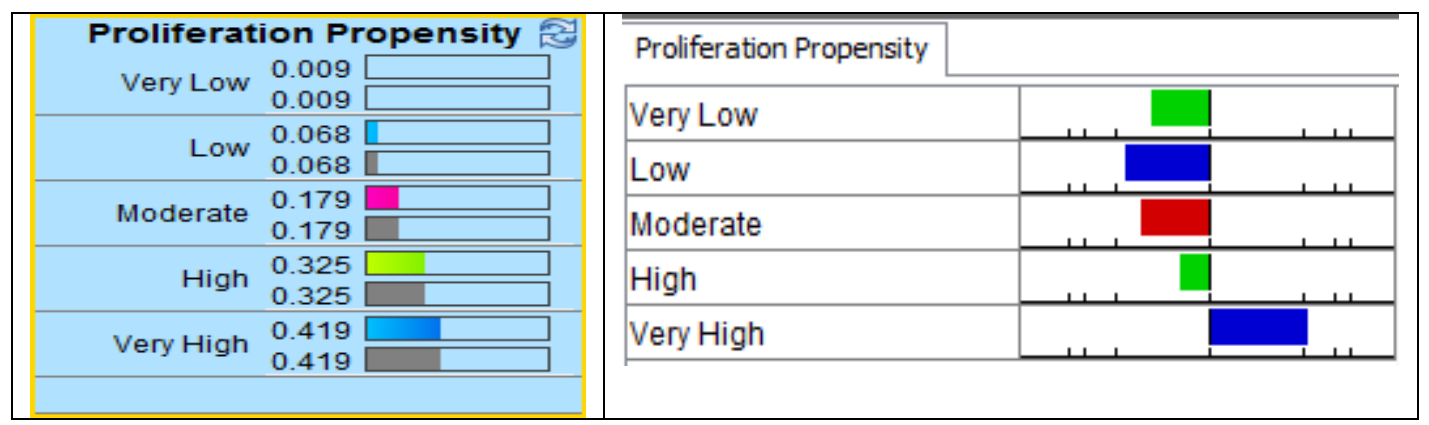

Figure 3.16. South Africa Proliferation Propensity

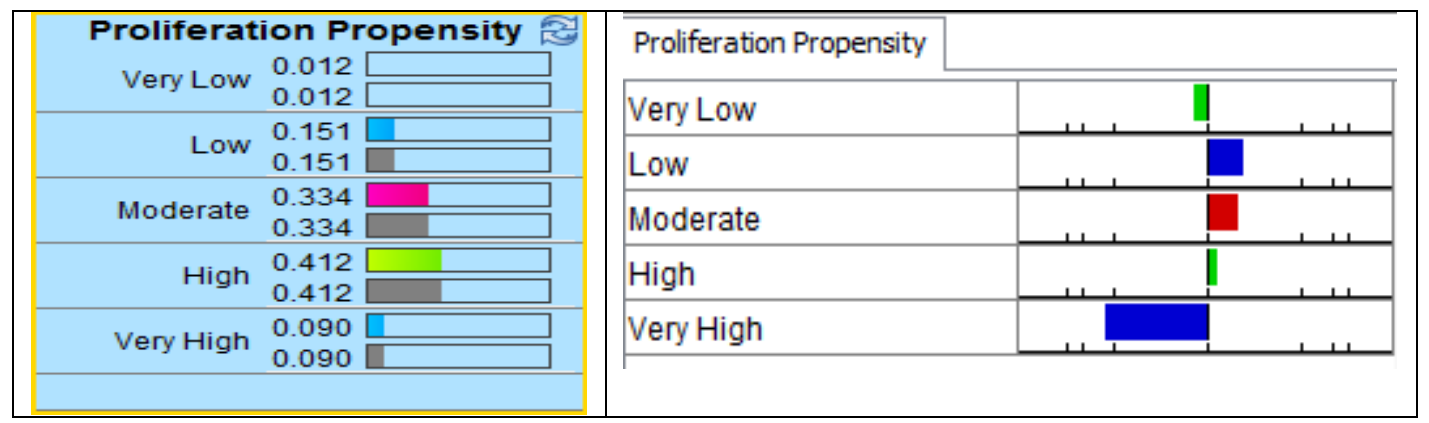

Figure 3.17 Uganda Proliferation Propensity

\subsection{BN Proliferation Propensity Model Assessment Results}

This section presents model prediction results for past years based on technical factors, social factors, and a composite of the technical and social factors. As mentioned earlier, we wrote a computer program that allowed us to exercise the model for all countries for all years. The model predicts back in time for given countries what the proliferation propensity should be, given the input in the models for the year in which the "bask-cast" occurred. As part of this effort, we produced time-series plots for each country from prior to 1950 to 2000. This section discusses the prediction results for a representative set of countries. Plots for this selection of countries are shown in Figure 3.18 through Figure 3.34. Figure 3.18 is the plot for South Africa. 
The plots show the expected proliferation propensity values as calculated by the composite model, the purely technical model and a purely social model for the years 1945 to 2000 (we discuss in section 3.4.1 how we created a purely social and purely technical model from our composite model). Also shown are the Singh and Way expected values of explore, pursue, acquire, and no interest as mapped into five dimensional space. Expected values were calculated based on the proliferation propensity probability distributions by assigning numeric values of one to five to each of the levels of proliferation propensity and computed the resulting expected values. The Singh and Way proliferation states (i.e., Not interested, Exploring, Pursuing, and Acquiring) values are shown in tturquoise. As can be seen in Figure 3. 18, South Africa was initially was not interested in proliferation but then explored, pursued and acquired a weapon, which they subsequently gave up. This is depicted by the rise and fall of the turquoise dots. The blue dots are the weighted average of proliferation propensity as calculated by the BN proliferation propensity diagnostic model. The red and green dots are the predictions of the technical and social models respectively. As can be seen in the graph, the three BN prediction models reflect the general trend of South Africa's proliferation activities over time to varying degrees.

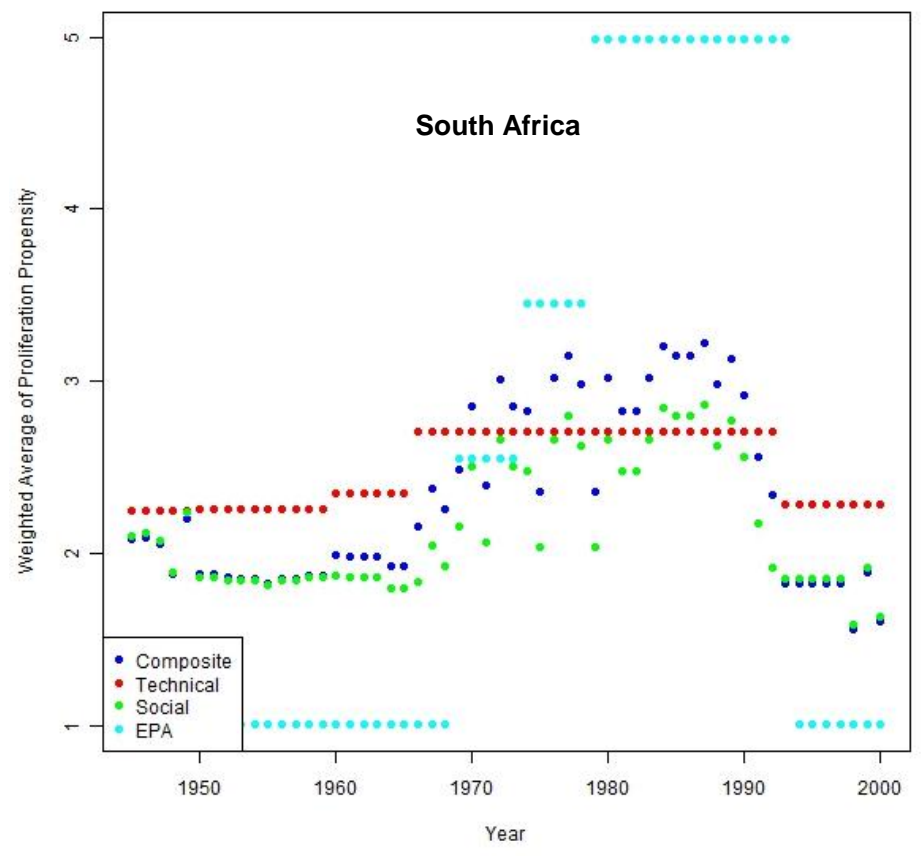

Figure 3.18 South Africa Proliferation Propensity Time series

The series plots score can be understood in terms of the following model:

$$
\text { PPScore }_{i j}=\text { PPTrend }_{j}+\text { PPCountry }_{i j}+\text { PPError }_{i j}
$$

Where PPScore ${ }_{i j}$ is the score for the $i^{\text {th }}$ country for the $\mathrm{j}^{\text {th }}$ year; PPTrend $\mathrm{j}_{\mathrm{j}}$ is the general proliferation propensity across all countries for a given year; PPCountry ${ }_{\mathrm{ij}}$ is the true proliferation propensity for country $i$ for the $j^{\text {h }}$ year; and PPError ${ }_{i j}$ is the error in the data for the $i^{\text {th }}$ country for year $j$. The proliferation score ranges between a value of 1.0 and 5.0 where a value of 4.0 and above is considered very high and a value of 2.0 and below is considered very low. Trend captures general changes averaged across all countries. For example, one would expect technical capability to rise on average over time as a result of the general trend in increased knowledge and technology. Similarly, there is a general tendency 
for a growth in domestic productivity over time. PPError captures the fallibility of the data sources, whether they result from hard data or expert judgment. This result is borne-out by looking at the time series plots across different countries. There are some patterns that are observed from many countries that were accentuated or attenuated for specific countries.

We randomly selected countries from four groups to discuss the results from our BN proliferation propensity model. Group A consists of economically and technologically advanced countries that appear to have limited motivation (e.g. no security threat) to pursue a nuclear weapons program (e.g., Australia, Belgium, Canada, and Germany). Group B consists of economically and technologically more challenged countries that appear to have some motivation (e.g. a security threat) to pursue a nuclear weapons program (e.g., Afghanistan, Libya, North Korea, and Pakistan). Group C consists of economically and technologically capable countries that appear to have some motivation (e.g. a security threat) to pursue a nuclear weapons program (e.g., India, Iran, Israel, and South Africa). Group D consists of economically and technologically more challenged countries that appear to have limited motivation (e.g. no security threat) to pursue a nuclear weapons program (e.g., Equator, Nigeria, Panama, and Thailand). This grouping and selection of countries was done subjectively without quantitative criteria but generally confirmed by information from our dataset.

In the following we discuss the trends in these plots and argue that what is presented is consistent what is known about these and similar kinds of countries. At the outset, it is important to highlight an exception to this general assertion. In all the plots presented in this section as well as the majority of plots for countries not presented, there seems to be a consistent discontinuity in the time series for each of the three predictions. Note the discontinuity, for example, in the composite (blue), technical (red), and social (green) predictions for Australia in Figure 3.19. Investigation reveals that this discontinuity is likely an artifact of missing data in the Jo and Gartzke dataset (i.e. a majority of the data entries for the years starting in 1992 are missing). For this reason we do not attempt to attribute a proliferation meaning to this discontinuity.

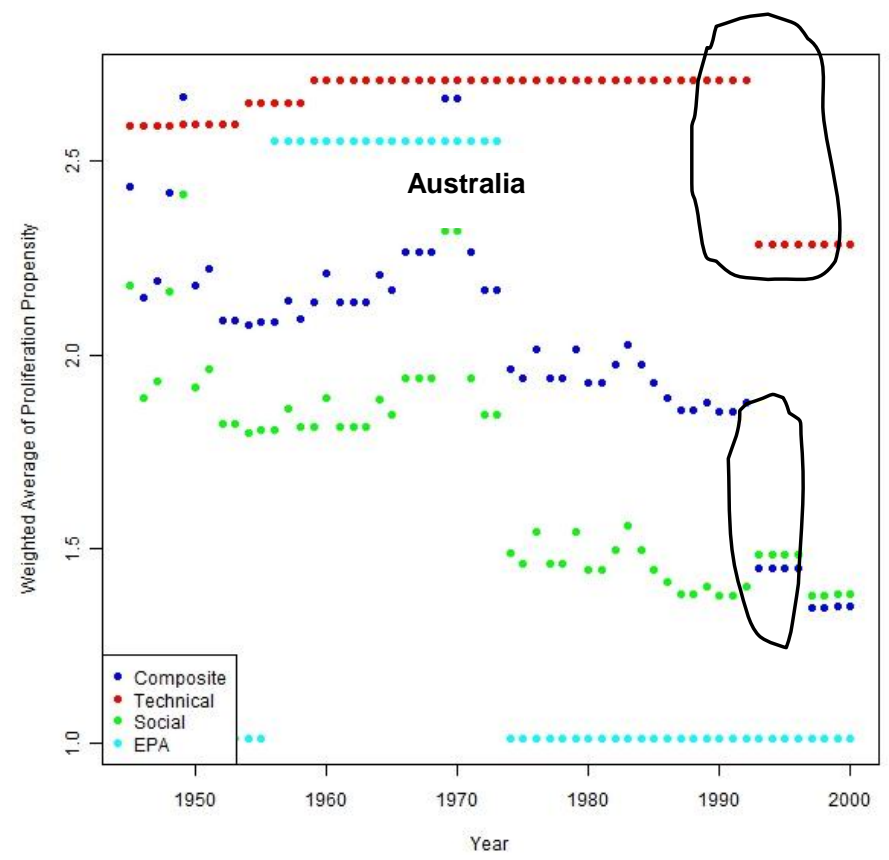

Figure 3.19 Australia Proliferation Propensity Time Series 
To represent Group A, which consists of economically and technologically advanced countries that appear to have limited motivation (e.g. no security threat) to pursue a nuclear weapons program , plots are provided for Australia, Belgium, Canada, and Germany in Figure 3.19 through Figure 3.22. As mentioned previously there is a discontinuity at year 1992 in each of the three trend lines for all four of these countries for the reason explained above. In general, the proliferation propensity predicted by the technical factors (i.e., red dots) is higher than predicted by the social factors (i.e., green dots), as would be expected for economically and technologically advanced countries that appear to have limited motivation to pursue a nuclear weapons program. The predictions based on the composite factors (i.e., blue dots) falls in between the predictions based on the technical and social factors for all four countries over the entire time span except for Germany between 1950 and 1970, and ranges in value from slightly higher than 2.0 to slightly lower than 2.0 on a scale of 1.0 to 5.0. For Germany the dataset shows disputes ending with other countries in 1968, rivalries ending in 1971, and the NPT being ratified in 1975 all of which contribute to decrease in motivation proliferate. For all four countries in Group A, there appears to be a downward trend of proliferation propensity based on social factors that translates to a reduction in the composite proliferation propensity. This slightly decreasing proliferation propensity might be explained by the gradual strengthening of the nonproliferation regime. The general proliferation patterns of the countries in Group A as predicted by the BN proliferation propensity model are fairly consistent with the documented proliferation history for all four of these countries.

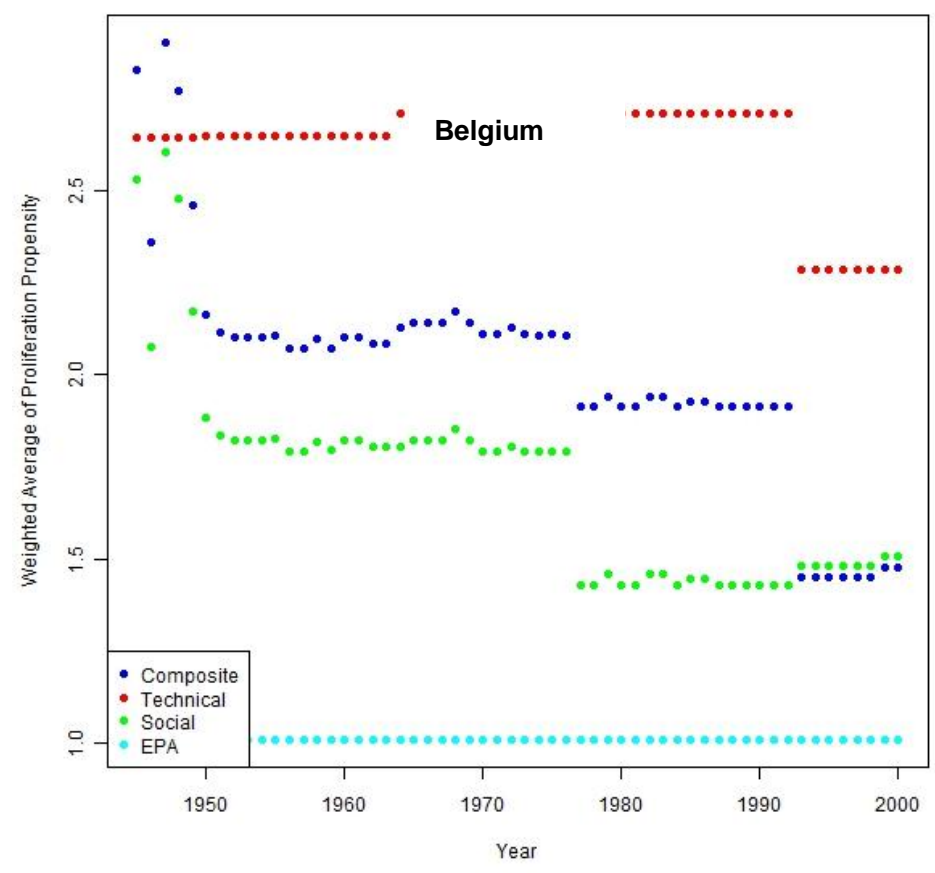

Figure 3.20 Belgium Proliferation Propensity Time Series 


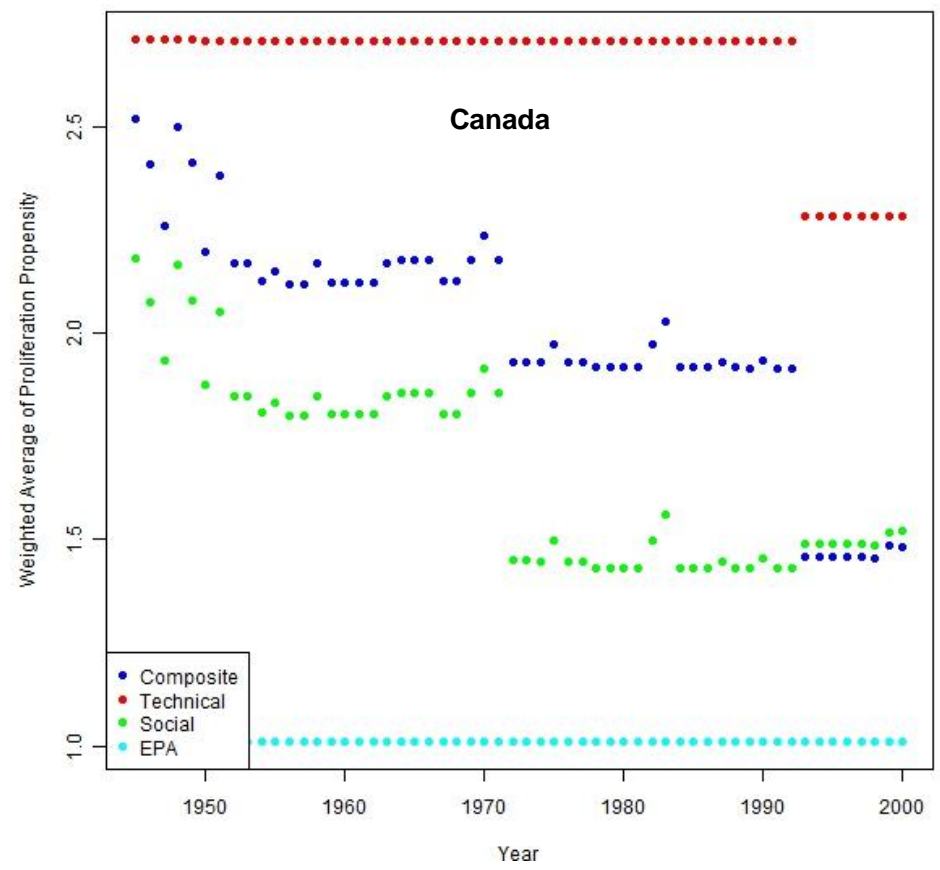

Figure 3.21 Canada Proliferation Propensity Time Series

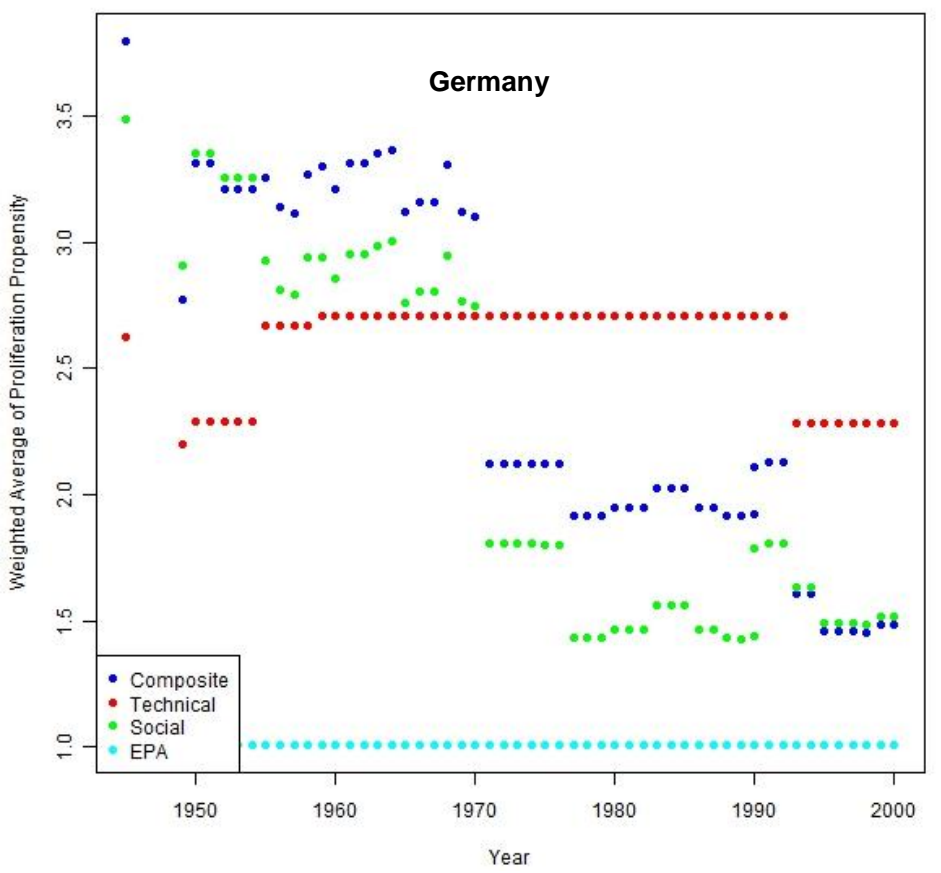

Figure 3.22 Germany Proliferation Propensity Time Series 
To represent Group B, which consists of economically and technologically more challenged countries that appear to have some motivation (e.g. a security threat) to pursue a nuclear weapons program, plots are provided for Afghanistan, Libya, North Korea, and Pakistan in Figure 3.19 through Figure 3.26. As mentioned previously there is a discontinuity at year 1992 in each of the three trend lines for all four of these countries for the reason explained above. In general, the proliferation propensity predicted by the social factors (i.e., green dots) is higher than predicted by the technical factors (i.e., red dots) as would be expected for economically and technologically more challenged countries that appear to have some motivation to pursue a nuclear weapons program. The predictions based on the composite factors (i.e., blue dots) primarily falls in between the predictions based on the technical and social factors over the entire time span except for Libya, and except for Libya the proliferation propensity ranges in value from 2.0 to 3.5. For Libya the proliferation propensity prediction is low based on both the technical and social factors predictors, so the model fails to show that Libya pursued a nuclear weapons program for a period of time . For North Korea and Pakistan, the proliferation propensity predictions match what we know about their pursuit and acquisition of nuclear weapons. For Afghanistan, although the social factors predict higher proliferation propensity than technical ones, the composite prediction is low, ranging from 2.0 to 2.5. This might suggest that if Afghanistan acquires technical capability, they might become a proliferation threat. The BN proliferation propensity model predicts well for three out of four of these countries. In future refinements of the model, factors that might have motivated Libya to pursue a nuclear weapons program should be investigated to determine if the model can be adjusted to appropriately reflect this proliferation propensity.

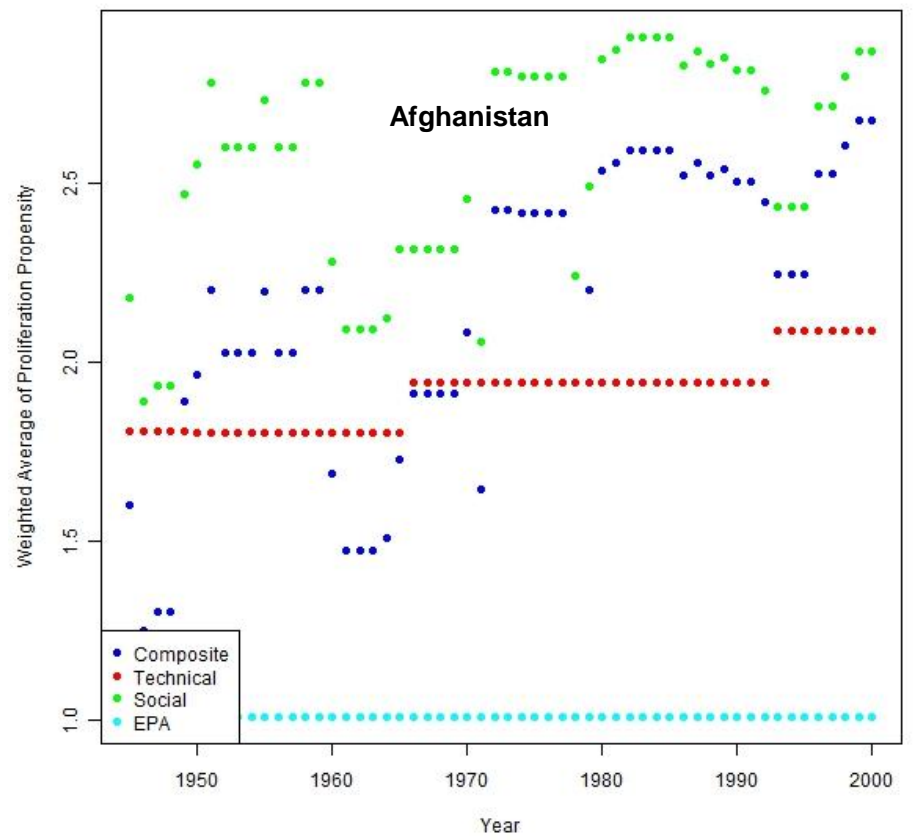

Figure 3.23 Afghanistan Proliferation Propensity Time Series 


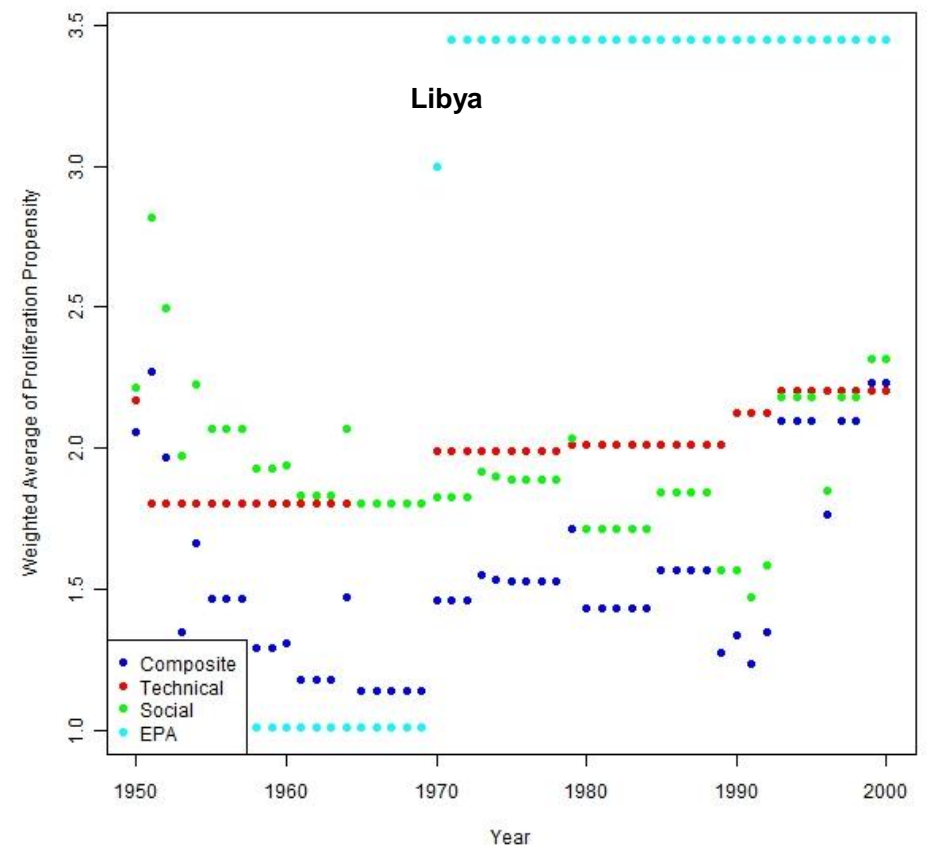

Figure 3.24 Libya Proliferation Propensity Time Series

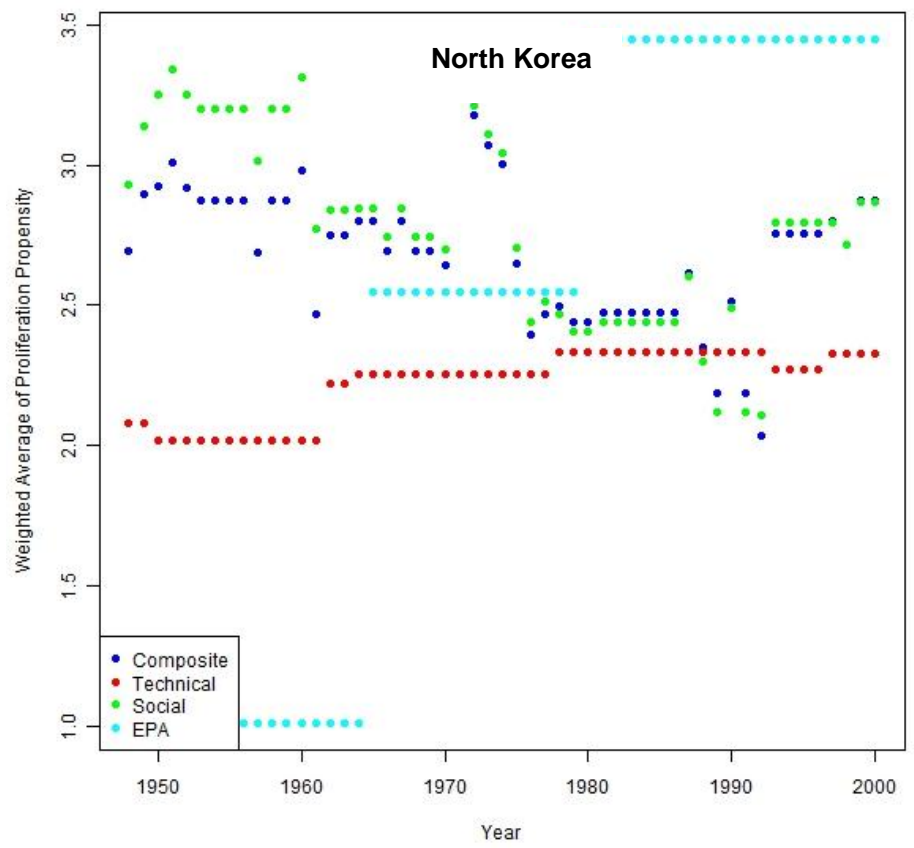

Figure 3.25 North Korea Proliferation Propensity Time Series 


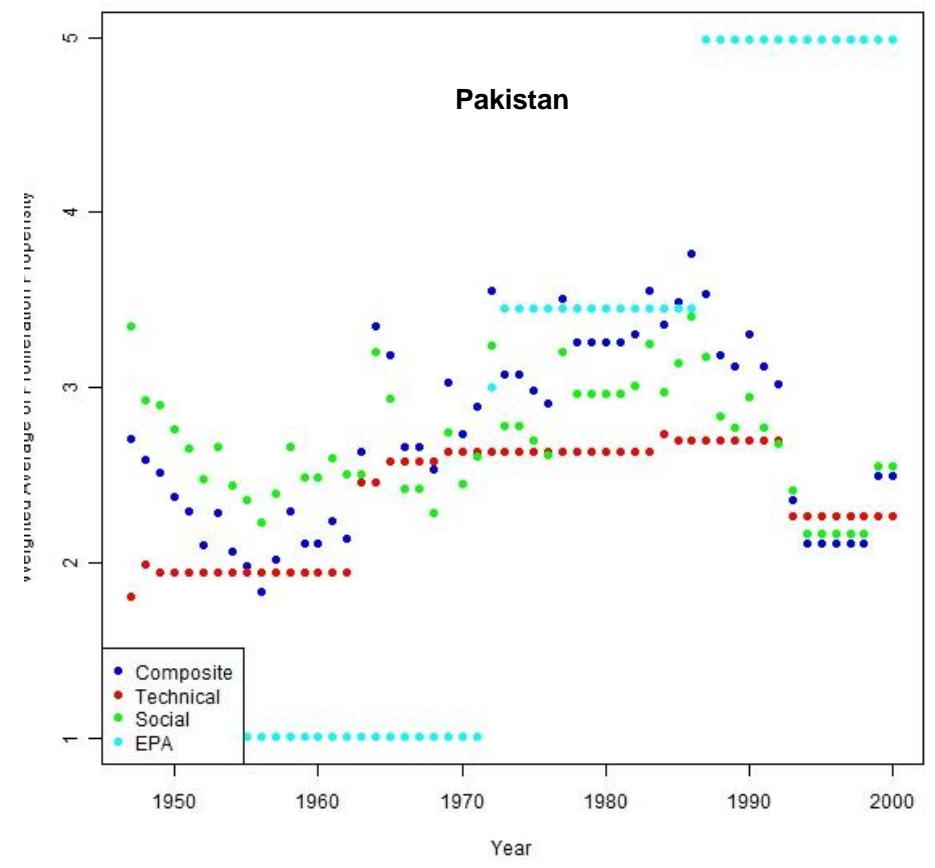

Figure 3.26 Pakistan Proliferation Propensity Time Series

To represent Group C, which consists of economically and technologically capable countries that appear to have some motivation (e.g., a security threat) to pursue a nuclear weapons program, plots are provided for India, Iran, Israel, and South Africa in Figure 3.27 through Figure 3.30. As mentioned previously there is a discontinuity at year 1992 in each of the three trend lines for all four of these countries for the reason explained above. For India and Israel the proliferation propensity predicted by the social factors (i.e., green dots) is higher than predicted by the technical factors (i.e., red dots) while the composite prediction is (i.e., blue dots) is higher still, as might be expected for economically and technologically capable countries that appear to have some motivation to pursue a nuclear weapons program,. The composite proliferation propensity for both these countries is high over most of the time span ranges in value from 3.0 to 4.0. For Iran and South Africa the proliferation propensity predicted by the social factors (i.e., green dots) trends with technical factors (i.e., red dots) while the composite prediction is (i.e., blue dots) is a bit higher. The composite proliferation propensity for both these countries range from low to high (i.e., 2.0 to 3.2), which is not inconsistent with economically and technologically capable countries that appear to have some motivation to pursue a nuclear weapons program but may or may not done so yet. Again, the proliferation propensity predictions produced by the $\mathrm{BN}$ model are generally consistent with the actual documented proliferation history of the four countries in Group C. 


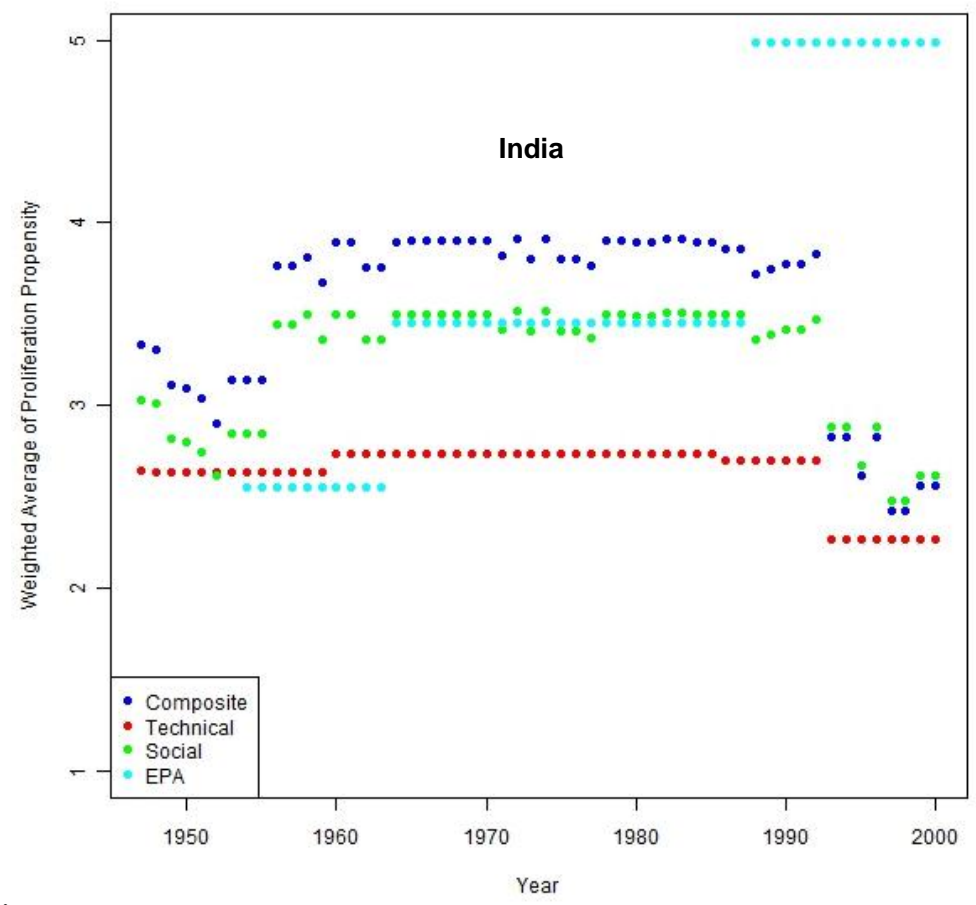

Figure 3.27 India Proliferation Propensity Time series

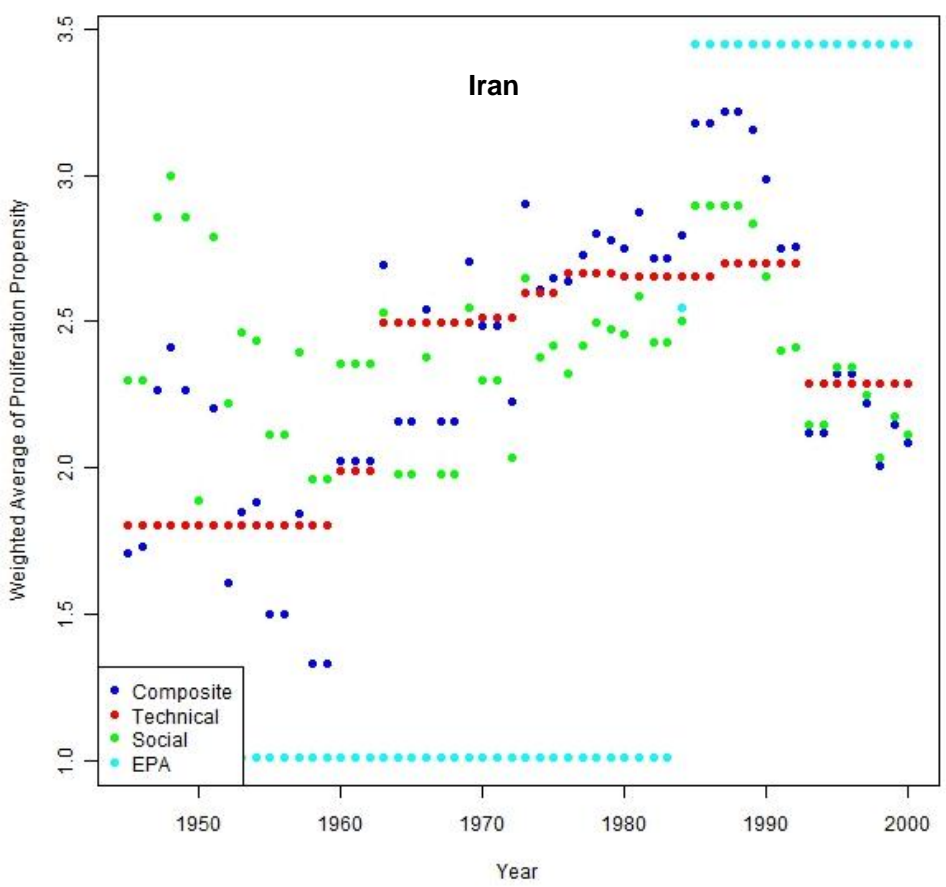

Figure 3.28 Iran Proliferation Propensity Time series 


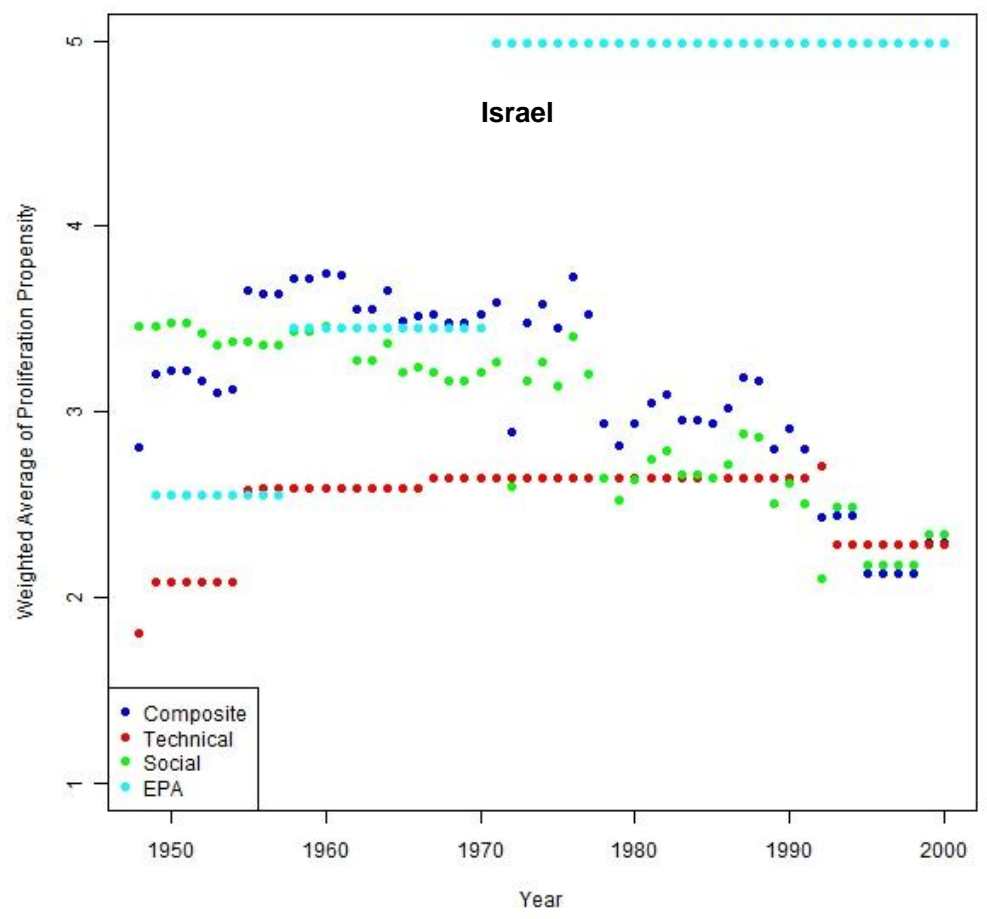

Figure 3.29 Israel Proliferation Propensity Time Series

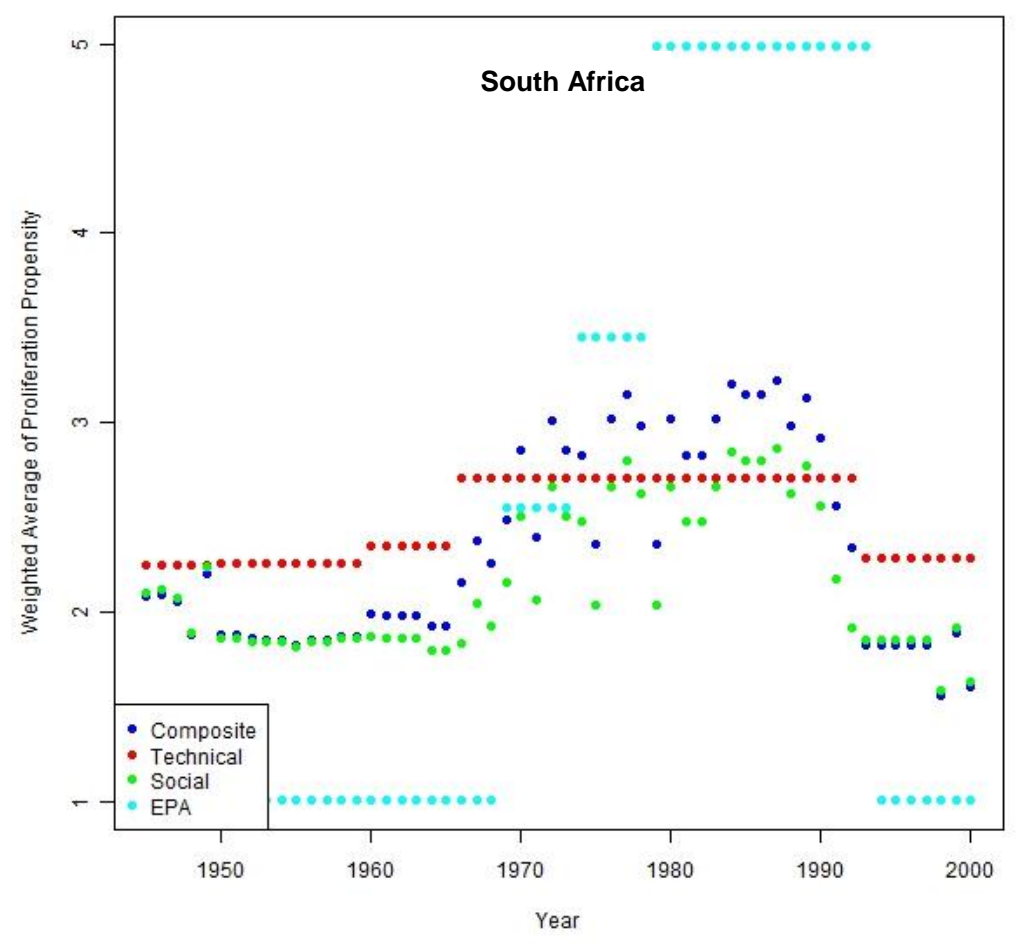

Figure 3.30 South Africa Proliferation Propensity Time Series 
To represent Group D, which consists of economically and technologically more challenged countries that appear to have limited motivation (e.g. no security threat) to pursue a nuclear weapons program , plots are provided for Ecuador, Nigeria, Panama, and Thailand in Figure 3.31 through Figure 3.34. As mentioned previously there is a discontinuity at year 1992 in each of the three trend lines for all four of these countries for the reason explained above, except that in these cases it is most apparent in the technical factors trend line (i.e., red dots). In all four cases there are no clear proliferation propensity trends predicted by the social (i.e., green dots), technical (i.e., red dots), or composite (green dots) factors as the prediction are scattered across the time span. However, all proliferation propensity predictions are low, ranging from a proliferation propensity value of 1.2 to 2.6 as might be expected from countries that are economically and technologically more challenged countries that appear to have limited motivation (e.g. no security threat) to pursue a nuclear weapons program. Although the BN model predictions do not closely mirror the actual observed proliferation trends for the countries in Group D, the fact that the BN proliferation propensity model produced low proliferation propensity values for these countries is in general agreement with historical data.

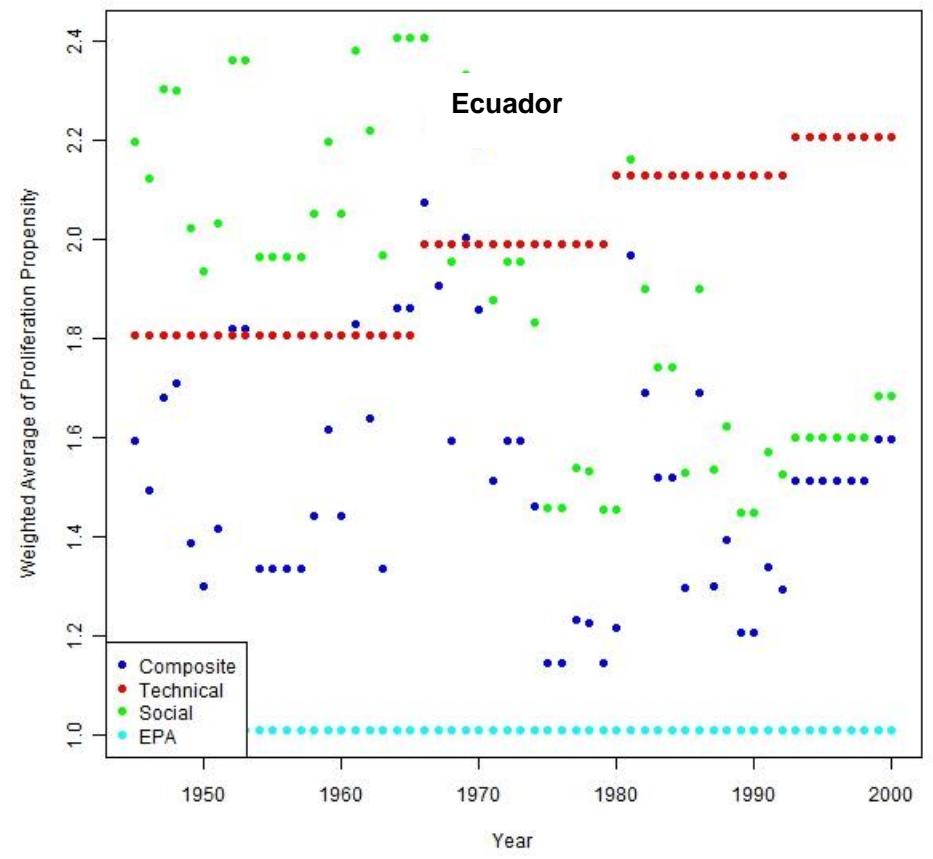

Figure 3.31 Ecuador Proliferation Propensity Time Series 


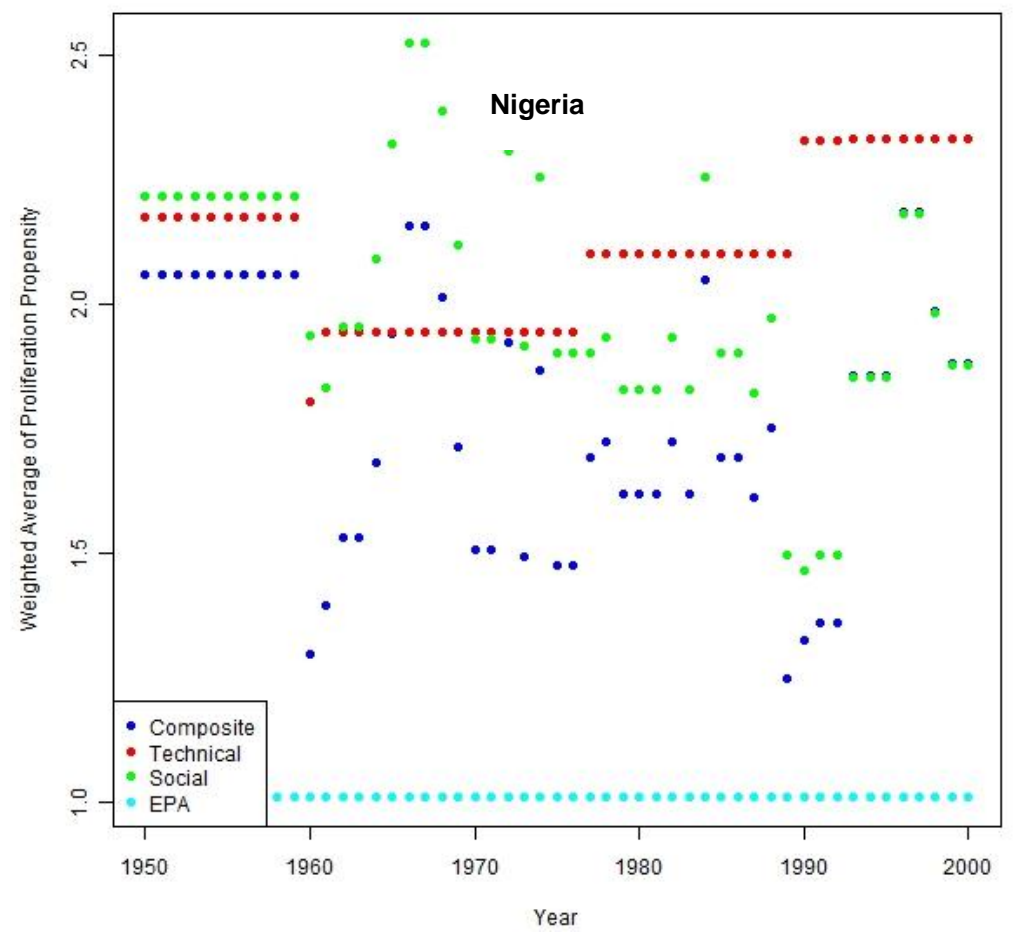

Figure 3.32 Nigeria Proliferation Propensity Time series

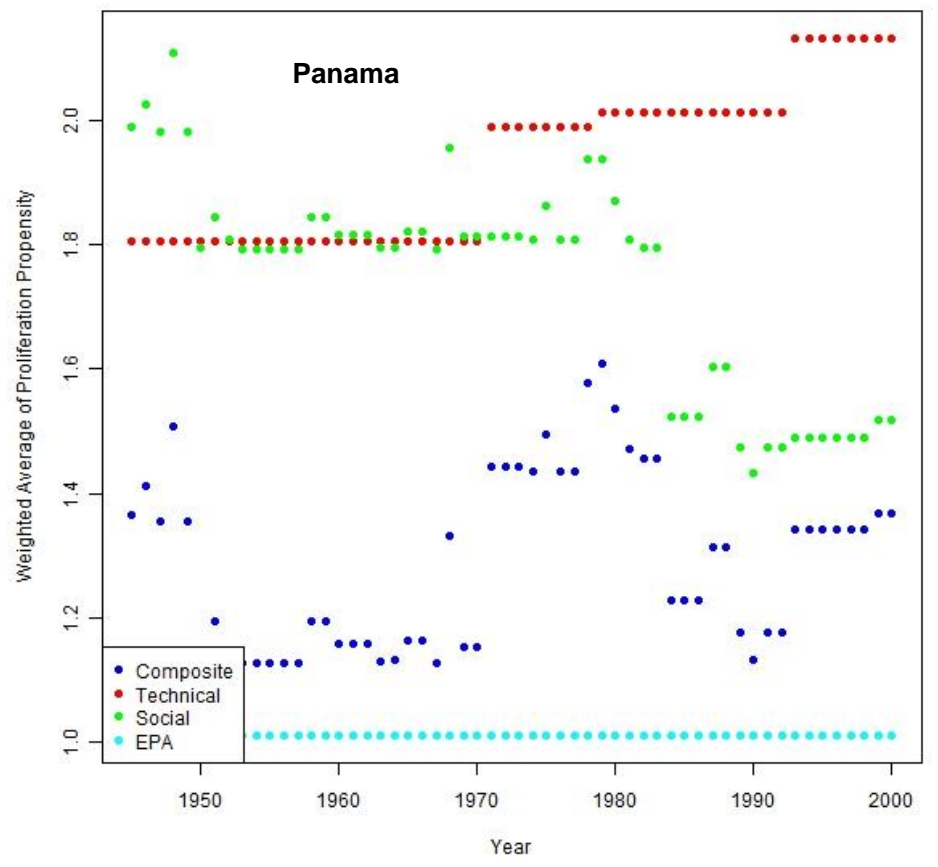

Figure 3.33 Panama Proliferation Propensity Time Series 


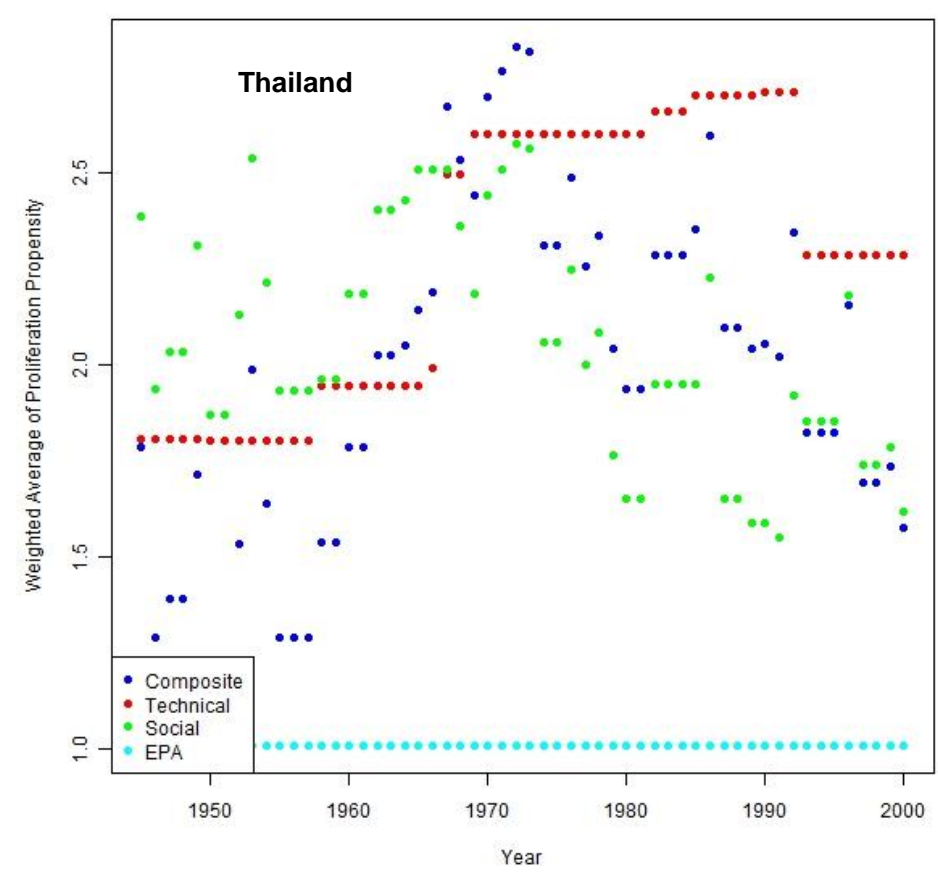

Figure 3.34 Thailand Proliferation Propensity Time Series

In summary, the time-series plots for four groups of countries which present "back-casts" of the proliferation propensity shows that the diagnostic BN proliferation propensity model produced reasonably consistent propensity predictions for all four countries types defined in our case study. The one exception out of sixteen cases was that the model did not predict that Libya pursued a nuclear weapons program. To address this limitation, we propose as a future activity to explore this case in detail to see if the model can be adjusted to provide good prediction results for Libya while still providing good results for other countries.

The volume of these time series plots makes it too impractical to present in this report, but the foregoing examples are representative. Further plots can be obtained from the authors (garill.coles@pnl.gov).

\subsection{Another Modeling Approach: System Dynamics Modeling}

The BN composite model is a snapshot of proliferation propensity for a given country and a specific time. The model can be used to see how this propensity has changed over the years, but it doesn't explicitly capture the dynamic cause and effect interactions in a world in which some countries are motivated to acquire nuclear weapons and other countries are trying to prevent the spread of nuclear weapons. In order to gain a more dynamic understanding of policy implications with regard to proliferation, we began the development of a system dynamic (SD) model. System Dynamics (SD) (Sterman 2000) is a type of modeling that allows one to understand the interactions of cause and effect relationships in complex systems in which there is feedback. These multiple interactions among variables are difficult, if not impossible, to understand intuitively. System dynamics was invented by Jay Forrester (1968) as an outgrowth of systems engineering concepts being applied to organizations. It has been used extensively to model the behavior of business systems, organizations, and ecologies (Ford, 1989). The goal of this effort is to better understand the dynamic influences of social and cultural factors on nuclear 
proliferation. The SD model incorporated key variables used in the BN model as they were identified by relevant literature as contributors to States' proliferation propensity. Additional literature searches were carried out in order to obtain the data needed to quantify specific variables in the model.

\subsubsection{System Dynamics Modeling}

The SD modeling process is unusual in that it is a two stage process. One first constructs a causal loop diagram (CLD), which captures the cause and effect relationships among the variables, in this case the essential elements that account for nuclear proliferation. The second stage is to construct a stock and flow simulation model using the CLD as a guide. In the CLD, relationships between the elements are represented by arrows that are labeled either positively or negatively to show their causal relationship. All authorities on System Dynamics models strongly emphasize that the identified relationships should be "causal" in nature; hence the term Causal Loop Diagram or CLD. Positive labels indicate a direct causal relationship for which an increase (decrease) in the cause leads to an increase (decrease) in the effect. Negative labeled arrows indicate an indirect causal relationship for which an increase (decrease) in the cause leads to a decrease (increase) in the effect. Another key element of causal loop diagrams is feedback. Feedback arises when the causal loop structure is such that the cause-and-effect chain loops back to the original cause. Feedback loops can be either positive or negative. Positive loops, also called reinforcing loops, are characterized by exponential growth or decay. Negative loops, also called balancing loops are goal seeking loops that tend to rise or fall to a specific level. An example of a positive loop is the growth of a savings account as interest accumulates. An example of a negative loop is the interaction of a furnace and a thermostat to achieve a specific room temperature.

\subsubsection{Causal Loop Diagram}

The CLD we constructed for nuclear proliferation is shown in Error! Reference source not found. It was constructed by considering the variables in the BN proliferation propensity model as a starting point. In particular, the variables initially considered for this model were the following:

- Motivation

- Regional Stability

- Allies

- Disputes

- Economic Interdependencies (on initial list but didn't make into this version)

- Domestic Unrest

- Economic Capacity

- Democracy 


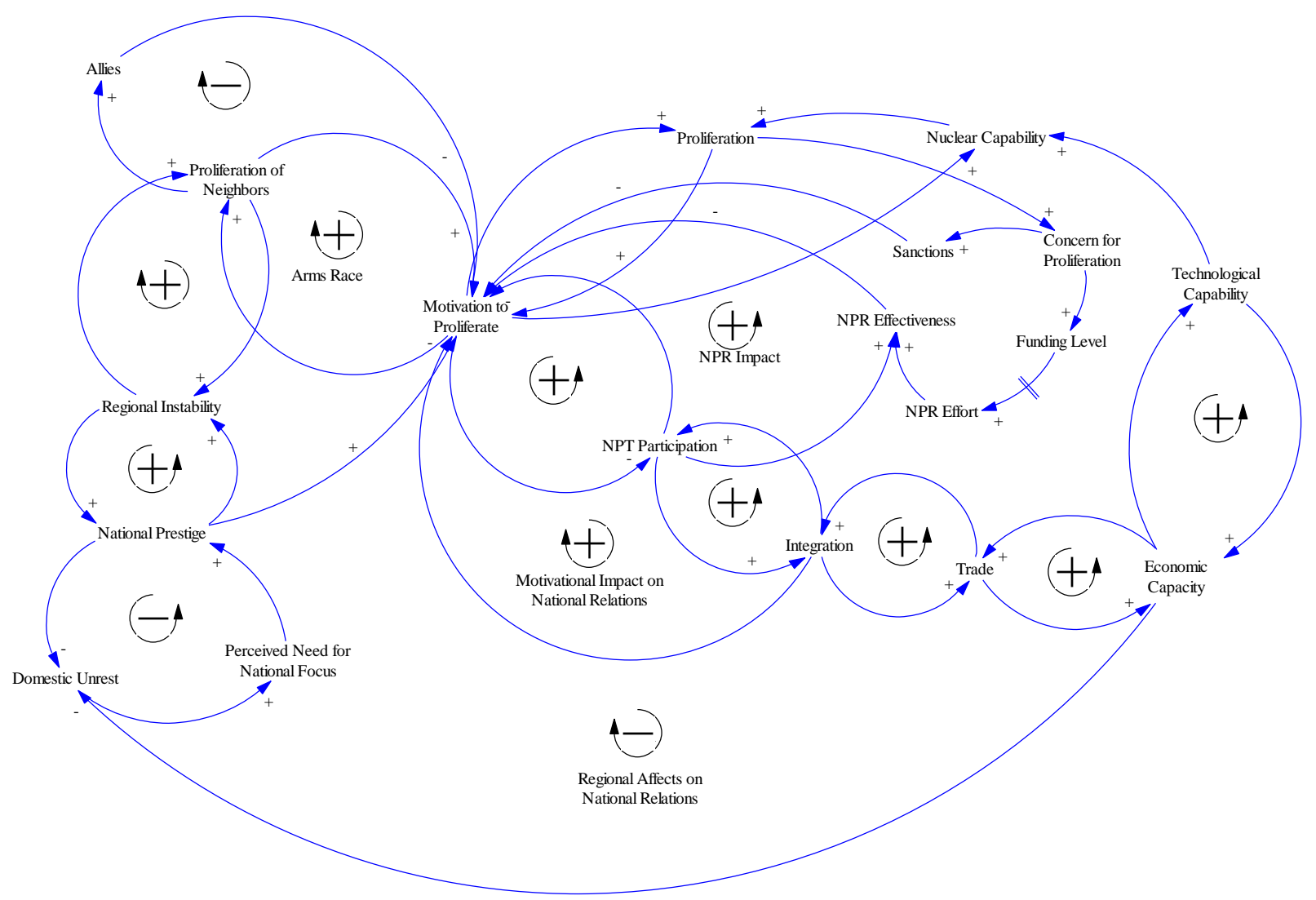

Figure 3.35. Causal Loop Diagram for System Dynamics Model for Proliferation Propensity

System dynamics models are characterized by interacting feedback loops of cause and effect variables. In looking at all the $\mathrm{BN}$ models we developed so far and based on the political science literature, a fundamental concept central to all theories (with the possible exception of the technological imperative) is motivation. Latent capacity without motivation doesn't result in a weapon. There are a number of factors that influence the level of motivation with regard to nuclear weapons. Some of them are listed here. Many of the causal loops in the CLD, shown in Figure 3.35, interact directly with motivation. A central feature of this draft model is the classic characterization of the arms race, in which weapons production by rivals spurs increased weapons production, which increases the rival's weapons production, in an ever increasing spiral. Of course the real world finds limits for any spiral and there are always mitigating factors.

One of these mitigating factors is having allies. An alternative response to the proliferation of one's neighbors is to seek out nuclear protectors in the form of allies rather than developing one's own nuclear weapons. Another mitigating factor is non-proliferation regime (NPR) effectiveness. This is the effectiveness of efforts to minimize proliferation by the world community including IAEA. These efforts include encouragements to sign non-proliferation treaties and creating economic and political sanctions against nations that pursue proliferation activities. The model captures other themes identified in the literature, such as the interaction between technical capability and nuclear capability. Also identified in the CLD are issues of domestic unrest and perceived need for a national focus, the impact of trade on integration into the world community, and economic capacity. 
We have analyzed behavior patterns in the databases in order to further model development. As previously discussed, we looked at correlations among the variables across countries and found some support for the postulated causal relations. However, we came to realize the need to look at behavior patterns within countries. Looking within countries provides some additional support for the correlations postulated in the CLD model. Some of these results were described above.

\subsubsection{Stock and flow Model}

The CLD is the first stage of model development. The next stage is to create a stock and flow model, which quantifies the model so its behavior can be simulated. It is beyond normal human capacity to look at more than one or two loops in a CLD and predict the effect of all the interacting loops on behavior. The stock and flow model operationalizes the CLD and through simulation one can observe how the individual loops interact to produce the overall behavior of the system. We used the CLD as a template to build a portion of the stock and flow model. We searched the internet to determine specific relationships between variables in order to quantify the model. Our initial draft SD model is presented in Figure 3.36

Exploratory simulations of this draft model revealed results that are consistent with proliferation literature. For example, simulation results show that democratic states become increasingly integrated as result of economic trade whereas autocratic states become only marginally integrated over time. The impact of this feedback loop on the level of proliferation motivation is shown in Figure 3.37 for democratic versus autocratic political systems.

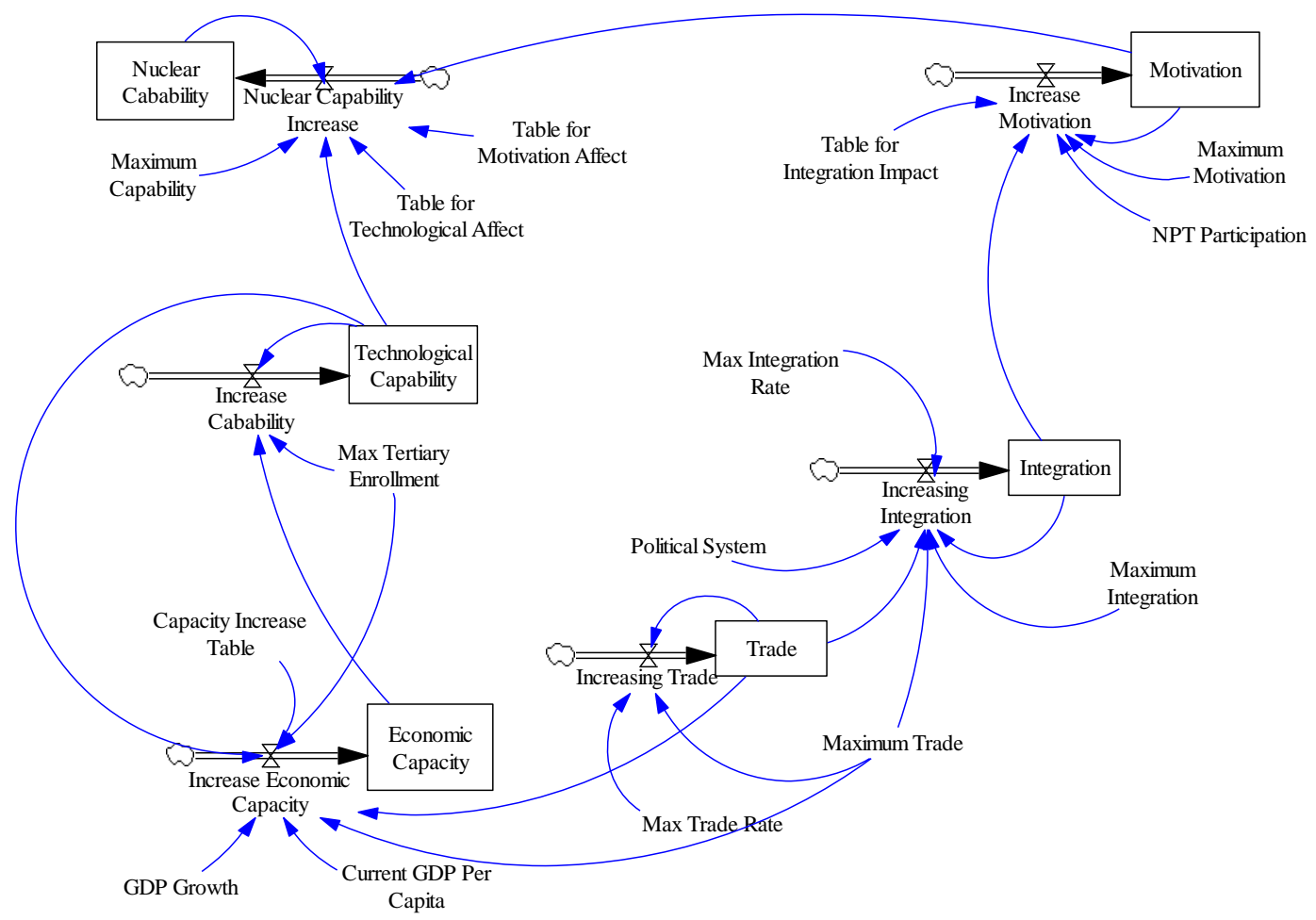

Figure 3.36. Stock and Flow Model of Nuclear Proliferation 
As can be seen in the figure, autocratic states proliferation motivation grew over time, whereas, for democratic states it remained relatively constant over time. This is a very preliminary model that an early stage of development; however, it has potential to provide some interesting insights into how a number of factors relevant to proliferation can interact over time to produce greater nuclear proliferation or to inhibit it.

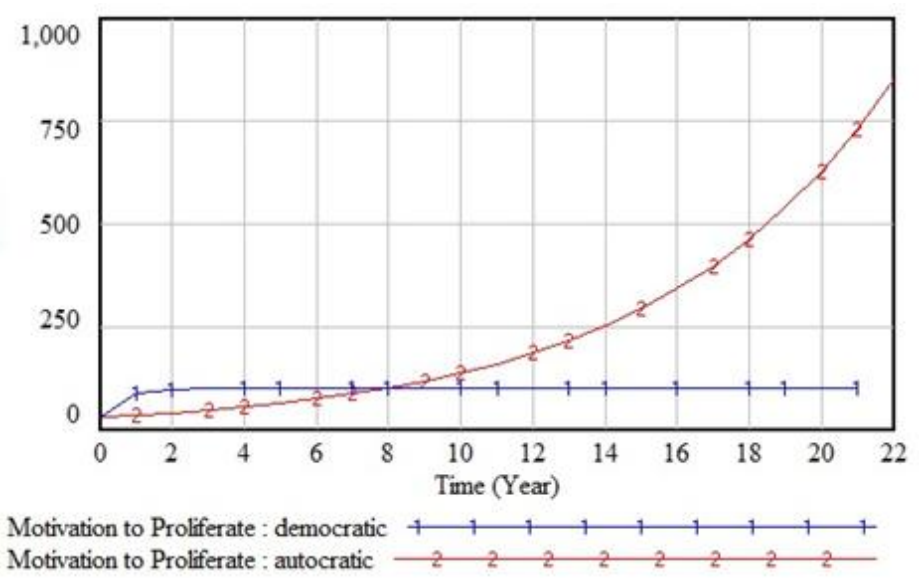

Figure 3.37. Motivation to Proliferate - Democratic versus Autocratic 


\subsection{User Framework for BN Proliferation Propensity Model}

This section discusses implementation in a user framework for the BN State proliferation propensity model. It discusses the potential uses and users of the model, how updates are incorporated into the model, and how users interface with the model, particularly how they might use the model for analysis.

\subsection{Uses and Users}

Proliferation propensity information is potentially valuable to a range of experts and decision-makers including the following:

1) international safeguards inspectorates;

2) nuclear energy policy and nonproliferation decision-makers;

3) national licensing and regulatory and export control authorities.

These three user groups and the potential value gained by them from conducting proliferation propensity assessments are illustrated in Table 4.1. Safeguards inspectorates should have an understanding of factors that contribute to proliferation or indicators that proliferation is taking place. Policy makers or implementers must take proliferation propensity into consideration, to some extent, when developing or implementing policy. The same is true for nuclear licensing and regulatory authorities and export control authorities. On the other hand designers, producers, utility owners and operators may take proliferation propensity into consideration but are more apt to abide by whatever policies and/or regulations apply to them.

Table 4.1. Potential Users and Uses of BN Proliferation Model

Potential Users of a Proliferation Propensity Assessment
Illustrative Uses of Proliferation Propensity Information
1. International, bilateral, and multilateral safeguards inspectorates;
- What are the relative proliferation risk merits of various inspection regimes?

- What is the proliferation risk associated with fissile material inventories in a particular State?

- In general, what social and technical factors contribute to proliferation and what is their significance?

- What specific domestic, political, geostrategic, defense, societal, and security factors contribute to proliferation and what is their significance?

- What specific economic, technology, technical capability, material resources, and existence of fissile material factors contribute to proliferation and what is their significance?

- What has been the impact on proliferation of the implementation of different nonproliferation regime elements to date? 
1. Nuclear energy policy and nonproliferation decision-makers;

2. National licensing and regulatory authorities and export control authorities;
- What is the relative proliferation risk of multiple distributed plutonium recycle plants versus a smaller number of centralized plants?

- What is the proliferation impacts of given negotiations positions?

- What is the proliferation impact of supporting development of small modular reactors?

- What is the potential proliferation risk decrease from providing advanced safeguards technologies to the IAEA?

- What is the proliferation impact or revitalizing the Fast Reactor program?

- What is the proliferation risk of pursuing a renewed domestic uranium enrichment program?

- What is the proliferation risk associated with physical security of a nuclear energy system?

- What is the proliferation impact of legacy nuclear material in the U.S. or another State?

- What is the proliferation impact of introducing additional excess nuclear material in the domestic nuclear fuel cycle $\mathrm{n}$ the U.S. or another State?

- What is the proliferation impact of exporting nuclear technology from the U.S?

- What are the proliferation impacts of particular nuclear fuel cycle technology, material, or information export?

\subsection{Updating the Model}

The section describes the fundamental modeling elements of our causal and diagnostic BN models and how the models can be updated to make adjustments to these modeling elements. Further refinement, such as identifying additional data or finely tuning conditional probabilities, may be desired. We propose to think of the current prototype as a "living" model that should be further refined as new information is uncovered or the understanding of proliferation evolves. The discussion is not intended to be a tutorial on BN modeling but rather as helpful to developers with a limited understanding of BN modeling.

The BN software that we used is Graphical Network Interface (GeNIe) ${ }^{1}$ which is a publically available software package and is graphical click-and-drop interface to SMILE, a portable Bayesian inference engine developed by the Decision Systems Laboratory tested in the field since 1998 and has received a wide acceptance within both academia and industry. GeNIe is capable of learning both structure and probabilities from data.

\footnotetext{
${ }^{1}$ http://genie.sis.pitt.edu/

Decision Systems Laboratory, University of Pittsburgh
} 
The structure of a $\mathrm{BN}$ represents the interactions and quantitative relationships among a set of variables that it models. Each node is described by a probability distribution conditional on its direct processors. Nodes with no predecessors (referred to as "root node") are described by prior probability distributions. So in the "causal version" of our BN proliferation propensity model, presented in Section 3.1, the root nodes are those outermost nodes with arrows pointing to inner nodes. An example of a root node from the causal proliferation propensity model is presented below in Figure 4.1. It is labeled "Level of Democracy: S\&W, Polity" and represents a variable identified by Singh and Way. It has four possible states: Highly Autocratic, Autocratic, Democratic, and Highly Democratic.

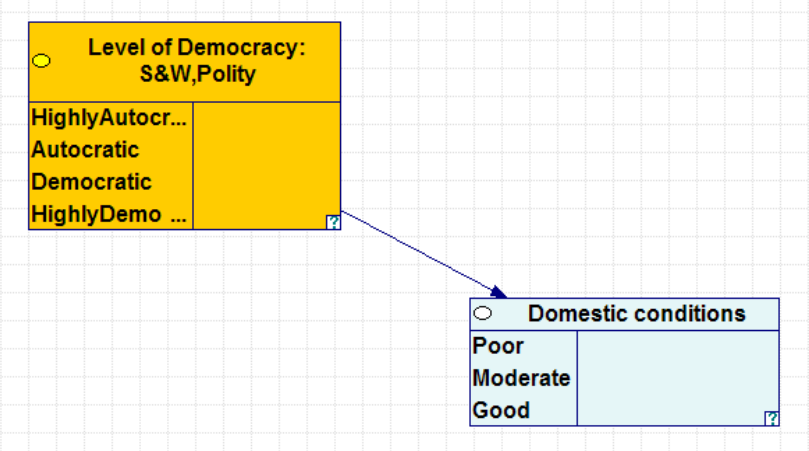

Figure 4.1. Example Root Node - Level of Democracy

The root node in this model is defined by its prior probability distribution over these four states which is based on all countries and all years in the dataset in support of the model. Figure 4.2 shows the probability table for the "Level of Democracy" node from the causal model.

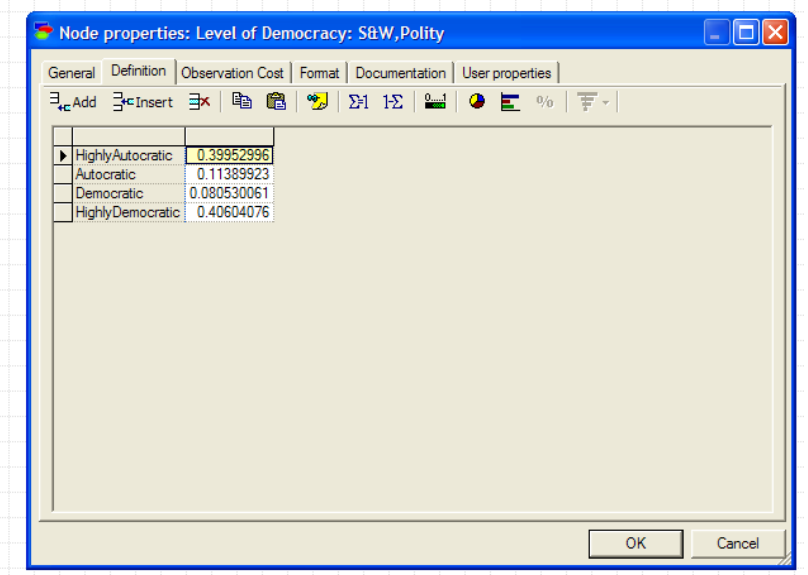

Figure 4.2. Example Properties Table for a Root Node

If different or further relevant data is identified, then these changes can be made by adjusting these probabilities. In general, knowing the priors is useful for assessing a global proliferation propensity with consideration given to all countries. For predictions for a specific country, the root nodes are instantiated to represent the current states of that country and knowledge of the priors is not critical. For the research project, we wrote a Java software program to exercise GeNIe based on information in a spreadsheet and produce predictions for countries requested. Because our principle interest was in validation of the model, 
our software program was a way to run the BN proliferation propensity model for every country and year in the dataset.

In contrast to the root nodes are the forecast nodes. Forecast nodes are determined by a probability distribution over a set of outcomes conditional on the outcomes of its predecessors. So, again using the "causal version" of our BN proliferation propensity model presented in Section 3.1, the forecast nodes are those interior nodes with arrows pointing into them. An example of a forecast node from the causal proliferation propensity model is presented below in Figure 4.3. It is labeled "Domestic Conditions" and its predecessor nodes are the root node that we just discussed, Level of Democracy, and another root node labeled: "domestic Unrest, J\&G LN_XST1" which represents a variable identified by Jo and Gartzke. Another way of referring to these nodes is as "parent" and "child" nodes. We would refer to "Level of Democracy" and "Domestic Unrest" as the parents and "Domestic Conditions" as the child. The probability distribution of child nodes is conditioned on parent nodes. If different or additional predecessor nodes are identified, the need incorporate these changes can be made by changing the model structure.

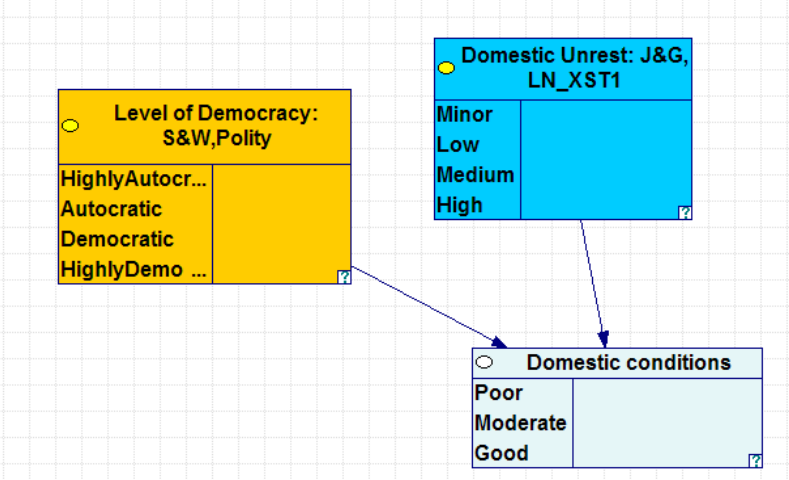

Figure 4.3. Example Forecast Node - Domestic Conditions

Figure 4.4 shows the conditional probability table for Domestic Conditions. The probability distributions for Poor, Moderate, and Good are based on the outcomes of the probability of its predecessor outcomes. In the causal model for many of the interior forecast nodes (i.e. those child nodes with multiple parents), we used an approach referred to as a noisy OR-gate. A noisy OR-gate is appropriate when the parents can be thought of as independent causes of the child. A noisy OR-gate is like a "logical OR-gate" in which the child can occur if any of the parents occur. The difference between a "logical ORgate" and a noisy OR-gate is that in a noisy OR-gate, even if a parent occurs there is some possibility that it will not cause the child; consequently, it is said to be "noisy" (Henrion 1989, 1991). One can think of each parent as having an associated inhibitor that will prevent the child from occurring even if the parent occurs. In order for the noisy-OR to be an appropriate model, all the inhibitors are assumed to be independent. If $\mathrm{P}\left(\mathrm{C} \mid \mathrm{P}_{\mathrm{i}}\right)=\mathrm{p}_{\mathrm{i}}$, where $\mathrm{C}$ is the child and $\mathrm{P}_{\mathrm{i}}$ is the $\mathrm{i}^{\text {th }}$ parent, then the probability of the $\mathrm{i}^{\text {th }}$ inhibitor is $1-\mathrm{p}_{\mathrm{i}}$. The probabilities shown in Figure 4.4 in the conditional probability definition window is based on judgment informed by our literature search. If further refinement of judgments about specific conditional probabilities is desired in a forecast node, then it would be performed using a different set of defined probabilities. 


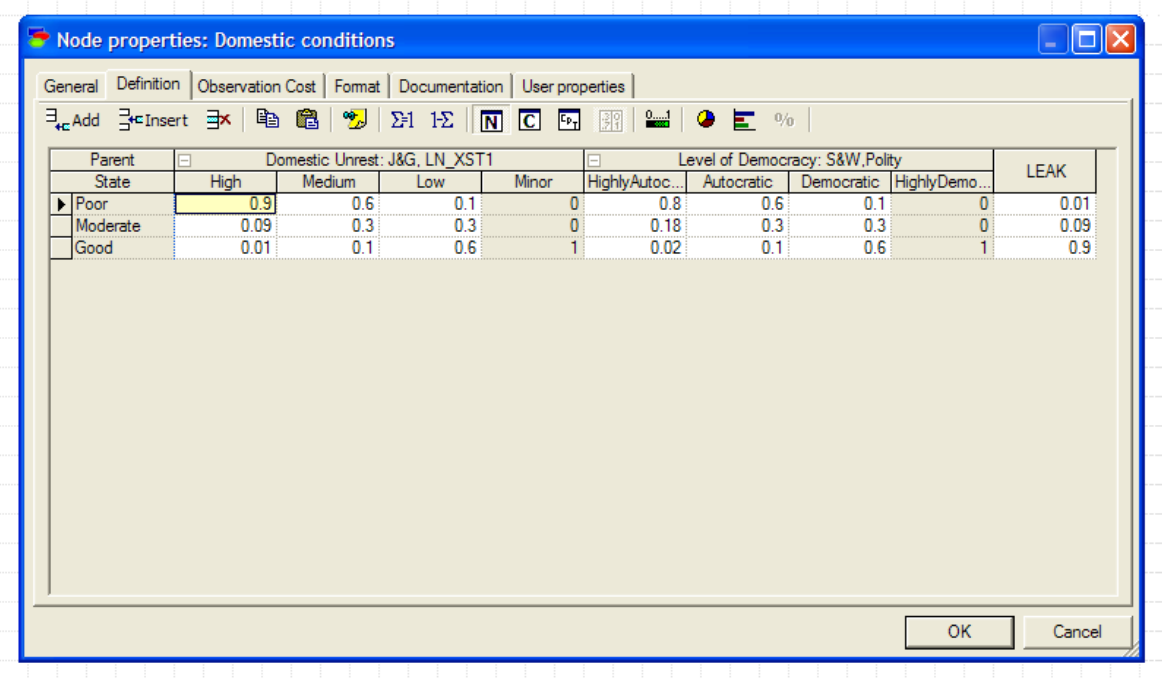

Figure 4.4. Example Defined Probabilities Table for an Example Forecast Node

In our "diagnostic model," which is presented in Figure 3.2, the arrows related to the motivation node are reversed and intermediate nodes (i.e., Domestic Conditions, Geopolitical Security, and Integration into the World Community") are removed as shown Figure 4.5.

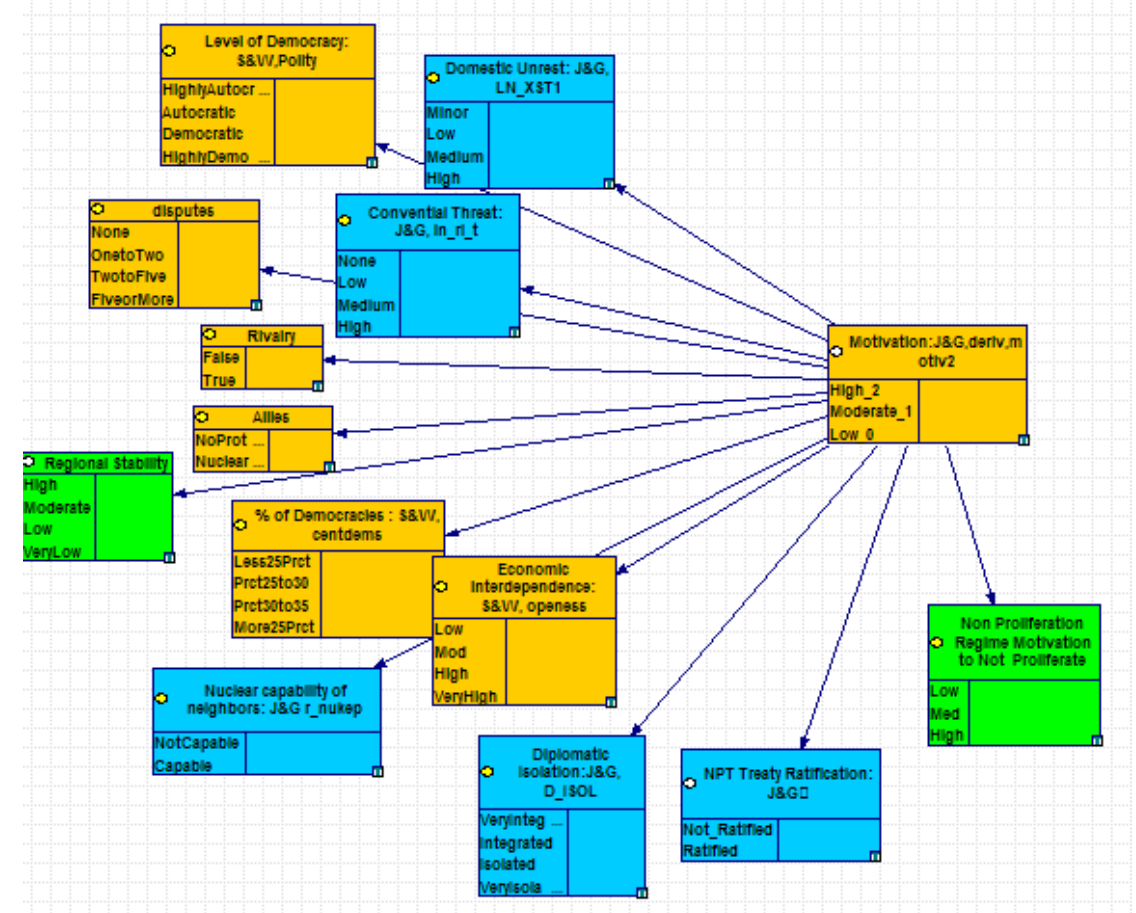

Figure 4.5. Diagnostic Model Related to Motivation Node

In this way variables related to motivation can be thought of as indicators of motivation, and the management of conditional probabilities becomes easier, because forecast nodes just have one predecessor. The conditional probabilities for specific country and year cases were determined by a 
specially designed expert elicitation exercise described in Section 3.2.2.2. The resulting conditional probabilities for one of the indicator nodes, "Diplomatic Isolation," are shown in Figure 4.6.

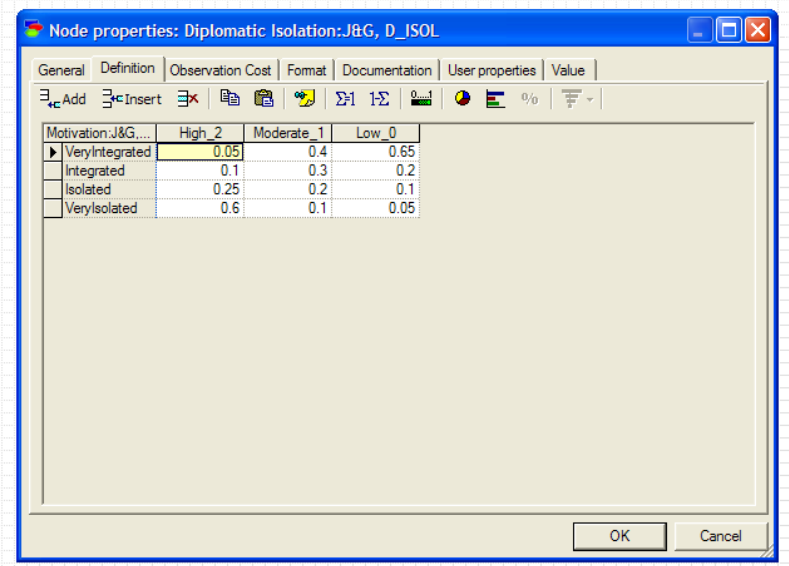

Figure 4.6. Defined Probability Table for Example Indicator Node

When we ran the validation test described in Section 3.4.1, we ran the model for each country and year in the dataset. In this case the indicator nodes were instantiated for a particular country and year and the model calculated the motivation level based on the probability distributions using Bayes Theorem. A conceptual instantiation of a particular case is illustrated in Figure 4.

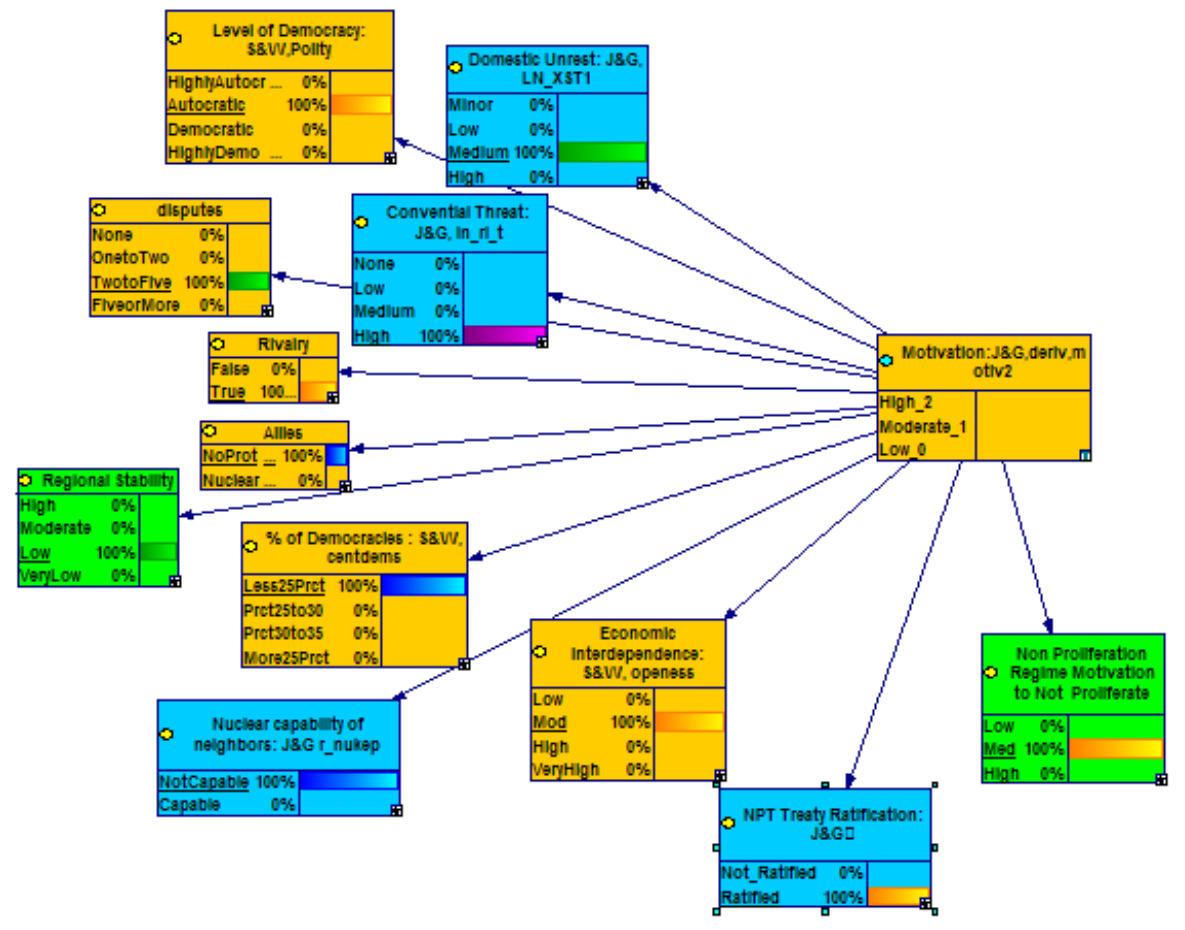

Figure 4.7. Instantiation of Indictor Nodes Related to Motivation in Diagnostic Model 
If we wanted to run the diagnostic BN proliferation propensity model to forecast the proliferation propensity of a particular State in some future year then estimates of these indicators would be to be developed as input in a similar way.

We contend that the conditional probabilities for both the causal and diagnostic models should be further refined, and the priors will evolve over time.

\subsection{User Interaction and Analysis Functions}

In addition to updating the model to produce more accurate predictions, we envision that the primary interaction that users will have with the model is to use the model for analysis. The user interface is through GeNIe or any other BN software program. Accordingly, this section discusses specific functions of BN software that may be helpful in performing proliferation assessment.

BN software like GeNIe can support simple "what-if" analysis, perform sensitivity analysis, and provide diagnostic functionality via interface with the graphical models. Using the BN proliferation propensity model presented in Figure 3.2, we can show that it is straightforward to evaluate what-if scenarios. For the sake of illustration suppose that Figure 4.8 represents the instantiation of a particular State of interest and that its manifestation of the nonproliferation is moderate in this case.

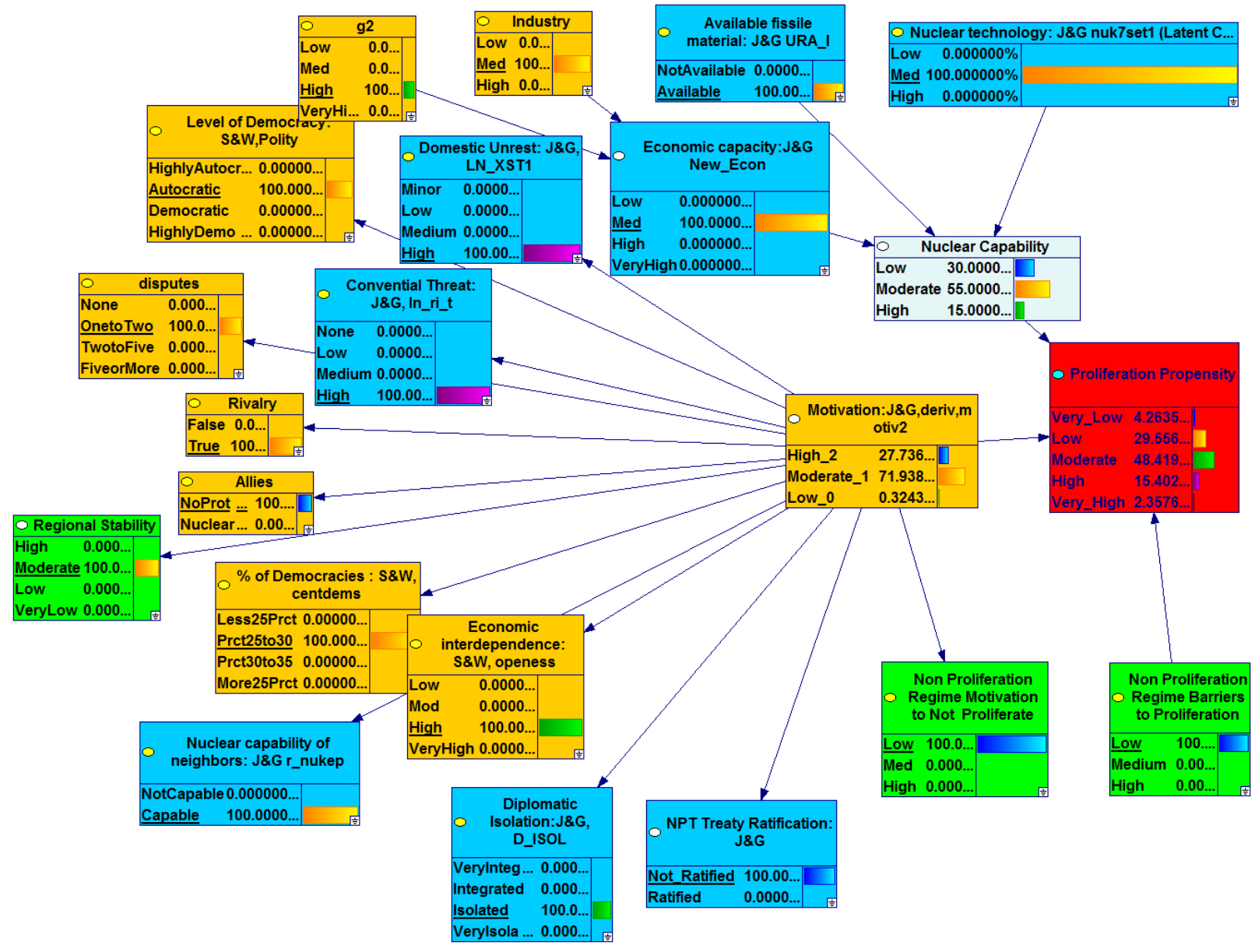

Figure 4.8. Example What If Analysis on Effect of Nonproliferation Regime - Step 1 
One might ask what the effect on proliferation propensity would be if the nonproliferation regime was stronger for this State. Using the graphical interface, the probabilities for the "Nonproliferation regime motivation not to proliferate", "Nonproliferation regime barriers to proliferation", and "NPT Treaty ratification" can be set to "High" and "Ratified" with a few clicks of the mouse. The resulting impact to the calculated probability propensity is presented in Figure 4.9. As can be seen in the figure there is less motivation to proliferate and proliferation propensity has decreased as demonstrated by the shift of the distributions for these two variables toward lower states.

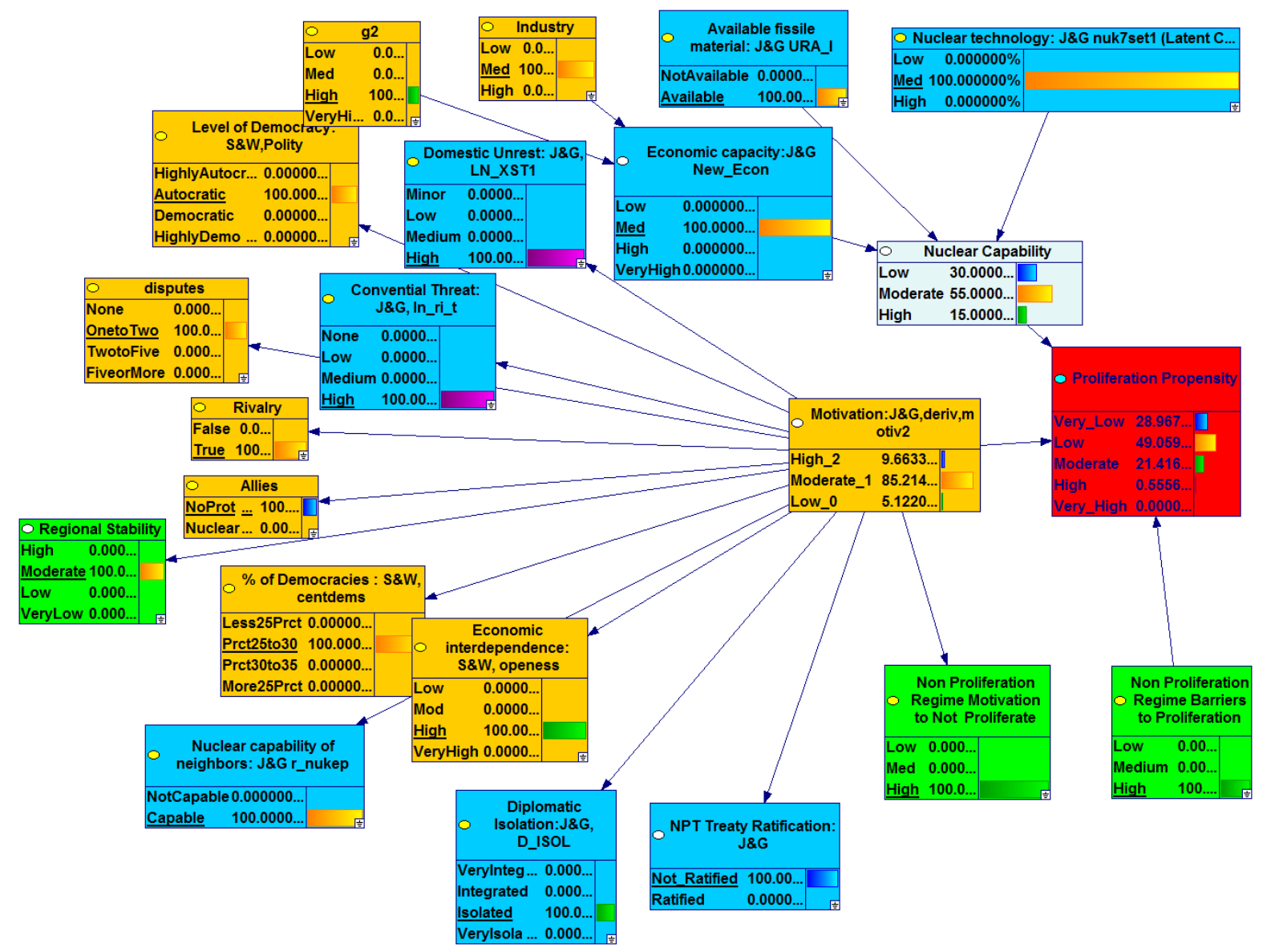

Figure 4.9. Example What If Analysis on Effect of Nonproliferation Regime - Step 2

The GeNIe software can perform sensitivity analysis explicitly. To perform a sensitivity analysis, an indexing variable can be added (not illustrated here but not difficult to do) to the variable in question so that the impact of various indexed values can be computed against the forecast results. Using this indexing variable, the degree of belief about the variable to which it is connected can be expressed to capture sensitivity related to uncertainty. For example, we might express the nominal value as one probability, the low value as another, and the high value as yet another. The states of the added "sensitivity node" will index the parameters in question and will allow specification of those low, nominal and high values. When the model is updated, the resulting impact can be observed. If the range of values makes little or no difference in the forecast node, then forecast is insensitive to that variable.

Another valuable function of the GeNIe BN software uses the concept of "diagnosticity' we discussed in an earlier section of this report. Diagnosticity is defined as away to measure of how much the 
uncertainty in the variable of interest would be reduced if one knew the value of the indicator. Calculation of diagnosticity is a feature of GeNIe. Using the "Testing diagnosis" option on the "Diagnosis" tab for the final BN proliferation propensity mode illustrated in Figure 3.2 produced the diagnosis values shown below in Figure 4.10. This analysis shows the international security related variables to be most important, but also shows nonproliferation regime, other social factors, and nuclear technology factors to also be important.

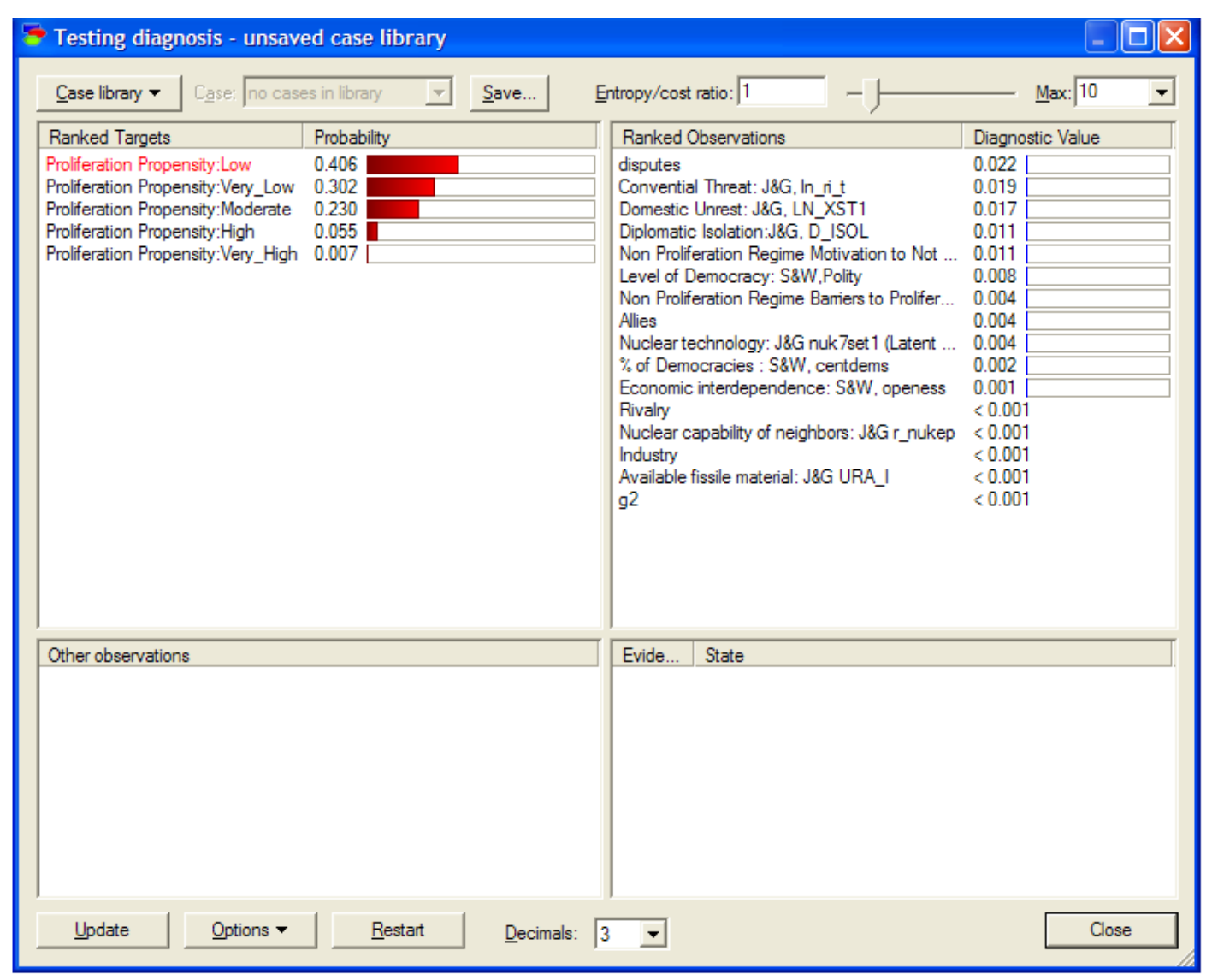

Figure 4.10. Example Diagnostic Testing of Final Proliferation Propensity Model

Other functions are available that can be used to support analysis and may be variable depending on the BN software. For example, the PNNL BACH software that we discussed in an earlier section allows the users to "weight evidence," so that as information accumulates it can be input into the model. We do not claim to have covered all potential analysis function of BN software in the section but believe that we have presented representative ones that illustrate how a user is likely to interact with the model. 



\subsection{Conclusions}

We built a BN State proliferation propensity model to leverage the quantitative analytical capability of a $\mathrm{BN}$ and to facilitate the consideration of social factors along with technical ones. We supported this modeling by first reviewing the literature primarily by social scientists on factors related to the propensity of a State to proliferate We constructed a composite dataset using existing data compiled by social scientists and data based on our own research of that body of literature. We performed data analysis, including correlation analysis, cluster analysis, principal component analysis, and created dendrograms, in an attempt to better understand the relationship between the variables. We also looked for correlations between variables that lag in time, recognizing that acquisition of nuclear weapons occurs in phases over a span of several years. Additionally, we identified additional sources of data that might be leveraged in future refinements of our models.

In our approach, we identified and incorporated key theoretical constructs into the basic model structure, calibrated the model parameters with expert elicitation using laboratory SMEs, and used the merged existing datasets to validate the model. We then exercised different validation tests to gauge the accuracy of the model and made further refinements. These tests included a primary validation exercise to test the utility of social modeling in proliferation assessment. The results of this validation exercise shows that use of only technical or only social factors is inferior to using a combination of technical factors and social factors to predict proliferation. Although our model is intended to be used to forecast, a central feature of our validation test was the use of "back-casting". What we mean by "back-casting" is that the model was used to predict the proliferation propensity for a given State in a past year by using model inputs from the year for which the prediction was being made. If we just used the current year to validate our model the data would be limited as the number of State's in some stage of proliferation is few. This approach to validating the model makes available more cases to test the validity of the model. A given prediction (i.e. "back-cast") was then compared to data considered in this research to represent proliferation "truth". The proliferation truth about a country was considered to be the proliferation category determined by Singh and Way in their dataset (i.e. Not interested, Exploring, Pursuing, Acquiring).

We acknowledge that our final models are not perfectly calibrated but as they currently exist they produce logical and consistent results, and show in general that considering social factors results in better predictions than considering technical factors alone. We propose that further refinement of the BN diagnostic model (e.g., further refinement of the conditional probability estimates at particular nodes) in a way that further minimizes the distance between the predictions and "truth" would produce an even better prediction model. The BN model is easy to refine and use to perform "what if" scenarios. We maintain that the virtues of $\mathrm{BN}$ models for analysis and exploration include:

- The structure and the numerical parameters can be learned from data or they can be elicited from experts, or they can be a mixture of both;

- It is easy to run cases specific to a particular country;

- Readily available off-the-shelf software displays the models and supports direct interaction with the models;

- Software calculates diagnostic information indicating importance of model components; and

- BN models can combine variables from different models. 
One limitation of the current BN proliferation propensity model is that it represents a snapshot of proliferation propensity for a given country and a specific time so in this way does not capture feedback. The model can be used to see how propensity has changed over the years, but it does not make explicit the dynamic cause and effect interactions in a world in which some countries are motivated to acquire nuclear weapons and other countries are trying to prevent the spread of nuclear weapons. A conceptual proliferation propensity model is presented in this report that uses system dynamic (SD) modeling, which is a type of modeling that allows one to understand the interactions of cause and effect relationships in complex systems in which there is feedback.

We propose that even without explicitly considering feedback mechanisms that SD modeling may offer a further refinement of the current $\mathrm{BN}$ proliferation propensity model that could be the basis for a tool that would provide useful information to a range of experts and decision makers. We suggest that the BN proliferation propensity model, further refined to produce back-casts as accurately as possible, provides a valid basis for such a tool. The range of experts and decision makers that might find such a tool useful includes international safeguards inspectorates, nuclear energy policy and nonproliferation decision-makers, and national licensing and regulatory authorities and export control. We describe in this report how to interface and update the model using publically available BN software and ways in which the model can be used by analysts to understand the contributors and sensitivities of the factors contributing to proliferation. 


\subsection{References}

Bennet, D. Scott Jr. 1996. "Security, bargaining, and the end of interstate rivalry." International Studies Quarterly 40 (2): 157-84.

Campell, Kurt M. 2004. "Reconsidering a Nuclear Future: Why Countries Might Cross Over the Other Side." The Nuclear Tipping Point: Why States Reconsider Their Nuclear Choices. Kurt M. Campbell, Robert J. Einhorn, and Mitchell B. Reiss (ed). Brookings Institution. Washington D.C.

Campbell, Kurt M., Robert J. Einhorn, Mitchell B. Reiss, et. al. 2004. “The Nuclear Tipping Point: Prospects for a World of Many Nuclear Weapons Sates." The Nuclear Tipping Point: Why States Reconsider Their Nuclear Choices. Kurt M. Campbell, Robert J. Einhorn, and Mitchell B. Reiss (ed). Brookings Institution. Washington D.C.

Coles G., Z. Gastelum, A. Brothers, S. Thompson. 2009a. Utility of Social Modeling for Proliferation Assessment - Preliminary Assessment. PNNL-18438. Pacific Northwest National Laboratory, Richland, Washington.

Coles G., A. Brothers, Z. Gastelum, J. Olson, S. Thompson. 2009b. Utility of Social Modeling for Proliferation Assessment - Enhancing a Facility-Level Model for Proliferation Resistance Assessment of a Nuclear Energy System. PNNL-18923. Pacific Northwest National Laboratory, Richland, Washington.

Diehl, P. F. 1998. The dynamics of enduring rivalries. Urbana: University of Illinois Press. Champaign Illinois.

Einhorn, Robert J. 2004. "Will the Abstainers Reconsider? Focusing on Individual Cases." The Nuclear Tipping Point: Why States Reconsider Their Nuclear Choices. Kurt M. Campbell, Robert J. Einhorn, and Mitchell B. Reiss (ed). Washington D.C. : The Brookings Institution, 2004.

Epstein W. 1977. "Why States Go-And Don't Go-Nuclear." The Annals of American Academy of Political and Social Science 430(1):16-28. Accessed March 24, 2009, at http://ann.sagepub.com/cgi/content/abstract/430/1/16.

Ford, Andrew and Michael Bull. 1989. "Using System Dynamics for Conservation Policy Analysis in the Pacific Northwest." System Dynamics Review 5(1): 1-16.

Forester, Jay. 1968. Prinicples of Systems. Pegasus Communications. Waltham, Massachusetts.

Fuhrmann, Mathew. 2008. "Importing Mass Destruction? The Determinants of Dual-Use Trade." Journal of Peace Research, 45(5), 2008, 633-652.

Grimmet, Richard F., and Gerald M. Perkins. The War Powers Resolution: After Thirty Years. Novinka Books. Hauppauge, New York.

Henrion, M. 1989. "Some Practical Issues in Constructing Belief Networks." Uncertainty in Artificial Intelligence. Kanal, T. Levitt, and J. Lemmer (ed). Elsevier Science Publishing Company. New York, New York. 
Henrion, M, JS Breese, and EJ Horvitz. 1991. “Decision Analysis and Expert Systems.” AI Magazine 12(4): 64-91.

Heston, Alan, Robert Summers and Bettina Aten, 2002. "Penn World Table Version 6.1," Center for International Comparisons of Production, Income and Prices. Center for International Comparisons at the University of Pennsylvania.

Hymans J. 2006. The Psychology of Nuclear Proliferation: Identify, Emotions, and Foreign Policy. Cambridge University Press, Cambridge, Massachusetts. Accessed March 24, 2009, at http://books.google.com/books?hl=en\&lr=\&id=EoNoZom3TIwC\&oi=fnd\&pg=PA1\&dq=+The+Psycholo gy+of+Nuclear+Proliferation:+Identify,+emotions, +and+Foreign+Policy,\&ots=hwkxuIwBHN\& $\underline{\text { sig=FQm_6F-9BNi7TUcqnymPswclpGU. }}$

Jenson F.V. 1996. An Introduction to Bayesian Networks. Springer, New York.

Jo D-J and E Gartzke. 2007. "Determinants of Nuclear Weapons Proliferation." Journal of Conflict Resolution 51(1):167-194. Accessed March 24, 2009, at http://jcr.sagepub.com/cgi/content/abstract/51/1/167.

Jones, Daniel M., Stuart A. Bremer, and J. David Singer. "Militarized Interstate Disputes, 1816-1991: Rationale, Coding Rules, and Empirical Patterns." Conflict Management and Peace Science, Vol. 15, no. 2 (1996): 163- 215.

Kokoski R. 1996. Technology and the Proliferation of Nuclear Weapons. Sipri Oxford University Press, New York.

Kreyling S., J. Phillips, A. Brothers, S. Short, and M. Weimar. 2010. "An Analytical Framework for Assessing Reliable Nuclear Fuel Service Approaches: Economic and Non-proliferation Merits of Nuclear Fuel Leasing." In: The $51^{\text {st }}$ Annual Meeting: Institute of Nuclear Materials Management, July 13-17, Baltimore, Maryland.

Kroenig, Mathew. 2010. Importing the Bomb: Technology Transfer and the Spread of Nuclear Weapons. Cornell University Press. Ithaca, New York.

Kwon, Eun-ha, Won II Ko, 2009. "Evaluation method of nuclear nonproliferation credibility.” Annals of Nuclear Energy, www.elsevier.com/locate/anucene.

Levi, Michael. 2007. On Nuclear Terrorism. Harvard University Press. Cambridge, Massachusetts.

Marshall, Monty G., and Keith Jaggers. 2009. Polity IV Project: Political Regime Characteristics and Transitions, 1800-2007-Dataset Users' Manual. Arlington, Virginia: Polity IV Project.

Mistry, Dinshaw. 2003. Containing Missile Proliferation: Strategic Technology, Security Regimes, and International Cooperation in Arms Control. University of Washington Press. Seattle Washington..

Meyers S. 1984. The Dynamics of Nuclear Proliferation. The University of Chicago Press. Chicago, Illinois. 
Most, Benjamin A. and Harvey Starr. 1989. Inquiry. Logic and International Politics. Columbia SC University Press. Columbia South Carolina.

Neapolitan RE. 2003. Learning Bayesian Networks. Prentice Hall, Upper Saddle River, New Jersey.

Nelson, Paul and Christopher Sprecher. 2010. "Are Sensitive Technologies Enablers of Civil Nuclear Power? An Empirical Study.” Atoms for Peace - An International Journal, 3(2), 2010.

Ogilvie-White T. 1996. "Is There a Theory of Nuclear Proliferation? An Analysis of the Contemporary Debate." The Nonproliferation Review (Fall Issue):43-60.

Phillips J., S. Kreyling, S. Short, and M. Weimar. 2010. "Economic and Nonproliferation Analysis Framework for assessing Reliable Nuclear Fuel Service Arrangements." Procs. Pacific Northwest International Conference on Global Nuclear Security - the Decade Ahead, April 11-16, 2010, Portland, Oregon. (CD format)

Reiss, Mitchell B. 2004. "The Nuclear Tipping Point: Prospects for a World of Many Nuclear Weapons Sates." The Nuclear Tipping Point: Why States Reconsider Their Nuclear Choices. Kurt M. Campbell, Robert J. Einhorn, and Mitchell B. Reiss (ed). Washington D.C. : The Brookings Institution, 2004.

Reiss M and RS Litwak, Editors. 1994. Nuclear Proliferation after the Cold War. Woodrow Wilson Center Press.

Roos T, H Wettig, P Grunwald, P Myllymaki, and H Tirri. 2005. "On Discriminative Bayesian Network Classifiers and Logistic Regression.” Machine Learning 59:267-296.

Rublee M. 2008. "Taking Stock of the Nuclear Nonproliferation Regime: Using Social Psychology to Understand Regime Effectiveness." International Studies Review 10(3):420-450. Accessed March 24, 2009, at http://www3.interscience.wiley.com/journal/121385697/abstract.

Sagan S. 1997. "Why Do States Build Nuclear Weapons? Three Models in Search of a Bomb." International Security 21(3):54-86.

Singh S and CR Way. 2004. "The Correlates of Nuclear Proliferation: A Quantitative Test." Journal of Conflict Resolution 48(6):859-885.

Sagan SD and AH Montgomery. 2009. "The Perils of Predicting Proliferation." Journal of Conflict Resolution 53(2):302-328.

Signorino, Curtis and Jeff Ritter. 1999. “Tau-b or Not Tau-b." International Studies Quarterly 43(1):115-144.

Sterman JD. 2000. Business Dynamics: Systems Thinking and Modeling for a Complex World. Irwin McGraw-Hill, Boston, Massachusetts.

Sweeney, D.J., W.S. Charlton. 2009. "Latency as a Basis for Safeguards," Transactions of the 2009 American Nuclear Society Winter Meeting, Washington, D.C., November 15-19, 2009. 
Thayer, B. A. 1995. "The causes of nuclear proliferation and the nonproliferation regime." Security Studies 4(3): 463-519.

Williams L. 2010. State Level Factors as Proliferation Indicators. L. Williams. PNNL-19183-1. Pacific Northwest National Laboratory, Richland, Washington. 


\section{Appendix A \\ Data Analysis}





\section{Appendix A}

\section{Data Analysis}

This appendix provides an overview of our analysis of the Singh and Way and Jo and Gartzke data in an effort to better understand relationships between the variables. As a part of a data analyses exercise, we conducted correlation analysis, cluster analysis, principal component analysis, and created dendrograms. To examine the strength of the relationship among the explanatory variables, we ran both pairwise correlation and correlation matrix with visualization tools to identify interdependence among the constructs.

The volume of these materials makes it too impractical to present in this report, but samples are provided and further data can be obtained from the authors (garill.coles@pnl.gov).

\section{A.1 Identification of Important Correlations}

Table A.1. Identification of Important Potential Correlations

\begin{tabular}{|c|c|c|c|c|c|}
\hline $\begin{array}{l}\text { Variable } \\
1\end{array}$ & Variable 2 & $\begin{array}{l}\text { Correlatio } \\
\mathbf{n}\end{array}$ & $\begin{array}{l}\text { Sample } \\
\text { Size }\end{array}$ & $\begin{array}{l}\text { If } \\
\text { question } \\
\text { - actual } \\
\text { size } \\
\end{array}$ & Reason for question \\
\hline new_econ & Polity & 0.17 & 4656 & 0.1651 & $\begin{array}{l}\text { Logically would be connected because } \\
\text { economic capacity index is similar to GDP, } \\
\text { and GDPcap and Polity are connected. } \\
\text { Although a key difference is that this may } \\
\text { not consider per capita vs. aggregate. It } \\
\text { remains speculative if the lag will make a } \\
\text { difference. }\end{array}$ \\
\hline Polity & openness & 0.17 & 4741 & 0.1661 & $\begin{array}{l}\text { Many would argue this connection in the } \\
\text { political science world, but this } \\
\text { relationship remains inconclusive. A time } \\
\text { lag could definitely show a connection } \\
\text { because many argue that increased } \\
\text { openness and exchange is the way to bring } \\
\text { democracy to countries. }\end{array}$ \\
\hline dch5 & centdems & 0.16 & 5159 & 0.1582 & $\begin{array}{l}\text { Many would argue that there is a causal } \\
\text { relationship whereas a greater number of } \\
\text { democracies in an area drives democratic } \\
\text { change. }\end{array}$ \\
\hline dch5 & ln_xst1 & 0.11 & 5159 & & $\begin{array}{l}\text { There is a fair argument to be made that a } \\
\text { large number of domestic unrest would } \\
\text { drive a change in the type of governance. } \\
\text { Dch } 5 \text { might just be a weak variable for } \\
\text { this. }\end{array}$ \\
\hline
\end{tabular}




\begin{tabular}{|c|c|c|c|c|}
\hline GDPcap & DCH5 & 0.05 & 4599 & $\begin{array}{l}\text { A causal relationship might exist between } \\
\text { GDPcap and change in governance, much } \\
\text { like with domestic disputes. However, this } \\
\text { might not be an effective variable at } \\
\text { capturing the information. }\end{array}$ \\
\hline GDPcap & ln_xst1 & 0.05 & 4599 & $\begin{array}{l}\text { A causal relationship between GDPcap and } \\
\text { ln_xst1 (domestic disputes) might exist for } \\
\text { the same reason identified immediately } \\
\text { above. }\end{array}$ \\
\hline G2 & chopen5 & 0.03 & 4599 & $\begin{array}{l}\text { A tenuous causal relationship might be } \\
\text { possible where chopen } 5 \text { impacts } \mathrm{G} 2 \text { over } \\
\text { time. }\end{array}$ \\
\hline GDPcap & chopen5 & 0.02 & 4599 & $\begin{array}{l}\text { A tenuous causal relationship might be } \\
\text { possible where chopen5 impacts GDPcap } \\
\text { over time. }\end{array}$ \\
\hline new_econ & openness & -0.16 & 4656 & $\begin{array}{l}\text { new_econ would probably be impacted by } \\
\text { changes in openness, much like } \\
\text { GDPcap/G2 would be. }\end{array}$ \\
\hline
\end{tabular}




\section{A.2 Correlation of Variables Matrix}

Table A.2. Pairwise Correlation of Variables Matrix

\begin{tabular}{|c|c|c|c|c|c|}
\hline & gdpcap & 92 & industry1 & industry2 & industry \\
\hline gdpcap & 1.000000000 & 0.924861224 & 0.397573343 & 0.4629993589 & 0.466557137 \\
\hline 92 & 0.924861224 & 1.000000000 & 0.276883687 & 0.3415290875 & 0.334699224 \\
\hline industry1 & 0.397573343 & 0.276883687 & 1.000000000 & 0.6850191586 & 0.929537083 \\
\hline industry2 & 0.462999359 & 0.341529088 & 0.685019159 & 1.0000000000 & 0.905378764 \\
\hline industry & 0.466557137 & 0.334699224 & 0.929537083 & 0.9053787641 & 1.000000000 \\
\hline rivalry & -0.067752392 & -0.045986266 & 0.157908507 & 0.1062690633 & 0.145819513 \\
\hline disputes & -0.017577403 & -0.002682964 & 0.201801057 & 0.1926652589 & 0.214784543 \\
\hline allies & 0.187534684 & 0.091391066 & 0.210821001 & 0.1934098395 & 0.220690870 \\
\hline olity & 0.472681603 & 0.346300442 & 0.333998541 & 0.3305975680 & 0.362 \\
\hline ch5 & 0.009859944 & -0.009422490 & 0.058986908 & 0.0524263435 & 0.061 \\
\hline centdems & 0.132402103 & 0.144809371 & 0.090131265 & 0.0868443906 & 0.096 \\
\hline ness & 0.237460004 & 0.196431507 & -0.119356697 & -0.1146974085 & $5-0.127679471$ \\
\hline sen 5 & -0.011578258 & 0.001447539 & 0.009329737 & -0.0003196154 & $4 \quad 0.005221182$ \\
\hline nuk 7 set 1 & 0.423722981 & 0.288661225 & 0.852528634 & 0.7031376648 & 0.856077 \\
\hline new_econ & 0.238984444 & 0.197449833 & 0.282147095 & 0.3880867010 & 0.361 \\
\hline ln_żst1 & 0.058527184 & 21006 & 0.2904 & 0.2678342433 & 0.305 \\
\hline r_ñukep & 0.021763965 & 511128 & 0.263205396 & 0.2825387822 & 0.297 \\
\hline $\mathrm{UR} A \_I$ & 0.255851810 & 1225738 & 0.604911685 & 0.5598308446 & 0.638 \\
\hline $\operatorname{mot} \bar{i} v 2$ & -0.013508799 & -0.044367848 & 0.239606472 & 0.2418306469 & 0.261952 \\
\hline easEPA2 & 0.154426397 & 0.106590682 & 0.348791204 & 0.4224928693 & 0.416978 \\
\hline easEPA3 & -0.002939901 & -0.0 & 0.263373086 & 0.2820374971 & 10.297 \\
\hline Regional.stability & $\begin{array}{c}-0.527814313 \\
\text { rivalry }\end{array}$ & $\begin{array}{c}-0.385974645 \\
\text { disputes }\end{array}$ & $\begin{array}{c}-0.325897297 \\
\text { allies }\end{array}$ & $\begin{array}{c}-0.3097339360 \\
\text { polity }\end{array}$ & $0-0.34824$ \\
\hline gdpcap & -0.06775239 & -0.017577403 & 0.187534684 & 0.472681603 & 0.00985 \\
\hline 92 & -0.04598627 & -0.002682964 & 0.091391066 & 0.346300442 & -0.00942 \\
\hline industry1 & 0.15790851 & 0.201801057 & 0.210821001 & 0.333998541 & 0.05898 \\
\hline industry2 & 0.10626906 & 0.192665259 & 0.1934098 & 0.330597568 & 0.05242 \\
\hline industry & 0.14581951 & 0.21 & 0.22069 & 0.362685838 & 0.0610 \\
\hline & 1.00 & 9223 & -0.076021533 & -0.093638938 & -0.024 \\
\hline disputes & 0.48654922 & 1.000000000 & -0.093711651 & $-0.015509229-$ & -0.02076 \\
\hline allies & -0.07602153 & -0.093711651 & 1.000000000 & 0.219375907 & 0.03330 \\
\hline & -0.09363894 & -0.015509229 & 0.219375907 & 1.000000000 & 0.25177 \\
\hline & -0.02418704 & -0.020769168 & 0.033306140 & 0.251774872 & 1.00000 \\
\hline tdems & -0.08739238 & 526625 & -0.038988515 & 0.196402015 & $0.180^{\circ}$ \\
\hline ness & -0.21651925 & -0.204527058 & -0.017172313 & 0.178500289 & 0.0363 \\
\hline en 5 & -0.01702479 & -0.017780674 & -0.025634082 & 0.033135318 & 0.02096 \\
\hline nuk7set 1 & 0.21106348 & 0.265903328 & 0.282373934 & 0.336109331 & 0.088808166 \\
\hline new econ & 0.21768067 & 0.405519242 & -0.041479381 & 0.164877775 & $0.01011 \mathrm{~s}$ \\
\hline ln $\bar{x}$ st 1 & 0.22594342 & 0.185513312 & 0.128552820 & 0.190668864 & 0.112186294 \\
\hline r_nukep & 0.42585426 & 83093 & -0.046078497 & -0.011848185 & 0.02426 \\
\hline $\mathrm{UR} \bar{R} A I^{\prime}$ & 0.11810899 & 0.189217191 & 0.221084484 & 0.153429022 & 0.06598 \\
\hline iv 2 & 0.17792896 & 0.256588044 & 0.000692913 & -0.002410324 & 0.01352 \\
\hline measEPA2 & 0.29928218 & 0.504731369 & -0.030451022 & 0.132308477 & 0.010589933 \\
\hline measEPA3 & 0.20461863 & 0.357393962 & -0.003161408 & 0.012329783 & 0.014677549 \\
\hline Regional.stability & 0.25813460 & 0.142148516 & -0.308944673 & -0.444687002 & 0.002087760 \\
\hline & centdems & & & & \\
\hline gdpcap & 0.132402103 & 0.23746000 & -0.0115782581 & 0.423722981 & $0.2389 \overline{8} 4444$ \\
\hline 92 & 0.144809371 & 0.19643151 & 0.0014475393 & 0.288661225 & 0.197449833 \\
\hline industry1 & 0.090131265 & -0.11935670 & 0.0093297374 & 0.852528634 & 0.282147095 \\
\hline industry2 & 0.086844391 & -0.11469741 & -0.0003196154 & 0.703137665 & 0.388086701 \\
\hline dustry & 0.096485615 & -0.12767947 & 0.0052211823 & 0.856077452 & 0.361603189 \\
\hline valry & -0.087392385 & -0.21651925 & -0.0170247873 & 0.211063483 & 0.217680674 \\
\hline disputes & -0.077526625 & -0.20452706 & -0.0177806742 & 0.265903328 & 0.405519242 \\
\hline
\end{tabular}




\begin{tabular}{|c|c|c|c|c|c|}
\hline allies & -0.038988515 & -0.01717231 & -0.0256340818 & 0.282373934 & -0.041479381 \\
\hline polity & 0.196402015 & 0.17850029 & 0.0331353176 & 0.336109331 & 0.164877775 \\
\hline dch 5 & 0.180747056 & 0.03630428 & 0.0209681041 & 0.088808166 & 0.010119870 \\
\hline centdems & 1.000000000 & 0.06708885 & 0.0335105686 & -0.004156065 & 0.020329652 \\
\hline openness & 0.067088851 & 1.00000000 & 0.2439044737 & -0.184073377 & -0.144622416 \\
\hline chopen 5 & 0.033510569 & 0.24390447 & 1.0000000000 & -0.006564282 & -0.005456379 \\
\hline nuk 7 set 1 & -0.004156065 & -0.18407338 & -0.0065642824 & 1.000000000 & 0.308449362 \\
\hline new_econ & 0.020329652 & -0.14462242 & -0.0054563792 & 0.308449362 & 1.000000000 \\
\hline ln_ōst 1 & 0.047591713 & -0.15260984 & -0.0238022893 & 0.313755893 & 0.225521547 \\
\hline r_ñukep & -0.009051875 & -0.12911256 & -0.0003009033 & 0.289838023 & 0.453667271 \\
\hline URA_I & 0.009754454 & -0.18224123 & -0.0045883873 & 0.699149852 & 0.270626866 \\
\hline motīv2 & -0.008236850 & -0.11200445 & -0.0186106458 & 0.264478460 & 0.018140165 \\
\hline measEPA2 & 0.005320750 & -0.14252221 & -0.0182847268 & 0.402662278 & 0.553532952 \\
\hline measEPA3 & -0.008996961 & -0.11901889 & -0.0187051816 & 0.297680387 & 0.219999533 \\
\hline \multirow[t]{2}{*}{ Regional.Stability } & 0.012615079 & -0.17612203 & -0.0207377391 & -0.318041672 & -0.101961797 \\
\hline & ln_xst1 & r_nukep & URA_I & motiv2 & measEPA2 \\
\hline gdpcap & $0.058 \overline{5} 2718$ & $0.0217 \overline{6} 39654$ & $0.2558518 \overline{1} 0$ & -0.013508799 & 0.15442640 \\
\hline 92 & 0.01822101 & 0.0295111276 & 0.174225738 & -0.044367848 & 0.10659068 \\
\hline industry1 & 0.29041355 & 0.2632053960 & 0.604911685 & 0.239606472 & 0.34879120 \\
\hline industry2 & 0.26783424 & 0.2825387822 & 0.559830845 & 0.241830647 & 0.42249287 \\
\hline industry & 0.30509527 & 0.2971880146 & 0.638037652 & 0.261952323 & 0.41697824 \\
\hline rivalry & 0.22594342 & 0.4258542609 & 0.118108985 & 0.177928955 & 0.29928218 \\
\hline disputes & 0.18551331 & 0.4827830928 & 0.189217191 & 0.256588044 & 0.50473137 \\
\hline allies & 0.12855282 & -0.0460784969 & 0.221084484 & 0.000692913 & -0.03045102 \\
\hline polity & 0.19066886 & -0.0118481853 & 0.153429022 & -0.002410324 & 0.13230848 \\
\hline dch 5 & 0.11218629 & 0.0242647624 & 0.065982666 & 0.013525180 & 0.01058993 \\
\hline centdems & 0.04759171 & -0.0090518746 & 0.009754454 & -0.008236850 & 0.00532075 \\
\hline openness & -0.15260984 & -0.1291125631 & -0.182241235 & -0.112004448 & -0.14252221 \\
\hline chopen 5 & -0.02380229 & -0.0003009033 & $3-0.004588387$ & -0.018610646 & -0.01828473 \\
\hline nuk7set 1 & 0.31375589 & 0.2898380231 & 0.699149852 & 0.264478460 & 0.40266228 \\
\hline new econ & 0.22552155 & 0.4536672710 & 0.270626866 & 0.018140165 & 0.55353295 \\
\hline ln_ôst1 & 1.00000000 & 0.2135116027 & 0.252732529 & 0.143003688 & 0.30965318 \\
\hline r_ñukep & 0.21351160 & 1.0000000000 & 0.187558818 & 0.203893266 & 0.42745529 \\
\hline $\mathrm{U} \overline{\mathrm{R}} \mathrm{A}_{-} \mathrm{I}$ & 0.25273253 & 0.1875588179 & 1.000000000 & 0.207719244 & 0.32900400 \\
\hline $\operatorname{mot} \bar{i} v 2$ & 0.14300369 & 0.2038932657 & 0.207719244 & 1.000000000 & 0.45933199 \\
\hline measEPA2 & 0.30965318 & 0.4274552891 & 0.329003999 & 0.459331985 & 1.00000000 \\
\hline measEPA3 & 0.17500388 & 0.2699119660 & 0.234197852 & 0.962368609 & 1.00000000 \\
\hline \multirow[t]{2}{*}{ Regional.Stability } & -0.05770753 & 0.2015504146 & -0.124298130 & 0.093031173 & -0.01591620 \\
\hline & \multicolumn{3}{|c|}{ measEPA3 Regional. Stability } & & \\
\hline gdpcap & -0.002939901 & -0.52 & 781431 & & \\
\hline 92 & -0.038019449 & -0.38 & 3597465 & & \\
\hline industry1 & 0.263373086 & -0.32 & 589730 & & \\
\hline industry2 & 0.282037497 & -0.30 & 973394 & & \\
\hline industry & 0.297702949 & -0.34 & 824913 & & \\
\hline rivalry & 0.204618627 & 0.25 & 813460 & & \\
\hline disputes & 0.357393962 & 0.14 & 214852 & & \\
\hline allies & -0.003161408 & -0.30 & 894467 & & \\
\hline polity & 0.012329783 & -0.44 & 468700 & & \\
\hline $\operatorname{dch} 5$ & 0.014677549 & 0.00 & 208776 & & \\
\hline centdems & -0.008996961 & 0.01 & 261508 & & \\
\hline openness & -0.119018888 & -0.17 & 612203 & & \\
\hline chopen 5 & -0.018705182 & -0.02 & 073774 & & \\
\hline nuk7set 1 & 0.297680387 & -0.31 & 804167 & & \\
\hline new_econ & 0.219999533 & -0.10 & 196180 & & \\
\hline ln_xst1 & 0.175003880 & -0.05 & $\$ 770753$ & & \\
\hline r. ñukep & 0.269911966 & 0.20 & 155041 & & \\
\hline $\mathrm{U} \bar{R} A_{-} I$ & 0.234197852 & -0.12 & 429813 & & \\
\hline motiver & 0.962368609 & 0.09 & 303117 & & \\
\hline measEPA2 & 1.000000000 & -0.01 & 591620 & & \\
\hline measEPA3 & 1.000000000 & 0.08 & 3847399 & & \\
\hline Regional.Stability & 0.088473989 & 1.00 & 000000 & & \\
\hline
\end{tabular}




\section{A.3 Example Pairwise Scatter Plots}

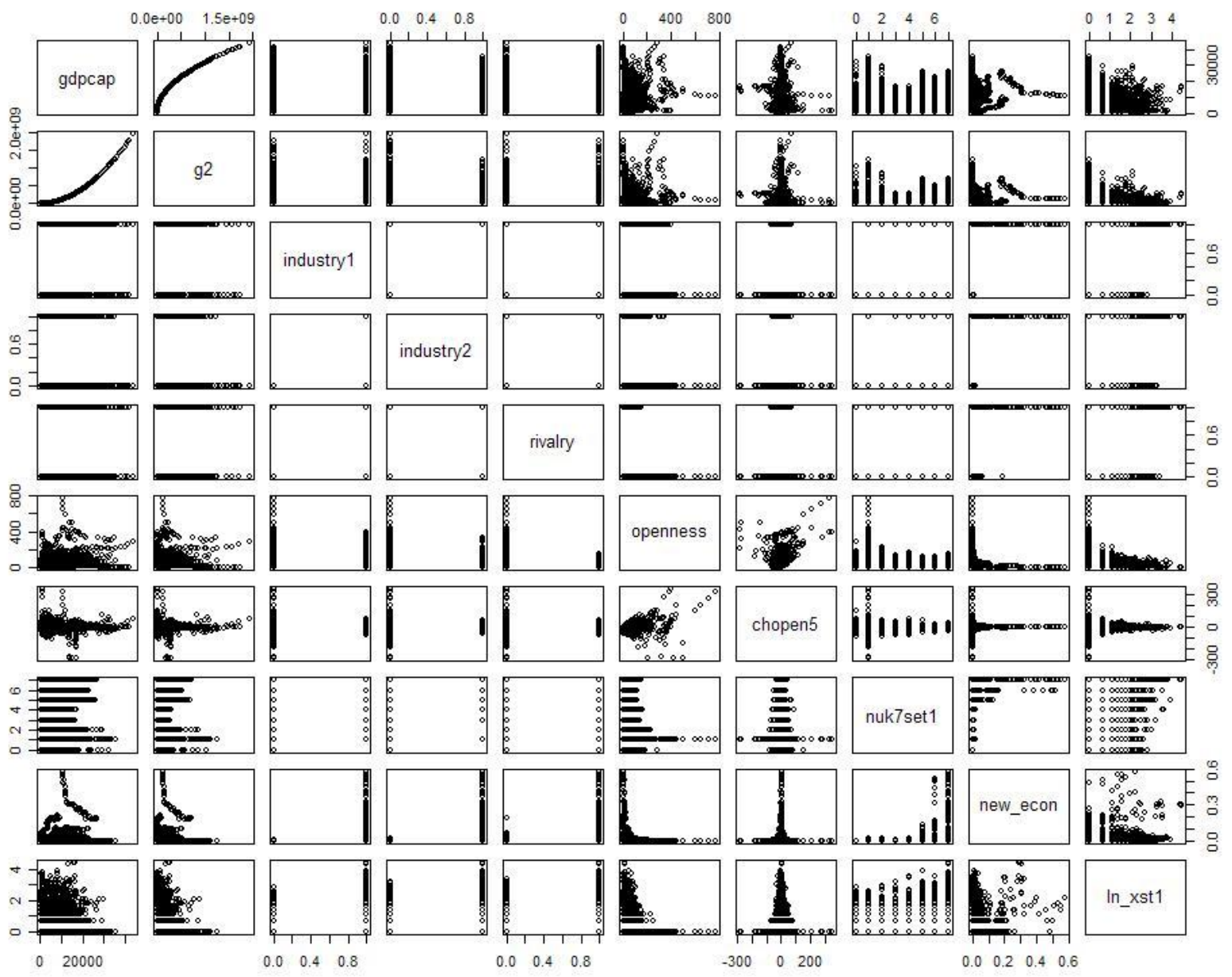

Figure A.1. Pairwise Scatter Plots for All Countries and Country-Years 
Select Variables, Color Represents measEPA

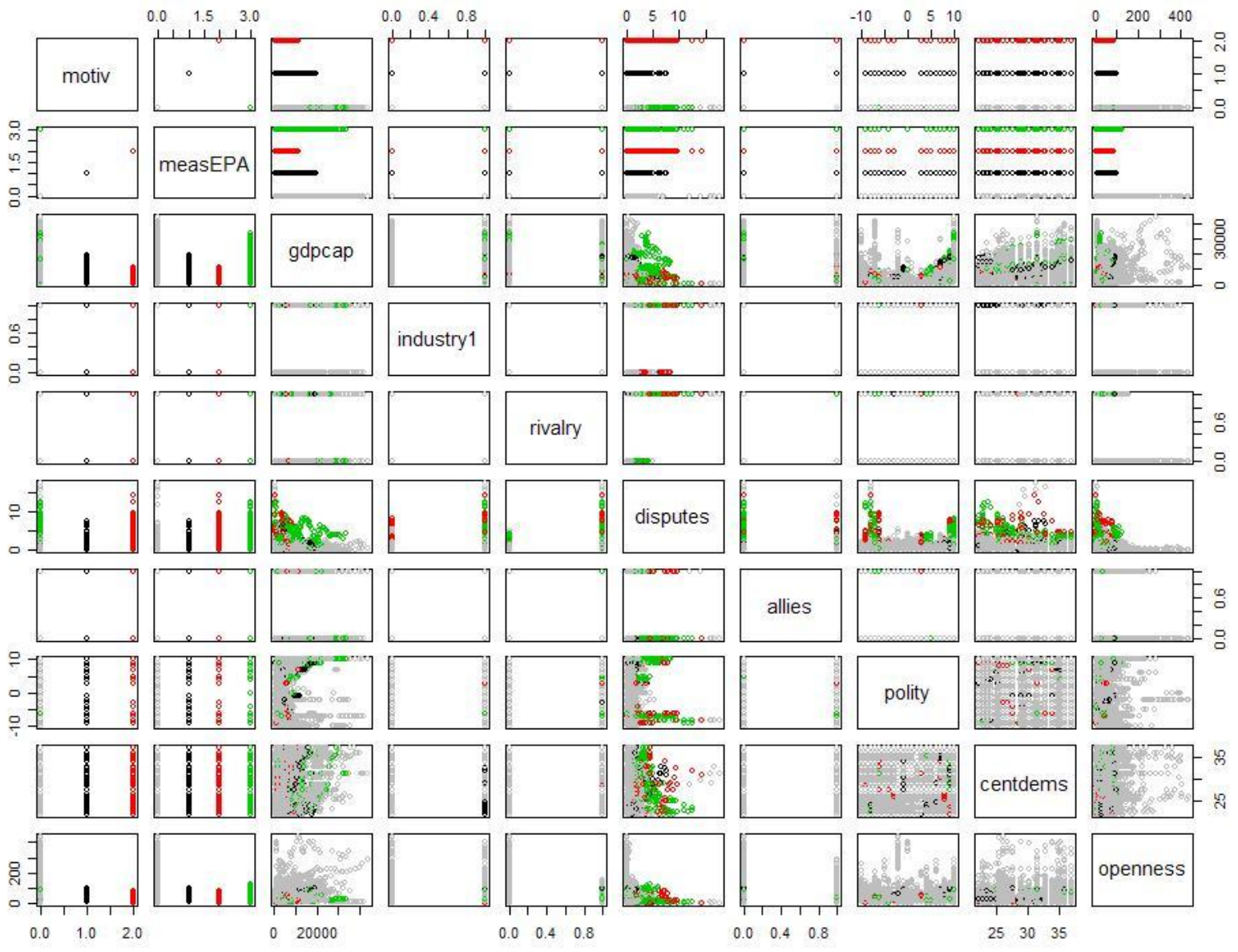

Figure A.2. Pairwise Scatter Plots for Selected Variables and Country-Years ${ }^{1}$

${ }^{1}$ This is a pairwise scatter plot for selected dependent variables against the dependent variables of Explore (green), Pursue (red) and Acquire (black). 


\section{A.4 Example Correlations of Lagged Variables}
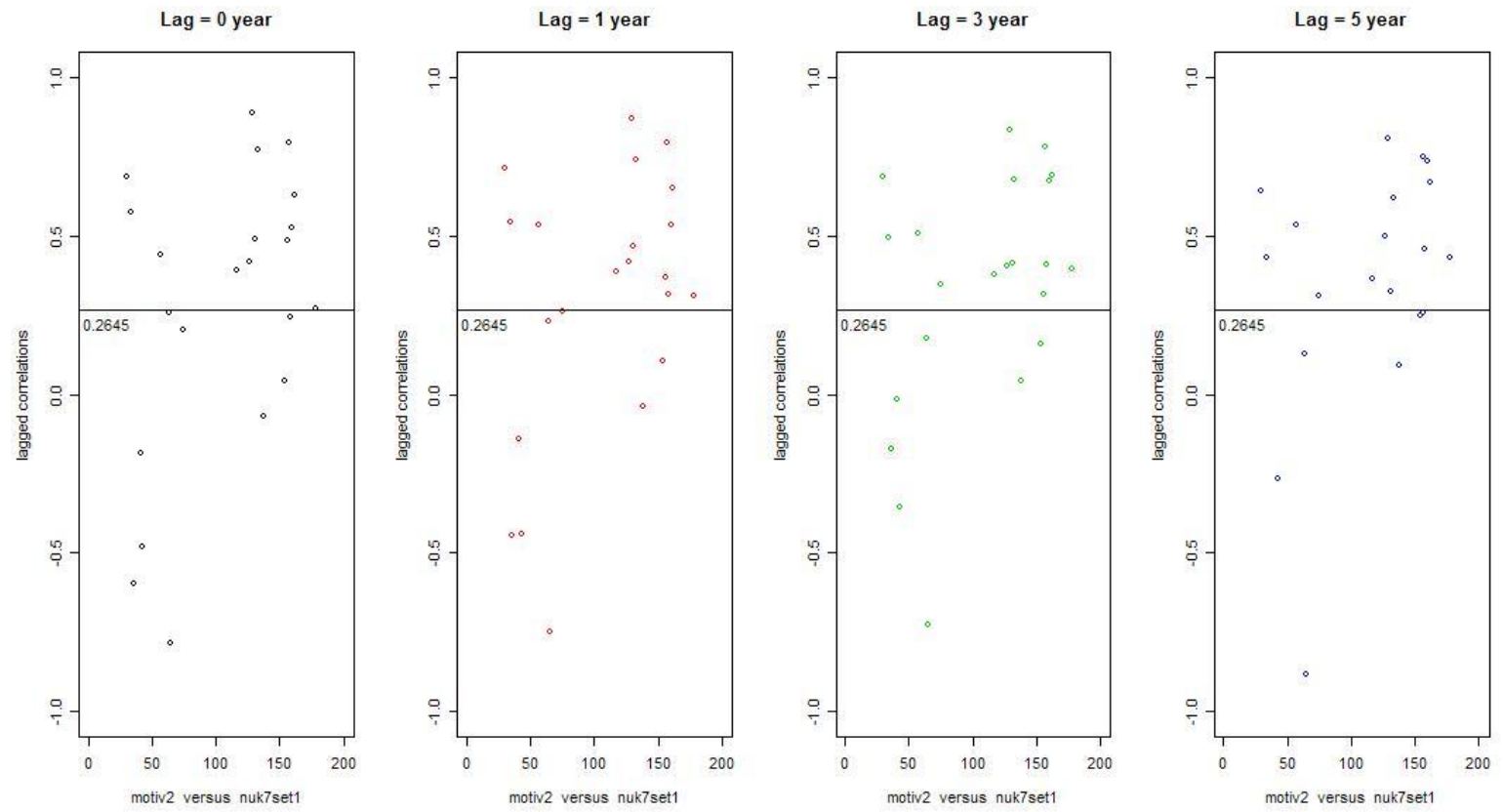

Figure A.3. Time Lag Correlations between Motivation (“motiv2”) \& Nuclear Technology ("nuk7set1”)
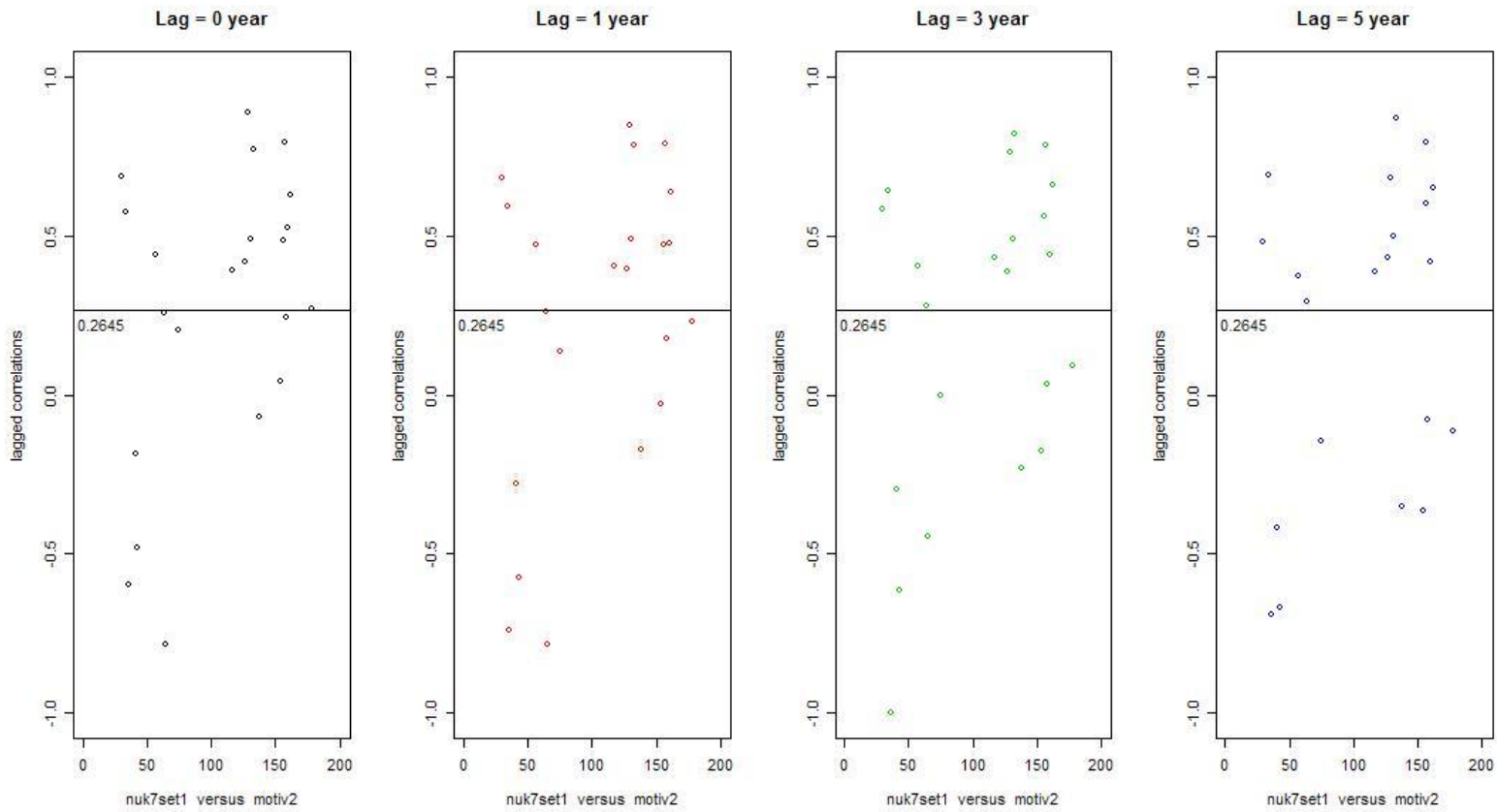

Figure A.4. Time Lag Correlations between Nuclear Technology (“nuk7set1”) \& Motivation (“motiv2”) 

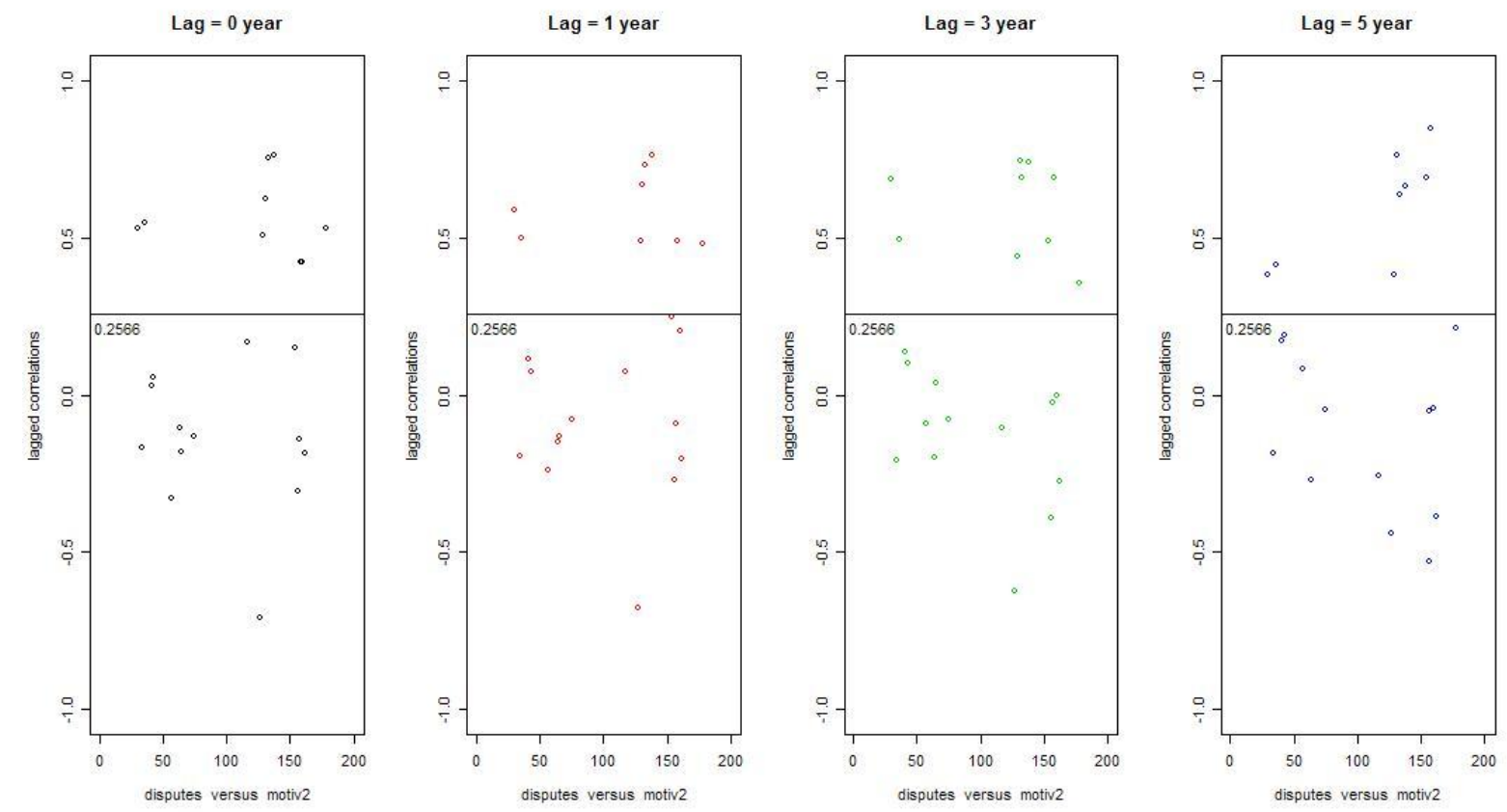

Figure A.5. Time Lag Correlations between "disputes" and Motivation ("motiv2")
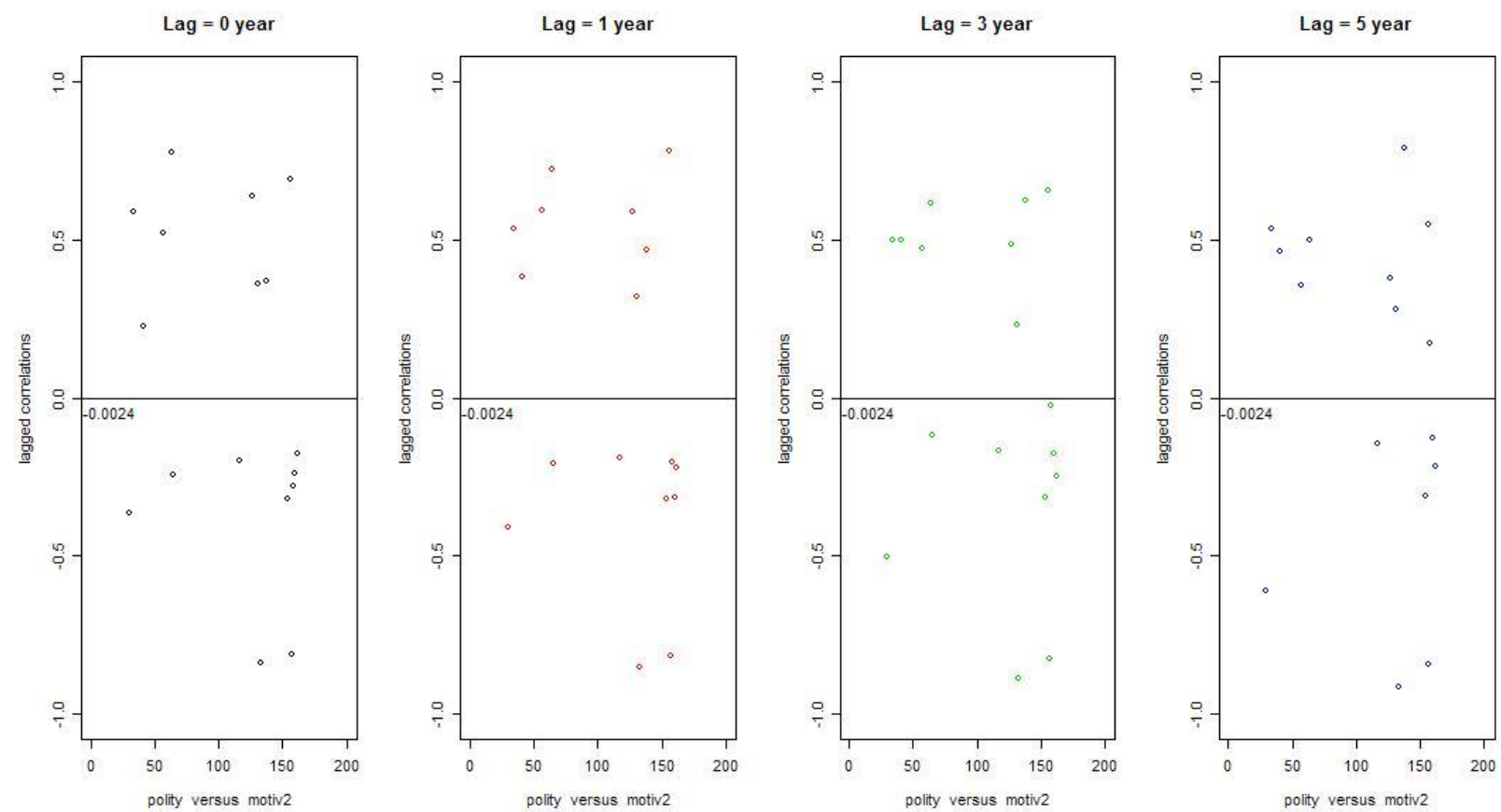

Figure A.6. Time Lag Correlations between "polity" and Motivation ("motiv2") 

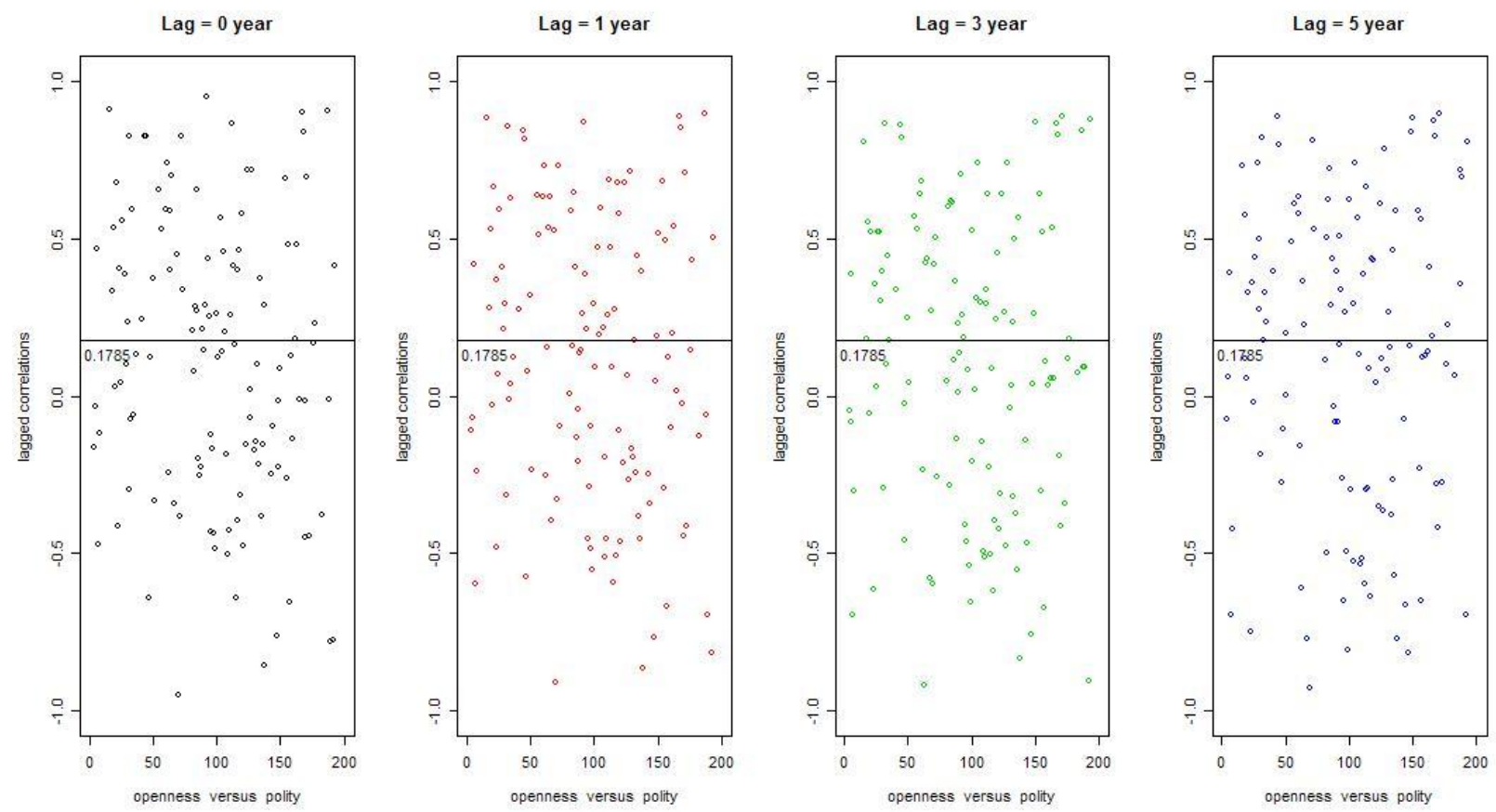

Figure A.7. Time Lag Correlations between "openness" and "polity"
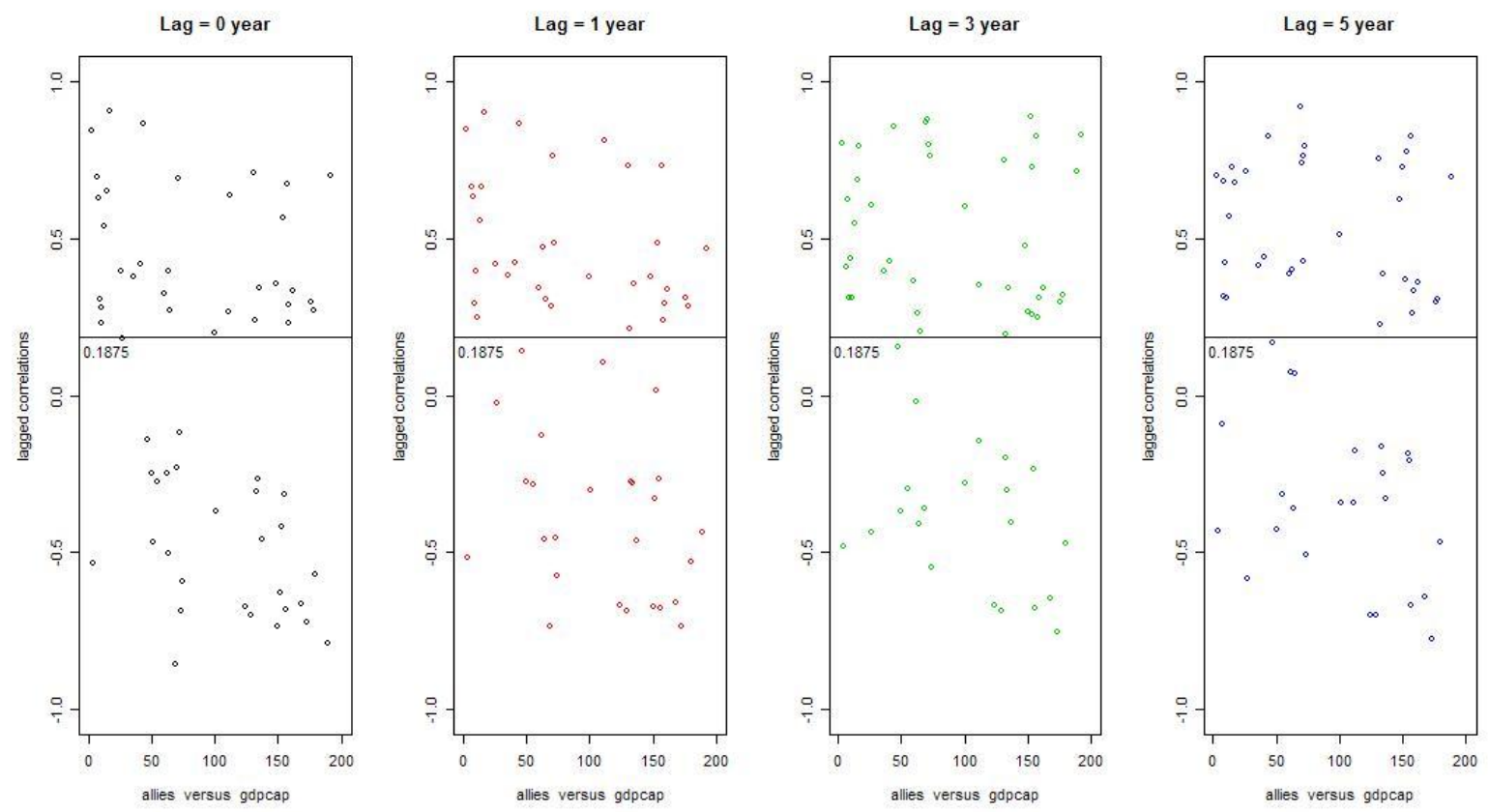

Figure A.8. Time Lag Correlations between "allies" and "GDPcap" 


\section{A.5 Pairwise Color Plot History of Selected Variables \& Countries}

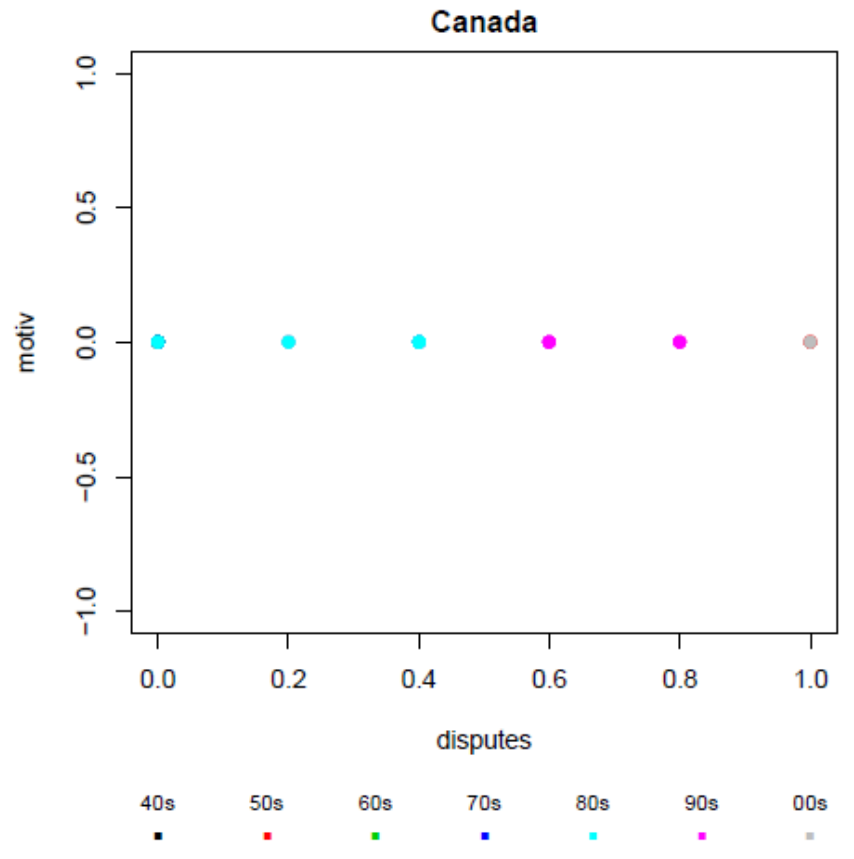

Figure A.9. Pairwise Color Block Plot History for "motiv2" and "disputes" for Canada

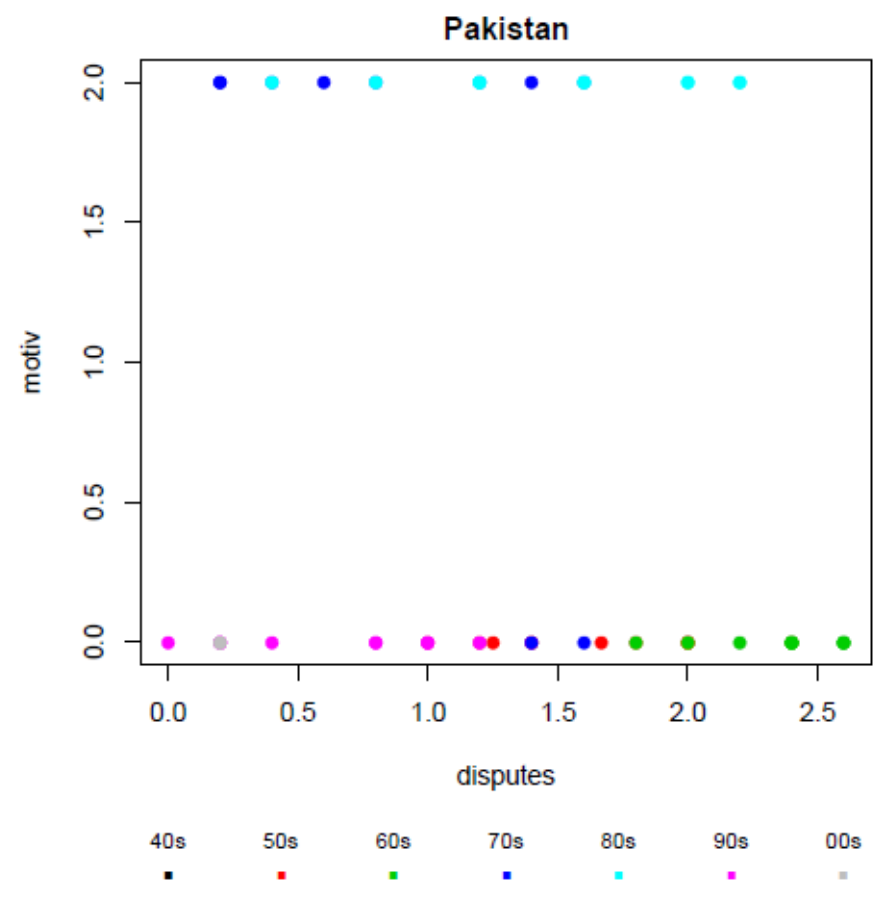

Figure A.10. Pairwise Color Block Plot History for "motiv2" and "disputes" for Pakistan 


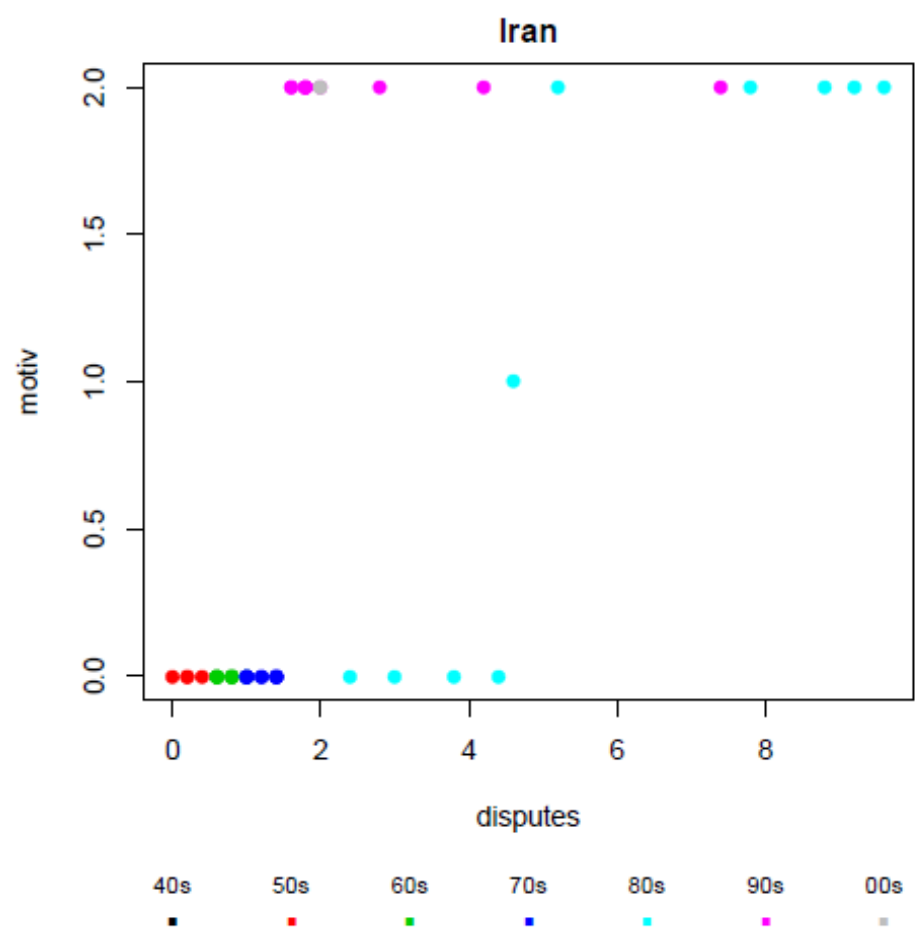

Figure A.11. Pairwise Color Block Plot History for "motiv2" and "disputes" for Iran

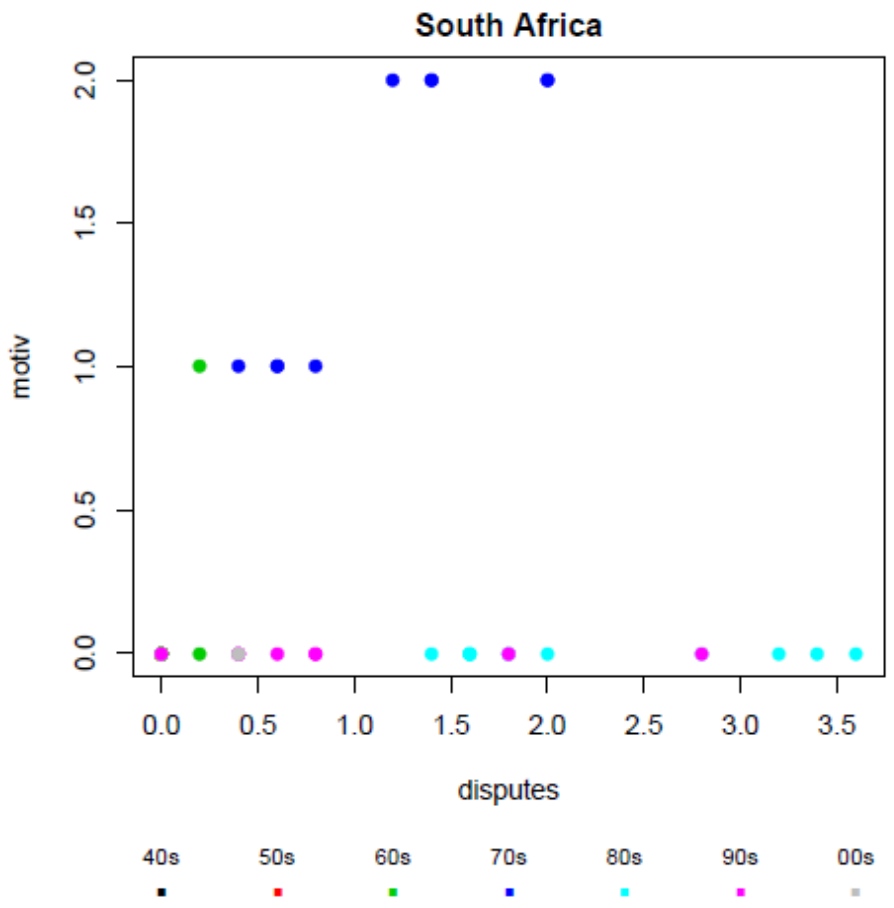

Figure A.12. Pairwise Color Block Plot History for "motiv2" and "disputes" for South Africa 

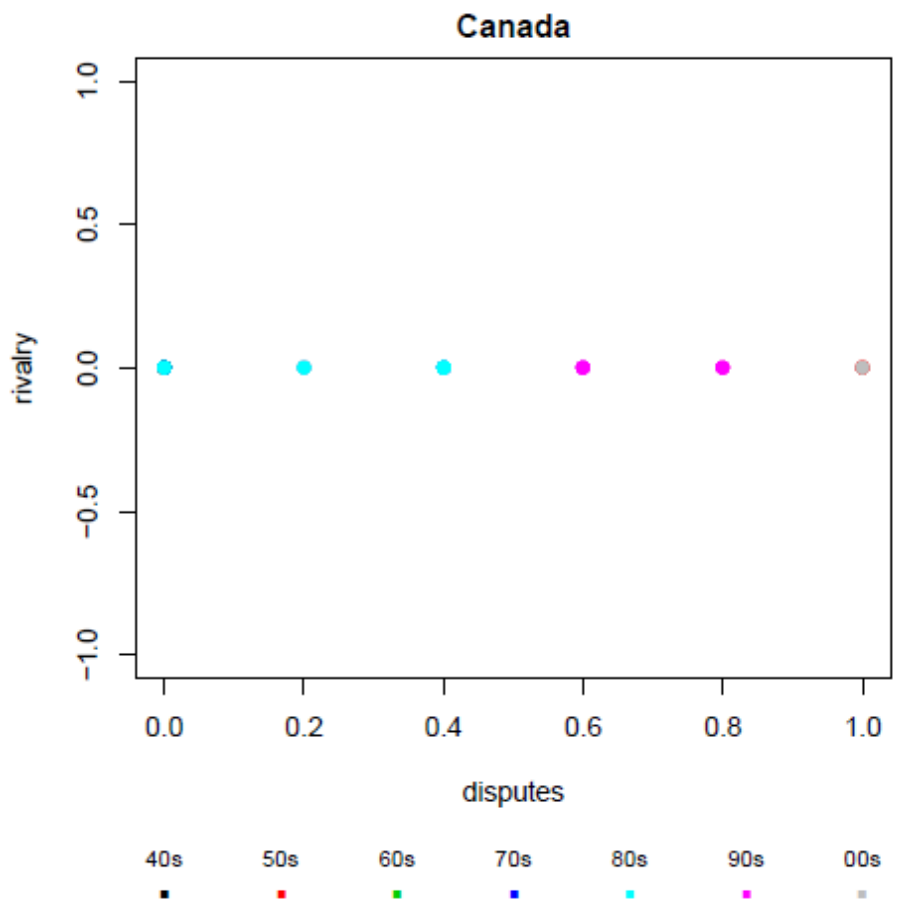

Figure A.13. Pairwise Color Block Plot History for "rivalry" and "disputes" for Canada

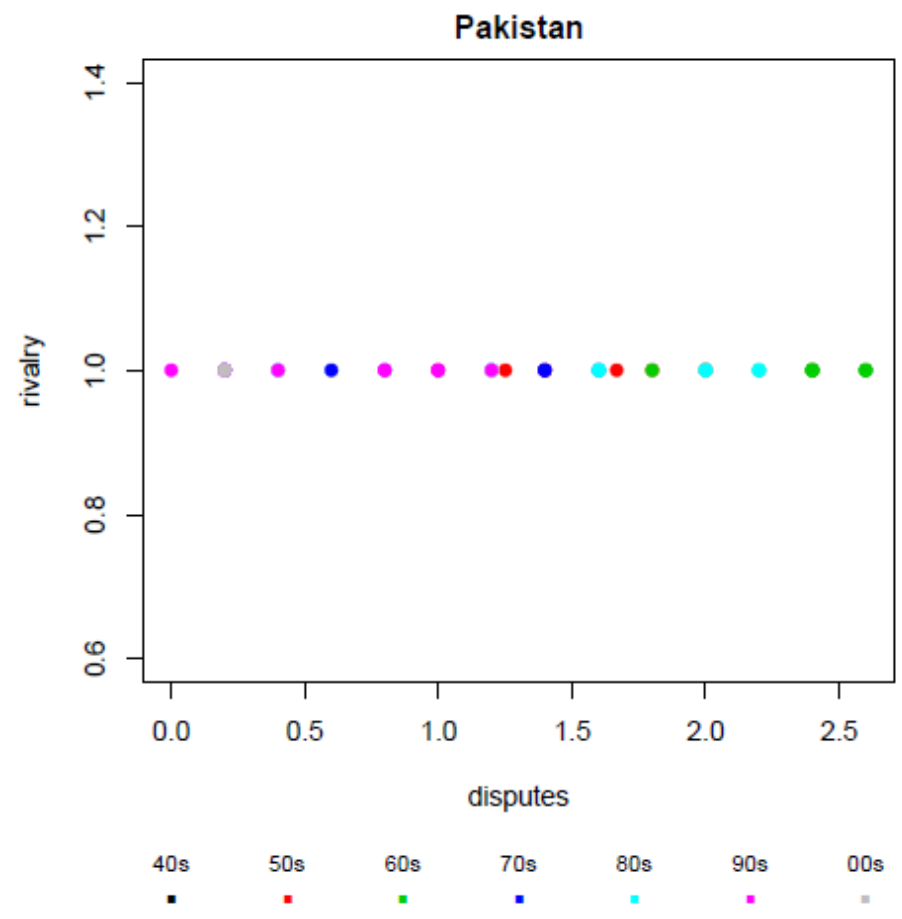

Figure A.14. Pairwise Color Block Plot History for "rivalry" and "disputes" for Pakistan 

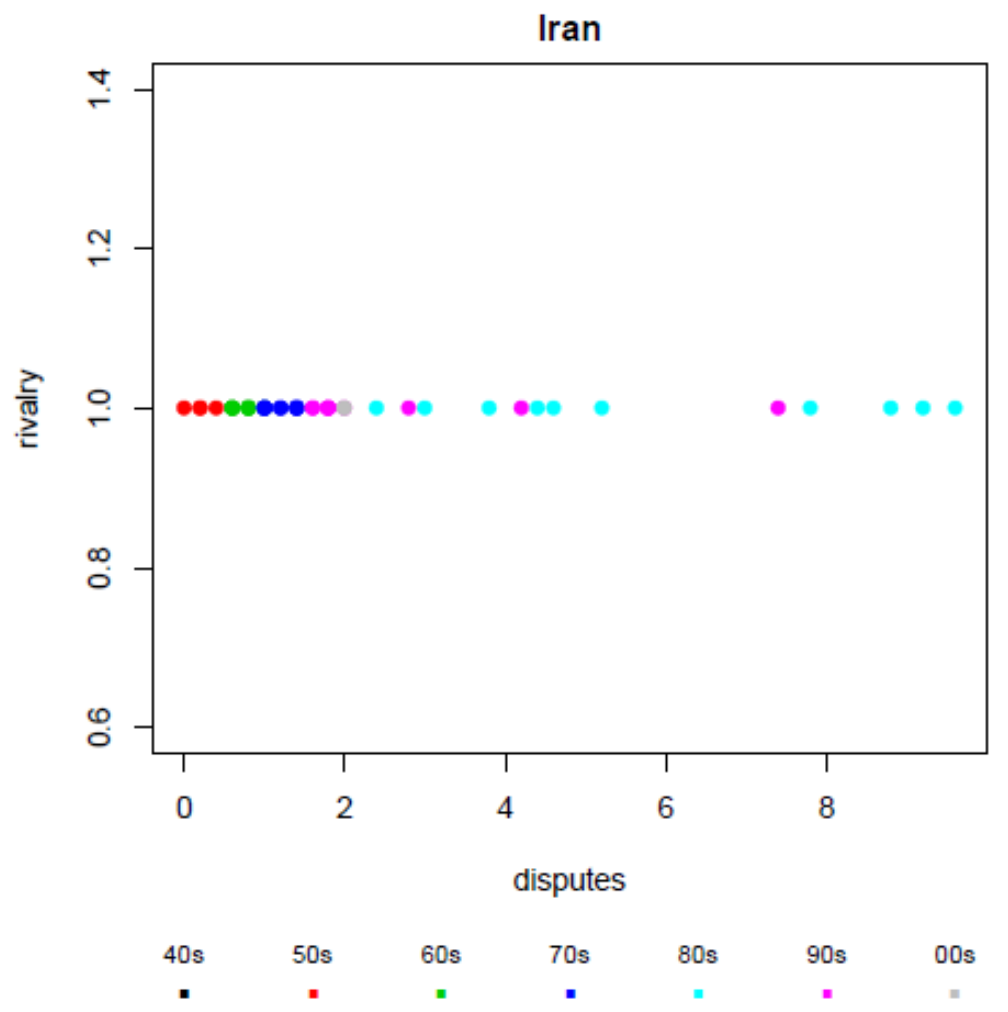

Figure A.15. Pairwise Color Block Plot History for "rivalry" and "disputes" for Iran

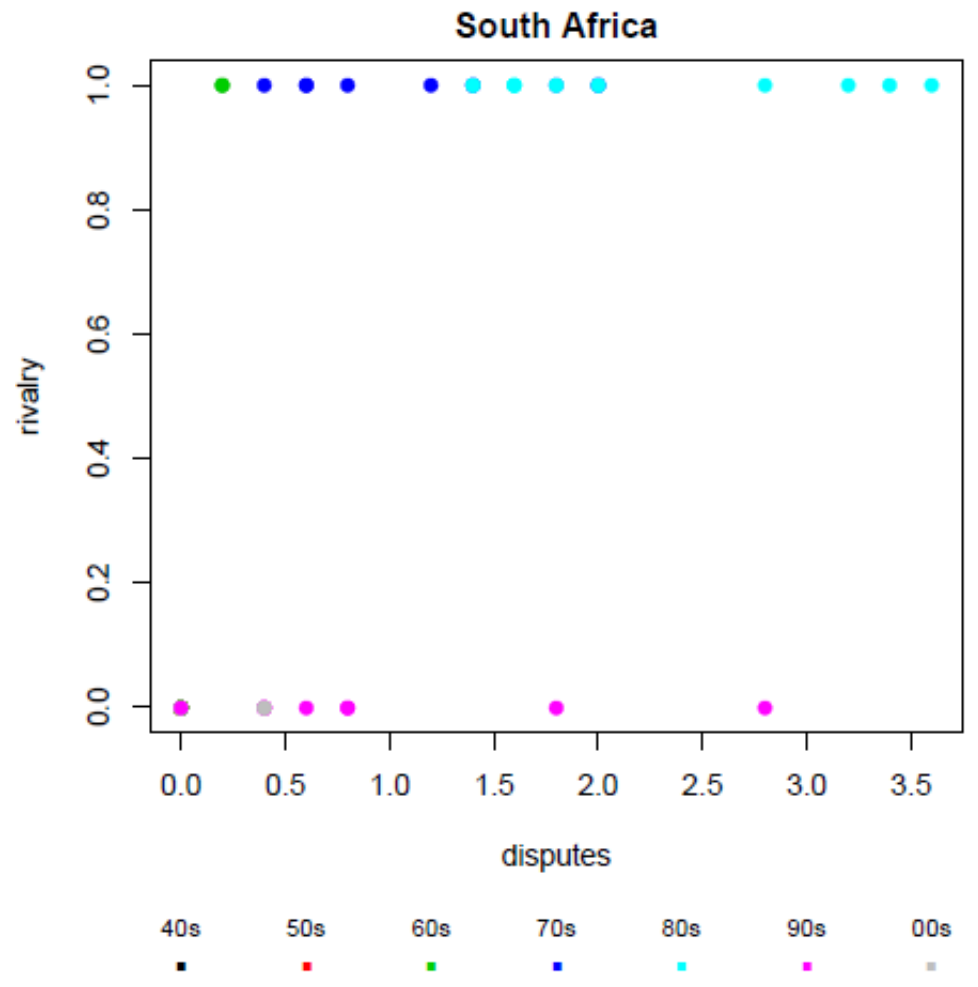

Figure A.16. Pairwise Color Block Plot History for "rivalry" and "disputes" for South Africa 


\section{A.6 K Mean Clustering}

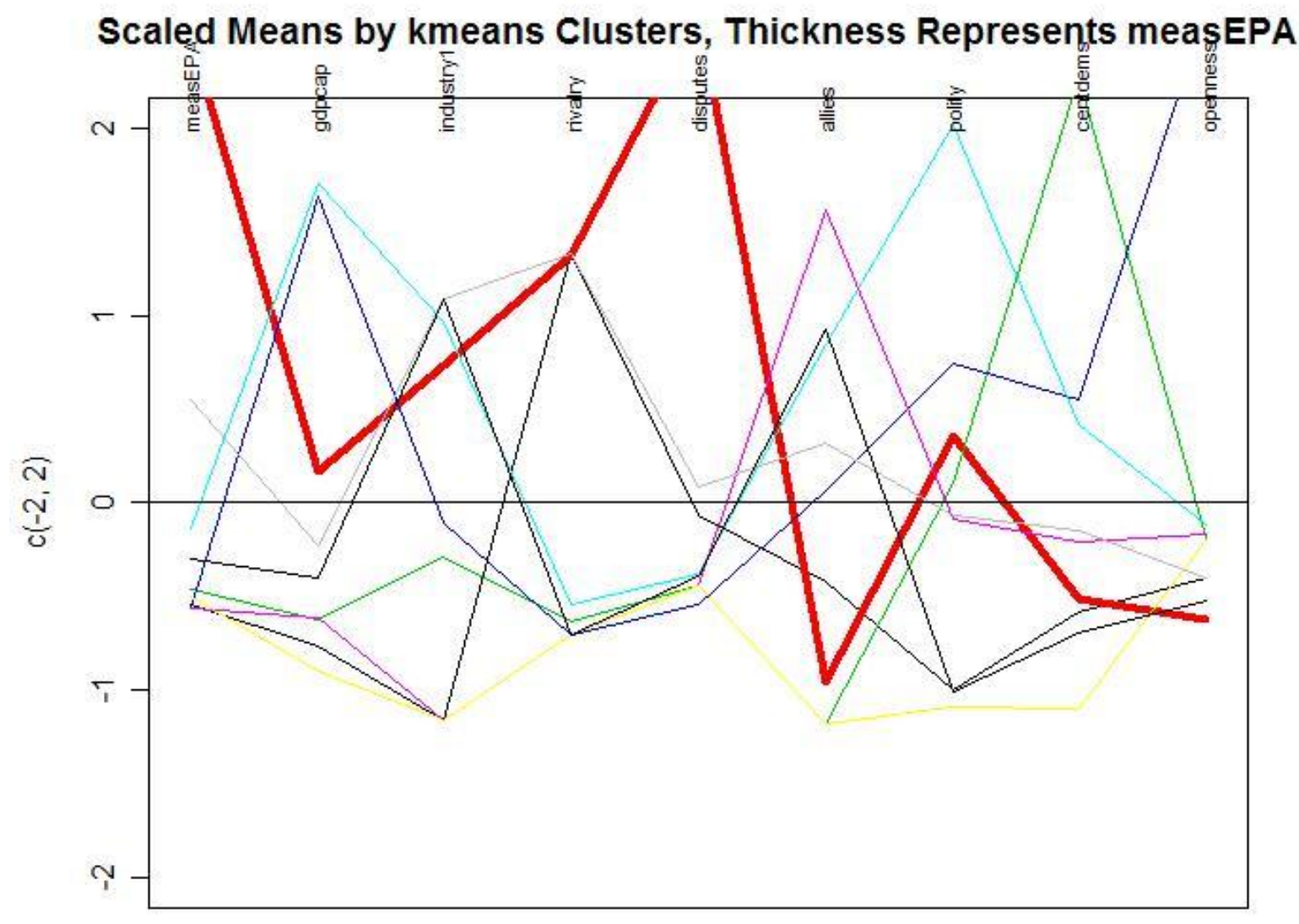

Figure A.17. K Means Lines Plot for Selected Variables ${ }^{1}$

\footnotetext{
${ }^{1}$ This K Means line graph is for dependent variables against the dependent variables of Explore (thin), Pursue (thicker), and Acquire (thickest).
} 
kmeans Cluster Means, Size Represents Mean measEPA

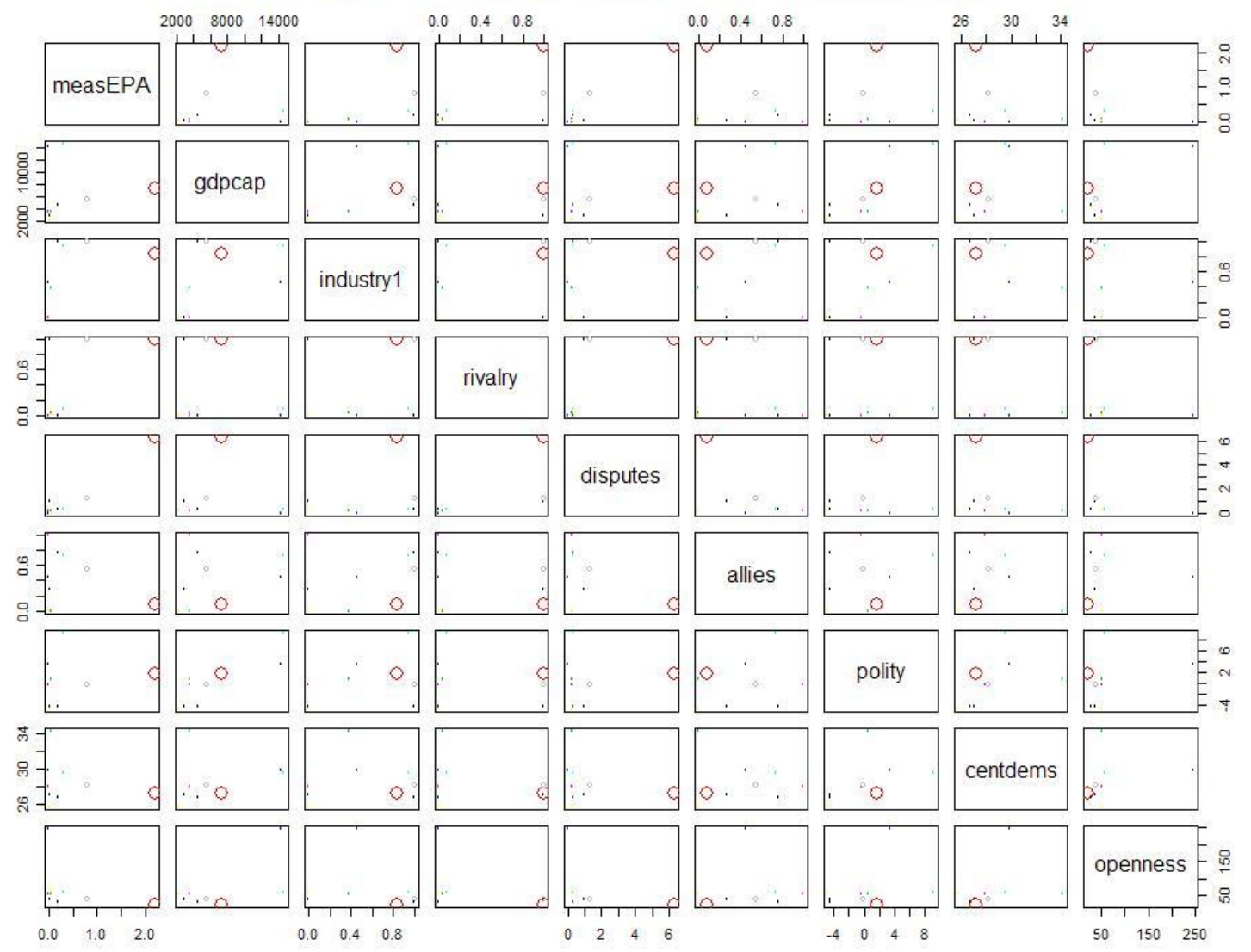

Figure A.18. K Means Bubble Chart for All Countries and Country-Years 


\section{A.7 Principal Component Analysis}

\section{First Two PCs, Color Represents True measEPA}

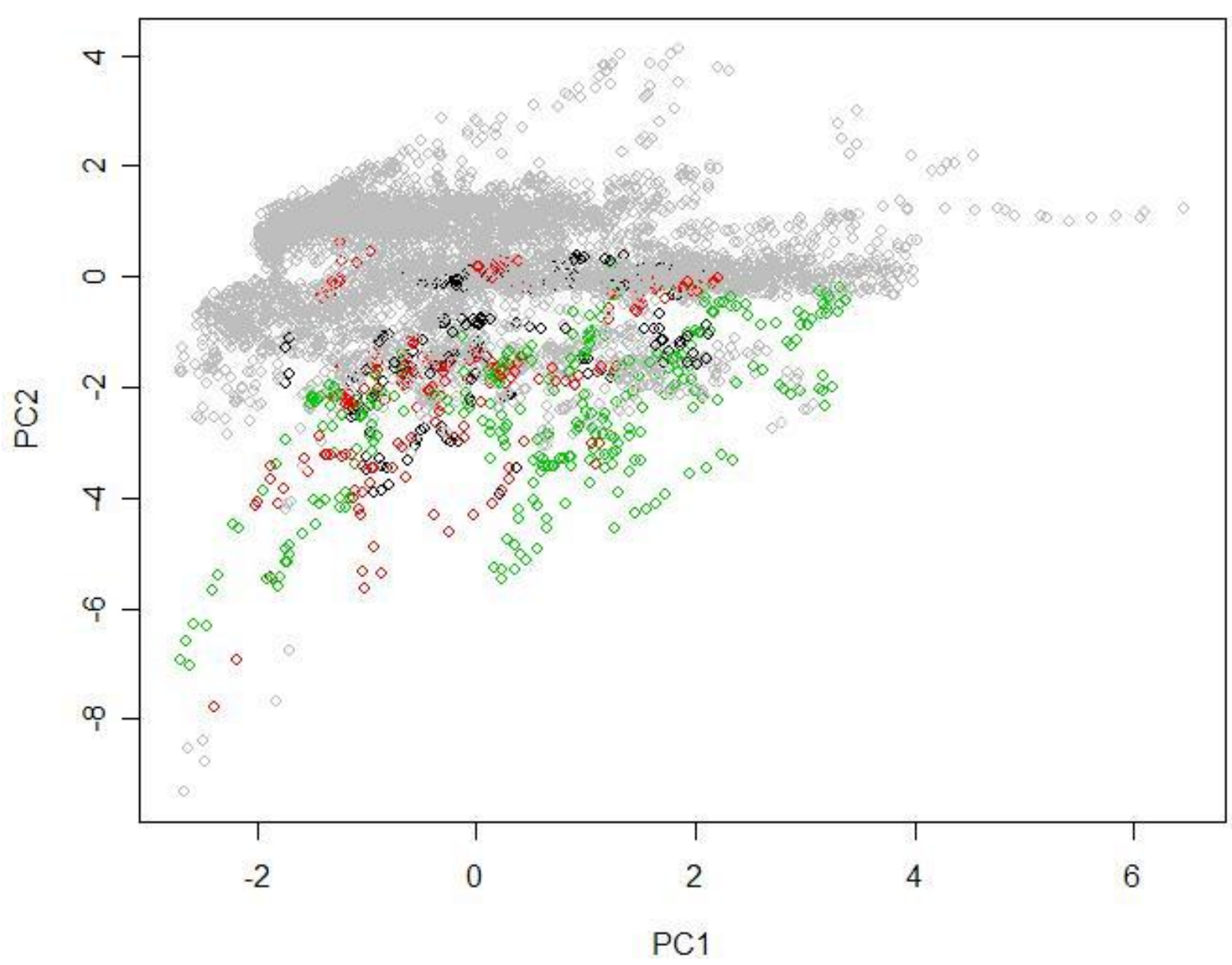

Figure A.19. Principal Component Analysis for All Countries and Country-Years

\footnotetext{
${ }^{2}$ This is a Principal Component Analysis for variables in all country-years the dependent variables of Explore (green), Pursue (red) and Acquire (black).
} 


\section{A.8 Hierarchal Cluster Analysis}

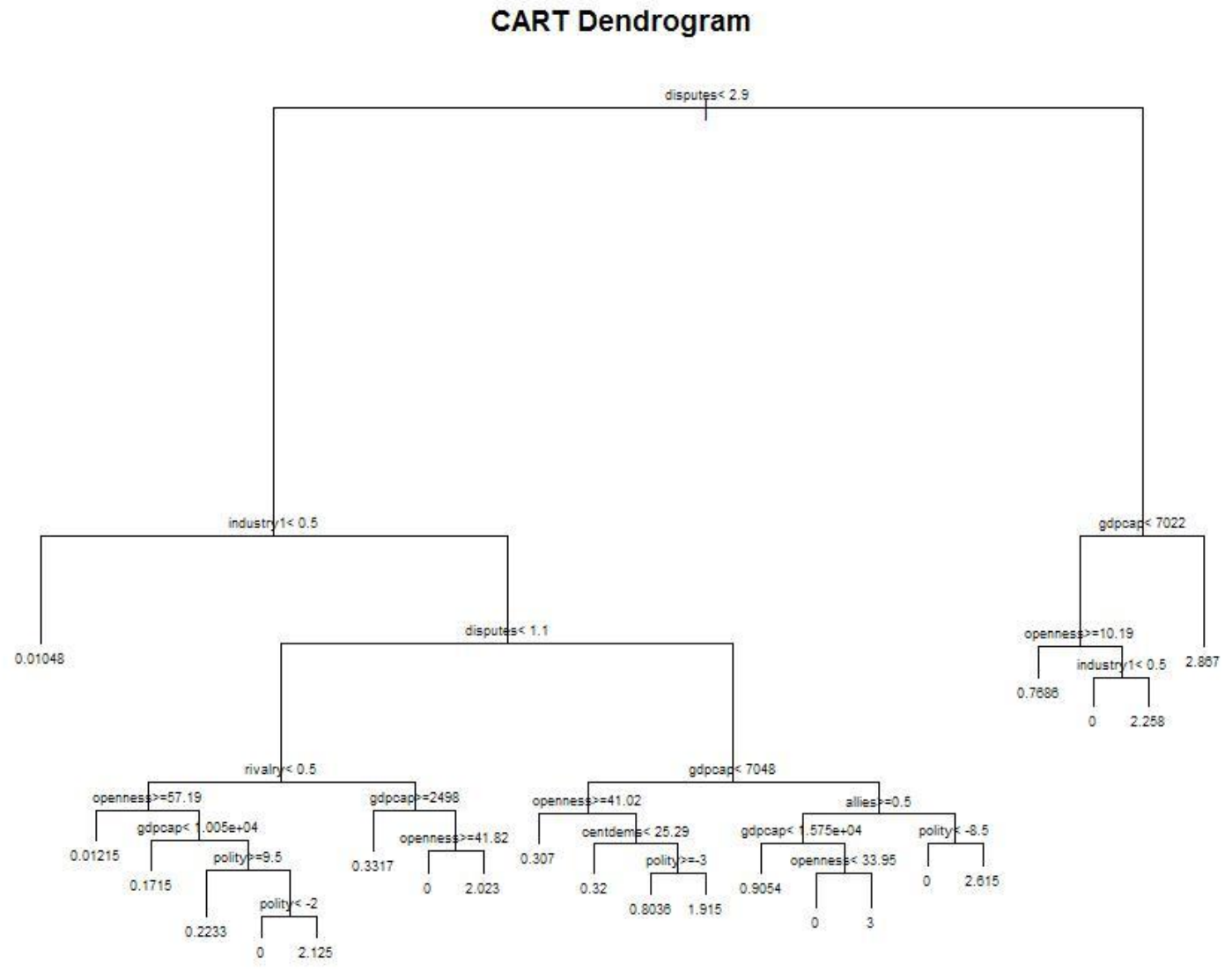

Figure A.20. CART Dendrogram Analysis for All Countries and Country-Years 



\section{Appendix B}

\section{Identification of Other Datasets}





\section{Appendix B}

\section{Identification of Other Datasets for Future Use}

Described here is list of publicly available datasets from various academic projects with potential application to proliferation modeling. All were identified via internet exploration. All datasets unless otherwise noted have been down-loaded and examined for applicability to future revisions of the BN proliferation propensity model. Organizations with data that were investigated include the Correlates of War Project, Alliance Treaty Obligations and Provisions project, Issue Correlates of War project International Crisis Behavior Project, Uppsala Conflict Data Program, World Bank, World Trade Organization, United Nations, Nuclear Threat Initiative, James Martin Center for Nonproliferation Studies, , World Values, Pew Global Attitudes, and the Gallop World.

\section{B.1 Correlates of War Project}

The Correlates of War $^{1}$ (COW) dataset was founded in 1963 by J. David Singer at the University of Michigan. The project establishes a goal to not only house time series datasets of conflicts but to also describe the factors which contribute to the onset and severity of conflict. Representative elements from the COW dataset are described below.

- National Materials Capabilities (NMC). Contains data to describe the military capabilities of a State. Variables include military expenditure, military personnel, energy consumption, iron and steel production, urban population, and total population. Variables are used to create a Composite Index of National Capabilities (CINC) score for each State and year. Data is available from 1816-2001.

Pros - Data is widely used indicator for national capabilities in the CINC score, and was, for example used by Jo and Gartzke.

Cons - Data only available up to Year 2001. Given this limitation, they might not be the best possible indicators for such an index.

- Alliance. Contains data on all formal alliances including, mutual defense pacts, neutrality or nonaggression pacts, and ententes. Data is organized by alliance member. Data is available from 18162000.

Pros - Non-aggression and neutrality pacts included.

Cons - Data only available up to Year 2000. There was no description about the structure and purpose of the said alliance.

- International Governmental Organizations (IGO). We downloaded the data file but were unable to open the data set due to its large size. This dataset provides the membership and status of

\footnotetext{
${ }^{1}$ Correlates of War Project. Accessed July 2010: http://dvn.iq.harvard.edu/dvn/dv/cow.
} 
intergovernmental organization with 3 or more member states. Data can be organized by state, or by organization. Data is available from 1815-2000.

Pros - Data can be used to identify states who share common interests and areas of regional influence.

Cons - Data only available up to Year 2000. Could not open large data file with excel.

- Territorial Change. This dataset records all peaceful and violent exchanges of territory in which at least one recognized State was involved. It contains information on the parties involved, the land gained or lost, and if military force was used. Data is available from 1816-2000.

Pros - Contains data in which violence was not used.

Cons - Data only available up to Year 2000. It forces the user to infer information about which State is the aggressor.

- Militarized Inter-State Disputes (MID). This data includes all instances in which one State threatened, displayed, or used force against another. Among other variables, the highest level of actions by each state (threat to use force, blockade, declaration of war etc.) is included. Data is available from 1816-2001.

Pros - Level of actions by each state, includes data for disputes not involving the use of force. This is the most inclusive dataset available.

Cons - Data only available up to Year 2000. The dataset does not give much detail into events surrounding the dispute.

- Trade ${ }^{2}$. This data contains information on the amount of trade occurring between two nations. The trade variable is reported as imports into State A from State B and the imports into State B from State A. There is one data entry per pair of States per year. Data is available from 1870-2006.

Pros - Values for trade between nations.

Cons - No breakdowns of industry.

Other potentially relevant datasets include, Intra-State Wars, Extra-State Wars, Direct Contiguity, Interstate System, and Diplomatic Exchange.

\section{B.2 Alliance Treaty Obligations and Provisions Project}

The Alliance Treaty Obligations and Provisions project ${ }^{3}$ (ATOP) dataset is hosted by Rice University and operated by Brett Ashley Leeds. The project provides data on military alliance agreements. The project takes a deep look at alliances and describes them as contracts and institutions. The projects wants to help

\footnotetext{
${ }^{2}$ Correlates of War Project. "Trade." Accessed July 2010: http://www.correlatesofwar.org/COW2\%20Data/Trade/Trade.html.

${ }^{3}$ Alliance Treaty Obligations and Provisions Project. Accessed July 2010: http://atop.rice.edu/.
} 
the user identify the condition under which an agreement is signed and why, the provisions and obligations of the agreement, and how effective the alliance is towards eliciting compliance and achieving their goals.

- Alliance Treaty Obligations and Provisions (ATOP). This dataset contains a variety of information for each military alliance and can be obtained in various formats for optimal usage. Data is available from 1815-2003.

Pros - Contains much more information about each treaty in comparison to the COW dataset.

Cons - Data is still not up to date in only having data up to 2003. Discerning information about each treaty seems like it will be a hassle.

\section{B.3 Issue Correlates of War Project}

The Issue Correlates of $\mathrm{War}^{4}$ (ICOW) project is co-directed by Paul Hensel at the University of North Texas and Sarah McLaughlin Mitchell at the University of Iowa. The project collects data on contentious issues in world politics. In particular, information is contained pertaining to land, river, and maritime territorial claims.

- Issue Correlates of War (ICOW). This dataset contains information for territorial claims, including land, river, and maritime claims. Dataset creates an index for the salience of disputed territory to each State involved. Also, identifies attempts at dispute resolutions, be it a militarized attempt or not.

Pros - Contains data for claims regardless of whether or not militarized conflict was involved. Much more expansive dataset than the territorial change because information about disputes in which territory did not exchange States is present.

Cons - Data is only available up to Year 2001.

\section{B.4 International Crisis Behavior Project}

The C (ICB) project ${ }^{5}$ is part of the Center for International Development and Conflict Management at the University of Maryland. The dataset contains information on international crisis pertaining to securitymilitary concerns.

- International Crisis Behavior (ICB). Dataset contains 452 international crises in which there was heightened concern over State securities. Information includes what state triggered the dispute, level of communication between parties during the dispute, the method of crisis management undertaken, whether or not there was international involvement, and the ultimate outcome of dispute.

Additionally, a dataset to define interstate rivals is derived from this dataset and has been included. Data is available from 1918-2006.

\footnotetext{
${ }^{4}$ Issue Correlates of War Project. Accessed July 2010: http://www.paulhensel.org/icow.html.

${ }^{5}$ International Crisis Behavior Project. Accessed July 2010: http://www.cidcm.umd.edu/icb/.
} 
Pros - Gives very good representation to the level of tensions which may have been felt during each crisis. Rivalry data is done well and can easily be modified to any separate definition.

Cons - Smaller data set, but it may capture the important crisis relevant to international tensions.

\section{B.5 Uppsala Conflict Data Program}

The Uppsala Conflict Data Program ${ }^{6}$ (UCDP) collects data on armed conflicts and organized violence. The project captures information including acts of violence by non-State actors.

- PRIO Armed Conflict Dataset. This dataset provides conflict data for which at least one party was a State actor. Data is available from 1946-2008.

Pros - Gives information specific on non-State actors such as Hamas.

Cons - No information as to the home base of non-State actor. Information regarding reasons for conflict and conflict intensity is not specific. Extracting all the relevant data from spreadsheet seems like it could be a hassle.

\section{B.6 World Bank}

The World Bank ${ }^{7}$ is an international organization created during the Bretton Woods conference of 1944. The World Bank provides financial assistance to developing countries and has a stated goal of reducing global poverty. Along with this, the World Bank also houses many potentially valuable datasets.

- Per Capita Electric Power Consumption. Dataset records electric power consumption in units of kWh per capita. Data is available from 1960-2007 for 135 States.

Pros - None identified.

Cons - Most of the data is missing until around 1990 (this goes for most World Bank data).

- Energy Production. Records energy production converted into kt of oil equivalents. Data is available from 1960-2007 for 135 States.

Pros - Production comparison to consumption may useful indicator.

Cons - A lot of data is missing.

- Energy Imports, Net Percent of Energy Use. Net percent of energy use is estimated by calculating energy use less production, both measured in terms of oil equivalents. Data is available from 19602007 for 135 States.

\footnotetext{
${ }^{6}$ Uppsala Conflict Data Program. Accessed July 2010: http://www.pcr.uu.se/research/ucdp/.

${ }^{7}$ World Bank. Accessed July 2010: http://econ.worldbank.org/WBSITE/EXTERNAL/EXTDEC/0,,menuPK:476823 pagePK:64165236 piPK:6416514 1 theSitePK:469372,00.html.
} 
Pros - Combines previous two datasets into one without need for unit conversion. May show dependence of State's economy on other economies.

Cons - Does not separate the form of energy being imported.

- Gross Domestic Products (GDP). GDP is the sum of gross value added by all resident producers plus any product taxes and minus any subsidies not included in value of product. The GDP is given in current US dollars. Another data set is available for per capita GDP. Data is available from 19602008 for 202 States.

Pros - Fairly complete dataset.

Cons - None identified.

- Exports of Goods and Services. This data measures the value of all goods and services provided to the rest of the world. Data is given as a percent of GDP. Data is available from 1960-2008 for 189 States.

Pros - Fairly complete dataset.

Cons - No information as to commodity or destination.

- Imports of Goods and Services. This data measures the value of all goods and services received from the rest of the world. Data is given as a percent of GDP. Data is available from 1960-2008 for 189 States.

Pros - Fairly complete dataset.

Cons - No information as to commodity or origin.

- High Technology Exports. This data measures the value of high technology exports for each State in current US dollars. A high technology good is one with a high R\&D intensity, such as in aerospace, computers, pharmaceuticals, scientific instruments, and electrical machinery. Data is given in current US dollars; another dataset is available and provides data as a $\%$ of manufactured exports. Data is available from 1960-2008 for 173 States.

Pros - Provides a different measure for economic development than those commonly seen in literature.

Cons - May need to standardize data by population or other means.

- Research and Development Expenditures. Data provides the current and capital expenditures on creative work undertaken to increase knowledge and use of knowledge for new applications. Data is given in terms of \% GDP. Data is available from 1960-2007 for 115 States.

Pros - The dataset is in a form good for standardized use. Dataset provides a different measure for economic development than those commonly seen in literature. 
Cons - Missing data, however, it could be these states simply did not have any research.

- Military Expenditures. Military expenditures are derived from the NATO definition. Data is provided in \% GDP and also \% central government expenditures. Both data sets go unto year 2008, GDP data is available for 158 States while \% central government expenditure is available for 133 States.

Pros - New perspective in considering the $\%$ of central government expenditures.

Cons - May not be as complete a dataset as hoping for, needs a more careful look.

- Foreign Direct Investment, net inflows. This data measures net inflows of foreign investments to acquire a long term lasting management interest (10\% of voting stocks). Data shows new investment less disinvestment in current US dollars. Data is available for 185 State from 1960-2008.

Pros - Fairly complete dataset.

Cons - None identified.

- Net Official Development Assistance (ODA) Received. This data consists of loans and grants of official members of the Development Assistance Committee (DAC), by multilateral institutions, and by non-DAC countries to promote growth and development. Data is given as a percentage of Gross National Income (GNI). Data is available from 1960-2008 for 157 States.

Pros - Indentifies struggling States dependent on foreign bodies for economic growth.

Cons - Unclear if the dataset contains aid from charities and similar non-governmental organizations.

- Population. Records total population for 210 States from 1960-2008.

Pros - Fairly complete dataset.

Cons - None identified.

- Governance Indicators. This dataset reports aggregate and individual governance indicators for the following factors, Voice and Accountability, Political Stability and Absence of Violence, Government Effectiveness, Regulatory Quality, Rule of Law, Control of Corruption. The aim is to describe the perceived effectiveness of each governing body. Data is available from 1996-2008.

Pros - Has a variety of indicators and should be independent of government type.

Cons - Not entirely sure how applicable data is in respect to proliferation.

\section{B.7 World Trade Organization}

The World Trade Organization (WTO) has a goal to oversee and liberalize international trade. Starting in 1995, the WTO has dealt with regulating trade between member States. 
- Imports and Exports by Main Industry. Records merchandise trade by import and export for different commodities such as food, textiles, fuels, etc. Data from 1980-2008.

Pros - Gives a more detailed analysis into the trade structure of a nation, looking at the broad industry level.

Cons - not clear this represents the correct amount of specificity.

- Tariff Data. We only looked at one industry for the U.S. as a complete data set would be very large. Offers tariff rates for products at the highest level of detail for comparison between countries. Data is available for the last few years and for a large set of countries. Also shows trade agreements between states.

Pros - Extremely complete dataset potentially indicating economic nationalism. The dataset describes general policy of State to imports from other States.

Cons - Difficult to try and aggregate data. Extracting data for many countries and industries is very difficult.

\section{B.8 United Nations Data}

The United Nations (UN) data ${ }^{8}$ was founded after WWII the United Nations works to facilitate international cooperation towards achieving the goal of global peace. The United Nations hosts an extremely large statistics database for economic development and other global indicators.

- UNcomtrade. We only downloaded the multilateral State level import and export for 2008. Comtrade hosts international trade statistics, including separation between imports and exports. The statistics involve detailed commodity level trade, as well as partner level trade. The database is extremely in depth. For instance, in 2008 the dataset containing trade for all commodities and reporting nations and partners is around $1800 \mathrm{MB}$. Once specific commodities are removed and commodities are aggregated the dataset falls to around 2 MB. Data is available from 1962-2005 for varying numbers of States.

Pros - Extraordinarily detailed and fairly complete dataset. Gives us all the trade information we could ever want.

Cons - May be more specific than what we are looking for.

- UNdata. There seems to be a plethora of data in this dataset but we only downloaded the gross value of economic activity dataset. This dataset contains a variety of data including Human Development Indices and demographic data. Of interest are the industrial indicators and a few trade indicators. The industrial indicators provide data as to economic value added by broad industry sectors, and production levels of very specific industry level data (for instance Metric tons of optical fiber cable). Specific commodity trade data is also present but does not include information on trading partner.

\footnotetext{
${ }^{8}$ United Nations data. Accessed July 2011: http://comtrade.un.org/db/default.aspx and http://data.un.org/Explorer.aspx.
} 
Pros - There are a variety of choices for economic metrics and industrial capacity.

Cons - May be more specific than what we are looking for.

\section{B.9 Nuclear Threat Initiative}

Founded in 2001, the Nuclear Threat Initiative ${ }^{9}$ is a private charity working towards building global awareness and attempts to provide programs to inspire private and governmental efforts towards threat reductions.

- United Nations Security Council Resolution 1540 Database. This dataset provide the membership of states in nonproliferation and Nuclear Weapons Free Zone (NWFZ) agreements.

Pros - Contains the only easy to read table of agreements

Cons - Doesn't describe compliance to said agreements.

- Inventory of International Nonproliferation Organizations \& Regimes. We did not download this dataset. It provides links to the texts and overviews of nonproliferation organizations $\&$ regimes.

Pros - Can help provide a better understanding to safeguards structures and legal ramifications.

Cons - Contains external links and requires reading or prior knowledge on agreements.

- Nuclear Disarmament. We did not down load this dataset. This dataset provides a map and list of nations who have nuclear arms or have ever had nuclear armaments, including shared nuclear armaments.

Pros - Includes nuclear sharing States.

Cons - Does not have tables, need to transcribe manually.

\section{B.10 James Martin Center for Nonproliferation Studies}

The Center for Nonproliferation Studies ${ }^{10}$ strives to combat the spread of Weapons of Mass Destruction. The center is the largest nongovernmental organization in the United States devoted to research and training of nonproliferation issues.

- Chemical and Biological Weapons Resource Page. This site gives a table for States who have proven and or have been expected of possessing chemical or biological weapons of mass destruction.

Pros - Lists dates of WMD programs, even those suspected and not proven.

Cons -Table may need to be transcribed.

\footnotetext{
${ }^{9}$ Nuclear Threat Initiative. Accessed July 2010: http://www.nti.org/e_research/e7_databases.html.

${ }^{10}$ Center for Nonproliferation Studies. Accessed July 2010: http://cns.miis.edu/cbw/possess.htm.
} 


\section{B.11 Survey Centers}

These data sources conduct surveys on an array of subjects with the goal of assessing the moral, cultural, and political values around the world. They are a potentially valuable source of information on public views.

- World Values Survey Data ${ }^{11}$. The World Values Survey data does not come in excel readable format, but can be downloaded using "Stattransfer." This organization has conducted surveys for the past 30 years. The most recent survey was conducted for 2005 and another is scheduled for 2010.

Pros - Large number of countries polled (57 in 2005). More useful than Pew and free.

Cons - Data comes prepared for statistical programs and will need to be transferred. A lot of data is useless. Will need manual identification of useful questions. Questions are not always standardized.

Survey questions that seemed relevant from the dataset include:

○ How much freedom of choice of control

- Aims of Country (i.e., what should be most important aim of country, economic growth, or national defense, and others?)

○ -Attending lawful/peaceful demonstrations (have done, willing to do, will never do)

- -Strong Leader is important (Do not have to deal with parliament of elections)

- -Having the army rule (Important in case of failure of government?)

- -Who should decide international peacekeeping in region (national governments, UN, national governments with $\mathrm{UN}$ )

○ -How proud of nationality

○ -Trust: People of another nationality

○ -Trust: People of another religion

○ -See myself as a world citizen

- - See myself as a citizen of [home country]

- Pew Global Attitudes Project ${ }^{12}$. This project is directed by Andrew Kohut, president of the Pew Research Center a nonpartisan "fact tank" in Washington, DC funded by the Pew Charitable Trusts. We did not download this dataset. It is based on public opinion surveys that provide information on the issues, attitudes and trends shaping America and the world today.

Pros - None identified.

\footnotetext{
${ }^{11}$ World Values Survey. Accessed July 2010: http://www.worldvaluessurvey.org/.

${ }^{12}$ Pew Global Attitudes Project. Accessed July 2010: http://pewglobal.org/category/data-sets/.
} 
Cons - Almost all data is useless and comes in tables in "pdf" format which makes it awkward for data analysis. In comparison to the political science data it draws from a smaller set of polled countries. Questions are not always standardized.

- Gallup World View ${ }^{\mathbf{1 3}}$. We do not have a subscription and could not find a means of downloading tables of data. It is described to provide data from public opinion polls conducted in over 150 countries. Gallup is viewed as the world leader in public opinion research.

Pros - Very complete questions and very large selection of countries.

Cons -Can't access all data without subscription. I can't find way to download data in any sort of usable form. Even though it appears there are some useful questions, there is certainly a huge repository of irrelevant data.

Survey questions that seemed relevant from the dataset include:

- Life hard for government opposition

○-Government is responsible for tension

○ -Opposition responsible for tension

- Other countries responsible for tensions

- Confidence in national government

○ -Approval of this country's leadership

○ -Muslim/West relations important

- Corruption in government

○ -Confidence in State media objectivity

- -Confidence in non-State media objectivity

- -Racial/Ethnic minorities (a good place for them)

$\circ \quad$-Religious minorities (a good place for them)

○ -Freedom of Assembly

- - Peaceful means alone (for conflicts)

○ - Citizen engagement index

○ -Corruption index

${ }^{13}$ Gallop World View. Accessed July 2010: https://worldview.gallup.com/signin/login.aspx. 


\section{Appendix C}

\section{BACH Proliferation Propensity Model Queries}





\section{Appendix C}

\section{BACH Proliferation Propensity Model Queries}

Listed here are the evidence queries made as internet searches to support evidence and bias assessment of the BACH version of the proliferation propensity model validation exercise described in Section 3.4.3. These search terms were developed on the basis of the node names in the BN model. As listed below, for some nodes, more than one query variations were created to enhance the Internet search coverage in order to obtain the desired information. To conduct a case study for any country of interest, the country's name should be added to each query. For instance, if we are interested in using the BN model to assess the proliferation propensity of Country X, then a query for the node, Contributing Technologies, becomes "Country X has latent nuclear weapons production capability," or for the node, Available Fissile Material, the query becomes "availability of fissile material in Country X." Of course, queries are highly malleable and they should by no means be limited by what is listed here. The fundamental goal of queries is to design a set of tailored phrases or sentences that will fetch Internet search results to effectively inform the node and the country under consideration.

Relevant Nodes and Query Terms for Composite Model:

1. Contributing Technologies:

"latent nuclear weapons production capability"

2. Available Fissile Material

"availability of fissile material"

3. Industry

"industrial capability" "nuclear weapons" "steel production" electricity

4. $\mathrm{GDP}^{\wedge} 2$

"gross domestic product per capita"

5. Domestic Unrest

"internal regime stability" "anti-government demonstrations" strikes riots

6. Level of Democracy

democracy autocracy

7. Regional Stability

"regional security environment" "conflicts" "militarized conflicts"

8. \% of Democracies

"prevalence of democracies"

9. Nuclear Capability of Neighbors

10. Allies 
"Nuclear Protector"

11. Rivalry

"Enduring Rivalry"

"Ongoing military disputes"

12. Disputes

"Interstate militarized disputes"

13. Conventional Threat

"Balance of military power"

14. Economic Interdependence

"economic interdependence" "integrated economy"

15. Diplomatic Isolation

"diplomatic isolation" "official diplomatic relationships" 



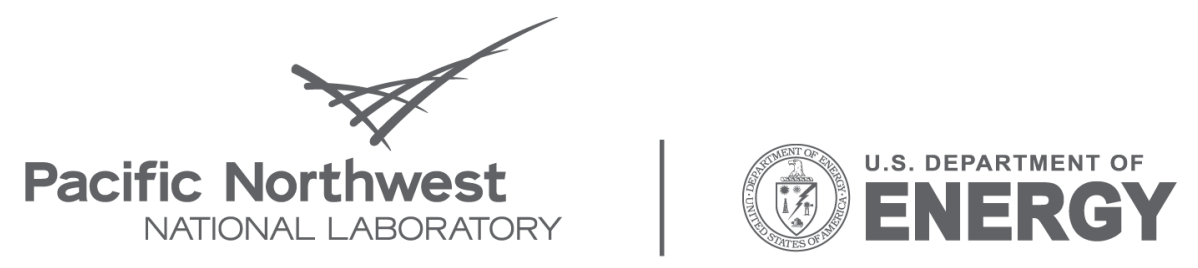

Proudly Operated by Battelle Since 1965

902 Battelle Boulevard

P.O. Box 999

Richland, WA 99352

1-888-375-PNNL (7665)

www.pnl.gov 